\title{
A Quantitative Model-Based Fault Detection \& Diagnostics (FDD) System for Zone-Level Inefficiencies
}

by

Justin Berquist, B.Sc., Mechanical Engineering

\author{
A thesis submitted to the \\ Faculty of Graduate and Postdoctoral Affairs \\ in partial fulfillment of the requirements for the degree of
}

Master of Applied Science in Mechanical Engineering

Department of Mechanical and Aerospace Engineering

Carleton University

Ottawa, Ontario

August, 2017

(C) Copyright

Justin Berquist, 2017 


\section{Abstract}

Heating, ventilation and air-conditioning (HVAC) systems account for a significant portion of energy consumption in buildings. The majority of fault detection research has neglected zone-level faults. In this study, the methodology of a quantitative model-based fault detection and diagnostics (FDD) system for the zone-level is presented. The creation of a basic model was completed using Matlab. Analyses were conducted, identifying five zone-level inefficiencies. The severity of these inefficiencies was analyzed and an excessive amount of air handling unit (AHU) fan energy consumption was detected. The redundancy of these faults in the building force the AHU to expend an unwarranted amount of energy, highlighting the importance of utilizing FDD. Benefits of this methodology include the detection of pre-existing faults originating from the initial design and the ability to apply this to new or existing buildings, improving the efficiency of the building. 


\section{Acknowledgments}

I would like to thank all those who supported this research. To my supervisor, Dr. William O'Brien, thank you for your constant support, and for the knowledge you provided me with during this graduate work. To the PhD students in my research group, Ali Abdelalim, Jayson Bursill, Burak Gunay, and Shawn Shi thank you for answering my countless questions. To Mario Santana, the lead investigator for the CREATE Heritage program, thank you for making this research possible. I also want to thank the Natural Sciences and Engineering Research Council (NSERC) for funding the CREATE Heritage program and my work during my two-year graduate program.

Mom - thank you for your guidance throughout my program. Having not completed a significant research study before it was extremely beneficial to have you here helping me understand how to conduct a proper literature review and to stay motivated. Mom and Dad - thank you for supporting me in my decision to continue my education in this graduate program. Mom, Dad, Melissa and Courtney - thank you for talking to me about my thesis work, it helped a great deal to talk about any issues that I was encountering and allowed me to resolve them faster. 


\section{Table of Contents}

Abstract ii

Acknowledgments iii

Table of Contents iv

\begin{tabular}{ll}
\hline List of Tables & $\mathbf{x}$ \\
\hline
\end{tabular}

List of Figures $\quad$ xii

Nomenclature $\quad$ xvi

\begin{tabular}{|ll}
\hline Abbreviations & xxi
\end{tabular}

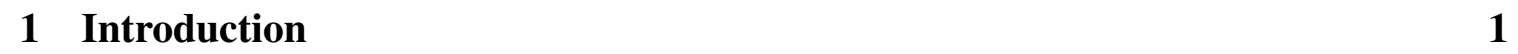

1.1 Background $\ldots \ldots \ldots \ldots \ldots \ldots$

1.2 Problem Definition $\ldots \ldots \ldots \ldots \ldots$

1.3 Contribution of Thesis $\ldots \ldots \ldots \ldots$

1.4 Organization of Thesis $\ldots \ldots \ldots \ldots \ldots$ 
\begin{tabular}{|lll}
\hline 2 & Literature Review & 9
\end{tabular}

$2.1 \quad$ Introduction to Faults $\ldots \ldots \ldots \ldots \ldots$

2.1 .1 Soft Faults $\ldots \ldots \ldots \ldots \ldots$

$2.1 .2 \quad$ Hard Faults . . . . . . . . . . . . . . . . . . . . . . . . . 12

$2.1 .3 \quad$ Design Faults $\ldots \ldots \ldots \ldots$

2.1 .4 Occupant Faults $\ldots \ldots \ldots \ldots \ldots$

2.2 Introduction to FDD $\ldots \ldots \ldots \ldots \ldots \ldots \ldots \ldots$

$2.2 .1 \quad$ Qualitative Model-Based FDD . . . . . . . . . . . . . 16

2.2 .2 Quantitative Model-Based FDD . . . . . . . . . . . . . . . 19

$2.2 .3 \quad$ Process History-Based FDD $\ldots \ldots \ldots \ldots$

2.3 Summary . . . . . . . . . . . . . . . . . . . . 27

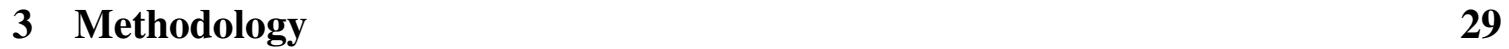

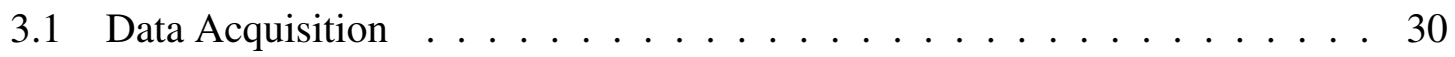

$3.1 .1 \quad$ Static Information . . . . . . . . . . . . . . . . . . . 32

3.1 .2 Dynamic Information $\ldots \ldots \ldots \ldots \ldots$

3.1 .3 Measured Temperatures \& Heating/Cooling Rates . . . . . . . . 35

3.2 Model Development $\ldots \ldots \ldots \ldots$ 
$3.2 .1 \quad$ Explicit Finite Difference Method . . . . . . . . . . . . . . . 43

3.2 .2 Internal Convection Coefficients . . . . . . . . . . . . . 60

3.2 .3 Internal Radiant Heat Exchange $\ldots \ldots \ldots$

3.2 .4 Time Step Selection $\ldots \ldots \ldots \ldots$

3.2 .5 Hydronic-Based Heating Rate . . . . . . . . . . . . . . 67

$3.2 .6 \quad$ Air-Based Heating \& Cooling Rate $\ldots \ldots \ldots \ldots$

3.3 Model Verification . . . . . . . . . . . . . . . . . . . 73

3.4 Fault Detection $\ldots \ldots \ldots \ldots \ldots \ldots \ldots \ldots \ldots \ldots \ldots$

3.4 .1 Temperature Profile Fault Detection Threshold $\ldots . . . . . .83$

3.4.2 $\quad$ Air-Based Heating \& Cooling Profile Fault Detection Threshold . . 88

$3.4 .3 \quad$ Hydronic-Based Heating Profile Fault Detection Threshold . . . . . 92

3.4 .4 Analysis Duration $\ldots \ldots \ldots \ldots \ldots$

3.5 Fault Diagnostics $\ldots \ldots \ldots \ldots \ldots$

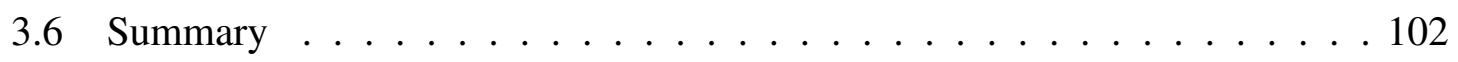

\begin{tabular}{|lll}
\hline 4 & Results & 103
\end{tabular}

4.1 SAT Sensor Offset . . . . . . . . . . . . . . . . . . . . . 103

$4.1 .1 \quad$ Fault Detection . . . . . . . . . . . . . . . . . . 104 
$4.1 .2 \quad$ Fault Diagnostics $\ldots \ldots \ldots \ldots$. . . . . . . . . . . 106

4.1 .3 Fault Evaluation . . . . . . . . . . . . . . . 110

4.2 Poor SD and RG Selection/Placement . . . . . . . . . . . 110

$4.2 .1 \quad$ Fault Detection . . . . . . . . . . . . . . . . . . . . . . 111

4.2 .2 Fault Diagnostics $\ldots \ldots \ldots \ldots \ldots$

4.2 .3 Fault Evaluation . . . . . . . . . . . . . . . . 115

4.3 Poor Thermostat Placement . . . . . . . . . . . . . . . . . . . 116

$4.3 .1 \quad$ Fault Detection . . . . . . . . . . . . . . . . . . . . 117

$4.3 .2 \quad$ Fault Diagnostics $\ldots \ldots \ldots \ldots \ldots \ldots$

4.3 .3 Fault Evaluation . . . . . . . . . . . . . . . . 125

4.4 Poor VAV Box Selection . . . . . . . . . . . . . . . . . . . 127

$4.4 .1 \quad$ Fault Detection . . . . . . . . . . . . . . . . . . 128

$4.4 .2 \quad$ Fault Diagnostics . . . . . . . . . . . . . . . . . . . . . . . 129

4.4 .3 Fault Evaluation . . . . . . . . . . . . . . . 132

$4.5 \quad$ Poor VAV box Control Sequence $\ldots \ldots \ldots \ldots$

$4.5 .1 \quad$ Fault Detection . . . . . . . . . . . . . . . . . . 138

$4.5 .2 \quad$ Fault Diagnostics $\ldots \ldots \ldots$. . . . . . . . . . . . 140

4.5 .3 Fault Evaluation . . . . . . . . . . . . . . . . 142 
4.6 Summary . . . . . . . . . . . . . . . . . . . . 143

$\begin{array}{lll}5 & \text { Discussion } & 145\end{array}$

$5.1 \quad$ Significance of Research and Findings . . . . . . . . . . . . . . . 145

5.2 Applicability of Development in Other Buildings . . . . . . . . . . . . . 146

$5.2 .1 \quad$ Applicability of Development in Existing Buildings . . . . . . . . . 147

5.2 .2 Applicability of Development in New Buildings . . . . . . . . . . . 147

5.3 Conveying Design Faults to Designers . . . . . . . . . . . . . . . . . 148

5.3 .1 Conveying Design Faults in BIM. . . . . . . . . . . . . . . . . 148

5.3.2 Conveying Design Fault in New Design Standards . . . . . . . . . 149

5.4 Limitations of Research . . . . . . . . . . . . . . . . . . . . 150

5.4 .1 Quantitative Model-Based Fault Detection . . . . . . . . . . . . 150

$5.4 .2 \quad$ Heuristic-Based Rule Set Fault Diagnostics . . . . . . . . . . . . . 151

5.5 Recommended Future Work . . . . . . . . . . . . . . . 152

5.5 .1 Continuation of Work . . . . . . . . . . . . . . . 152

5.5 .2 New Research Areas . . . . . . . . . . . . . . . . . . . . . . 154

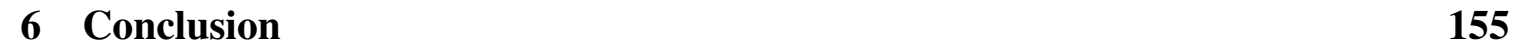

6.1 Overview of Research \& Findings . . . . . . . . . . . . . . 156 
6.2 Autodesk Internship . . . . . . . . . . . . . . . . . . . . 158

6.3 Closing Remarks . . . . . . . . . . . . . . . . . . 158

\begin{tabular}{ll}
\hline List of References & 160
\end{tabular}

\begin{tabular}{|ll|}
\hline Appendix A & Model Software Matlab Scripts \\
\hline
\end{tabular} 


\section{List of Tables}

2.1 Soft faults addressed in the literature . . . . . . . . . . . . . . . . 11

2.2 Hard faults addressed in the literature . . . . . . . . . . . . . 13

2.3 Pros and cons of the three FDD methodologies . . . . . . . . . . 28

3.1 Required static data $\ldots \ldots \ldots \ldots \ldots \ldots \ldots$

3.2 Required static data - Material properties . . . . . . . . . . . 33

3.3 Required dynamic data $\ldots \ldots \ldots \ldots . \ldots . \ldots . \ldots 34$

3.4 Measured air-based heating and cooling rate calculation assumptions . . . . 37

$3.5 \quad$ Measured hydronic-based heating rate calculation assumptions . . . . . . . 39

3.6 Energy simulation tool comparison . . . . . . . . . . . . . 41

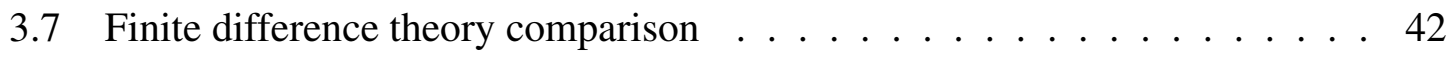

3.8 View factors determined through ESP-r - The view factors represent how well the vertically listed surface sees each horizontally listed surface. . . . . 65

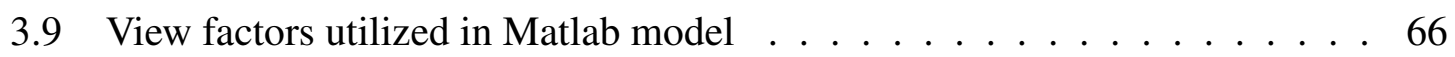

3.10 Underlying model assumptions . . . . . . . . . . . . . . 84

3.11 Temperature fluctuations caused by alteration in material properties . . . . 85

3.12 Uncertainty in sensor measurements for energy simulation program . . . . 86 
3.13 Uncertainty in the measured air-based heating and cooling rate sensors . . . 89

3.14 Uncertainty in the measured hydronic-based heating rate sensors . . . . . 93

$4.1 \quad$ Supply air flow rate and power increase . . . . . . . . . . . . . 126

4.2 VAV box results $\ldots \ldots \ldots \ldots \ldots$. . . . . . . . . . . . . . . . . . . . . . . . . . .

4.3 VAV box's influence on AHU fan energy consumption . . . . . . . . . 136 


\section{List of Figures}

1.12010 Commercial building energy consumption breakdown [3] . . . . . . 2

1.2 Mechanical system description $\ldots \ldots \ldots \ldots \ldots \ldots$

1.3 Thermostat misreading example $\ldots \ldots \ldots \ldots \ldots \ldots \ldots \ldots$

1.4 Short-circuiting example $\ldots \ldots \ldots \ldots \ldots \ldots \ldots \ldots$

$2.1 \quad$ EnteliWEB fault notifications $\ldots \ldots \ldots \ldots \ldots$. . . . . . . . . 17

$3.1 \quad$ Picture of typical office under evaluation captured by Burak Gunay . . . . . 31

$3.2 \quad$ Plan view of typical office under evaluation captured by Burak Gunay . . . 31

$3.3 \quad$ Mesh for a semi-infinite strip of material [54] $\ldots \ldots \ldots \ldots$

3.4 Office energy balance $\ldots \ldots \ldots \ldots \ldots \ldots \ldots \ldots$

3.5 Simplified room thermal network diagram $\ldots \ldots \ldots \ldots \ldots$

3.6 Room thermal network diagram $\ldots \ldots \ldots \ldots \ldots \ldots \ldots$

3.7 Wall thermal network diagram $\ldots \ldots \ldots \ldots \ldots \ldots$

$3.8 \quad$ Floor thermal network diagram $\ldots \ldots \ldots \ldots \ldots \ldots$

$3.9 \quad$ ESP-r model surface topology $\ldots \ldots \ldots \ldots \ldots$

3.10 Radiator outlet temperature $\ldots \ldots \ldots \ldots$. . . . . . . . 68 
3.11 Radiator outlet temperature with corresponding first order response. . . . . 68

3.12 Radiator thermograph captured during steady state operation . . . . . . . 70

3.13 Room air temperature profiles for office 1 in November . . . . . . . . . . . 74

3.14 Hydronic-based heating profile for office 1 in November . . . . . . . . 75

3.15 Room air temperature profiles for office 2 in November . . . . . . . . . 76

3.16 Hydronic-based heating profile for office 2 in November . . . . . . . . . 77

3.17 Room air temperature profiles for office 3 in November . . . . . . . . . . . 78

3.18 Hydronic-based heating profile for office 3 in November . . . . . . . . . . 79

3.19 Room air temperature profiles for office 4 in November . . . . . . . . . . . 80

3.20 Hydronic-based heating profile for office 4 in November . . . . . . . . . . 81

3.21 Measured air-based heating \& cooling rate without uncertainty of propagation 90

3.22 Measured air-based heating \& cooling rate with uncertainty of propagation. 90

3.23 Measured hydronic-based heating rate without uncertainty of propagation . 94

3.24 Measured hydronic-based heating rate with uncertainty of propagation . . . 94

3.25 Heuristic-based rule set for diagnosing system faults . . . . . . . . . . . 99

3.26 Heuristic-based rule set for diagnosing sensor faults . . . . . . . . . . . 101

4.1 Room air temperature profiles for office 2 in November . . . . . . . . . . . 104

4.2 Hydronic-based heating profile for office 2 in November . . . . . . . . 105 
4.3 Air-based heating and cooling profile for zone 1 in November. . . . . . . . 106

4.4 VAV box annual supply air flow rate $\ldots \ldots \ldots$. . . . . . . . . . 108

4.5 VAV box 1 and VAV box 2 SAT . . . . . . . . . . . . . . . 109

4.6 VAV box 1 and AHU SAT . . . . . . . . . . . . . . . . . . . . 109

4.7 Room air temperature profiles for office 3 in October . . . . . . . . . . 111

4.8 Air-based heating and cooling profile for zone 1 in October . . . . . . . . . 112

4.9 Supply, return and thermostat readings during a week in February . . . . . 114

4.10 Supply, return and thermostat readings during a week in July . . . . . . . . 114

4.11 Room air temperature profiles for office 1 in August . . . . . . . . . . . . . 117

4.12 Room air temperature profiles for office 2 in August . . . . . . . . . . . . 118

4.13 Room air temperature profiles for office 3 in August . . . . . . . . . . . . 118

4.14 Room air temperature profiles for office 4 in August . . . . . . . . . . . . . 119

4.15 Theoretical and measured room air temperature difference for office 1 . . 120

4.16 Theoretical and measured room air temperature difference for office 3 . . 120

4.17 Zone layout . . . . . . . . . . . . . . . . . . 122

4.18 Thermostats that do not see direct sunlight $\ldots \ldots$. . . . . . . . 123

4.19 Thermostats that could see direct sunlight . . . . . . . . . . . 123

4.20 Daylighting results for a representative time each month of the year . . . . 124 
4.21 Measured performance for zone 1 and office 3 on August $26^{\text {th }}, 2016 \ldots 125$

4.22 Room air temperature profiles for office 1 in August . . . . . . . . . . . . 128

4.23 Theoretical and measured room air temperature difference for office 1 . . . 129

4.24 Air-based heating and cooling profiles for zone 1 in August . . . . . . . . . 130

4.25 Measured VAV box supply air flow rate for zone 1 in December . . . . . . 132

4.26 Room air temperature profiles for office 1 in May . . . . . . . . . . 138

4.27 Theoretical and measured room air temperature difference for office 1 in May 139

4.28 Air-based heating and cooling profiles for zone 1 in May . . . . . . . . . 140

4.29 Measured VAV box air flow rate for zone 1 in May . . . . . . . . . . . . . 141 


\section{Nomenclature}

\begin{tabular}{|c|c|c|}
\hline Symbol & Full Name & Units \\
\hline A & Area of emitting surface & $m^{2}$ \\
\hline $\mathrm{ACH}$ & Air changes per hour & $1 / \mathrm{h}$ \\
\hline$A_{\text {Rad }}$ & Area of the radiator & $m^{2}$ \\
\hline $\mathrm{c}_{\mathrm{p}_{\text {Air }}}$ & Specific heat capacity of air & $\frac{k J}{k g . K}$ \\
\hline $\mathrm{c}_{\mathrm{p}_{\mathrm{water}}}$ & Specific heat capacity of water & $\frac{k J}{k g \cdot K}$ \\
\hline $\mathrm{C}_{\mathrm{air}}$ & Thermal capacitance of the room air & $\frac{k J}{K}$ \\
\hline $\mathrm{C}_{\text {AirP }}$ & Thermal capacitance of the plenum air & $\frac{k J}{K}$ \\
\hline $\mathrm{C}_{\text {carp }}$ & Thermal capacitance of the carpet & $\frac{k J}{K}$ \\
\hline $\mathrm{C}_{\text {ceil }}$ & Thermal capacitance of the ceiling tiles & $\frac{k J}{K}$ \\
\hline $\mathrm{C}_{\mathrm{cs}}$ & Thermal capacitance of the concrete slab & $\frac{k J}{K}$ \\
\hline $\mathrm{C}_{\mathrm{Eq}}$ & Thermal capacitance of the equivalent wall & $\frac{k J}{K}$ \\
\hline $\mathrm{C}_{\mathrm{Ext}}$ & Thermal capacitance of the external wall & $\frac{k J}{K}$ \\
\hline $\mathrm{C}_{\text {mat1 }}$ & Thermal capacitance of material 1 & $\frac{k J}{K}$ \\
\hline$\frac{d E_{\mathrm{CV}}}{\partial t}$ & Energy differential for a given control volume & $\mathrm{W}$ \\
\hline$\frac{d M_{\mathrm{CV}}}{\partial t}$ & Time rate change of mass for a given control volume & $\frac{\mathrm{kg}}{\mathrm{s}}$ \\
\hline $\mathrm{D}_{\mathrm{h}}$ & Hydraulic diameter of horizontal surfaces & $m^{2}$ \\
\hline $\mathrm{E}$ & Enthalpy & $\frac{k J}{k g \cdot K}$ \\
\hline $\mathrm{F}$ & View factor & Unitless \\
\hline $\mathrm{g}$ & Acceleration due to gravity & $\frac{m}{s^{2}}$ \\
\hline $\mathrm{h}$ & Convection coefficient & $\frac{W}{m^{2} \cdot K}$ \\
\hline $\mathrm{H}$ & Height of vertical surfaces & $\mathrm{m}$ \\
\hline $\mathrm{h}_{\mathrm{r}}$ & Radiative coefficient & $\frac{W}{m^{2} \cdot K}$ \\
\hline $\mathrm{H}_{\mathrm{R}}$ & Height of the room & $\mathrm{m}$ \\
\hline $\mathrm{k}_{\mathrm{p}}$ & Proportional control constant & $\frac{W}{K}$ \\
\hline $\mathrm{L}_{\mathrm{PC}}$ & Percent of the lighting load that is convective & Unitless \\
\hline $\mathrm{L}_{\mathrm{PR}}$ & Percent of the lighting load that is radiative & Unitless \\
\hline$\dot{m}$ & Mass flow rate & $\frac{k g}{s}$ \\
\hline$\dot{m}_{\text {Air }}$ & Mass flow rate of air & $\frac{k g}{s}$ \\
\hline
\end{tabular}




\begin{tabular}{|c|c|c|}
\hline$\dot{m}_{\text {water }}$ & Mass flow rate of water & $\frac{\mathrm{kg}}{\mathrm{s}}$ \\
\hline $\mathrm{Occ}_{\mathrm{PC}}$ & Percent of the occupant load that is convective & Unitless \\
\hline $\mathrm{Occ}_{\mathrm{PR}}$ & Percent of the occupant load that is radiative & $\mathrm{W}$ \\
\hline $\mathrm{P}$ & Perimeter of the space & $\mathrm{m}$ \\
\hline $\mathrm{PL}_{\mathrm{PC}}$ & Percent of the plug load that is convective & Unitless \\
\hline $\mathrm{PL}_{\mathrm{PR}}$ & Percent of the plug load that is radiative & Unitless \\
\hline$\dot{Q}$ & Rate of heat addition & $\mathrm{W}$ \\
\hline $\mathrm{Q}_{\text {Airt }}$ & Theoretical air-based heating and cooling rate & $\mathrm{W}$ \\
\hline$Q_{\text {conv }}$ & Rate of convective heat addition & $\mathrm{W}$ \\
\hline$Q_{D R}$ & Diffuse solar radiation load & $\mathrm{W}$ \\
\hline $\mathrm{Q}_{\text {inf }}$ & Office infiltration load & $\mathrm{W}$ \\
\hline $\mathrm{Q}_{\text {InfP }}$ & Plenum infiltration load & $\mathrm{W}$ \\
\hline $\mathrm{Q}_{\mathrm{L}}$ & Lighting load & $\mathrm{W}$ \\
\hline Qocc & Occupant load & $\mathrm{W}$ \\
\hline $\mathrm{Q}_{\mathrm{PL}}$ & Plug load & $\mathrm{W}$ \\
\hline $\mathrm{Q}_{\mathrm{rad}}$ & Rate of radiative heat addition & $\mathrm{W}$ \\
\hline $\mathrm{Q}_{\text {Radt }}$ & Theoretical hydronic-based heating rate & $\mathrm{W}$ \\
\hline $\mathrm{Q}_{\mathrm{RP}}$ & Room and plenum load exchange & $\mathrm{W}$ \\
\hline $\mathrm{Q}_{\mathrm{SR}}$ & Direct solar radiation load & $\mathrm{W}$ \\
\hline$\dot{Q}_{\text {water }}$ & Rate of heat addition to water & $\mathrm{W}$ \\
\hline$\Delta \mathrm{t}$ & Change in time & $\mathrm{s}$ \\
\hline $\mathrm{t}$ & Time & $\mathrm{s}$ \\
\hline$\Delta \mathrm{T}$ & Absolute surface-air temperature difference & $\mathrm{K}$ \\
\hline $\mathrm{T}_{1}$ & Temperature of surface 1 & $\mathrm{~K}$ \\
\hline $\mathrm{T}_{2}$ & Temperature of surface 2 & $\mathrm{~K}$ \\
\hline $\mathrm{T}_{\text {air }}$ & Temperature of air & $\mathrm{K}$ \\
\hline $\mathrm{T}_{\text {Ceil1 }}$ & Temperature of the ceiling surface & $\mathrm{K}$ \\
\hline $\mathrm{T}_{\text {Ceil2 }}$ & Internal temperature of the ceiling & $\mathrm{K}$ \\
\hline $\mathrm{T}_{\text {Ceil3 }}$ & Temperature of the ceiling top's surface & $\mathrm{K}$ \\
\hline $\mathrm{T}_{\mathrm{EqW} 1}$ & Temperature of the equivalent wall's surface & $\mathrm{K}$ \\
\hline $\mathrm{T}_{\mathrm{EqW} 2}$ & Internal temperature of the equivalent wall & $\mathrm{K}$ \\
\hline $\mathrm{T}_{\text {ExtW1 }}$ & Temperature of the external wall's surface & $\mathrm{K}$ \\
\hline $\mathrm{T}_{\mathrm{ExtW} 2}$ & Internal temperature of the external wall & $\mathrm{K}$ \\
\hline
\end{tabular}


$\begin{array}{lll}\mathrm{T}_{\mathrm{F} 1} & \text { Temperature of the carpet's surface } & \mathrm{K}\end{array}$

$\begin{array}{lll}\mathrm{T}_{\mathrm{F} 2} & \text { Internal temperature of the carpet } & \mathrm{K}\end{array}$

$\begin{array}{lll}\mathrm{T}_{\mathrm{F} 3} & \text { Internal temperature of the top half of the concrete slab } \mathrm{K}\end{array}$

$\mathrm{T}_{\mathrm{F} 4} \quad$ Internal temperature of the bottom half of the concrete slab $\mathrm{K}$

$\mathrm{T}_{\mathrm{F} 5} \quad$ Temperature of the bottom surface of the concrete slab $\mathrm{K}$

$\begin{array}{lll}\mathrm{T}_{\mathrm{G}} \quad \text { Global average temperature of the space } \mathrm{K} & \mathrm{K}\end{array}$

$\begin{array}{lll}\mathrm{T}_{\text {int1 }} \quad \text { Internal temperature } & \mathrm{K}\end{array}$

$\begin{array}{lll}\mathrm{T}_{\text {Inlet }} \quad \text { Temperature at the radiator inlet } \mathrm{K} & \mathrm{K}\end{array}$

$\begin{array}{lll}\mathrm{T}_{\mathrm{m}} & \text { Arithmetic mean of } \mathrm{T}_{1} \text { and } \mathrm{T}_{2} & \mathrm{~K}\end{array}$

$\begin{array}{lll}\mathrm{T}_{\mathrm{O}} & \text { Temperature outside } & \mathrm{K}\end{array}$

$\begin{array}{lll}\mathrm{T}_{\text {Outlet }} & \text { Temperature at the radiator outlet } \mathrm{K}\end{array}$

$\begin{array}{lll}\mathrm{T}_{\mathrm{P}} & \text { Temperature of the plenum air } \mathrm{K}\end{array}$

$\begin{array}{lll}\mathrm{T}_{\mathrm{R}} & \text { Temperature of the return air } & \mathrm{K}\end{array}$

$\begin{array}{lll}\mathrm{T}_{\text {Radt }} \quad \text { Temperature of the radiant panel's surface } \mathrm{K} & \mathrm{K}\end{array}$

$\begin{array}{lll}\mathrm{T}_{\mathrm{Rt}} & \text { Temperature of the room air } \mathrm{K}\end{array}$

$\begin{array}{lll}\mathrm{T}_{\mathrm{s} 1} & \text { Temperature of surface } 1 & \mathrm{~K}\end{array}$

$\begin{array}{lll}\mathrm{T}_{\mathrm{s} 2} & \text { Temperature of surface } 2 & \mathrm{~K}\end{array}$

$\begin{array}{lll}\mathrm{T}_{\mathrm{S}} & \text { Temperature of a surface } & \mathrm{K}\end{array}$

$\mathrm{T}_{\mathrm{sp}} \quad$ Set-point temperature $\mathrm{K}$

$\begin{array}{lll}\mathrm{T}_{\text {Sup }} & \text { Temperature of the supply air } & \mathrm{K}\end{array}$

$\begin{array}{lll}\mathrm{T}_{\text {Win }} & \text { Temperature of the window's surface } & \mathrm{K}\end{array}$

UA $_{\text {carp }}$ Carpet $\mathrm{UA}_{\text {cond }} \quad \frac{W}{K}$

$\mathrm{UA}_{\text {Ceil }}$ Ceiling $\mathrm{UA}_{\text {conv }} \quad \frac{W}{K}$

$\mathrm{UA}_{\text {Ceil3F5 }} \quad \mathrm{UA}_{\text {rad }}$ between the ceiling and the bottom of the slab $\frac{W}{K}$

$\mathrm{UA}_{\mathrm{CeilEq}} \quad \mathrm{UA}_{\text {rad }}$ between equivalent wall and ceiling $\quad \frac{W}{K}$

$\mathrm{UA}_{\text {CeilExt }} \quad \mathrm{UA}_{\text {rad }}$ between ceiling and external wall $\frac{W}{K}$

$\mathrm{UA}_{\text {CeilF }} \quad \mathrm{UA}_{\text {rad }}$ between ceiling and floor $\quad \frac{W}{K}$

$\mathrm{UA}_{\text {ceiltile }} \quad \mathrm{UA}_{\text {cond }}$ of the ceiling $\frac{W}{K}$

$\mathrm{UA}_{\text {CeilWin }} \quad \mathrm{UA}_{\text {rad }}$ between ceiling and window $\quad \frac{W}{K}$

$\mathrm{UA}_{\text {cond }}$ Conduction UA value $\frac{W}{K}$

$\mathrm{UA}_{\text {conv }}$ Convective UA value $\frac{W}{K}$

$\mathrm{UA}_{\mathrm{cs}} \quad \mathrm{UA}_{\text {cond }}$ of the concrete slab $\quad \frac{W}{K}$

$\mathrm{UA}_{\mathrm{Eq}} \quad \mathrm{UA}_{\text {cond }}$ of the equivalent wall $\frac{W}{K}$ 
$\mathrm{UA}_{\mathrm{EqCeil}} \quad \mathrm{UA}_{\mathrm{rad}}$ between equivalent wall and ceiling $\quad \frac{W}{K}$

$\mathrm{UA}_{\mathrm{EqExt}} \quad \mathrm{UA}_{\text {rad }}$ between equivalent and external wall $\frac{W}{K}$

$\mathrm{UA}_{\mathrm{EqF}} \quad \mathrm{UA}_{\text {rad }}$ between equivalent wall and floor

$\mathrm{UA}_{\mathrm{EqRad}} \quad \mathrm{UA}_{\mathrm{rad}}$ between equivalent wall and radiant panel

$\mathrm{UA}_{\mathrm{EqW}} \quad \mathrm{UA}_{\text {conv }}$ between the equivalent wall and room air

$\mathrm{UA}_{\mathrm{EqWin}} \quad \mathrm{UA}_{\mathrm{rad}}$ between equivalent wall and window

$\mathrm{UA}_{\mathrm{Ext}} \quad \mathrm{UA}_{\text {cond }}$ of the external wall

$\mathrm{UA}_{\text {ExtCeil }} \quad \mathrm{UA}_{\text {rad }}$ between external wall and ceiling

$\mathrm{UA}_{\text {ExtEq }} \quad \mathrm{UA}_{\text {rad }}$ between external and equivalent wall

$\mathrm{UA}_{\mathrm{ExtF}} \quad \mathrm{UA}_{\mathrm{rad}}$ between external wall and floor

$\mathrm{UA}_{\text {ExtP }} \quad \mathrm{UA}_{\text {conv }}$ between the external wall and plenum air

$\mathrm{UA}_{\text {ExtRad }} \quad \mathrm{UA}_{\text {rad }}$ between external wall and radiant panel

$\mathrm{UA}_{\mathrm{ExtW}} \quad \mathrm{UA}_{\text {cond }}$ of the external wall

$\mathrm{UA}_{\text {ExtWin }} \quad \mathrm{UA}_{\text {rad }}$ between external wall and window

$\mathrm{UA}_{\mathrm{F}} \quad \mathrm{UA}_{\text {conv }}$ between the floor and room air

$\mathrm{UA}_{\mathrm{F} 5 \mathrm{Cei13}}$

$\mathrm{UA}_{\text {rad }}$ between ceiling top and floor bottom

$\mathrm{UA}_{\mathrm{FCeil}}$

$\mathrm{UA}_{\text {rad }}$ between floor and ceiling

$\mathrm{UA}_{\mathrm{FEq}}$

$\mathrm{UA}_{\text {rad }}$ between equivalent wall and floor

$\mathrm{UA}_{\mathrm{FExt}}$

$\mathrm{UA}_{\text {rad }}$ between external wall and floor

$\mathrm{UA}_{\mathrm{FRad}}$

$\mathrm{UA}_{\text {rad }}$ between floor and radiant panel

$\mathrm{UA}_{\mathrm{FWin}}$

$\mathrm{UA}_{\text {rad }}$ between floor and window

$\mathrm{UA}_{\mathrm{rad}}$

Radiative UA value

$\mathrm{UA}_{\mathrm{Rad}}$

$\mathrm{UA}_{\mathrm{RadEq}}$

$\mathrm{UA}_{\text {conv }}$ between radiator panel and room air

$\mathrm{UA}_{\text {RadExt }}$

$\mathrm{UA}_{\text {rad }}$ between equivalent wall and radiator panel

$\mathrm{UA}_{\mathrm{RadF}}$

$\mathrm{UA}_{\text {rad }}$ between radiator and external wall

$\mathrm{UA}_{\text {RadWin }}$

$\mathrm{UA}_{\text {rad }}$ between the radiator and the floor

$\mathrm{UA}_{\mathrm{PC}}$

$\mathrm{UA}_{\text {rad }}$ between radiator panel and window

$\mathrm{UA}_{\mathrm{PF}}$

$\mathrm{UA}_{\text {conv }}$ between the ceiling and plenum air

$\mathrm{UA}_{\text {Win }}$

$\mathrm{UA}_{\text {conv }}$ between the ceiling top and plenum air

$\mathrm{UA}_{\text {WinCeil }}$

$\mathrm{UA}_{\text {conv }}$ between the window and room air

$\mathrm{UA}_{\text {Window }}$

$\mathrm{UA}_{\text {rad }}$ between window and ceiling

$\mathrm{UA}_{\text {WinEq }}$

$\mathrm{UA}_{\text {cond }}$ of the window

$\mathrm{UA}_{\text {rad }}$ between equivalent wall and window 


\begin{tabular}{clc}
$\mathrm{UA}_{\text {WinExt }}$ & $\mathrm{UA}_{\text {rad }}$ between external wall and window & $\frac{W}{K}$ \\
$\mathrm{UA}_{\text {WinF }}$ & $\mathrm{UA}_{\text {rad }}$ between window and floor & $\frac{W}{K}$ \\
$\mathrm{UA}_{\text {WinRad }}$ & $\mathrm{UA}_{\text {rad }}$ between window and radiant panel & $\frac{W}{K}$ \\
$\mathrm{v}$ & Velocity & $\mathrm{m} / \mathrm{s}$ \\
$\dot{W}$ & Rate of work & $\mathrm{W}$ \\
$\mathrm{z}$ & Height & $\mathrm{m}$ \\
$\epsilon_{1}$ & Emissivity of surface 1 & Unitless \\
$\epsilon_{2}$ & Emissivity of surface 2 & Unitless \\
$\epsilon_{\mathrm{Rad}}$ & Emissivity of the radiator & Unitless \\
\hline
\end{tabular}




\section{Abbreviations}

\begin{tabular}{|c|c|}
\hline Abbreviation & Full Name \\
\hline AHU & Air handling unit \\
\hline ANN & Artificial neural network \\
\hline BAS & Building automation system \\
\hline BIM & Building information modeling \\
\hline BMS & Building management system \\
\hline CAV & Constant air volume \\
\hline $\mathrm{CHW}$ & Chiller water \\
\hline $\mathrm{CT}$ & Cooling tower \\
\hline DDC & Direct digital control \\
\hline EER & Energy efficiency ratio \\
\hline FDD & Fault detection and diagnostics \\
\hline FTCS & Forward time, centered space \\
\hline GHG & Greenhouse gas \\
\hline HFM & Heat flow model \\
\hline HVAC & Heating, ventilation and air-conditioning \\
\hline HW & Hot water \\
\hline MIMO & Multi-input-multi-output \\
\hline MFM & Multi-level flow models \\
\hline $\operatorname{Rad}$ & Radiator panel \\
\hline RG & Return grille \\
\hline RH & Reheat coil \\
\hline SAT & Supply air temperature \\
\hline SD & Supply diffuser \\
\hline SEER & Seasonal energy efficiency ratio \\
\hline SHR & Sensible heat ratio \\
\hline $\mathrm{TU}$ & Terminal unit \\
\hline VAV & Variable air volume \\
\hline VAVAC & Variable air volume air-conditioning \\
\hline
\end{tabular}




\section{Chapter 1}

\section{Introduction}

\subsection{Background}

Buildings account for an enormous amount of the world's total energy consumption. Internationally, the energy consumed by buildings is approximately $20.1 \%$ of the total delivered energy consumed worldwide [1]. The International Energy Outlook 2016 (IEO2016) Reference Case has predicted that the energy consumed in buildings will continue increasing by an average of $1.5 \%$ per year from 2012 to 2040 [1]. The IEO2016 Reference Case also predicts that the commercial sector's energy consumption will grow by $1.6 \%$ per year from 2012 to 2040, which is the fastest growing energy demand sector [1]. North America is partially responsible for this high global average. In 2015, approximately $40 \%$ of the United States energy consumption was due to residential and commercial buildings and in 2009, Canadian buildings accounted for approximately $31 \%$ of total energy use [2]. Of the $31 \%$ of energy consumed by buildings in Canada, residential and commercial buildings accounted for $17 \%$ and $14 \%$, respectively. The total greenhouse gas (GHG) emissions for buildings in Canada was 28\%, $15 \%$ for residential buildings, and $13 \%$ for commercial buildings [2].

From a 2010 Commercial Building Energy Consumption Survey conducted by Natural Resources Canada, it was determined that HVAC accounted for half of the total energy consumed in buildings [3]. The breakdown of the energy consumption in commercial buildings 
can be seen in Figure 1.1 .

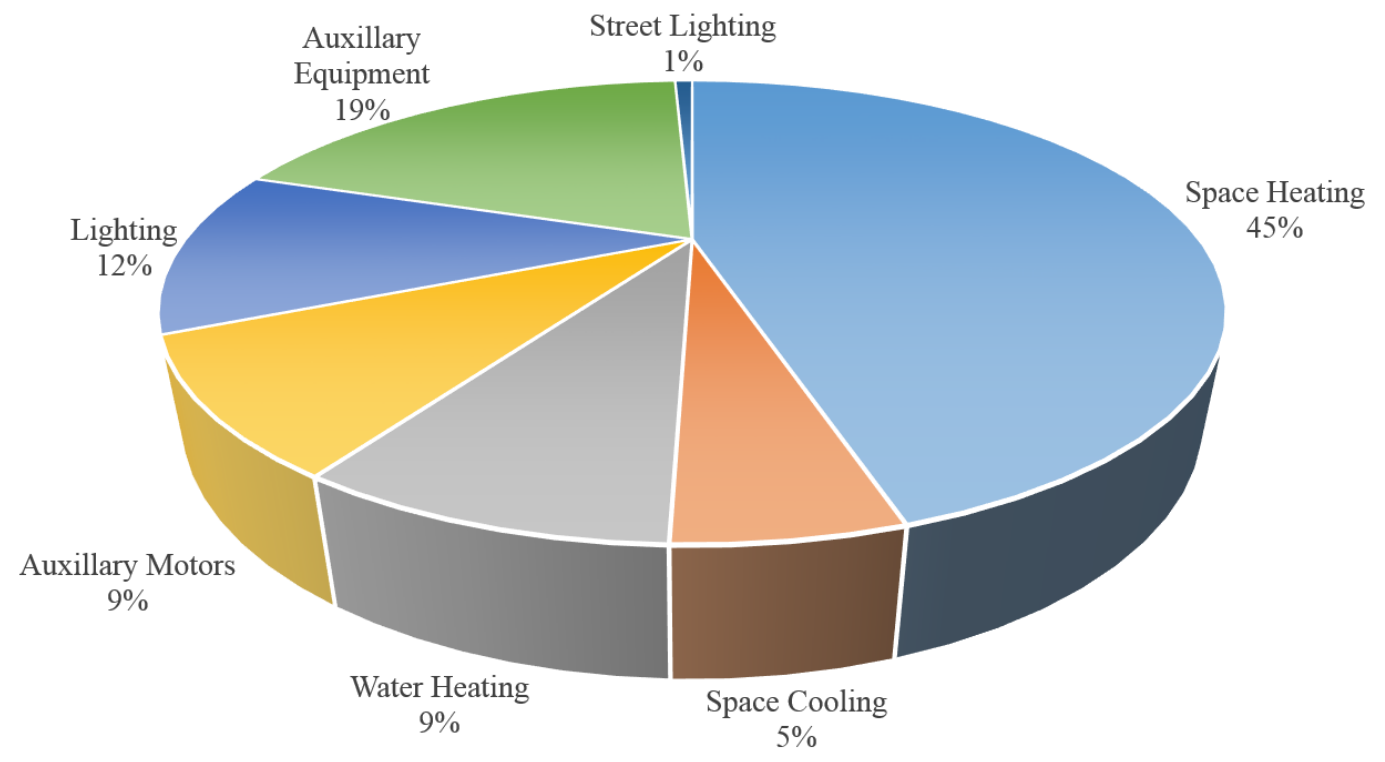

Figure 1.1: 2010 Commercial building energy consumption breakdown [3]

Buildings have been reported to operate inefficiently [4] due to various faults within the mechanical system. These faults are often broken into two categories, soft and hard faults [5, 6, 7, 8]. Hard faults deal with equipment malfunctioning [7] and soft faults are mainly issues with control programming [5]. Since hard faults refer to equipment malfunctioning they require manual labour to replace the component [9]. However, if sensor redundancy is present, these types of faults might not require immediate attention. For example, if two sensors are measuring the same variable and one sensor breaks, the other sensor can still be used to obtain measurements. Soft faults, on the other hand, can typically be corrected without on-site, human intervention [9].

Faults can arise in many areas of the mechanical system and it is common to distinguish between areas of focus by using the terms building-level, distribution-level and zone-level. Figure 1.2 shows the areas that are related to these different level classifications. The building-level focuses primarily on the larger equipment contained in the mechanical room. 
These large pieces of equipment, such as air handling units (AHUs), chillers, boilers and cooling towers (CTs) are used to provide the building with heating, cooling and fresh air. The distribution-level refers to all of the ductwork used to transport the air from the AHU to the zones and vice versa. The zone-level consists of any equipment within the office spaces, such as return grilles (RGs), supply diffusers (SDs), thermostats and radiant panels (Rad). A radiant panel has a valve connected to the hot water supply and is controlled by the thermostat in the room. Also included in this grouping are the pieces of equipment that permit air to a zone, terminal units (TUs), such as variable air volume (VAV) boxes and constant air volume (CAV) boxes. A VAV box is a piece of equipment that varies the amount of air that enters into a zone. These TUs can also be equipped with a reheat coil $(\mathrm{RH})$, allowing for the air to be heated up at the zone-level. The reheat valve is controlled by the thermostats in the zone and permits hot water to warm up the air before it enters into the spaces. A thermal zone is an area in the building which has its own temperature control [10]. It is common practice to group multiple single occupant offices into a single zone, as would be the case in the scenario displayed in Figure 1.2

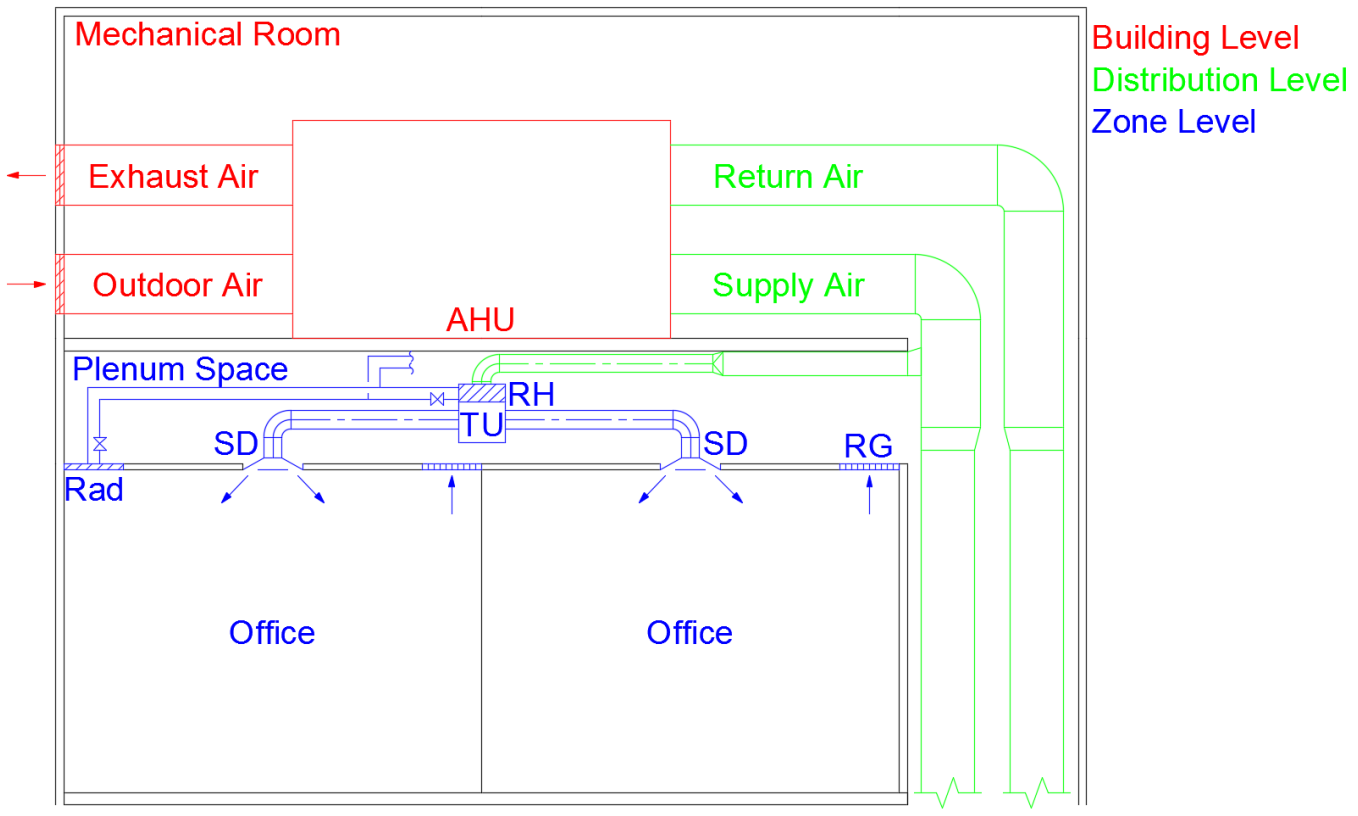

Figure 1.2: Mechanical system description 
Soft and hard faults in mechanical systems are frequently discussed and little consideration is given to inefficiencies caused by flaws in the original design of the building. Issues such as poor thermostat placement, poor SD and RG placements, oversizing TUs and many more design inefficiencies result in an unwarranted amount of energy to be consumed by HVAC systems. National Resources Canada conducted a survey for the year 2010, where it was determined that HVAC systems accounted for approximately $50 \%$ of the energy consumption in commercial buildings [3]. For example, Figure 1.3 shows a thermostat in a west facing office which is hit by sunlight in the late afternoon during select months. The solar radiation on the thermostat causes the zone to appear as though it requires cooling when it does not. Ultimately, excess cooling is supplied to the zone which has a negative effect on both energy consumption and occupant comfort.

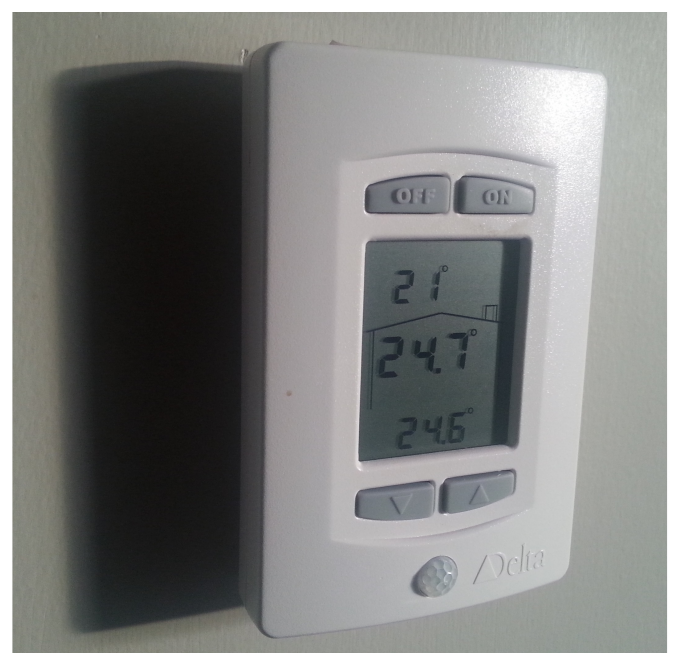

Figure 1.3: Thermostat misreading example

Figure 1.4 shows a RG located beside the SD, resulting in short-circuiting, where a portion of the supply air is not able to mix in the room and instead follows a direct path to the return plenum. 


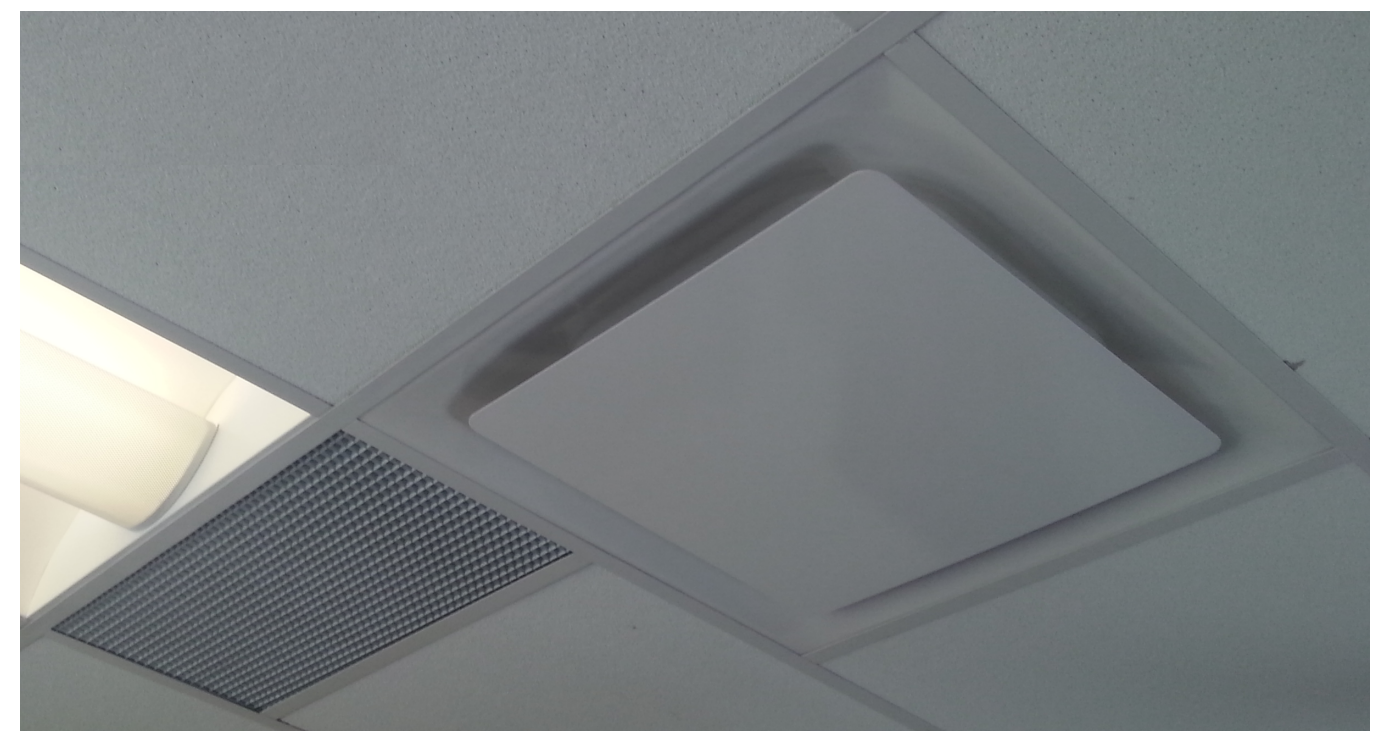

Figure 1.4: Short-circuiting example

Poor system operations [4] make improving the performance of buildings a main focal point when attempting to reduce energy consumption and GHG emissions. FDD has proven to be successful in reducing buildings' energy consumption, with an average energy savings of greater than $20 \%$, with a typical payback period of fewer than two years [11]. The National Institute of Standards and Technologies (NIST) has found that FDD has the ability to save between 10 and 40 percent of HVAC energy consumption depending on the age and condition of the equipment, maintenance practices, climate and building use [12]. Furthermore, various field experience has shown that savings between 5 and 30 percent are possible through an FDD application and by fixing the diagnosed fault [13]. FDD has a relatively low-cost and non-intrusive means associated with it when considering it can be paired with a commercial buildings' building automation system (BAS). Commercial buildings typically have a BAS set in place. These systems offer plenty of information regarding the system's functionality and building status. FDD offers a way to exploit the already streaming data to address inefficiencies within the building. Pairing FDD with BASs can inform new building designs, from either a building or zone-level perspective, ultimately 
reducing inefficiencies in the future. Previous research has been successful utilizing FDD on the building-level, however, there has been very little research for the zone-level [14].

\subsection{Problem Definition}

The significant number of faults diagnosed in previous research, along with the substantial portion of energy consumption in buildings suggests a continued need for research on FDD for buildings. Furthermore, there is a lack of literature pertaining to zone-level inefficiencies. This thesis aims to address the gap in research regarding FDD for building systems, by developing an FDD tool in Matlab for zone-level inefficiencies.

\subsection{Contribution of Thesis}

The most significant contributions of this thesis are as follows:

1. A parametric energy model for rooms and zones was developed in Matlab utilizing the explicit finite difference method. By utilizing occupant, plug load, lighting load, outdoor air temperature and solar radiation data the room air temperature, air-based and hydronic-based heating and cooling rates were predicted for several spaces within a zone.

2. A program in Matlab was developed to compute temperature and energy-related metrics for multiple spaces contained within a zone. These metrics were measured using on-site measurements and include the space temperature, air-based and hydronic-based heating and cooling rates. 
3. A parametric energy model was created for a thermal zone containing four offices in the Canal Building, located on Carleton Campus. The measured temperature and energyrelated metrics were then compared to the results from the parametric energy model. This comparison allowed the functionality of the model to be verified and ultimately allowed for the detection of various inefficiencies within the zone under evaluation.

4. The cause of the discrepancies between the parametric energy model results and the measured temperature and energy-related metrics was determined. The effect of these diagnosed faults was then analyzed and quantified.

\subsection{Organization of Thesis}

The thesis is divided into the following chapters:

Chapter 2 discusses a survey of literature on the use of FDD in building applications, as well as the fault categories the literature addressed. The chapter concludes with a summary that discusses the motivation for this work.

Chapter 3 describes the data acquisition process, model development, model verification, fault detection tool and the fault diagnostics methodology in detail. The fault detection section describes the model-based approach that was undertaken and the fault diagnostics section discusses the heuristic-based rule set used to explain various discrepancies between the measured and theoretical zone performance.

Chapter 4 begins by presenting the faults that the system detected. Each fault is then addressed individually, starting with an analysis of the results obtained through the fault detection tool, which compares the simulation and real model results. The fault diagnostics 
section follows, which contains an analysis of each result and the depiction of the inefficiency that is present. Afterward, the severity of the fault is quantified in the fault evaluation section.

Chapter 5 begins with a discussion of the significance of the research and findings. The FDD tool's applicability in other buildings is then discussed, followed by methods to convey the identified design faults to designers. The chapter closes by addressing the limitations of the development and the required future work.

Chapter 6 provides a conclusion regarding the FDD methodology and implementation. The chapter contains an overview of the research and findings, how it ties in with the required internship and finishes with a closing remark.

Appendix A presents additional material which supports the presented research. Included in Appendix A is a link to the developed FDD tool's Matlab scripts and functions. 


\section{Chapter 2}

\section{Literature Review}

Chapter 1 outlined the issue that is being addressed in this research. Chapter 2 presents a review of the literature that is relevant to the present work and research. A brief overview of soft, hard, design and occupant faults in the building context is conducted, followed by an investigation of the faults that past studies have addressed. The qualitative modelbased, quantitative model-based and process history-based FDD methodologies are then

reviewed, followed by an investigation of past literature and applications of FDD in the building context.

\subsection{Introduction to Faults}

Problems often arise in buildings, causing an excess amount of energy consumption [4].

"These problems, or "faults", include mechanical failures such as stuck, broken, or leaking valves, dampers, or actuators; control problems related to failed or drifting sensors, poor feedback loop tuning or incorrect sequencing logic; fouled heat exchangers; design errors; or inappropriate operator intervention. Such faults often go unnoticed for extended periods of time until the deterioration in performance becomes great enough to trigger comfort complaints or gross equipment failure [12]."

These faults are often divided into two categories: hard and soft faults [5, 6, 7, 8]. An 
additional category was identified by Schein, Bushby, Castro and House (2006) [12] as design faults, although this has not actually been addressed in many of the previous FDD for HVAC application literature. Finally, an occupant faults category was addressed by Yu, Paassen and Riahy (2003) [15], but was not discussed in great detail.

\subsubsection{Soft Faults}

Soft faults are also referred to as "software faults" [5]. As the name implies, software misconfigurations are the focus in this category and can cause over-cooling, under-cooling, in addition to hardware deterioration, occupant discomfort and a waste of energy [5]. In addition to software misconfigurations, the fouling of tubes of condensers and evaporators are also considered in this category [7]. Soft faults have been receiving an increase in attention due to the difficulty to detect them [16]. Furthermore, this fault type may also be increasing in importance with the recent movement from mechanical control systems to integrated software-dominated control systems. Table 2.1 lists the various soft faults that were addressed in the reviewed literature, as well as what level the faults were associated with. 
Table 2.1: Soft faults addressed in the literature

\begin{tabular}{|c|c|c|}
\hline Article & Soft Faults Addressed & Fault Level \\
\hline [12] & $\begin{array}{l}\text { Controller programming errors related to tuning, set-points } \\
\text { and sequencing logic }\end{array}$ & $\begin{array}{l}\text { Zone \& } \\
\text { Building }\end{array}$ \\
\hline [17] & Incorrect SAT set-point and wrong AHU mode activated & Building \\
\hline$[18]$ & $\begin{array}{l}\text { Offsets in return, outdoor, mixed and supply air } \\
\text { temperature (SAT) sensors }\end{array}$ & Building \\
\hline [7] & Condenser fouling & Building \\
\hline [19] & Condenser and evaporator fouling & Building \\
\hline$[20,21]$ & Heat exchanger fouling & Building \\
\hline [22] & $\begin{array}{l}\text { Condenser and evaporator fouling, and capacity, energy } \\
\text { efficiency ratio (EER), sensible heat ratio (SHR) and } \\
\text { seasonal energy efficiency ratio (SEER) degradation }\end{array}$ & Building \\
\hline [23] & Any soft faults in a cooling coil subsystem & Building \\
\hline$[24$ & Any soft faults in a mechanical draft-counter flow CT & Building \\
\hline [13] & AHU economizer & Building \\
\hline [25] & AHU and heating system degradation & Building \\
\hline [26, 27] & Whole building components, e.g. AHUs and meters & Building \\
\hline [28] & Chiller plant, boiler plant and AHU & Building \\
\hline
\end{tabular}




\subsubsection{Hard Faults}

Hard faults are also referred to as "hardware faults" [5] and are physical faults that cause the system to stop functioning [7]. These faults often occur abruptly, causing sudden failure to a part of the plant, generally making them easier to detect [5, 7]. The hard fault category includes issues in the system such as seized compressors, broken fan belts and malfunctioning electrical components [7]. Also included in this category are sensor failures, broken or stuck dampers, or valve leakages [5]. Essentially, if a fault requires physical human intervention, it is considered a hard fault [29]. Hardware faults have been the focus of a major portion of the previous literature on FDD for HVAC applications, primarily focusing on these failures in large central chilled water distribution systems and air handling systems [19]. Table 2.2 lists all of the different hard faults that were addressed in the reviewed literature, as well as what level the faults were associated with. 
Table 2.2: Hard faults addressed in the literature

\begin{tabular}{|c|c|c|}
\hline Article & Hard Faults Addressed & Fault Level \\
\hline [15] & Jammed radiator valve & Zone \\
\hline [30] & Stuck cooling coil valve and VAV box damper & $\begin{array}{c}\text { Zone \& } \\
\text { Building }\end{array}$ \\
\hline [31] & $\begin{array}{c}\text { Frozen AHU supply fan, stuck VAV box damper and } \\
\text { broken outdoor air temperature }\end{array}$ & $\begin{array}{l}\text { Zone \& } \\
\text { Building }\end{array}$ \\
\hline [17] & Mixed air, return air and SAT sensor faults & Building \\
\hline [12] & $\begin{array}{l}\text { Stuck or leaking mixing box dampers, heating and cooling } \\
\text { coil valves, and temperature sensor faults }\end{array}$ & Building \\
\hline [18] & $\begin{array}{l}\text { Stuck or leaky outdoor and return air dampers, and heating } \\
\text { and cooling coil valves }\end{array}$ & Building \\
\hline [19] & $\begin{array}{l}\text { Refrigerant leakage, liquid line restriction and compressor } \\
\qquad \text { valve leakage }\end{array}$ & Building \\
\hline [20, 21] & $\begin{array}{l}\text { Compressor valve leakage, liquid line restriction, presence } \\
\text { of non-condensables and low or high refrigerant charges }\end{array}$ & Building \\
\hline [24] & Any hard faults in a mechanical draft-counter flow CT & Building \\
\hline [22] & $\begin{array}{l}\text { Low/high refrigerant charges, liquid line restrictions, } \\
\text { non-condensable gas and compressor leakage }\end{array}$ & Building \\
\hline [26, 27] & Whole building components, e.g. AHUs and meters & Building \\
\hline
\end{tabular}




\subsubsection{Design Faults}

Design faults, as the name suggests, are sub-optimal design aspects in the system that are designed by the engineer or architect, and are present prior to the operation of the building. There are many design objectives when designing a building and even though the strategy may reduce the efficiency of the building it is important to not categorize them as a fault since they could serve another purpose, such as large windows for visual comfort. The design fault category includes faults such as poor thermostat placement, short-circuiting, and the undersizing or oversizing of equipment. Although it is known that project time constraints can lead to buildings being designed and constructed with faults, it is still rarely mentioned in the application of FDD for HVAC. Design faults limit the maximum potential efficiency of the system and do so for the entire life of the building. Based on an evaluation of the faults detected it may not be feasible to fix these in the building that they are detected, however, it can give valuable insight for future building design. Aspects of the design that may have been neglected in the past could become a focal point if it is determined to yield significant cost savings.

A total of 36 articles and papers were reviewed, of which, only Schein et al. (2006) [12] mentioned design faults as an issue and stated that their methodology could be used to detect design faults such as undersized coils.

\subsubsection{Occupant Faults}

Occupant faults can be thought of as any human interaction (or lack thereof) that results in an increase in energy consumption. An occupant's primary concern is their comfort, not 
the building's energy consumption. Although opening a window could have negative effects on the building's energy consumption if it is done in order to ensure that the occupant is thermally comfortable or for indoor air quality purposes it cannot be considered a fault. Thus, it is important to distinguish between these actions and the unnecessarily faulty actions of occupants, such as leaving that same window open during unoccupied times. The occupant fault category includes faults such as leaving the window open, leaving the computer or lights on overnight and fighting over the set-point temperature in a grouped office zone. Previous studies have shown that excessive energy consumption can be caused by occupant actions, ultimately negating the technological improvements in buildings, as cited by Schenin \& Bushby [32]. Yet, this fault type was not mentioned in any of the articles or papers that were reviewed. However, Yu, Paassen, Riahy (2003) did aim to detect the occupant fault of leaving a window open [15].

\subsection{Introduction to FDD}

FDD is a methodology which utilizes systematic techniques to detect and diagnose these various faults [33]. Fault detection is used to indicate a deviation from the expected performance, whereas fault diagnosis is the step that determines the cause of the fault [19]. An additional step in FDD is the evaluation process, which assesses whether the impact of the fault is severe enough to justify service [19].

FDD has been utilized in various applications for many years, however, research on automated FDD for mechanical systems did not begin until the late 1980's [34]. It became a major area of interest towards the beginning of the $21^{\text {st }}$ century [34] and interest has continued to grow as a result of the increasing focus in global energy consumption, and increased complexity of building systems [34]. There are three FDD techniques that may be 
utilized: Qualitative Model-Based, Quantitative Model-Based, and Process History-Based $[13,18,26,35,36,37,38]$.

\subsubsection{Qualitative Model-Based FDD}

The qualitative model-based techniques utilize either a rule-based system or qualitative physics [37, 39]. Rule-based systems use a set of if-then statements that consider the equipment control limits [17]. A sequential rule set for the utilization in an FDD tool was developed by Yang, Cho, Tae and Zaheeruddin (2008) [17]. In particular a rule from Yang et al. (2008) [17] can be used to display how this type of FDD tool functions. The rule states that if equation 2.1 is true, there is a fault in the system [17].

$$
T_{\text {oa }}<T_{\text {co }}-\varepsilon_{\mathrm{t}}
$$

This rule follows that if the outdoor air temperature $\left(\mathrm{T}_{\mathrm{oa}}\right)$ is less than the change over temperature $\left(\mathrm{T}_{\mathrm{co}}\right)$, minus the error associated with this sensor then a fault occurred when selecting the AHU mode [17].

Rule-based systems are based on either expert knowledge or first principle analysis [26] and are simpler for domain experts to set up [5]. These systems are able to identify common faults seen in practice, with low false alarm rates for appropriate thresholds [5].

"However, if generic rules are written to cover numerous faults which may not be applicable to a particular buildings situation, they result in a large number of false alarms. Writing specific rules for all possible faults that may occur in a particular building requires considerable knowledge about the building location, equipment and usage [5]."

This scenario is illustrated in Figure 2.1. EnteliWEB is a web-based building management system (BMS) which is utilized at Carleton University and is frequently notifying 
building operators that there are issues in the system. Figure 2.1 shows a number of new alarms that the rule-based system found during June $29^{\text {th }}, 2017$, some of which occur within minutes of each other. It is unlikely that 14 new faults occurred in the system over a span of 7 hours and thus, it is probable that a majority of these are false alarms.

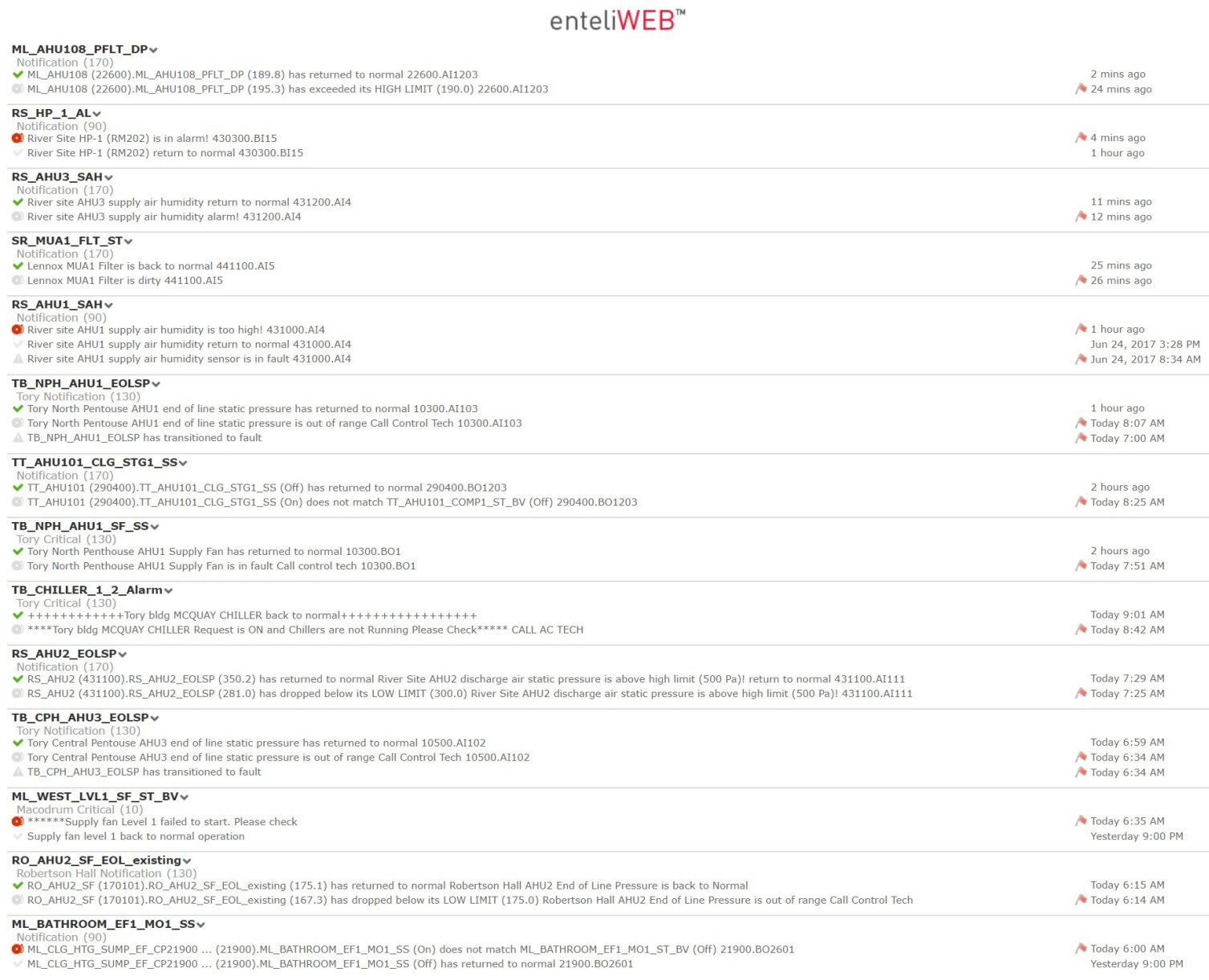

Figure 2.1: EnteliWEB fault notifications

Although there are some disadvantages to the rule-based technique, its simplicity, ability to identify many common faults seen in practice and many other advantages have allowed this approach to fall among the most widely used methods of supervised FDD in buildings [5, 19]. Previous literature that has applied this methodology will now be discussed. 
Schein \& Bushby (2006) developed a system-level FDD tool that combined a hierarchical decision-making framework and a set of rules to detect faults in chiller plants, boiler plants, AHUs, and TUs [28]. The tool was tested by utilizing the simulation tool "HVACSim+" to analyze a three-story building [28]. One week long simulation studies were performed for 20 different fault cases in the heating, cooling, and changeover seasons. Of the 60 simulations, the actual source of the fault was identified 49 times, 8 times it correctly identified non-fault scenarios, and 3 times it incorrectly identified scenarios as faults [28].

Schein et al. (2006) presented air handling unit performance assessment rules (APAR) [12]. APAR utilizes a set of expert rules based on mass and energy balances as the method for detecting faults in AHUs [12]. APAR determines the mode of operation of the AHU through control signals and occupancy information [12]. Based on the mode of operation, a specific set of rules is analyzed [12]. If a rule was satisfied then a fault was present. However, additional effort was required to pinpoint the problem since it does not have a diagnostics tool built in [12]. An office building, restaurant, university campus building and community college building were used as case studies for the APAR tool [12]. These buildings consisted of both CAV and VAV box systems [12]. In the studies, APAR detected that an AHU switched between modes a total of 26 times in one-hour [12]. Through further evaluation, the operations staff confirmed this fault to be caused by poor tuning of the temperature control PID loop in the AHU controller [12]. More faults were detected in these studies, such as AHU SAT set-point fault, AHU outdoor air temperature sensor fault and AHU simultaneous heating and cooling fault [12]. The tool displayed promising results as it produced consistent results through all of the case studies and detected several common mechanical and control faults [12].

Yang et al. (2008) developed sequential rule-based algorithms to detect several faults 
in AHUs [17]. The algorithms primarily focused on temperature control in the AHU [17]. Rules were developed that could detect if there were mixed air, return air and SAT sensor faults, if there was an incorrect SAT set-point and if the wrong AHU mode was activated [17]. The ability of this development was tested by artificially inducing faults in an AHU for a green building [17]. Sometimes if faults are not present in the system, artificial experiments are conducted, where external devices are implemented as a means of simulating the presence of a particular fault. The FDD system is then tested, by evaluating the system and determining whether the fault of interest is present. Yang et al. (2008) artificially induced faults into the AHU by connecting a variable resistance device in both series and parallel [17]. In the end, it was concluded that the presented algorithm accurately detected and isolated sensor faults better than existing methods [17].

\subsubsection{Quantitative Model-Based FDD}

The quantitative model-based approaches exploit first principles models and are referred to as "white box" [26]. They are based on fundamental physical relationships and can be described as either simplified or sophisticated models, depending on the detail of the mathematical model [18, 26, 37]. Sophisticated modeling tools like EnergyPlus typically require a large number of inputs to run a simulation [26]. Due to a large number of inputs, these types of models are often difficult to calibrate [26]. Simplified models require fewer inputs, which yields an easier calibration when compared to the more complex models [40].

Quantitative model-based techniques can be further categorized into bottom-up and top-down approaches [26, 41]. A bottom-up approach focuses on the component or subsystem level, whereas the top-down approach is based on a whole building-level analysis [26]. Both methods use explicit input-output models to compare the actual operation to 
the ideal operation [38]. However, in the bottom-up approach, this comparison is used to detect faults in the particular system element [13], as opposed to the top-down approach which detects faults in the whole building system [26]. Generally, the component-level approach requires a lot of detailed information and thus, is well suited for use with direct digital control (DDC) systems [26]. On the other hand, the whole building level analysis does not need the vast amount of information that the bottom-up approach requires and can be applied regardless of the availability of a DDC system [26]. Diagnosing the faults is often simple in bottom-up approaches since they are focused on a single component, although difficulty is often found in the number of faults that occur at any given time [26]. Furthermore, this approach does not clearly identify the effects of the detected fault(s) on the system as a whole, as cited by [26]. The downfall of whole building analysis lies in detailed diagnostics. However, it does make the effects of the fault on the system as a whole clear [26, 41].

Due to the data required in the quantitative model-based approach, it can be expensive, as it typically results in extensive experimental campaigns to set up and introduce additional input and output measurements that are not available through the BAS [38]. They are also a computationally demanding solution to FDD and require the use of a general-purpose computer since the BAS has limited available processor and memory capacity [28].

"Moreover, they are often tailored to specific system structures. HVAC systems are intrinsically nonlinear, multi-input-multi-output (MIMO) with interrelated parameters, and they exhibit such attributes as unmodelled dynamics, large-grained uncertainty, and incomplete knowledge of key parameter values. Therefore, the development of robust models for this kind of system is a burdensome task [38]."

However, previous research utilizing quantitative model-based FDD has been applied 
successfully to various system components and on the whole building, this work will now be discussed in further detail.

Dong, O’Neill \& Li (2014) developed a fully BIM enabled Information Infrastructure $\left(\mathrm{BIM} \mathrm{I}^{2}\right)$ for whole building analysis [13]. BIM I ${ }^{2}$ combined a first principles based model and a probabilistic graphical model which was tested in a building located in Great Lake, Illinois [13]. A fault in the AHU economizer was detected, the damper position remained at $100 \%$ open, when it should have been fluctuating [13]. Ultimately, the analysis found that the control sequence's enthalpy calculation was flawed [13].

Bynum, Claridge and Curtin (2012) presented an Automated Building Commissioning Analysis Tool (ABCAT) that utilized a calibrated mathematical model to predict energy consumption for given weather conditions [42]. ABCAT used first principles for a whole building level technique [42]. In a companion paper by Claridge and Lin this tool was tested on The Texas A\&M campus utilizing 15 years worth of building energy consumption data [27]. The data covered the operations of five buildings on the campus and was able to detect 18 different faults that had occurred over the years [27]. After having success with the tool based on historical data, live testing was conducted on two buildings, one in New York and the other in Nebraska [42]. ABCAT had success in detecting excess cooling energy which was related to a low discharge air temperature on two of the three AHUs, faulty meter calibration, and hot water (HW) metering failure [42], as well as chiller water (CHW) faults and HW faults [27]. The case studies displayed the value of the tools approach in detecting faults over weeks and months, as opposed to days [42].

Beghi, Cechinato, Paggiaro and Rampazzo (2013) presented a simplified modeling technique for FDD in variable air volume air-conditioning (VAVAC) systems [30]. They utilized a lumped-parameter model that was developed in Matlab/Simulink ${ }^{\mathrm{TM}}$ and a direct 
feedback linearization technique was used to control the resulting nonlinear system [30]. Simulations were run to detect the most common and relevant faults in a two zone VAVAC system, such as a stuck cooling coil valve and stuck VAV box dampers [30]. In the end, the test simulations displayed good performance of the control technique [30].

Gao, Wang, Shan and Yan (2016) utilized first-order differential equations to detect low delta-T syndrome in complex HVAC systems [25]. Low delta-T syndrome is when the cooling system is not extracting the quantity of heat it was designed to remove. Faults, such as dirty coils can cause the return water temperature to be lower than it was designed for, causing the chiller to operate inefficiently. A case study was conducted which consisted of the primary-secondary chilled water system in a building located in Hong Kong [25]. The building was selected due to the fact that after 2008, the central chilled water plant consistently encountered a deficit flow problem and low delta-T syndrome [25]. The reference models predicted the benchmark of the performance indices well and the model was capable of detecting and quantitatively evaluating the low delta-T syndrome [25].

Zimmermann, Lu, and Lo (2012) presented a quantitative model-based FDD tool, a Heat Flow Model (HFM) methodology that was automatically generated from BIMs for automatic FDD generation [39]. The HFM combined the advantages of multi-level flow models (MFM) and rule-based FDD approaches while overcoming the limitations of them [39]. To test the developed HFM, a small bank was selected for a case study [39]. The bank was comprised of an HVAC system that consisted of one AHU and three spaces controlled by VAV boxes with reheat [39]. The building was successfully imported into the engineering tool and an object-orientated engineering model was developed [39]. Further development of a fault simulator was completed with Matlab/Simulink ${ }^{\mathrm{TM}}$ for the generation of fault-free and faulty test data [39]. The aim of this tool was to detect faults such as offsets in the space, return, supply, outdoor, discharge, and mixed air temperature sensors, stuck 
VAV box, outdoor and return air dampers, stuck or leaking heating and cooling coil valves, and stuck or leaking reheat valves [39]. The case study proved the tools ability to detect such faults in the system [39].

Yu et al. (2003) presented a case study of an office building in the Netherlands, "Kropman BV" in Rijswijk. They created and tested their simulation models ability to predict the temperature of an office with a radiator and operable window in it [15]. The physical-based model was developed to detect when the window was open and the radiator valve jammed [15]. The tool displayed promising capabilities and was able to detect both of the faults it was designed for in this building [15].

Li, Li and Seem (2010) developed a simple dynamic model to detect faults in a typical mechanical counter-flow cooling tower [24]. The dynamic model applied the finite volume method to a one-dimensional heat and mass transfer analysis for the air and water sides of the cooling tower [24]. Experimental data from Simpson \& Sherwood [43] was used to evaluate the performance of the steady-state model [24]. The results were compared to previous steady-state models for the cooling tower and were found to be similar [24].

Busewell, Haves and Wright (2003) utilized first principle based methods for two separate tools to act as the reference models in each of the individual FDD tools [23]. The first method diagnosed the faults based on a set of rules, the second method came straight from the parameter values and in this system, rules are only employed to identify ambiguous diagnoses [23]. A building's cooling coil sub-system was analyzed for six months, this duration was selected in order to cover all of the operating conditions that the system can endure during an entire year [23]. In the end, both methodologies succeeded and were deemed suitable for online application and are capable of detecting faults, with some level of diagnosis as well [23]. 


\subsubsection{Process History-Based FDD}

Process history-based FDD can be further categorized as either "black box" or "grey box" models [18]. Black box models include statistical, artificial neural networks (ANN) and other pattern recognition techniques [18]. Grey box models can also be referred to as "fuzzy linguistic" models [22]. These types of models also include a theoretical structure, but only a partial one which is combined with data to complete the model [22]. Both concepts are based on a set of training data used to map inputs and outputs, and mainly involves comparing a calculated statistic for a given time frame with the same statistic from a previous frame of time [5]. Afterward, if this comparison contains discrepancies then the models have changed and this period of time is flagged as an anomaly [5].

Process history-based FDD methods do not require an explicit model of the system [38]. Not requiring an explicit model of the system is extremely advantageous when combining this with the large amount of data that can now be obtained through recent developments in monitoring systems [38]. Furthermore, this approach can easily be extended to systems that are comprised of different structures [38]. Conversely, this data-driven approach requires a lot of training data [5]. The performance of this method depends significantly on this training data and it may degrade with unknown system operation [38]. Process historybased FDD is less computationally demanding than the quantitative model-based method [28]. However, it still requires the use of a general-purpose computer due to the limited available processor and memory capacity in the BAS [28].

Process history-based FDD has proved to be a promising methodology for capturing the behavioural characteristics of HVAC systems, black-box models, in particular, have had high success [34, 44]. Previous literature on process history-based FDD will now be reviewed. 
Li \& Braun (2007) utilized mathematical models to detect multiple simultaneous faults in vapor-compression air conditioners [22]. To test this methodology, a 5-ton rooftop unit with an SEER of 11 was installed at Purdue University [22]. Artificial faults were primarily introduced in the summer and fall of 2003, but several additional ones were implemented in the spring of 2004 [22]. Further testing displayed that the tool could identify the faults before they caused a 5\% degradation in the cooling capacity, EER, and SHR. 41 simultaneous fault combinations were applied, of which no wrong diagnosis occurred [22]. However, twice the system falsely determined that a liquid line restriction was present [22].

Wu \& Sun (2011) presented a process history-based approach that utilized an energy flow model to approximate normal energy consumption levels for different time intervals [31]. These predicted values were then applied in real time to detect any faults in the current operations of the Science and Engineering Building on UC Merced Campus [31]. After four weeks of simulations, a fault was found in the AHU, the supply fan froze, which caused a change in the energy consumption levels for the week [31]. The energy flow model also detected a fault in the outdoor air temperature sensor [31]. Finally, the common VAV box stuck damper fault was artificially implemented by blocking the SD [31]. Artificially blocking the SD allowed them to evaluate how the performance of the system was affected and ultimately led to the detection of this fault in the system [31].

Cheung \& Braun (2013) used a grey box modeling technique to detect faults at various levels [20, 21]. Eight typical United States systems were considered to validate the tool's functionality in the companion articles [20, 21]. The systems consisted of a ducted airconditioning system and heat-pump equipment [20, 21]. The tool aimed to detect faults in the system that related to compressor valve leakages, liquid line restrictions, the presence of non-condensables, low or high refrigerant charge and heat exchanger fouling [20, 21]. Ultimately, the tool proved it's capability of predicting the trends in states and performance 
under both faulted and non-faulted conditions [20, 21].

Rossi \& Braun (1997) presented a rule-based approach that relied on the statistical analysis of online measurements [19]. The tool required limited sensor information and was able to detect refrigerant leakage, liquid-line restriction, compressor valve leakage, and condenser and evaporator fouling using only temperature measurements and one humidity sensor [19]. The rule-based methodology was tested on a 3-ton rooftop air conditioner [19]. The case study confirmed the tools ability to use such limited sensor measurements and detected a 5\% loss of refrigerant, although no other faults were detected [19].

Cui \& Wang (2005) used measurements from the BMS to calculate performance indexes for previous non-faulty times [7]. These reference performance indexes were calculated for a commercial building in Hong Kong to test the functionality of the FDD tool over the span of a month [7]. The aim of the test was to detect faults such as reduced evaporator water flow, refrigerant leakage, excess oil, condenser fouling and non-condensables in the refrigerant [7]. The tool found that the condenser in the 1500-ton York seawater cooled centrifugal chiller began to foul, due to the direct cooling by the seawater [7].

Angelov, Hanby, Buswell and Wright (2000) proposed evolutionary fuzzy rule-based (EFRB) models to detect faults in a boiler [45]. The tool was as flexible as other black box models, while also being more transparent [45]. Data regarding the typical ranges of operation for the natural gas-fired boiler was used to train the model [45]. Two models were created, one was able to predict the efficiency of the boiler, by only utilizing the boiler load and return water temperature as the inputs [45]. The other, predicted the flow temperature, using the return water temperature and the control signal [45]. By utilizing these methods in conjunction the fuel consumption and annual energy cost can be predicted [45]. These models displayed promising results, both yielding predictions with small errors [45]. 


\subsection{Summary}

An in-depth review of the three different FDD techniques and fault types was performed. Each of the FDD methods has strengths and weaknesses, which are listed in Table 2.3. All of these methodologies have been successfully implemented in previous studies and almost all studies focus on soft and hard faults, with a growing interest in soft faults as they are more difficult to detect [16]. These studies primarily focus on soft and hard faults in the larger components of the mechanical system, such as chillers and AHUs [5, 38]. Little attention has been given to the zone-level in building FDD [14], even though TUs, such as VAV boxes, are extremely common and numerous in HVAC systems [38]. Furthermore, the inefficiencies caused by occupants, as well as design errors have almost been neglected in past studies regarding building FDD. As a result, several gaps need to be addressed in future work: zone-level equipment, design and occupant faults in the FDD for buildings context. 
Table 2.3: Pros and cons of the three FDD methodologies

\begin{tabular}{|c|c|c|}
\hline $\begin{array}{c}\text { FDD } \\
\text { Methodology }\end{array}$ & Pros & Cons \\
\hline $\begin{array}{l}\text { Qualitative } \\
\text { model-based }\end{array}$ & $\begin{array}{l}\text { Simpler to set up. } \\
\text { Identifies common faults, with low } \\
\text { false alarm rates [5]. } \\
\text { Transparent, flexible and adaptable } \\
{[28] \text {. }} \\
\text { Suitable for embedment in a super- } \\
\text { visory controller [28]. }\end{array}$ & $\begin{array}{l}\text { Rules may not be applicable to ev- } \\
\text { ery building [5]. } \\
\text { Requires deep domain knowledge } \\
\text { to set up rules [5]. }\end{array}$ \\
\hline $\begin{array}{l}\text { Quantitative } \\
\text { model-based }\end{array}$ & $\begin{array}{l}\text { Does not require historical data. } \\
\text { Simple to diagnose the cause of de- } \\
\text { tected faults [42]. }\end{array}$ & $\begin{array}{l}\text { Can be difficult to calibrate [26]. } \\
\text { Can be expensive due to reliance } \\
\text { on sensors [38]. } \\
\text { Computationally demanding [28]. } \\
\text { Need to be tailored to specific sys- } \\
\text { tem structures [38]. }\end{array}$ \\
\hline $\begin{array}{l}\text { Process } \\
\text { history-based }\end{array}$ & $\begin{array}{l}\text { No need for an explicit model of } \\
\text { the system [38]. } \\
\text { Can be applied to different system } \\
\text { structures [38]. }\end{array}$ & $\begin{array}{l}\text { Requires a lot of training data [5]. } \\
\text { The training data needs to be fault } \\
\text { free [28] as it will not recognize } \\
\text { faults that are present at the begin- } \\
\text { ning of this data [5]. } \\
\text { Depends heavily on the training } \\
\text { data [38]. } \\
\text { Requires the use of a general- } \\
\text { purpose computer [28]. }\end{array}$ \\
\hline
\end{tabular}




\section{Chapter 3}

\section{Methodology}

In Chapter 2, the literature review uncovered the various strengths and weaknesses of three FDD methodologies: qualitative model-based, quantitative model-based and process history-based. Although each method has valuable characteristics, a quantitative bottomup model-based methodology was selected for the scope of this project. It was selected due to its advantages: the ability to easily detect faults [42] and its non-dependency on historical data. Although there are several downfalls to the quantitative model-based method, the concerns that have been raised are not necessarily of concern for this particular application. Firstly, a negative aspect of this technique is its dependency on a BAS [26] to obtain the data required to function. However, most new commercial buildings have a BAS implemented in them, resulting in an enormous amount of data that can be exploited. Furthermore, the building that was analyzed in the case study is a relatively new building which has a BAS. The BAS is accessible online, and for several years has been storing information from several sensors that are of value to the model. However, there are some sensors that were set up, but the measurements from these sensors were not actually being stored. Therefore, the selection of an approach that did not require historical data to train the model was vital. Minimal data needs to be obtained from the BAS since the model will be used to evaluate the zone-level and if necessary, the system could be implemented in a building that does not contain a BAS with relative ease. Finally, the aim of this research was to detect faults at the zone-level, particularly design faults, in order to give insight for future building design. Therefore, the development of a system which can be directly implemented into the BAS 
was not the priority and thus, requiring the CPU of an external computer to run the FDD tool [28] was acceptable.

Two main steps were required to identify the various inefficiencies that were occurring at the zone-level; fault detection and fault diagnosis. Data regarding the zone and mechanical system that were under analysis needed to be obtained in order for these two main steps to be completed. This chapter begins with an in-depth description of the data acquisition process, including the estimation of the actual system metrics. A description of the model development and verification has been provided. The fault detection stage required the comparison of the model predictions and the measured system metrics to detect faults. The fault detection section describes the difference that was required between the measured and modeled results for a discrepancy to be classified as a fault. Following the fault detection section, the fault diagnostics methodology has been discussed in detail.

\subsection{Data Acquisition}

The FDD methodology was developed and tested on a zone in the Canal Building, located on Carleton Campus. This zone consisted of four similar office spaces. Figure 3.1 shows the geometry and typical location of furniture for the offices within the zone. 


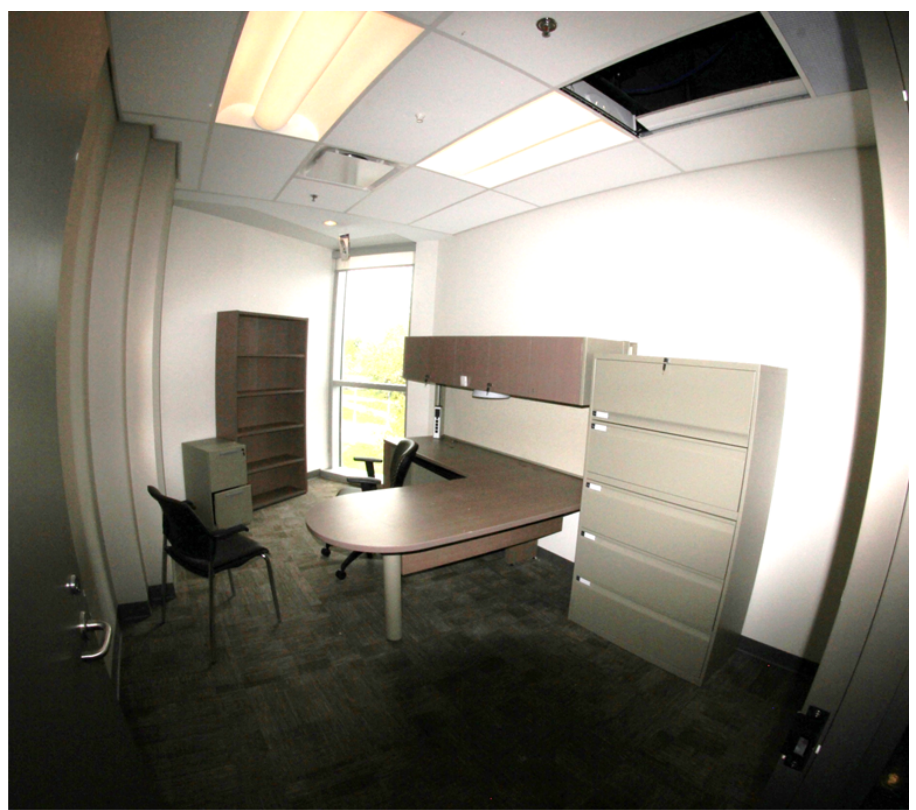

Figure 3.1: Picture of typical office under evaluation captured by Burak Gunay

Several metrics regarding these offices and the mechanical system were required for the FDD tool to be successful. Figure 3.2 represents a plan view of the typical office under evaluation and outlines various information regarding the space.
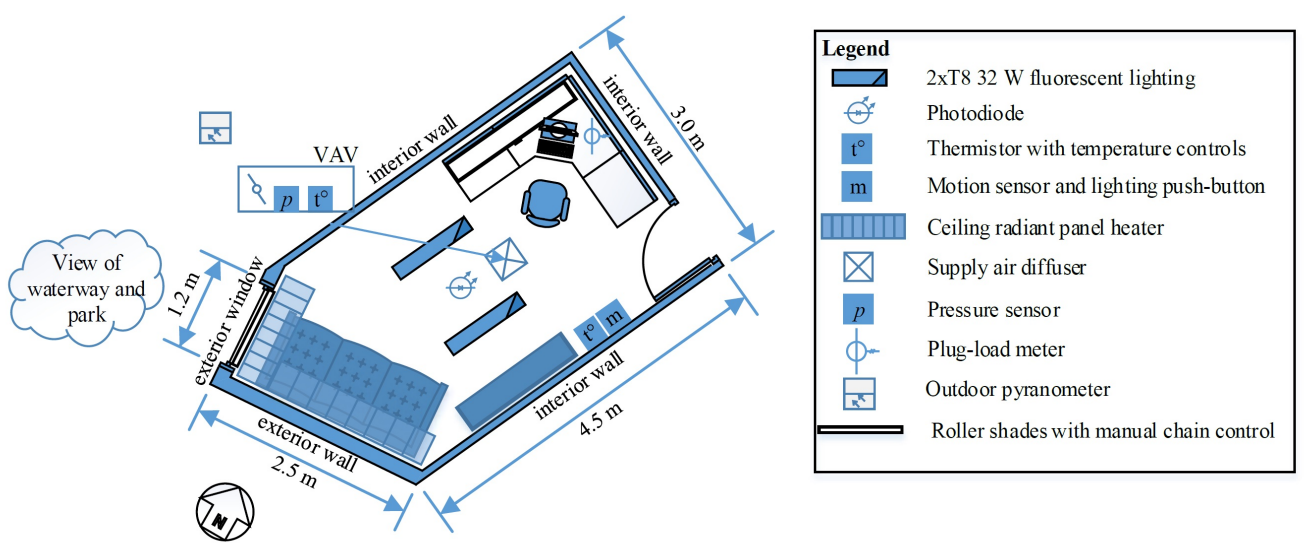

Figure 3.2: Plan view of typical office under evaluation captured by Burak Gunay

The required data can be separated into two categories; static or dynamic information 
[13]. In Figure 3.2 the lengths of the walls are displayed. The lengths of walls are an example of static information, information that does not change over time. Also included in Figure 3.2 are various sensors that the space was equipped with, these collect dynamic information. For example, a thermistor with temperature controls collects data at certain time intervals, information that is varying. The static and dynamic information that the FDD tool required to function will now be discussed in detail.

\subsubsection{Static Information}

Static information refers to information that can be found in as-built drawings, equipment schedules, and control drawings [13]. Static information was collected from the as-built drawings, on-site and through online sources. The information that was required were the floor, wall, ceiling and window geometric and physical details. These details consisted of the types of materials they were comprised of, their thermal properties, areas, densities and thicknesses. Tables 3.1 and 3.2 list all of the parameters that were considered static data, the respective value, and where the value was found.

Table 3.1: Required static data

\begin{tabular}{||c|c|c||}
\hline Data & Value & Value's source \\
\hline \hline Room height & $2.7 \mathrm{~m}$ & On-site \\
\hline Plenum height & $1 \mathrm{~m}$ & On-site \\
\hline Floor area & $12.096 \mathrm{~m}^{2}$ & As-built \\
\hline Internal wall area & $32.292 \mathrm{~m}^{2}$ & As-built \\
\hline External wall area & $4.622 \mathrm{~m}^{2}$ & As-built \\
\hline Window area & $3.026 \mathrm{~m}^{2}$ & As-built \\
\hline Window thermal transmittance & $3.194 \mathrm{~W} / \mathrm{mk}$ & LBNL \\
\hline Window solar heat gain coefficient & 0.655 & LBNL \\
\hline Ceiling area & $10.938 \mathrm{~m}^{2}$ & On-site \\
\hline Radiator area & $1.158 \mathrm{~m}^{2}$ & On-site \\
\hline
\end{tabular}


Table 3.2: Required static data - Material properties

\begin{tabular}{||c|c|c|c|c||}
\hline Material & $\begin{array}{c}\text { Resistance/ } \\
\text { conductivity }\end{array}$ & Thickness & Density & Specific heat \\
\hline \hline Carpet & $\begin{array}{c}0.2 \frac{\mathrm{W}}{\mathrm{m}^{2} \mathrm{~K}} \\
{[10]}\end{array}$ & $\begin{array}{c}0.00950 \mathrm{~m} \\
{[10]}\end{array}$ & $\begin{array}{c}290 \frac{\mathrm{kg}}{\mathrm{m}^{3}} \\
{[10]}\end{array}$ & $\begin{array}{c}1380 \frac{\mathrm{J}}{\mathrm{kgK}} \\
{[46]}\end{array}$ \\
\hline Concrete & $\begin{array}{c}2.85 \frac{\mathrm{W}}{\mathrm{mK}} \\
{[47]}\end{array}$ & $\begin{array}{c}0.2032 \mathrm{~m} \\
{[\text { As-built }]}\end{array}$ & $\begin{array}{c}2425 \frac{\mathrm{kg}}{\mathrm{m}^{3}} \\
{[47]}\end{array}$ & $\begin{array}{c}831 \frac{\mathrm{J}}{\mathrm{kgK}} \\
{[47]}\end{array}$ \\
\hline Gypsum board & $\begin{array}{c}0.16 \frac{\mathrm{W}}{\mathrm{mK}} \\
{[10]}\end{array}$ & $\begin{array}{c}0.016 \mathrm{~m} \\
{[\text { As-built] }}\end{array}$ & $\begin{array}{c}640 \frac{\mathrm{kg}}{\mathrm{m}^{3}} \\
{[10]}\end{array}$ & $\begin{array}{c}1150 \frac{\mathrm{J}}{\mathrm{kgK}} \\
{[10]}\end{array}$ \\
\hline $\begin{array}{c}\text { Sound batt } \\
\text { insulation }\end{array}$ & $\begin{array}{c}0.0425 \frac{\mathrm{W}}{\mathrm{mK}} \\
{[10]}\end{array}$ & $\begin{array}{c}0.0445 \mathrm{~m} \\
{[\text { As-built] }}\end{array}$ & $\begin{array}{c}10.75 \frac{\mathrm{kg}}{\mathrm{m}^{3}} \\
{[10]}\end{array}$ & $\begin{array}{c}800 \frac{\mathrm{J}}{\mathrm{kgK}} \\
{[10]}\end{array}$ \\
\hline Cavity rock & $\begin{array}{c}2.99 \frac{\mathrm{W}}{\mathrm{m}^{2} \mathrm{~K}} \\
{[\text { As-built] }}\end{array}$ & $\begin{array}{c}0.1 \mathrm{~m} \\
{[\text { As-built] }}\end{array}$ & $\begin{array}{c}82.5 \frac{\mathrm{kg}}{\mathrm{m}^{3}} \\
{[48]}\end{array}$ & $\begin{array}{c}800 \frac{\mathrm{J}}{\mathrm{kgK}} \\
{[10]}\end{array}$ \\
\hline Ceiling tile & $\begin{array}{c}0.037 \frac{\mathrm{W}}{\mathrm{mK}} \\
{[10]}\end{array}$ & $\begin{array}{c}0.0127 \mathrm{~m} \\
{[\text { On-site] }}\end{array}$ & $\begin{array}{c}160 \frac{\mathrm{kg}}{\mathrm{m}^{3}} \\
{[10]}\end{array}$ & $\begin{array}{c}800 \frac{\mathrm{J}}{\mathrm{kgK}} \\
{[10]}\end{array}$ \\
\hline
\end{tabular}

\subsubsection{Dynamic Information}

Dynamic information refers to real time data and requires sensors to accurately collect the parameter's information [13]. The majority of the dynamic information was collected through the enteliWEB building automation system (BAS). Sensors were set in place to collect any data that could not be found through the BAS and was referred to as external data. Included in this external data listing was the weather data: solar radiation and outdoor 
air temperature. The weather data was obtained from the Urbandale Centre for Home Energy Research. The dynamic information that was required for the energy simulation tool mainly consisted of parameters that either cause heat gains or losses within the zone. Whereas the measured system data pertained to the mechanical system. The required data was listed in Table 3.3 and was separated based on which aspect of the tool it was primarily used in.

Table 3.3: Required dynamic data

\begin{tabular}{||l||l||}
\hline \multicolumn{1}{|c||}{ Model system data } & Measured system data \\
\hline$\rightarrow$ Solar radiation & $\rightarrow$ Office air temperature \\
$\rightarrow$ Outdoor air temperature & $\rightarrow$ Supply air flow rate \\
$\rightarrow$ Occupancy & $\rightarrow$ Supply/return air temperature \\
$\rightarrow$ Lighting & $\rightarrow$ Radiator valve position \\
$\rightarrow$ Plug Loads & $\rightarrow$ Radiator water flow rate \\
$\rightarrow$ Heating set-point temperature & $\rightarrow$ Radiator water inlet temperature \\
$\rightarrow$ Cooling set-point temperature & $\rightarrow$ Radiator water outlet temperature
\end{tabular}

\section{Data Alignment}

The time and the frequency that the dynamic information was collected can vary. When utilizing the collected data in the FDD tool it was important to ensure the measurements that were being used for the various calculations were at the same point in time. A Matlab function "DataFrequencyAlignment" was developed to handle this occurrence. The "DataFrequencyAlignment" function imported the required .xls file datasets and interpolated the measurements to estimate the value at every time step. Afterward, the function 
would cut off any interpolated value that occurred before midnight so that each parameter began at the same time. Once this was completed the dataset was varied to a time frequency based on a user defined time step. The "DataFrequencyAlignment" function can be found by following the link in Appendix A The "DataFrequency Alignment" function was utilized in the main Matlab script "ZoneLoadScript" which can also be found by following the link provided in Appendix $\mathrm{A}$.

\subsubsection{Measured Temperatures \& Heating/Cooling Rates}

To determine if a fault existed in the system several system metrics needed to be measured: the temperature in the offices, the hydronic-based heating rate for each office and the air-based heating and cooling rate for the zone. These results then needed to be compared to predicted values. If the measured temperature, hydronic-based heating rate or air-based heating and cooling rate deviated from the model predictions a fault may have been detected. In this section, the calculations required to estimate the room air temperatures, hydronic-based heating rates and air-based heating and cooling rates were discussed. Sensors situated in various locations of the office, zone and mechanical equipment allowed for the measurement of these three parameters. Some sensors allowed for the direct measurement of the desired variable, whereas others were required in various equations. The measurement of the room air temperature, the air-based heating and cooling rate and the hydronic-based heating rate will now be discussed in further detail.

\section{Office Air Temperature}

The temperature of an office was a parameter that was directly measured through the use of a sensor. The thermostat provided representative office air temperature measurements. 
Utilizing the thermostat for this application was deemed adequate as the ventilation system that is utilized in the building under evaluation is an entrainment system, which aids in the mixing of air. Furthermore, the thermostat measurements provide a good approximation of the mean room air temperatures as they were installed at mid-height.

\section{Air-Based Heating \& Cooling Rate}

Unlike the office air temperature, calculations were required to estimate the total air and hydronic-based heating and cooling rates. The air-based heating and cooling rate can be estimated by creating a control volume around the room and using the first law of thermodynamics and the mass flow balance equations, equations 3.1 and 3.2 [49], respectively. A detailed list of the nomenclature utilized in these equations and all future equations was provided at the beginning of this thesis.

$$
\begin{gathered}
\frac{d E_{C V}}{\partial t}=-\dot{Q}+\dot{W}+\dot{m}_{1}\left(E_{1}+\frac{v_{1}^{2}}{2}+g z_{1}\right)-\dot{m}_{2}\left(E_{2}+\frac{v_{2}^{2}}{2}+g z_{2}\right) \\
\frac{d M_{C V}}{\partial t}=\dot{m}_{1}-\dot{m}_{2}
\end{gathered}
$$

Equation 3.3 was obtained by combining equations 3.1 and 3.2 and making the assumptions listed in Table 3.4 
Table 3.4: Measured air-based heating and cooling rate calculation assumptions

\begin{tabular}{|c|c|}
\hline Assumption & Assumption justification \\
\hline Steady state & $\begin{array}{l}\text { Significant fluctuations will not be observed in the } \\
\text { selected one minute intervals (refer to subsection 3.2.4). } \\
\text { Also, the thermal capacity of the terminal unit is } \\
\text { relatively insignificant compared to its heating/cooling } \\
\text { rate. }\end{array}$ \\
\hline No work & $\begin{array}{l}\text { The influence of the system on its surroundings is } \\
\text { limited, and vice versa. }\end{array}$ \\
\hline $\begin{array}{l}\text { Negligible kinetic energy } \\
\text { effects }\end{array}$ & $\begin{array}{l}\text { The velocity of the air entering and exiting the room are } \\
\text { small and relatively similar. }\end{array}$ \\
\hline $\begin{array}{l}\text { Negligible potential } \\
\text { energy effects }\end{array}$ & The air enters and exits the room at the same elevation. \\
\hline Negligible latent load & $\begin{array}{l}\text { The zone under analysis contains four single occupant } \\
\text { offices, where minimal activity occurs. Thus, the load } \\
\text { will be primarily sensible. Furthermore, the latent load } \\
\text { is not dealt with at the zone-level, it is dealt with at the } \\
\text { building-level, in the AHU. }\end{array}$ \\
\hline
\end{tabular}

Equation 3.3 was the equation utilized to estimate the air-based heating and cooling rate that was supplied to the zone at time $t$.

$$
\dot{Q}_{A i r, t}=\dot{m}_{A i r} \times c_{p_{A i r}} \times\left[T_{S u p, t}-T_{R, t}\right]
$$

The VAV box has sensors inside of it that measure both the temperature of the air flow and the stagnation pressure. The stagnation pressure was then utilized to measure the corresponding volumetric flow rate. The supply and return air temperature will range between $13{ }^{\circ} \mathrm{C}$ and $30^{\circ} \mathrm{C}$, the design temperatures of the system. These temperatures correspond to a specific heat capacity of approximately $1007 \mathrm{~J} / \mathrm{kg} . \mathrm{K}$ [50]. Given the minimal fluctuation in the specific heat capacity for air between $250 \mathrm{~K}$ and $300 \mathrm{~K}(1 \mathrm{~J} / \mathrm{kg} . \mathrm{K})$, this value was assumed to remain constant. The air in the room was originally assumed to be perfectly mixed, which allowed the thermostat to be used as the return air temperature. However, during the verification of the model, it was found that the measured air-based heating and 
cooling rate consistently exceeded the fault detection threshold of the predicted air-based heating and cooling rate. The discrepancy resulted in the placement of a temperature sensor on top of the RG, in order to evaluate the temperature difference between the two locations. There was a consistent difference between the two measurements during the December $12^{\text {th }}, 2016$ week. On average, the RG temperature sensor recorded values approximately $0.7^{\circ} \mathrm{C}$ higher than the thermostat. As a result, a simulation of this week was conducted to evaluate the influence of the sensor selection on the air-based heating and cooling rate predictions. The weekly air-based energy consumption when using the RG temperature, instead of thermostat temperature, produced a value approximately $40 \%$ lower. Since the RG temperature sensor was located in the most appropriate location it was used to perform the air-based heating and cooling rate calculation.

The Matlab function that utilized equation 3.3 to estimate the air-based heating and cooling rate was called "Actual" and can be found by following the link provided in Appendix A. The function "Actual" was utilized in the main Matlab script "ZoneLoadScript" which can also be found by following the link provided in Appendix A

\section{Hydronic-Based Heating Rate}

The hydronic-based heating rate followed a similar derivation as the air-based heating and cooling rate. Equation 3.4 was obtained by combining equations 3.1 and 3.2 and making the assumptions listed in Table 3.5 . 
Table 3.5: Measured hydronic-based heating rate calculation assumptions

\begin{tabular}{||c|c||}
\hline Assumption & Assumption justification \\
\hline \hline Steady state & $\begin{array}{c}\text { Significant fluctuations will not be observed in the } \\
\text { selected one minute intervals (refer to subsection 3.2.4 }\end{array}$ \\
\hline No work & $\begin{array}{c}\text { The influence of the system on its surroundings is } \\
\text { limited, and vice versa. E.g. losses due to friction are } \\
\text { minimal. }\end{array}$ \\
\hline $\begin{array}{c}\text { Negligible kinetic energy } \\
\text { effects }\end{array}$ & $\begin{array}{c}\text { The velocity of the water entering and exiting the } \\
\text { radiator are relatively similar. }\end{array}$ \\
\hline $\begin{array}{c}\text { Negligible potential } \\
\text { energy effects }\end{array}$ & $\begin{array}{c}\text { The radiator inlet and outlet are at the same elevation. } \\
\text { Incompressible fluid } \\
\text { The pressure drop through a heat exchanger is } \\
\text { the properties of the fluid are independent of pressure. }\end{array}$ \\
\hline
\end{tabular}

Equation 3.4 was the equation utilized to estimate the hydronic-based heating rate that was supplied to an office at any point in time.

$$
\dot{Q}_{\text {Rad }, t}=\dot{m}_{\text {water }} \times c_{p_{\text {water }}} \times\left[T_{\text {Inlet }, t}-T_{\text {Outlet }, t}\right]
$$

Three sensors were installed on a radiant panel to measure the water's temperature at the inlet and outlet, and the flow rate. The supply and return water temperature can range between $40{ }^{\circ} \mathrm{C}$ and $85^{\circ} \mathrm{C}$, during the heating season. These temperatures corresponded to specific heat capacities of approximately $4,179 \mathrm{~J} / \mathrm{kg} . \mathrm{K}$ and $4,199 \mathrm{~J} / \mathrm{kg} . \mathrm{K}$, respectively [50]. Given the minimal fluctuation in the specific heat capacity, $20 \mathrm{~J} / \mathrm{kg}$.K over $45^{\circ} \mathrm{C}$, the middle value, $4,189 \mathrm{~J} / \mathrm{kg} . \mathrm{K}$ was selected and assumed to remain constant.

The other three offices in the zone were not equipped with these same sensors. Instead, the information that was gathered from the sensors that were implemented in office 1 was utilized to estimate the steady state operations of the other three radiant panels. When a radiator valve was opened, a fixed rate of heat addition was assumed to be added to the corresponding office. Although there is a transient period when the radiator valve is initially 
opened, it was deemed okay given the scope of this thesis. Developing an accurate model representation of the radiator is a complex and time consuming task. One that would be necessary if the research aimed to optimized the operations of the radiator. This research aimed to detect more significant faults in the operations, such as a broken or faulty radiator valve, sensor faults and broken equipment at the building-level. Faults that can still be detected through the utilization of a steady state evaluation.

The Matlab function that utilized this equation to calculate the hydronic-based heating rate was called "Actual" and can be found by following the link provided in Appendix A The function "Actual" was utilized in the main Matlab script "ZoneLoadScript" which can also be found by following the link provided in Appendix A

\subsection{Model Development}

It was determined that a quantitative model-based methodology was to be used to detect faults at the zone-level. The selection of the quantitative model-based methodology meant that several system metrics needed to be estimated and compared to predicted values: the temperature in the offices, the hydronic-based heating rate for each office and the air-based heating and cooling rate for the zone. However, the modeling tool itself still needed to be selected. This raised the question of whether to use a recognized simulation tool, such as EnergyPlus, or to develop an energy simulation software program from scratch using a coding software, such as Matlab. Table 3.6 lists the benefits to utilizing an existing energy simulation tool and creating one. 
Table 3.6: Energy simulation tool comparison

\begin{tabular}{|c|c|}
\hline EnergyPlus Model & Matlab Model \\
\hline $\begin{array}{l}\rightarrow \text { Recognized software - reduces } \\
\text { need to implement algorithms from } \\
\text { scratch. }\end{array}$ & $\begin{array}{l}\rightarrow \text { Recognized theory - requires } \\
\text { additional algorithms to be } \\
\text { implemented. }\end{array}$ \\
\hline $\begin{aligned} \rightarrow & \text { Can export building design into } \\
& \text { EnergyPlus. }\end{aligned}$ & $\begin{aligned} \rightarrow & \text { Requires user to manually input } \\
& \text { room dimensions into Matlab. }\end{aligned}$ \\
\hline $\begin{aligned} \rightarrow & \text { More exact geometry being } \\
& \text { simulated. }\end{aligned}$ & $\begin{aligned} \rightarrow & \text { More flexible (e.g., model } \\
& \text { resolution, controls scheme). }\end{aligned}$ \\
\hline $\begin{array}{l}\rightarrow \text { Requires external developments - } \\
\text { no FDD system. }\end{array}$ & $\begin{array}{l}\rightarrow \text { All in one tool - FDD can be built } \\
\text { right in. }\end{array}$ \\
\hline
\end{tabular}

It was decided that flexibility and the ability to produce an all in one FDD tool were the most important features of this development and thus, a model in Matlab was selected. Deciding to utilize a model in Matlab resulted in the necessity to select the heat transfer theory that was employed in Matlab. Table 3.7 considers two recognized theories for utilization in this development, the implicit and explicit finite difference methods [51]. The finite difference methods are easy to understand and to set up [52]. They can be derived through Taylor series expansion [53], and allow for the approximation of a system's function through linearization [52]. Consequently, this methodology can produce error as a result of a finite time step. Although, the Crank-Nicolson method, is an implicit based method that has been successfully utilized in existing software tools, such as ESP-r [51]. 
The implicit method does have some beneficial characteristics over the explicit method. For example, the implicit method is unconditionally stable, meaning that the system of linear equations can function regardless of the selected time step. Whereas, the explicit method can become unstable based on the time step. However, the explicit finite difference method also has multiple beneficial characteristics when compared to the implicit theory. Most importantly, it does not require solving a system of linear equations which makes it easier to set up, as well as computationally faster than the implicit method [50, 51]. Another benefit of this method is its ability to be applied to different applications in the mechanical field. All of these methods can be used to predict the systems behaviour, however the explicit finite difference method predicts the systems future behaviour based on present conditions. Predicting the systems behaviour was appealing as it allows for this development to be furthered as a model predictive controls software for the mechanical system.

Table 3.7: Finite difference theory comparison

\begin{tabular}{||c|c||}
\hline \multicolumn{1}{||c|}{ Explicit } & Implicit \\
\hline$\rightarrow$ Relatively simple to set up [50, 51]. & $\rightarrow$ System of linear equations [50, 51]. \\
$\rightarrow$ Computationally fast [50]. & $\rightarrow$ Slower than explicit [50]. \\
$\rightarrow$ Predicts system behaviour, could be & $\rightarrow$ Uses current system status to \\
applied to different applications. & review previous system behavior. \\
$\rightarrow$ Is not unconditionally stable, model & $\rightarrow$ Unconditionally stable (no restric- \\
can become unstable based on time & tions on time step), but can produce \\
step [50, 54]. & inaccurate results [50]. \\
&
\end{tabular}


The explicit finite difference method was selected due to its several advantages over the implicit methodology. An in-depth discussion of this thermal analysis methodology will now be completed.

\subsubsection{Explicit Finite Difference Method}

An energy simulation tool that utilized the explicit finite difference method was developed in Matlab as a basis for detecting inefficiencies in the mechanical system due to its several advantages over the implicit methodology. The explicit finite difference method utilizes transient one-dimensional thermal analysis which can be applied to buildings to predict the heating and cooling rates, dynamic temperature variations within walls, room air temperature swings and condensation on wall interior surfaces [54]. This research relied on the explicit finite difference method to predict the room air temperature, the air-based heating and cooling rate and the hydronic-based heating rate for a set of offices. First, this methodology will be derived through a one-dimensional thermal analysis on a slab of material. The explicit finite difference method will then be applied to a simple room analysis, followed by a description of the explicit finite difference method and its application in a zone in the Canal Building.

\section{Derivation}

The explicit finite difference method can be derived based on the one-dimensional heat equation, seen in equation 3.5 [53].

$$
\frac{\partial \phi}{\partial t i m e}=\alpha \frac{\partial^{2} \phi}{\partial x^{2}}
$$


Equation 3.5 can be utilized to model the transient heat conduction in a slab of material. Where $x$ is a distance between zero and the thickness of the slab and $\alpha$ is the thermal diffusivity [53]. $\phi=\phi(\mathrm{x}$, time $)$ is the dependent variable, this is denoted by $\phi_{x, t i m e}$ in equation 3.5 to 3.9 . Figure 3.3 represents the mesh for the described scenario, a semi-infinite strip of material [53].

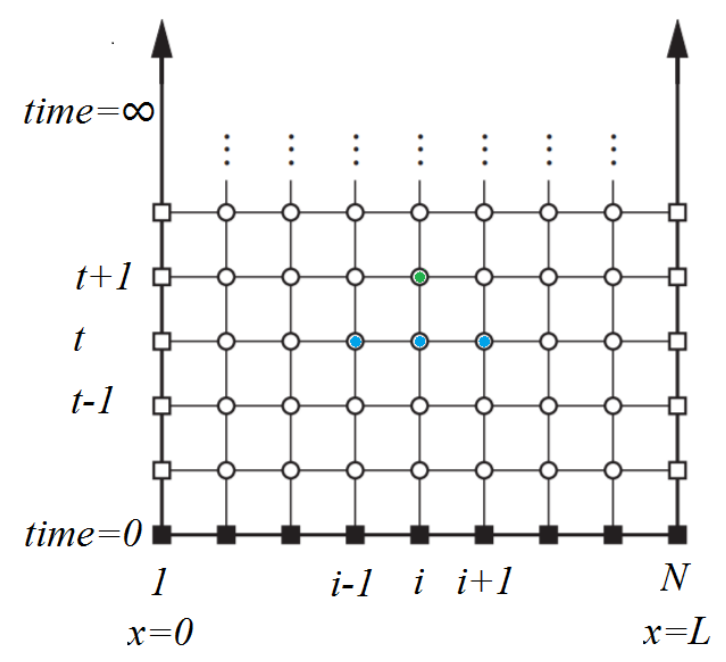

Figure 3.3: Mesh for a semi-infinite strip of material [54]

The slab under analysis is a semi-infinite strip, with a width of $L$, that continues indefinitely in time [53]. To obtain a solution through equation 3.5, boundary conditions need to be defined at $x=0$ and $x=L[53]$. There also needs to be initial conditions at time zero [53]. The time derivative in equation 3.5 can be approximated with the application of the forward difference technique, resulting in equation 3.6 [53].

$$
\left.\frac{\partial \phi}{\partial t i m e}\right|_{t+1, i}=\frac{\phi_{i, t+1}-\phi_{i, t}}{\Delta t}+\vartheta(\Delta t)
$$

The central difference approximation can then be applied to $\left(\partial^{2} \phi / \partial x^{2}\right)_{\mathrm{i}}[$ [53]. Evaluating node $i-1, i$ and $i+1$ at time $t$ yields equation 3.7 . 


$$
\left.\frac{\partial^{2} \phi}{\partial x^{2}}\right|_{i}=\frac{\phi_{i-1, t}-2 \phi_{i, t}+\phi_{i+1, t}}{\Delta x^{2}}+\vartheta\left(\Delta x^{2}\right)
$$

Equation 3.8 can be obtained [53] by substituting equation 3.6 into the left hand side of equation 3.5 , substituting equation 3.7 into the right hand side of equation 3.5 and collecting the truncation errors $(\vartheta)$.

$$
\frac{\phi_{i, t+1}-\phi_{i, t}}{\Delta t}=\alpha \frac{\phi_{i-1, t}-2 \phi_{i, t}+\phi_{i+1, t}}{\Delta x^{2}}+\vartheta(\Delta t)+\vartheta\left(\Delta x^{2}\right)
$$

Equation 3.9 can be obtained by rearranging equation 3.8 to solve for $\phi_{i, t+1}$ and dropping the truncation error terms [53]. The left hand side of equation 3.9 represents the dependent variable of node "i" at a future time. By utilizing the knowledge of the node's previous dependent variable and the previous dependent variable of the neighbouring nodes, the dependent variable at time $t+1$ can be determined.

$$
\phi_{i, t+1}=\phi_{i, t}+\frac{\alpha \Delta t}{\Delta x^{2}}\left(\phi_{i-1, t}-2 \phi_{i, t}+\phi_{i+1, t}\right)
$$

Equation 3.9 is called the forward time, centered space (FTCS) approximation [53], also known as the explicit finite difference method. The explicit finite difference method forms the basis of the energy simulation software program that was developed.

\section{Application in Building Thermal Analysis}

This methodology can also be applied to a thermal analysis in a building or office space. There are various parameters that influence thermal analysis in an office space at any given time. These parameters are: solar radiation, conduction through the exterior, infiltration/exfiltration through the exterior, occupant heat gains, lighting heat gains and plug load heat gains. Furthermore, this tool was created in a manner which allowed for it to be 
utilized on zones with either air-based or hydronic-based systems. A schematic representation of what the model considered can be seen in Figure 3.4.

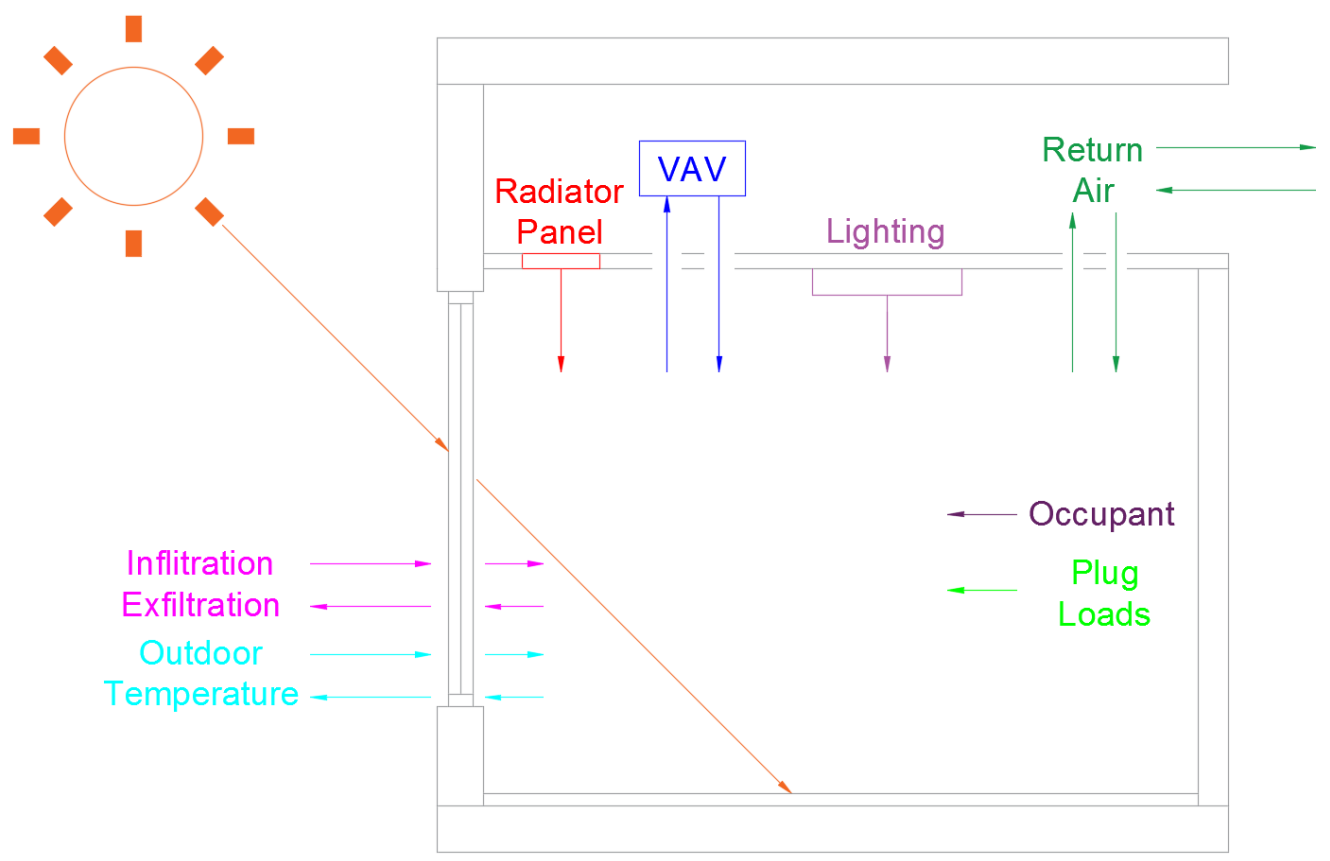

Figure 3.4: Office energy balance

The application of the explicit finite difference method in an office space consisted of situating several nodes in a manner which ensured that all of the surfaces, thermal capacitance and air in the space under evaluation were accounted for. These nodes represented the dependent variable "temperature" at their given location and can be placed in objects, or on their surface, as well as in the air. The prediction of the temperature of each node was based on how each node should theoretically interact with one another, as well as how any external parameters should influence their temperatures, such as environmental conditions and internal gains. Figure 3.5 represents a simplified nodal network for the office displayed in Figure 3.4 . 


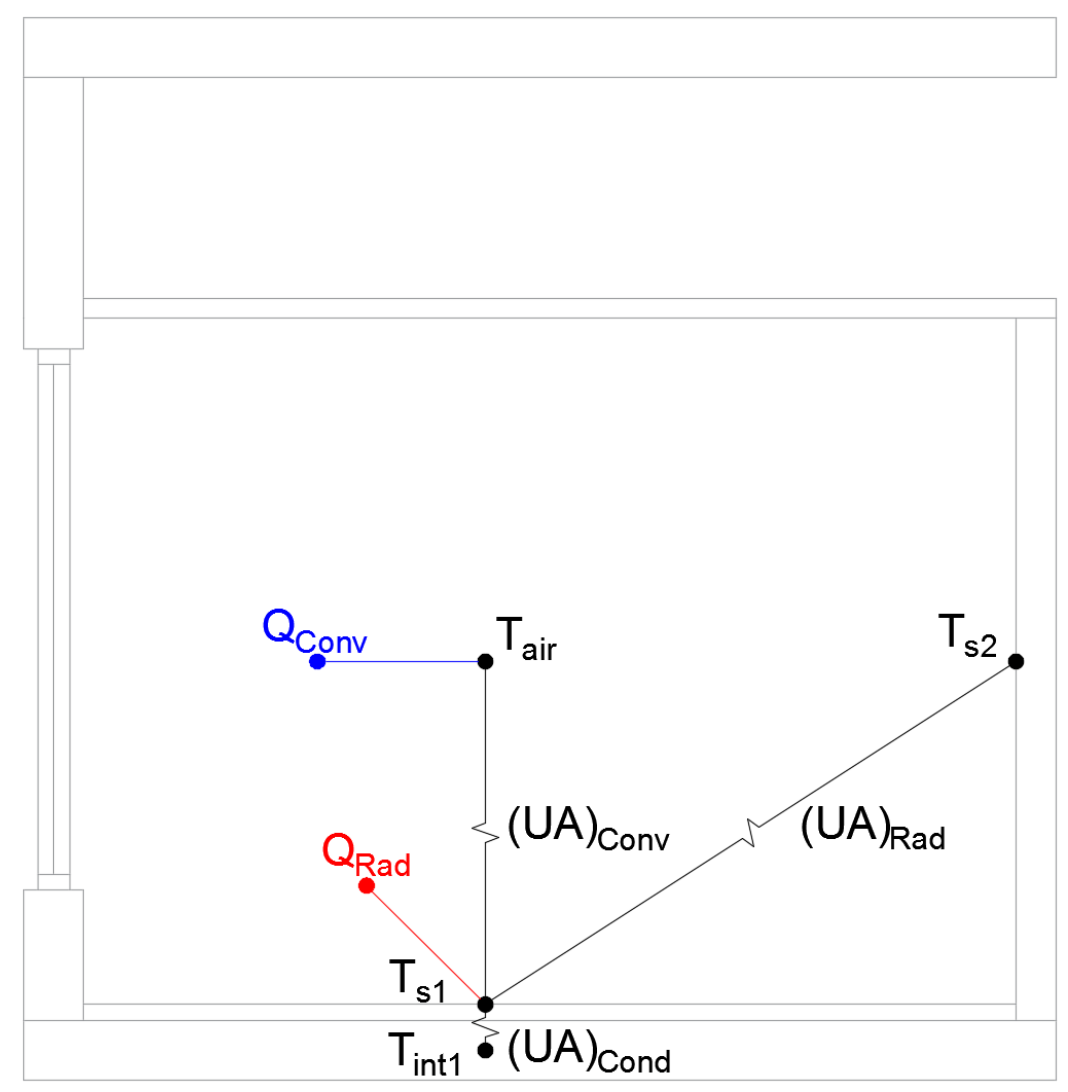

Figure 3.5: Simplified room thermal network diagram

In Figure 3.5 all sources of radiation were grouped together as one term and only influenced the floor temperature, $\mathrm{T}_{\mathrm{s} 1}$. Similarly, the sources of convection were also grouped together as one term and only influenced the air node. An additional surface was accounted for, $\mathrm{T}_{\mathrm{s} 2}$, to provide an example of radiation exchange between surfaces, but did not influence other nodes in this example, for simplicity. The explicit finite difference method can be applied to the network diagram displayed in Figure 3.5. The selected node locations resulted in equations 3.10 to 3.12 , which are basic examples that illustrate what the different node locations depend on. That is, the typical equation arrangement that will be obtained for nodes that were located in the air, on the surface of materials and within objects. A detailed list of the nomenclature utilized in these equations and all future equations was 
provided at the beginning of this thesis.

Equation 3.10 represents a basic case for determining the room air temperature one time step forward in time, and includes all possible modes of heat addition and rejection. Equation 3.10 is based on an energy balance and displays that the change of the air node's temperature is based on any surfaces that convect heat either to or from the air, any internal loads that convect heat to the air and any mechanical heating or cooling that add or reject heat to the air through convection. All of these parameters are based on the present time and the overall change in the air's temperature is based on the capacitance of the air, as well as the duration that these parameters are deployed (time step). Equation 3.10 also depends on the thermal capacitance of the air. The thermal capacitance of the air can be obtained by considering the volume of the space, the density of air and the specific heat capacity of air. However, the temperature in a space with no furniture fluctuates at a higher rate than if that space had a desk, chairs and book shelves in it. For this reason, it is common to consider the thermal capacitance of the furniture with the thermal capacitance of the air [55, 56, 57]. Some building performance analysis software tools, such as EnergyPlus, provide a zone capacitance multiplier which allows the user to scale the thermal capacitance of the air in order to account for the thermal capacitance of the furniture [58]. In this research, the thermal capacitance of the furniture was approximated and utilized to select an appropriate capacitance multiplier for each office space.

$$
T_{a i r, t+1}=T_{a i r, t}+\frac{\Delta t}{C_{a i r}}\left[\left(T_{s 1, t}-T_{a i r, t}\right) \times(U A)_{c o n v, t}+Q_{c o n v, t}\right]
$$

Equation 3.11 represents a basic case for determining the temperature of a surface one time step forward in time, and includes all possible modes of heat addition and rejection. Equation 3.11 is based on an energy balance and displays that the change in the surface temperature is based on the heat exchange due to convection from the air, the radiation 
exchange from other surfaces, the conduction exchange from other materials and any radiation load; solar radiation, internal loads and/or radiant heating.

$$
T_{s 1, t+1}=\frac{T_{a i r, t} \times(U A)_{c o n v, t}+T_{i n t 1, t} \times(U A)_{c o n d, t}+T_{s 2, t} \times(U A)_{r a d, t}+Q_{r a d, t}}{(U A)_{c o n v, t}+(U A)_{c o n d, t}+(U A)_{r a d}}
$$

Equation 3.12 represents a basic case for determining the internal temperature of a material one time step forward in time, and includes all possible modes of heat addition and rejection. Equation 3.12 is based on an energy balance and displays that the change of the internal node's temperature is based on any temperatures that conduct heat either to or from the node. It is important to note, that there could be additional heat provided from internal heat generation, similar to the convection loads that are applied to the air node in equation 3.10. An example of this would be if the floor had in floor heating, however this is not the case for the offices that were analyzed and as such were not incorporated in this type of equation. All of the material temperatures are based on the present time and the overall change in the internal node's temperature is based on the capacitance of the material, as well as the duration that these parameters are deployed (time step).

$$
T_{i n t 1, t+1}=T_{i n t 1, t}+\frac{\Delta t}{C_{m a t 1}}\left[\left(T_{s 1, t}-T_{i n t 1, t}\right) \times(U A)_{c o n d, t}\right]
$$

Once the representative equations are defined for each node the selection of an appropriate time step is required. The selection of an appropriate time step is vital to the functionality of the system as too large of a time step can cause the model to become unstable [50]. To determine the limit on the time step an analysis of the node's temperature at time $t$ needs to be conducted for each equation. If the summation of the coefficients of these terms is greater than zero an acceptable time step has been selected [50]. Equation 3.13 represents the summation of terms at time $t$ for the air node. 


$$
T_{a i r, t}\left[1-\frac{\Delta t}{C_{a i r}} \times \sum(U A)_{a i r, t}\right] \geqslant 0
$$

Applying equation 3.13 to the basic air node equation, equation 3.10 , results in equation 3.14. Equation 3.14 represents the summation of the coefficients for the air temperature at time t.

$$
1-\frac{\Delta t}{C_{\text {air }}} \times(U A)_{c o n v, t} \geqslant 0
$$

The time step that is selected cannot cause equation 3.14 to be false or else equation 3.10 will be unstable. All equations need to be evaluated in the same manner to determine the limiting equation. That is, the equation that requires the smallest time step in order to remain stable [50].

\section{Application in the Canal Building}

The heat network diagram displayed in Figure 3.5 represented a simplified analysis for an office space. For simplicity, one node can represent multiple walls or all of the air in the space. This can reduce the computational time required to run a simulation since there will be less nodes involved in the thermal analysis of the space. However, it can also jeopardize the accuracy of the predictions. For this reason, the grouping of the surfaces of the walls, or the capacitance of the walls should be done carefully. Walls of similar composition can be adequately represented by a single node, as long as the boundary conditions are similar. That is, if the interior and exterior walls were to have the same composition, they would not be grouped together because the outside of the exterior wall is influenced by the outdoor temperature, whereas the outside of the interior walls are influenced by the temperature in opposing offices. However, all interior walls may be represented by one node since they share similar boundary conditions and composition. 
The total number of nodes that is selected is based on the accuracy that is required for the application. Zimmermann et al. (2012) believe that more detailed models result in better fault detection [39]. However, this is not necessarily the case; trade-offs occur the more complex the system gets, such as how computationally demanding the tool is. The complexity that the system would be designed to was not selected before development. Instead, the tool was created to the zone's simplest form and was intensified as it was deemed necessary. Model resolution was added if the model predictions were not satisfactory in comparison to the measured performance of the zone.

Initially, the model was similar to Figure 3.5 and consisted of three nodes in each office; one that represented the room air, all of the surfaces in the room and the total capacitance in the room. The model progressed to the point that it was assumed that only surfaces with the same thermal properties and boundary conditions had a uniform temperature distribution and could be grouped together as one node. That is, the external wall has a different composition and boundary condition then the internal walls and thus, was analyzed separately. The internal walls have the same composition and were all assumed to operate adiabatically and were thus, represented by the same nodal points. The room air temperature was assumed to be well mixed and was represented by one nodal point. The model originally grouped the plenum space with the office space. However, from analyzing results it was found that the plenum had a significant impact on the performance of the room. It is common practice to group these two spaces together for design calculations, but further research revealed that "temperatures in these plenums, and the way that they behave, are significantly different from those of occupied spaces. Thus, they should be defined as a separate thermal zone [59]" which led to the addition of a separate node for the plenum air. Figure 3.6 shows all of the room's surfaces and air nodes that were modelled and how 
each interacts with each other. Figure 3.6 also displays how each external parameter interacts with the nodes and that there is a radiative and convective portion to the internal heat gains in the office. In this research, the radiative and convective portions of the internal gains were based on values outlined in Chapter 18 of the 2013 ASHRAE Fundamentals Handbook [10]. The occupant was considered to be seated, doing light work, with a low supply air velocity. From Table 1 the radiative fraction for the occupant was 40\% [10]. The lighting load for these offices is $128 \mathrm{~W}$ and from Table 3 the radiative fraction was $61 \%$ for a recessed fluorescent luminaire with lens [10]. Each office was assumed to have one desktop and monitor, values for these components were obtained from Table 8 which resulted in $20 \%$ of this heat gain being considered radiative [10]. The radiation exchange between surfaces was not displayed in order to ensure the diagram was clear, although this is significant and was modeled.

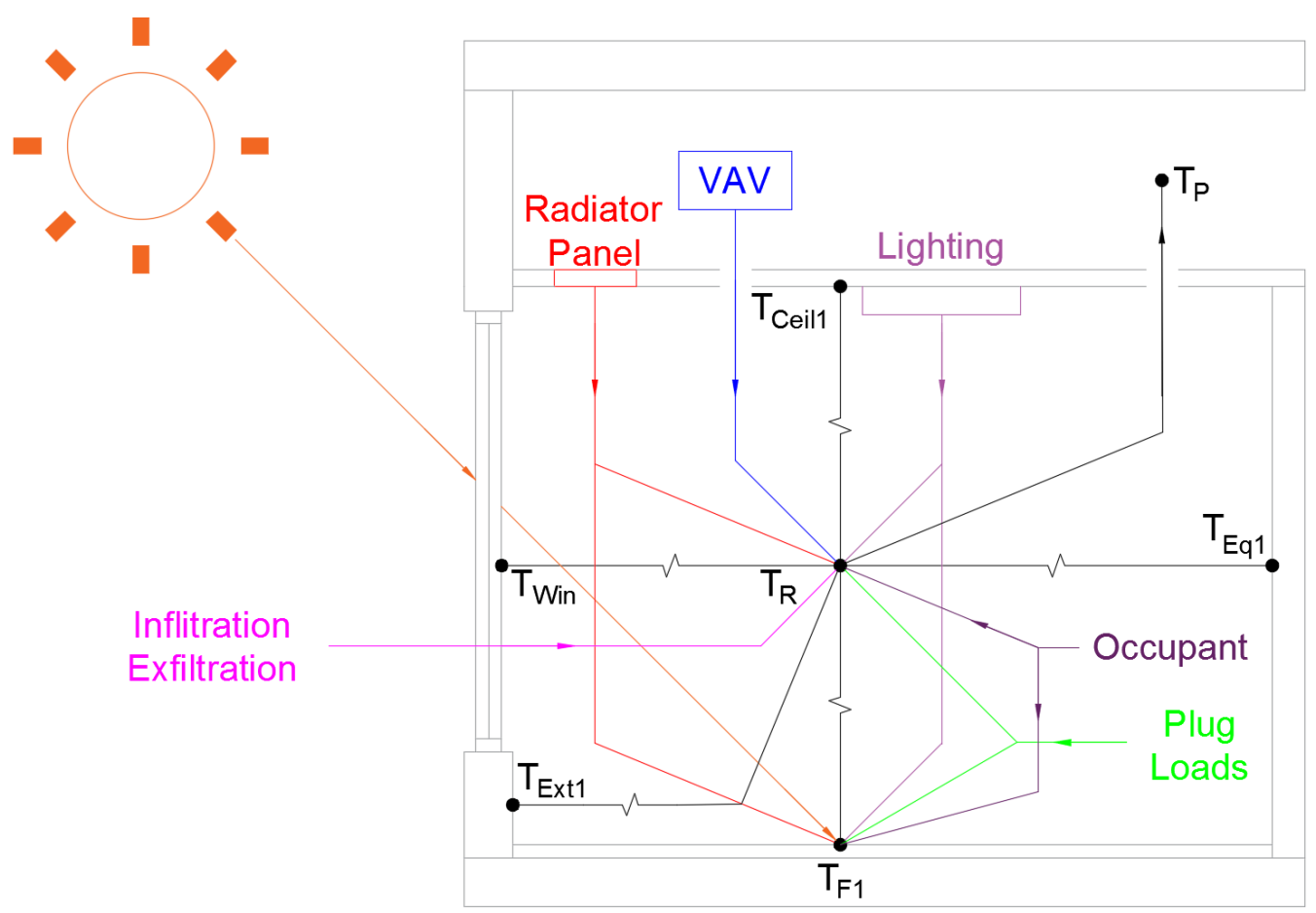

Figure 3.6: Room thermal network diagram 
The nodes that represent each wall composition were not displayed in Figure 3.6, instead separate diagrams were created in order to ensure clarity. Figure 3.7 shows that the external wall was represented by two nodes, one that represented its internal surface temperature and the other which was located at its midpoint and considered its thermal capacitance. Also displayed in Figure 3.7 is the equivalent wall which represented all of the internal walls. There was one node for the internal walls' surface temperature and another at the internal walls' midpoint, considering its thermal capacitance.
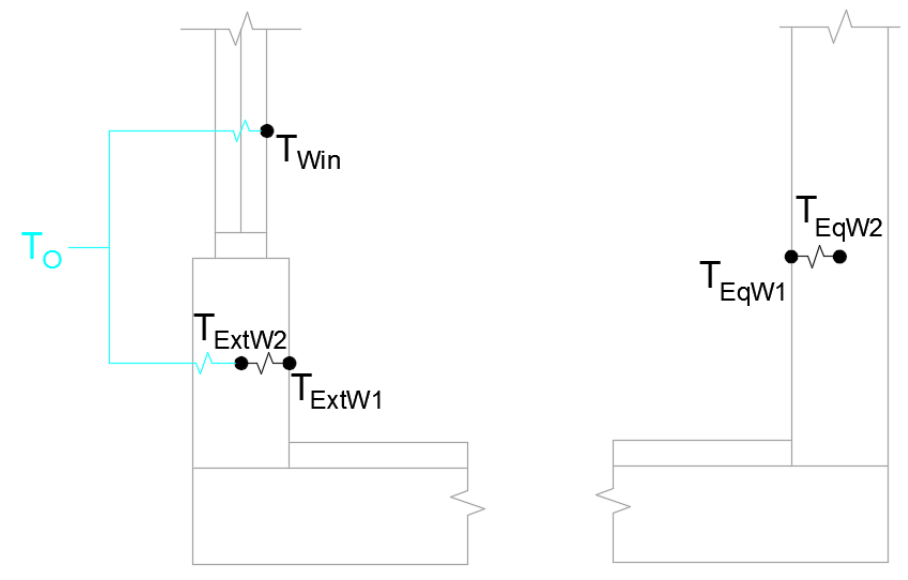

Figure 3.7: Wall thermal network diagram

The ceiling was represented by three nodes: one that represented the surface temperature within the room, a second at its midpoint which represented its thermal capacitance, and a third on the surface that was exposed to the plenum air. The floor was represented by five nodes due to the concretes high thermal mass. Figure 3.8 shows these five node locations. One point on the carpet's surface, at the midpoint of the carpet, two placed in the concrete slab, and the last one on the bottom of the concretes surface which interacted with the plenum air. 


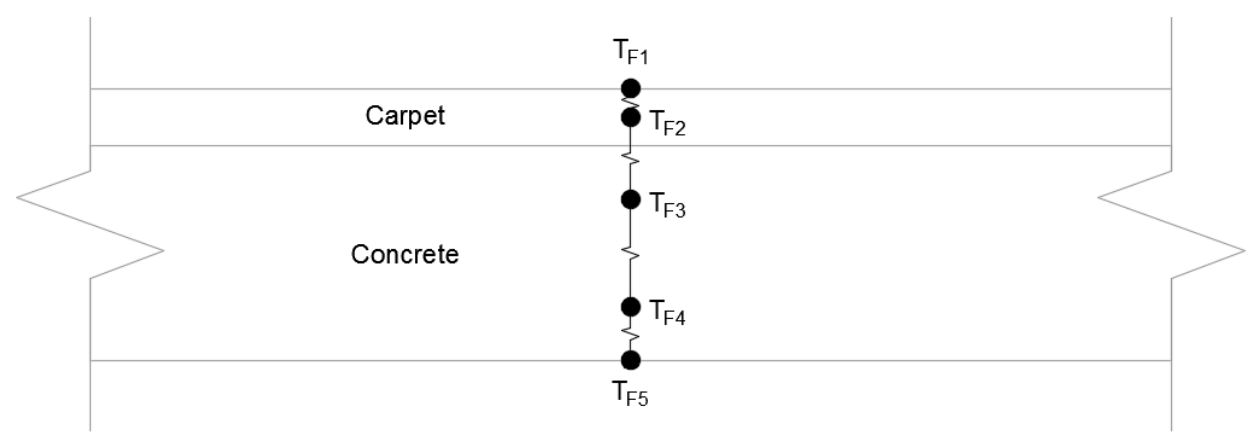

Figure 3.8: Floor thermal network diagram

A total of fifteen nodes were used to represent each office's and corresponding plenum's capacitance, surfaces and air temperatures. As well, an additional node that represented the radiant panel's surface temperature was defined. Equations 3.15 to 3.30 represent all of the nodes that were present in the model, and how they interacted with each other and the external parameters. The modeled hydronic and air-based systems influenced the temperature of several of these nodal points. This will be discussed in greater detail in sections 3.2 .5 and 3.2 .6 .

Equation 3.15 utilized all of the temperatures and heat gains/losses that were interacting with the air at the present time step to determine the temperature of the air node one time step forward in time.

$$
\begin{aligned}
T_{R t, t+1}= & T_{R t, t}+\frac{\Delta t}{C_{A i r}}\left[\left(T_{F 1, t}-T_{R t, t}\right)(U A)_{F, t}+\left(T_{E q W 1, t}-T_{R t, t}\right)(U A)_{E q W, t}\right. \\
& +\left(T_{E x t W 1, t}-T_{R t, t}\right)(U A)_{E x t W, t}+\left(T_{W i n, t}-T_{R t, t}\right)(U A)_{W i n, t} \\
& +\left(T_{C e i l 1, t}-T_{R t, t}\right)(U A)_{C e i l, t}+\left(T_{R a d t, t}-T_{R t, t}\right)(U A)_{R a d, t} \\
& \left.+Q_{A i r t, t}+Q_{i n f, t}+Q_{P L, t} \times P L_{P C}+Q_{O c c, t} \times O c c_{P C}+Q_{L} \times L_{P C}\right]
\end{aligned}
$$

Equation 3.16 utilized all of the room's surfaces' temperatures and their respective resistances at the present time step to determine the temperature of the node located on the 
carpet's surface.

$$
\begin{aligned}
T_{F 1, t+1}= & {\left[T_{R t, t} \times(U A)_{F, t}+T_{F 2, t} \times 2 \times(U A)_{c a r p}+T_{E q W 1, t} \times(U A)_{E q F, t}\right.} \\
& +T_{E x t W 1, t} \times(U A)_{E x t F, t}+T_{W i n, t} \times(U A)_{W i n F, t} \\
& +T_{C e i l 1, t} \times(U A)_{C e i l F, t}+Q_{S R, t}+Q_{O c c, t} \times O c c_{P R}+Q_{L, t} \times L_{P R} \\
& \left.+T_{R a d t, t} \times(U A)_{\text {RadF }, t}\right] \div\left[(U A)_{F, t}+2 \times(U A)_{c a r p}+(U A)_{W i n F, t}\right. \\
& \left.+(U A)_{E q F, t}+(U A)_{E x t F, t}+(U A)_{C e i l F, t}+(U A)_{R a d F, t}\right]
\end{aligned}
$$

Equation 3.17 utilized all of the temperatures that were influencing the carpet's internal node's temperature at the present time step to determine the internal temperature of the carpet one time step forward in time.

$$
\begin{aligned}
T_{F 2, t+1}= & T_{F 2, t}+\frac{\Delta t}{C_{\text {carp }}}\left[\left(T_{F 1, t}-T_{F 2, t}\right) \times 2 \times(U A)_{\text {carp }}+\left(T_{F 3, t}-T_{F 2, t}\right)\right. \\
& \left.\times\left(2 \times(U A)_{\text {carp }}+4 \times(U A)_{c s}\right)\right]
\end{aligned}
$$

Equation 3.18 utilized all of the temperatures that were influencing the temperature of the top half of the concrete slab at the present time step to determine the temperature of this node one time step forward in time.

$$
\begin{aligned}
T_{F 3, t+1}= & T_{F 3, t}+\frac{\Delta t}{0.5 \times C_{c s}}\left[\left(T_{F 2, t}-T_{F 3, t}\right)\left(2 \times(U A)_{c a r p}+4 \times(U A)_{c s}\right)\right. \\
& \left.+\left(T_{F 4, t}-T_{F 3, t}\right) \times 2 \times(U A)_{c s}\right]
\end{aligned}
$$

Equation 3.19 utilized all of the temperatures that were influencing the temperature of the bottom half of the concrete slab at the present time step to determine the temperature of this node one time step forward in time. 


$$
T_{F 4, t+1}=T_{F 4, t}+\frac{\Delta t}{0.5 \times C_{c s}}\left[\left(T_{F 3, t}-T_{F 4, t}\right) \times 2 \times(U A)_{c s}+\left(T_{F 5, t}-T_{F 4, t}\right) \times 4 \times(U A)_{c s}\right]
$$

Equation 3.20 utilized all of the plenum space's surfaces' temperatures and their respective resistances at the present time step to determine the temperature of the node located on the bottom of the concrete slab.

$$
\begin{aligned}
T_{F 5, t+1}= & {\left[T_{P, t} \times(U A)_{P C, t}+T_{F 4, t} \times 4 \times(U A)_{c s}+T_{C e i l 3, t} \times(U A)_{C e i l 3 F 5, t}\right] } \\
& \div\left[(U A)_{P C, t}+4 \times(U A)_{c s}+(U A)_{C e i l 3 F 5, t}\right]
\end{aligned}
$$

Equation 3.21 utilized all of the room's surfaces' temperatures, the equivalent wall's internal temperature and the respective resistances at the present time step to determine the temperature of the node located on the equivalent wall's surface.

$$
\begin{aligned}
T_{E q W 1, t+1}= & {\left[T_{R t, t} \times(U A)_{E q W, t}+T_{E q W 2, t} \times 2 \times(U A)_{E q}+T_{F 1, t} \times\right.} \\
& (U A)_{F E q, t}+T_{E x t W 1, t} \times(U A)_{E x t E q, t}+T_{W i n, t} \times(U A)_{W i n E q, t} \\
& +T_{C e i l 1, t} \times(U A)_{C e i l E q, t}+T_{R a d t, t} \times(U A)_{\text {RadEq,t }} \\
& \left.+Q_{P L, t} \times P L_{P R}\right] \div\left[(U A)_{E q W, t}+2 \times(U A)_{E q}+(U A)_{C e i l E q, t}\right. \\
& \left.+(U A)_{E x t E q, t}+(U A)_{W i n E q, t}+(U A)_{F E q, t}+(U A)_{\text {RadEq, }, t}\right]
\end{aligned}
$$

Equation 3.22 utilized all of the temperatures that were influencing the equivalent wall's internal node's temperature at the present time step to determine the internal temperature of the equivalent wall one time step forward in time.

$$
T_{E q W 2, t+1}=T_{E q W 2, t}+\frac{\Delta t}{C_{E q}} \times\left[\left(T_{E q W 1, t}-T_{E q W 2, t}\right) \times 2 \times(U A)_{E q}\right]
$$


Equation 3.23 utilized all of the room's surfaces' temperatures, the external wall's internal temperature and the respective resistances at the present time step to determine the temperature of the node located on the external wall's surface.

$$
\begin{aligned}
T_{E x t W 1, t+1}= & {\left[T_{R t, t} \times(U A)_{E x t W, t}+T_{E x t W 2, t} \times 2 \times(U A)_{E x t}+T_{E q W 1, t} \times\right.} \\
& (U A)_{E q E x t, t}+T_{F 1, t} \times(U A)_{F E x t, t}+T_{W i n, t} \times(U A)_{W i n E x t, t} \\
& \left.+T_{C e i l 1, t} \times(U A)_{C e i l E x t, t}+T_{R a d t, t} \times(U A)_{\text {RadExt, },}\right] \\
& \div\left[(U A)_{E x t W, t}+2 \times(U A)_{E x t}+(U A)_{\text {CeilExt, }, t}+(U A)_{F E x t, t}\right. \\
& \left.+(U A)_{W i n E x t, t}+(U A)_{E q E x t, t}+(U A)_{\text {RadExt, }, t}\right]
\end{aligned}
$$

Equation 3.24 utilized all of the temperatures that were influencing the external wall's internal node's temperature at the present time step to determine the internal temperature of the external wall one time step forward in time.

$$
\begin{aligned}
T_{E x t W 2, t+1}= & T_{E x t W 2, t}+\frac{\Delta t}{C_{E x t}}\left[\left(T_{O, t}-T_{E x t W 2, t}\right] \times 2 \times(U A)_{E x t}\right. \\
& \left.+\left(T_{E x t W 1, t}-T_{E x t W 2, t}\right) \times 2 \times(U A)_{E x t}\right]
\end{aligned}
$$

Equation 3.25 utilized all of the room's surfaces' temperatures, the outdoor air temperature and the respective resistances at the present time step to determine the temperature of the node located on the window's surface.

$$
\begin{aligned}
T_{W i n, t+1}= & {\left[T_{R t, t} \times(U A)_{W i n, t}+T_{O, t} \times(U A)_{\text {Window }}+T_{E x t W 1, t} \times\right.} \\
& (U A)_{E x t W i n, t}+T_{E q W 1, t} \times(U A)_{E q W i n, t}+T_{F 1, t} \times(U A)_{F W i n, t} \\
& \left.+T_{C e i l 1, t} \times(U A)_{\text {CeilWin }, t}+T_{R a d t, t} \times(U A)_{\text {RadWin }, t}\right] \\
& \div\left[(U A)_{W i n, t}+(U A)_{\text {Window }}+(U A)_{F W i n, t}+(U A)_{E x t W i n, t}\right. \\
& \left.+(U A)_{E q W i n, t}+(U A)_{\text {CeilWin }, t}+(U A)_{\text {RadWin }, t}\right]
\end{aligned}
$$


Equation 3.26 utilized all of the room's surfaces' temperatures, the ceiling internal temperature and the respective resistances at the present time step to determine the temperature of the node located on the bottom of the ceiling's surface.

$$
\begin{aligned}
T_{\text {Ceil1,t+1 }}= & {\left[T_{R t, t} \times(U A)_{\text {Ceil, } t}+T_{\text {Ceil }, t} \times 2 \times(U A)_{\text {ceiltile }}\right.} \\
& +T_{E x t W 1, t} \times(U A)_{E x t C e i l, t}+T_{E q W 1, t} \times(U A)_{E q C e i l, t} \\
& \left.+T_{F 1, t} \times(U A)_{F C e i l, t}+T_{W i n, t} \times(U A)_{W i n C e i l, t}\right] \div\left[(U A)_{\text {Ceil }, t}\right. \\
& +2 \times(U A)_{\text {ceiltile }}+(U A)_{\text {WinCeil }, t}+(U A)_{F C e i l, t}+(U A)_{E q C e i l, t} \\
& \left.+(U A)_{E x t C e i l, t}\right]
\end{aligned}
$$

Equation 3.27 utilized all of the temperatures that were influencing the ceiling's internal node's temperature at the present time step to determine the internal temperature of the ceiling one time step forward in time.

$$
\begin{aligned}
T_{\text {Ceil } 2, t+1}= & T_{\text {Ceil } 2, t}+\frac{\Delta t}{C_{\text {ceil }}}\left[\left(T_{\text {Ceil } 1, t}-T_{\text {Ceil } 2, t}\right) \times 2 \times(U A)_{\text {ceiltile }}\right. \\
& \left.+\left(T_{\text {Ceil } 3, t}-T_{\text {Ceil }, t}\right) \times 2 \times(U A)_{\text {ceiltile }}\right]
\end{aligned}
$$

Equation 3.28 utilized all of the plenum space's surfaces' temperatures, the ceiling internal temperature and the respective resistances at the present time step to determine the temperature of the node located on the top of the ceiling's surface.

$$
\begin{aligned}
T_{\text {Ceil } 3, t+1}= & {\left[T_{\text {Ceil } 2, t} \times 2 \times(U A)_{\text {ceiltile }}+T_{P, t} \times(U A)_{P F, t}+T_{F 5, t} \times\right.} \\
& \left.(U A)_{F 5 \text { Ceil } 3, t}\right] \div\left[2 \times(U A)_{\text {ceiltile }}+(U A)_{P F, t}+(U A)_{F 5 \text { Ceil3, } t}\right]
\end{aligned}
$$

Equation 3.29 utilized all of the temperatures and heat gains/losses that were interacting with the plenum space's air at the present time step to determine the temperature of the plenum air node one time step forward in time. 


$$
\begin{aligned}
T_{P, t+1}= & T_{P, t}+\frac{\Delta t}{C_{A i r P}}\left[\left(T_{O, t}-T_{P, t}\right) \times(U A)_{E x t P}+\left(T_{C e i l 3, t}-T_{P, t}\right) \times(U A)_{P F, t}\right. \\
& \left.+Q_{I n f P, t}+Q_{R P, t}+\left(T_{F 5, t}-T_{P, t}\right) \times(U A)_{P C, t}\right]
\end{aligned}
$$

Equation 3.30 utilized all of the room's surfaces' temperatures and the respective resistances at the present time step to determine the temperature of the node located on the radiator panel's surface. It is important to note, that equation 3.30 was over-ruled by equation 3.41 when the office under evaluation required heating from the radiator. When heating was required the hot water running through the pipes dominated the heat balance at the surface of the radiator panel. For this reason, the surface temperature of the radiator panel was simplified, and neglected the temperature of the surfaces within the room, during times of heating.

$$
\begin{aligned}
T_{\text {Radt }, t+1}= & {\left[T_{F 1, t} \times(U A)_{F R a d, t}+T_{E q W 1, t} \times(U A)_{E q R a d, t}+T_{E x t W 1, t} \times\right.} \\
& \left.(U A)_{E x t R a d, t}+T_{W i n, t} \times(U A)_{W i n R a d, t}+T_{R t, t} \times(U A)_{R a d, t}\right] \\
& \div\left[(U A)_{F R a d, t}+(U A)_{E q R a d, t}+(U A)_{E x t R a d, t}\right. \\
& \left.+(U A)_{\text {WinRad }, t}+(U A)_{\text {Rad }, t}\right]
\end{aligned}
$$

Equations 3.15 to 3.30 represent the temperature at each node at a time $(\mathrm{t}+1)$, allowing for the prediction of each node's temperature at a future time. For the system to function, initial conditions had to be defined for each node's temperature. To obtain adequate initial conditions, two simulations were performed for each analysis. The first simulation acted as a "warm up", during this simulation the initial temperature of all nodes were assumed to be equal to thermostat reading, in the corresponding office. During this time, the average temperature of each node was recorded. Afterward, the average temperature was utilized as the initial temperature for each node, except for the room air temperature, which was 
assigned the temperature recorded by the thermostat.

The Matlab function that utilized equations 3.15 to 3.30 was called "ZoneFiniteDifference" and can be found by following the link provided in Appendix A The "ZoneFiniteDifference" function was utilized in the main Matlab script "ZoneLoadScript" which can also be found by following the link provided in Appendix A.

\subsubsection{Internal Convection Coefficients}

The rate at which energy is transferred between the internal surfaces and the air in the room is based on the convection coefficients. Several methods for determining these coefficients have been developed based on the type of surface, i.e. wall, window, floor and ceilings and for different room boundary conditions, i.e. heated ceiling or floor, or varying radiant panel locations. A detailed literature review on these theories can be found in [60]. Sensitivity analyses were conducted which examined the effect of employing these various methodologies for calculating the internal convection coefficients. Several simulations were run in EnergyPlus each using a different method for calculating the internal convection coefficients, while all other parameters remained fixed. From the results it could be seen that the selected convection coefficient method had a great influence on the final results, as the annual energy consumption fluctuated by up to $10 \%$. Of the various theories the adaptive convection coefficient method is the most intricate. It combines the Alamdari and Hammond correlations with the Fisher correlations [61]. Based on the temperature of the surface of interest and the air temperature, it determines whether buoyant forces are present or the air is stably stratified [61]. Once this is completed the most appropriate equation for determining the convection coefficient is selected [61]. The potential equations are displayed in equations 3.31 to 3.36 and depend on several variables, such as the air changes 
per hour $(\mathrm{ACH}), \mathrm{SAT}$, room air temperature and surface temperature [61].

Equation 3.31 represents the adaptive convection coefficient method for determining the convection coefficient for a wall that is undergoing assisting forces [60, 61]. Assisting forces means that the air is naturally moving downwards due to the temperature gradients in the room, in addition to the downward motion caused by the mechanical system [60, 61].

$$
h=\left[\left[\left(1.5\left(\frac{\Delta T}{H}\right)^{1 / 4}\right)^{6}+\left(1.23 \Delta T^{1 / 3}\right)^{6}\right]^{1 / 2}+\left[\left(\frac{T_{S}-T_{\text {Sup }}}{\Delta T}\right)\left(-0.199+0.19 A C H^{0.8}\right)\right]^{3}\right]^{1 / 3}
$$

Equation 3.32 represents the adaptive convection coefficient method for determining the convection coefficient for a wall that is undergoing opposing forces [60, 61]. Opposing forces means that the air is naturally moving upwards due to the temperature gradients in the room, counteracting the downward motion caused by the mechanical system [60, 61]. There are three equations that calculate the convection coefficient for a wall undergoing this scenario, the maximum value is ultimately selected [60, 61].

$$
\begin{aligned}
& h=\left[\left[\left(1.5\left(\frac{\Delta T}{H}\right)^{1 / 4}\right)^{6}+\left(1.23 \Delta T^{1 / 3}\right)^{6}\right]^{1 / 2}-\left[\left(\frac{T_{S}-T_{\text {Sup }}}{\Delta T}\right)\left(-0.199+0.19 A C H^{0.8}\right)\right]^{3}\right]^{1 / 3} \\
& \left.\left.h=80 \%\left[\frac{T_{S}-T_{\text {Sup }}}{\Delta T}\right)\left(-0.199+0.19 A C H^{0.8}\right)\right]^{3}\right]^{1 / 3} \\
& \left.h=80 \%\left[\left(1.5\left(\frac{\Delta T}{H}\right)^{1 / 4}\right)^{6}+\left(1.23 \Delta T^{1 / 3}\right)^{6}\right]^{1 / 2}\right]
\end{aligned}
$$

Equation 3.33 represents the adaptive convection coefficient method for determining the convection coefficient for the floor when it is undergoing buoyant forces [60, 61]. The floor is undergoing buoyant forces when it is warmer than the air, causing the air to rise [60, 61]. 


$$
\left.h=\left[\left[\left(0.6\left(\frac{\Delta T}{D_{h}^{2}}\right)^{1 / 5}\right)^{6}+1.63 \Delta T^{1 / 3}\right)^{6}\right]^{1 / 2}+\left[\left(\frac{T_{S}-T_{\text {Sup }}}{\Delta T}\right)\left(0.159+0.166 A C H^{0.8}\right)\right]^{3}\right]^{1 / 3}
$$

Equation 3.34 represents the adaptive convection coefficient method for determining the convection coefficient for the floor when it is stably stratified [60, 61]. The floor is stably stratified when it is cooler than the air, causing the air to stagnate [60, 61].

$$
h=\left[\left[\left(1.4\left(\frac{\Delta T}{D_{h}}\right)^{1 / 4}\right)\right]^{3}+\left[\left(\frac{T_{S}-T_{\text {Sup }}}{\Delta T}\right)\left(0.159+0.166 A C H^{0.8}\right)\right]^{3}\right]^{1 / 3}
$$

Equation 3.35 represents the adaptive convection coefficient method for determining the convection coefficient for the ceiling when it is undergoing buoyant forces [60, 61]. The ceiling is undergoing buoyant forces when it is cooler than the air, causing the air to fall [60, 61].

$$
\left.h=\left[\left[\left(0.6\left(\frac{\Delta T}{D_{h}^{2}}\right)^{1 / 5}\right)^{6}+1.63 \Delta T^{1 / 3}\right)^{6}\right]^{1 / 2}+\left[\left(\frac{T_{S}-T_{\text {Sup }}}{\Delta T}\right)\left(-0.166+0.484 A C H^{0.8}\right)\right]^{3}\right]^{1 / 3}
$$

Equation 3.36 represents the adaptive convection coefficient method for determining the convection coefficient for the ceiling when it is stably stratified [60, 61]. The ceiling is stably stratified when it is warmer than the air, causing the air to stagnate [60, 61].

$$
h=\left[\left[\left(1.4\left(\frac{\Delta T}{D_{h}}\right)^{1 / 4}\right)\right]^{3}+\left[\left(\frac{T_{S}-T_{\text {Sup }}}{\Delta T}\right)\left(-0.166+0.484 A C H^{0.8}\right)\right]^{3}\right]^{1 / 3}
$$

As detailed as this methodology is, the two theories that were combined do not consider the presence of a radiant panel in the office space. Considering how important internal convection coefficients were on the performance predictions it was deemed necessary to also include this consideration in the model. Therefore, a hybrid methodology was employed 
which selects between the adaptive convection coefficient and a heated ceiling methodology [60], since the radiators were located on the ceiling. The code selected the adaptive convection coefficient theory the majority of the time. However, it switched to the heated ceiling method when the ceiling mounted radiant panel was predicted to turn on. The convection coefficient equations for the heated ceiling method are displayed in equations 3.37 and 3.38

Equation 3.37 represents the heated ceiling methodology for determining the convection coefficient for vertical surfaces [60].

$$
h=\frac{1.646\left|T_{\text {Sup }}-T_{R}\right|^{0.32}}{H_{R}^{0.05}}
$$

Equation 3.38 represents the heated ceiling methodology for determining the convection coefficient for horizontal surfaces [60].

$$
h=\frac{0.233\left|T_{\text {Sup }}-T_{R}\right|^{0.32}}{P^{0.05}}
$$

The Matlab function for determining the internal convection coefficients in the office was called "UAConv" and can be found by following the link provided in Appendix A. The "UAConv" function was utilized in the "ZoneFiniteDifference" function which can also be found by following the link provided in Appendix $\mathrm{A}$.

\subsubsection{Internal Radiant Heat Exchange}

All surfaces are constantly exchanging energy through the form of radiation, so long as there is a temperature difference and the surfaces can see each other. How well each surface can see another surface is referred to as its "view factor". An ESP-r (building simulation tool) model was created for the office in the case study and computed all of the view factors 
based on the ray tracing theory. Figure 3.9 shows the geometry of the office's under analysis and the corresponding surface topology that was utilized within the ESP-r model.

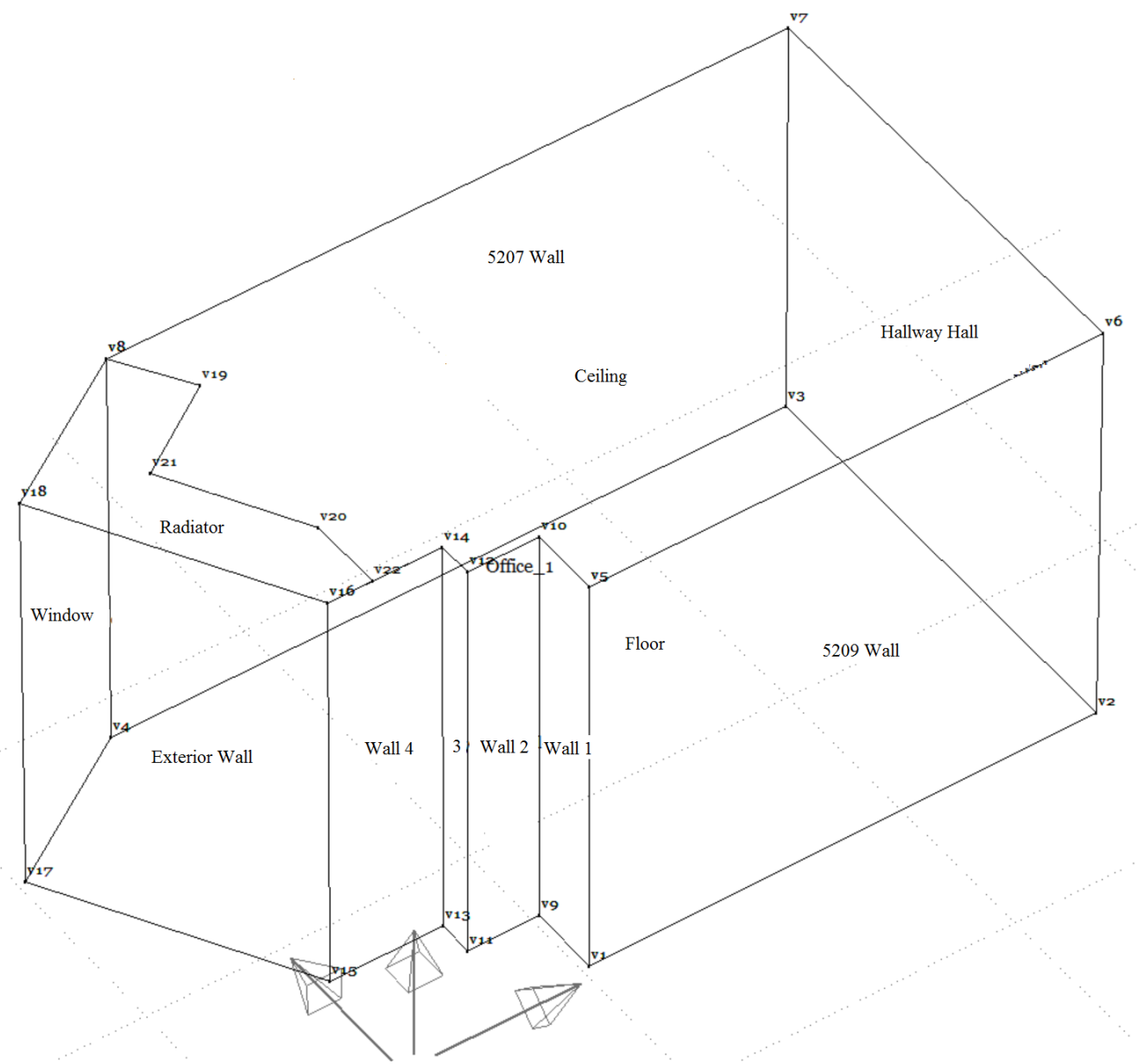

Figure 3.9: ESP-r model surface topology

Table 3.8 shows how well each surface views the other surfaces in the office space, as determined through the ray tracing theory. 
Table 3.8: View factors determined through ESP-r - The view factors represent how well the vertically listed surface sees each horizontally listed surface.

\begin{tabular}{|c||c|c|c|c|c|c|c|c|c|c|c|c|}
\hline & Wall 1 & Wall 2 & Wall 3 & Wall 4 & $\begin{array}{c}5207 \\
\text { Wall }\end{array}$ & $\begin{array}{c}5209 \\
\text { Wall }\end{array}$ & $\begin{array}{c}\text { Hallway } \\
\text { Wall }\end{array}$ & $\begin{array}{c}\text { Exterior } \\
\text { Wall }\end{array}$ & Window & Floor & Ceiling & Rad \\
\hline \hline Wall 1 & 0.0000 & 0.0000 & 0.0000 & 0.0000 & 0.0866 & 0.4074 & 0.1454 & 0.0000 & 0.0000 & 0.1804 & 0.1804 & 0.0000 \\
\hline Wall 2 & 0.0000 & 0.0000 & 0.1834 & 0.0000 & 0.2930 & 0.0000 & 0.0378 & 0.0123 & 0.0694 & 0.2021 & 0.1944 & 0.0077 \\
\hline Wall 3 & 0.0000 & 0.3684 & 0.0000 & 0.0000 & 0.1117 & 0.0272 & 0.1322 & 0.0000 & 0.0000 & 0.1803 & 0.1803 & 0.0000 \\
\hline Wall 4 & 0.0000 & 0.0000 & 0.0000 & 0.0000 & 0.2654 & 0.0000 & 0.0210 & 0.1563 & 0.1514 & 0.2030 & 0.1482 & 0.0548 \\
\hline 5207 Wall & 0.0081 & 0.0299 & 0.0088 & 0.0399 & 0.0000 & 0.1948 & 0.1436 & 0.0907 & 0.0122 & 0.2360 & 0.2237 & 0.0124 \\
\hline 5209 Wall & 0.0551 & 0.0000 & 0.0020 & 0.0000 & 0.2601 & 0.0000 & 0.1777 & 0.0138 & 0.0277 & 0.2318 & 0.2286 & 0.0033 \\
\hline Hallway Wall & 0.0216 & 0.0069 & 0.0091 & 0.0043 & 0.2203 & 0.2086 & 0.0000 & 0.0503 & 0.0270 & 0.2259 & 0.2220 & 0.0039 \\
\hline Exterior Wall & 0.0000 & 0.0032 & 0.0000 & 0.0648 & 0.2249 & 0.0228 & 0.0762 & 0.0000 & 0.1772 & 0.2155 & 0.1376 & 0.0779 \\
\hline Window & 0.0000 & 0.0266 & 0.0000 & 0.0940 & 0.0440 & 0.0816 & 0.0604 & 0.2716 & 0.0000 & 0.2109 & 0.1269 & 0.0840 \\
\hline Floor & 0.0166 & 0.0180 & 0.0082 & 0.0337 & 0.2216 & 0.1627 & 0.1364 & 0.0846 & 0.0548 & 0.0000 & 0.2442 & 0.0193 \\
\hline Ceiling & 0.0205 & 0.0193 & 0.0095 & 0.0290 & 0.2313 & 0.1760 & 0.1463 & 0.0622 & 0.0381 & 0.2683 & 0.0000 & 0.0000 \\
\hline Radiator & 0.0000 & 0.0096 & 0.0000 & 0.0890 & 0.1181 & 0.0225 & 0.0231 & 0.3076 & 0.2316 & 0.1985 & 0.0000 & 0.0000 \\
\hline
\end{tabular}


The ESP-r model output view factors for each surface that was defined. However, the model in Matlab was simplified in a manner which grouped all internal surfaces as a single surface. For this reason, the view factors that were utilized in Matlab were adjusted by summing all internal surface view factors together to form the equivalent wall view factors. Table 3.9 shows how well the Matlab defined surfaces view each other. The view factors that are shown in Table 3.9 represent how well the vertically listed surface sees each horizontally listed surface.

Table 3.9: View factors utilized in Matlab model

\begin{tabular}{|c||c|c|c|c|c|c||}
\hline & $\begin{array}{c}\text { Equivalent } \\
\text { Wall }\end{array}$ & $\begin{array}{c}\text { Exterior } \\
\text { Wall }\end{array}$ & Window & Floor & Ceiling & Radiator \\
\hline \hline Equivalent Wall & 0.4958 & 0.0462 & 0.0411 & 0.2085 & 0.1968 & 0.0117 \\
\hline Exterior Wall & 0.3919 & 0.0000 & 0.1772 & 0.2155 & 0.1376 & 0.0779 \\
\hline Window & 0.3066 & 0.2716 & 0.0000 & 0.2109 & 0.1269 & 0.0840 \\
\hline Floor & 0.5972 & 0.0846 & 0.0548 & 0.0000 & 0.2442 & 0.0193 \\
\hline Ceiling & 0.6315 & 0.0622 & 0.0381 & 0.2683 & 0.0000 & 0.0000 \\
\hline Radiator & 0.2623 & 0.3076 & 0.2316 & 0.1985 & 0.0000 & 0.0000 \\
\hline
\end{tabular}

The rate at which the internal surfaces exchange heat with each other can be characterized by a radiant coefficient. The radiant coefficient theory seen in equation 3.39 was selected to characterize the heat exchange occurring between the surfaces in the offices.

$$
\begin{gathered}
T_{m}=\left[\left(T_{1}+273\right)^{2}+\left(T_{2}+273\right)^{2}\right]\left[\left(T_{1}+273\right)+\left(T_{2}+273\right)\right] \\
h_{r}=\frac{5.67 \times 10^{-8} \times F \times T_{m}}{\left(\frac{1}{\epsilon_{1}}+\frac{1}{\epsilon_{2}}-1\right)} \\
(U A)_{\text {Rad }}=h_{r} \times A
\end{gathered}
$$

The Matlab function for determining the internal radiant heat exchange coefficients in the office was called "UARad" and can be found by following the link provided in Appendix A. The "UARad" function was utilized in the "ZoneFiniteDifference" function 
which can also be found by following the link provided in Appendix A

\subsubsection{Time Step Selection}

The selection of an appropriate time step was conducted once the explicit finite difference, internal convection coefficient and internal radiant coefficient methodologies were implemented in Matlab. These three methodologies were required for a numerical analysis of the coefficients to be completed. The analysis was performed in Matlab and displayed that equation 3.17 was the limiting equation. When a time step of one minute was selected the coefficients on the term $\mathrm{T}_{\mathrm{F} 2, \mathrm{t}}$ summed to approximately 0.04 . The selection of a larger integer for the time step resulted in a value below zero, causing the system to become unstable. For this reason, a one minute time step was utilized throughout this work.

\subsubsection{Hydronic-Based Heating Rate}

When the heating set-point is not being met in a room the primary source of heating is through a radiant panel. The function of this hydronic-based heating rate was simplified by separating the ceiling into two surfaces; the ceiling tile surface and the radiant panel surface. When the modeled office required heating, a theoretical radiator valve opened. At this point, the surface temperature of the panel was overridden from what was determined in equation 3.30, to incremental values. These temperature values were determined by analyzing the outlet water temperature during a time when the radiator valve was initially opened. Routine testing found that the radiator outlet temperature plot was consistent from day to day and given the scope of this thesis a one-day analysis was considered valid. Figure 3.10 shows the radiator outlet temperature during one of these days. 


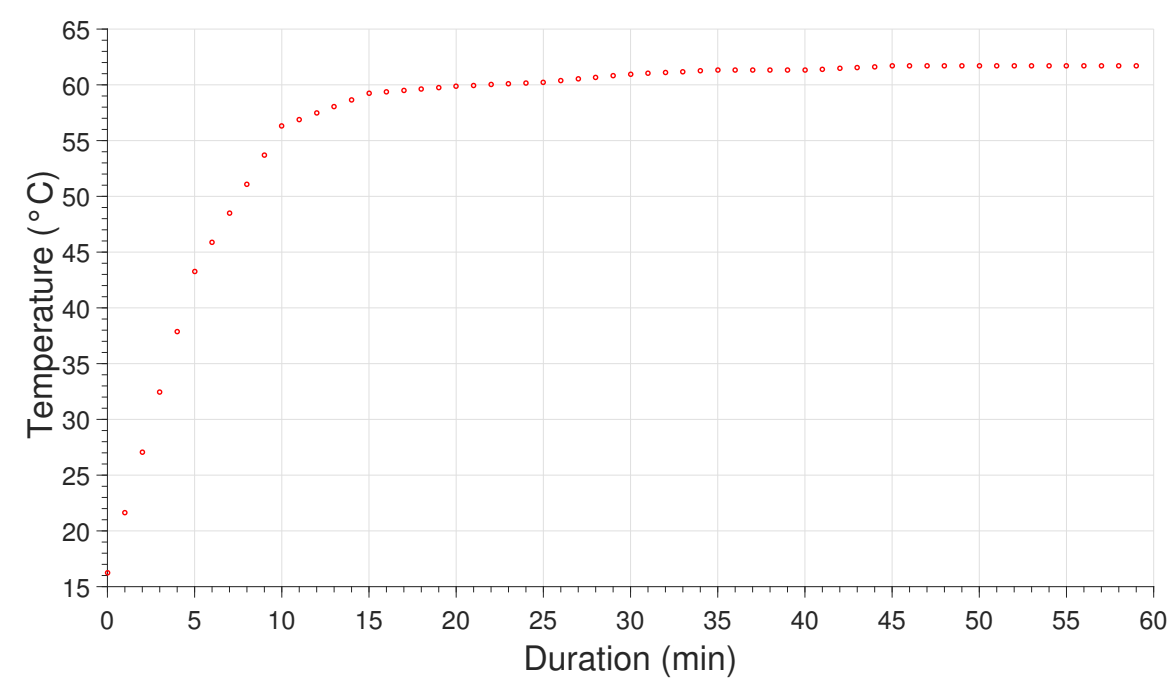

Figure 3.10: Radiator outlet temperature

Figure 3.10 shows that it took approximately fifteen minutes for the rate of temperature increase to minimize. At this point, the temperature of the water at the outlet of the radiator only increased by approximately $0.5{ }^{\circ} \mathrm{C}$ per five minutes. For this reason, it was assumed that the modeled radiant panel temperature reached its maximum temperature after fifteen minutes of being turned on.

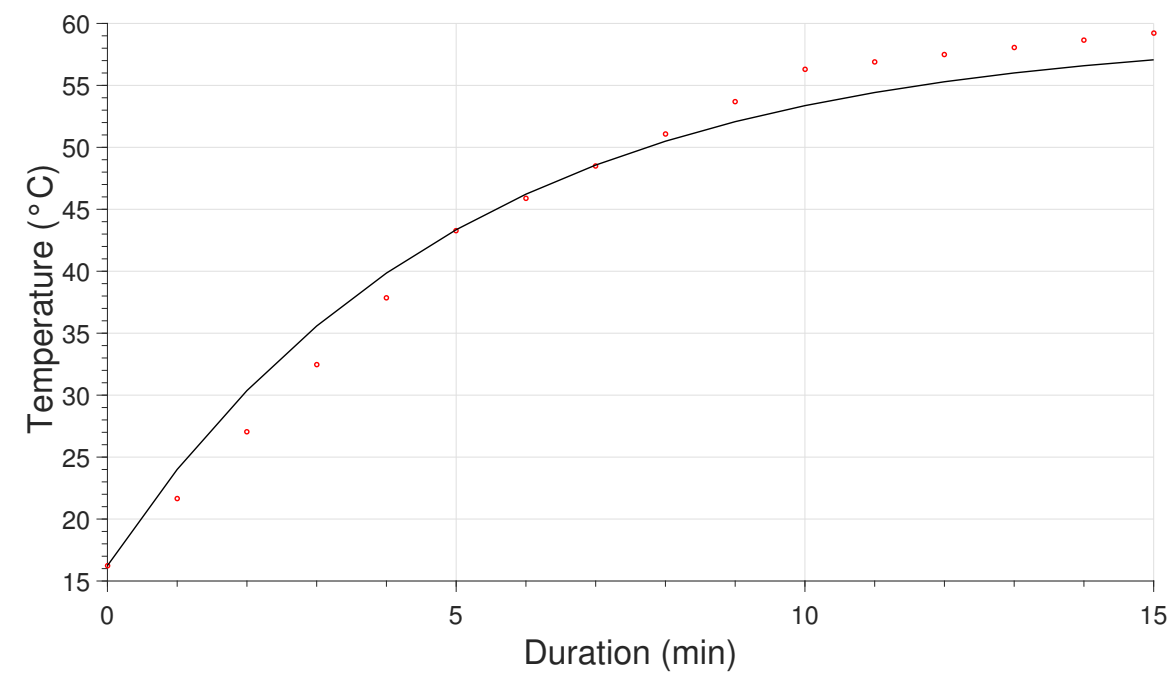

Figure 3.11: Radiator outlet temperature with corresponding first order response 
Figure 3.11 shows the first order response for the radiator outlet temperature data. Equation 3.40 represents the first order response equation that was determined through the utilization of time stepping.

$$
T_{\text {outlet }, t}=16.24+42.99 \times\left(1-e^{-\frac{t}{5.02}}\right)
$$

The first order response equation for the outlet temperature data was then used to determine the first order response for the radiant panel's surface temperature. Equation 3.41 represents the first order response function that was utilized to represent the radiant panel's surface temperature during times when the model predicted that heating was required.

$$
T_{\text {Radt }, t}=15.78+42.99 \times\left(1-e^{-\frac{t}{5.02}}\right)
$$

Equation 3.41 does not have the same y-intercept as the first order response function for the radiator outlet temperature. The difference in the y-intercept was due to the difference in magnitude between the radiant panel temperature and the outlet temperature reading. To account for this difference only the y-intercept was altered so that the trend would remain similar. The y-intercept was tailored in a manner which ensured the radiant panel's temperature reached its maximum value after fifteen minutes. The maximum value was found by Jayson Bursill by utilizing an IR camera. Figure 3.12 shows a maximum value of approximately $56.6^{\circ} \mathrm{C}$. By analyzing equation 3.41 at $\mathrm{t}=15$ and a surface temperature of $56.6^{\circ} \mathrm{C}$, a y-intercept of approximately $15.78{ }^{\circ} \mathrm{C}$ was determined. 


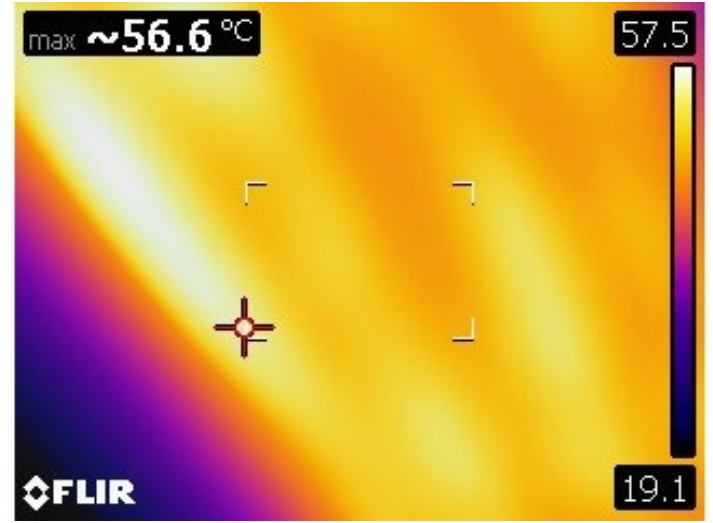

Figure 3.12: Radiator thermograph captured during steady state operation

The hydronic-based heating rate was predicted based on the heat exchange due to radiation and convection from the radiator panel's surface to the office space. Equation 3.42 sums together the heat gain in the office as a result of the radiation exchange between the radiator panel and the internal surfaces with the heat exchange due to convection from the radiator panel and the office air. The limitation of this methodology is that it assumes the top of the radiator is well insulated and therefore, the heat loss to the plenum is negligible.

$$
\begin{aligned}
Q_{\text {Radt }, t}= & \sigma \times \epsilon_{\text {Rad }} \times A_{\text {Rad }}\left[F_{\text {RadWin }} \times\left(\left(T_{\text {Radt }, t}+273\right)^{4}-\left(T_{\text {Win }, t}+273\right)^{4}\right)\right. \\
& +F_{\text {RadExt }} \times\left(\left(T_{\text {Radt }, t}+273\right)^{4}-\left(T_{E x t W 1, t}+273\right)^{4}\right) \\
& +F_{\text {RadEq }} \times\left(\left(T_{\text {Radt }, t}+273\right)^{4}-\left(T_{E q W 1, t}+273\right)^{4}\right) \\
& \left.+F_{\text {RadF }} \times\left(\left(T_{\text {Radt }, t}+273\right)^{4}-\left(T_{F 1, t}+273\right)^{4}\right)\right] \\
& +(U A)_{\text {Rad }, t} \times\left(T_{\text {Radt }, t}-T_{R t, t}\right)
\end{aligned}
$$

The Matlab function that utilized these equations was called "ZoneFiniteDifference" and can be found by following the link provided in Appendix A The "ZoneFiniteDifference" function was utilized in the main Matlab script "ZoneLoadScript" which can also be found by following the link provided in Appendix A. 


\subsubsection{Air-Based Heating \& Cooling Rate}

When the cooling set-point was not met in the spaces, the model supplied cooling to the rooms at a rate predicted through equation 3.43, which was defined by Athienitis (2000) [54]. The air-based heating operated in a similar fashion. However, the radiator is the primary source of heating for each office and the air-based system is the secondary source of heating for the zone. By design, the reheat valve will only initiate if the radiator in an office has been on for fifteen minutes and the heating set-point is still not met. The model was controlled in a similar fashion. If the modeled radiator was on for fifteen minutes the reheat valve opened. Once the reheat valve opened, equation 3.43 was utilized to predict the air-based heating rate.

$$
Q_{A i r t, t}=k_{p}\left(T_{s p, t}-T_{R t, t}\right)
$$

Equation 3.43 was defined by Athienitis (2000) [54] and utilized the proportional control constant $\mathrm{k}_{\mathrm{p}}$ to scale the difference between the set-point and room air temperature [54]. A good value for this was half of the peak load for the space that was being analyzed [54]. Since there was air-based heating and cooling, a separate proportional control constant needed to be defined based on the season that was being analyzed.

Chapter 18 of the 2013 ASHRAE Fundamentals Handbook outlines two methods for estimating the peak heating and cooling rate requirements, the heat balance and radiant time series methods [10]. Peak heating and cooling rate calculations can be thought of as worstcase scenarios, meaning that the peak cooling occurs when all possible internal gains are present, and the solar radiation and outdoor air temperature are at their highest. However, heat gains from infiltration can be neglected for commercial buildings when positive air pressure can be assumed [10]. Conversely, peak heating is calculated in the middle of the night when no solar gains and internal heat gains are present, the outdoor air temperature is 
at its lowest, and losses due to infiltration are taken into consideration. In this research, the radiant time series method was used to calculate the peak heating and cooling rates during the winter and summer, respectively.

There is a limitation of utilizing equation 3.43 as the method of predicting the air-based heating and cooling rates. Equation 3.43 is a theoretical method that estimates the rate of heating and cooling based on how significant the difference is between the room air and set-point temperature. It does not attempt to replicate the controls of the actual system. As a result, further investigation is required to diagnose discrepancies between the measured and predicted air-based heating and cooling rates. Replicating the controls of the actual air-based system requires a significant amount of data regarding the other zones in the building, as the AHU selects the SAT based on the measured temperatures in each zone. Collecting and storing this large quantity of data for each simulation is a burdensome task and was found unnecessary given the scope of this research. Instead, the tool was modified to predict the required air flow rate based on the room temperature prediction and the SAT measurement from the VAV box. However, utilizing the SAT measurement in both the measured and predicted air-based heating and cooling rates posed a different limitation. Although the controls of the model would closely resemble the actual system operations, utilizing the same measurement to predict and measure the air-base heating and cooling rate would cause issues with the SAT sensor to go undetected, unless it completely failed. Due to this limitation equation 3.43 was selected for use in this research.

To make the utilization of equation 3.43 more similar to the actual operation of the system the maximum and minimum supply air temperatures were considered, as well as the maximum air flow rate of the VAV box. The maximum and minimum supply air temperatures are $30^{\circ} \mathrm{C}$ and $13{ }^{\circ} \mathrm{C}$, respectively. At each time step the system checks to ensure that the maximum air flow rate and corresponding supply air temperature would be capable of 
producing the predicted air-based heating or cooling rate obtained through equation 3.43 If it is not capable of producing the predicted air-based heating or cooling rate then the prediction is limited based on the determined value, otherwise, the prediction remains the same.

The Matlab function that utilized this equation was called "ZoneFiniteDifference" and can be found by following the link provided in Appendix A. The "ZoneFiniteDifference" function was utilized in the main Matlab script "ZoneLoadScript" which can also be found by following the link provided in Appendix A.

\subsection{Model Verification}

Once development was finalized, the functionality of the model had to be verified. A week early in the heating season was selected as both the air and hydronic-based systems were operating and could both be tested. The root mean square deviation between the measured and model predicted system metrics was determined during this week to quantify how different these values were, and for how long. Equation 3.44 represents the generic form of the root mean square deviation equation utilized throughout this research.

$$
R M S D=\sqrt{\sum_{t=1}^{n} \frac{\left(\hat{y}_{t}-y_{t}\right)^{2}}{n}}
$$

Figure 3.13 shows the temperature profiles for office 1. Generally, the measured and theoretical temperature profiles were similar. Figure 3.13 did show minor differences between the measured and the model predictions. For the majority of the week there appeared to be a slight phase shift between the measured and predicted temperatures. The delay in the predicted temperatures could be the result of a high air capacitance multiplier. As a 
result of the apparent phase shift, the root mean square deviation between the measured and predicted room air temperature for the week was calculated to be approximately 0.45 ${ }^{\circ} \mathrm{C}$. The root mean square deviation for the week fell within the fault detection threshold defined in section 3.4 for the temperature profiles. Thus, overall the model was capable of predicting the room air temperature in office 1 , with only minor deviations.

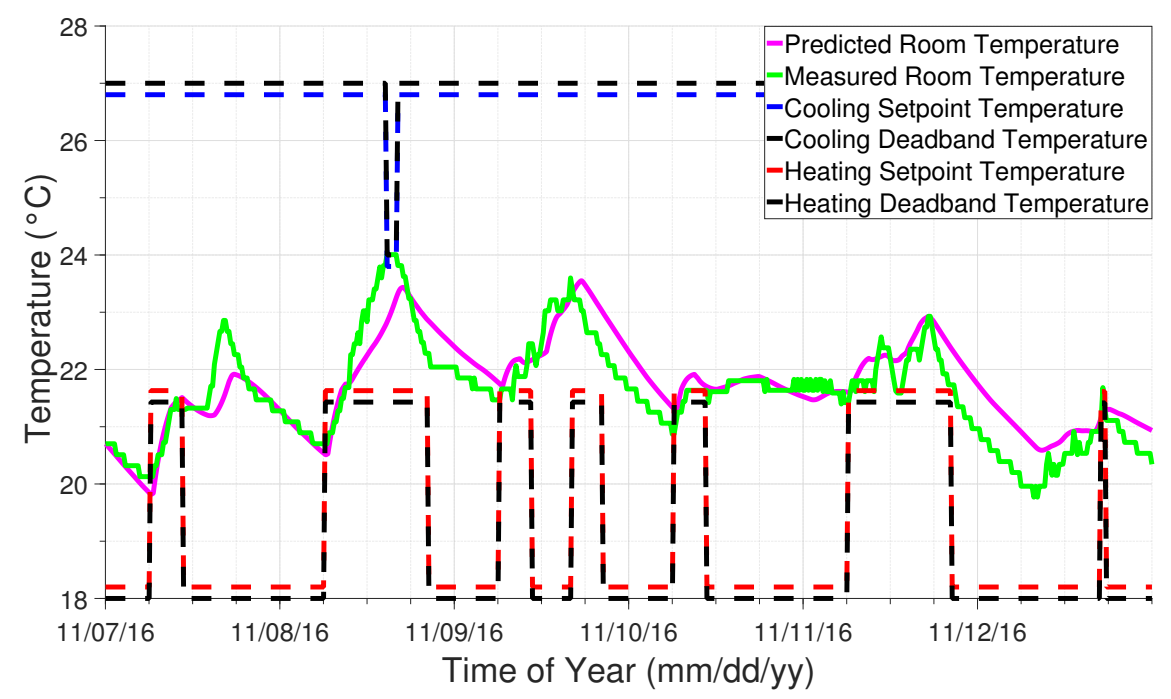

Figure 3.13: Room air temperature profiles for office 1 in November

Figure 3.14 shows the hydronic-based heating profiles for office 1 . The figure was plotted in a transparent manner as the predicted heating rate was not visible on November $12^{\text {th }}$, as the trends completely overlapped. The model typically predicted the radiator to be activated when the actual radiator was on. However, there were some noticeable discrepancies during the week, which resulted in a root mean square deviation of approximately $89 \mathrm{~W}$. The difference in the magnitudes were not of concern as the sensors that were implemented in the radiator in office 1 captured the initial transient heat transfer. However, it can be seen that after this initial instant that the measured heating rate dropped down to a similar magnitude as the predicted heating rate on November $7^{\text {th }}, 8^{\text {th }}$ and $10^{\text {th }}$. On the morning of November $9^{\text {th }}$ the model did not predict heating, while the radiator was actually 
on. The difference in the hydronic-based heating rate on the morning of November $9^{\text {th }}$ was a result of the difference in the temperature profiles, at the end of the day on November $9^{\text {th }}$. Overall, there were many similarities in the hydronic-based heating profiles for office 1 , which verified the functionality of the model.

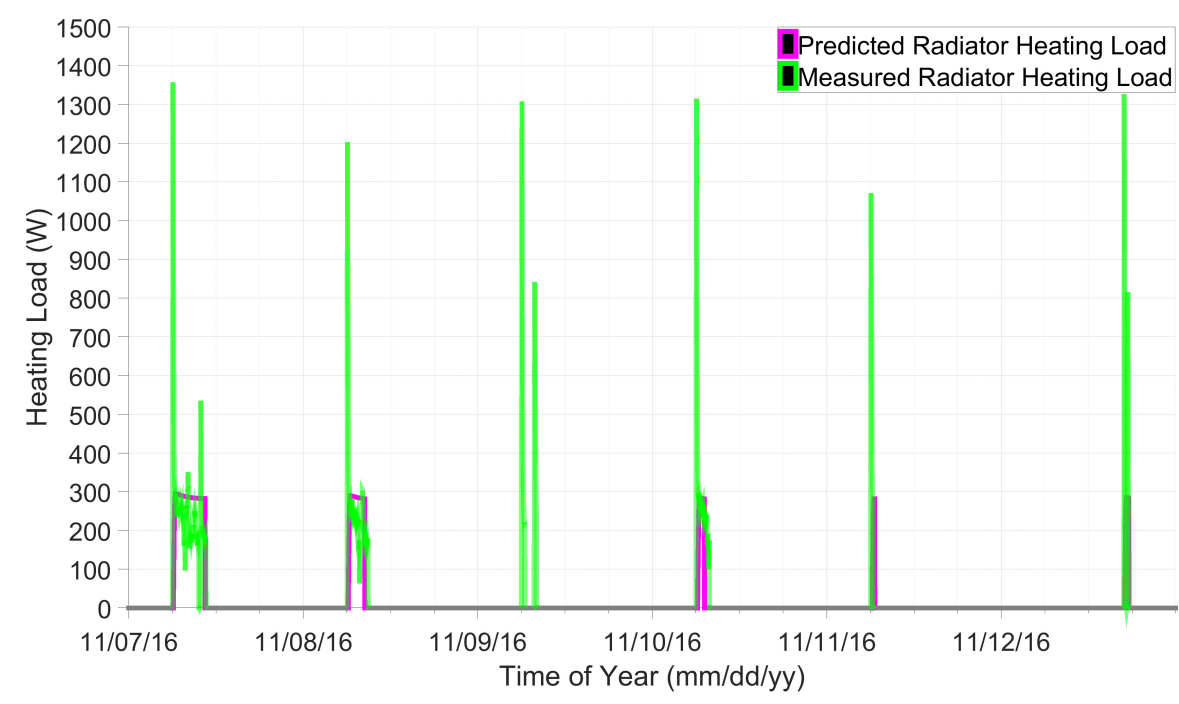

Figure 3.14: Hydronic-based heating profile for office 1 in November

Figure 3.15 shows the temperature profiles for office 2. Generally, the measured and theoretical temperature profiles were similar. Figure 3.15 did show minor differences between the measured and the model predictions. However, the root mean square deviation between the measured and predicted room air temperature for the week was calculated to be approximately $0.34{ }^{\circ} \mathrm{C}$. The root mean square deviation for the week fell within the fault detection threshold defined in section 3.4 for the temperature profiles. Thus, overall the model was capable of predicting the room air temperature in office 2 , with only minor deviations. 


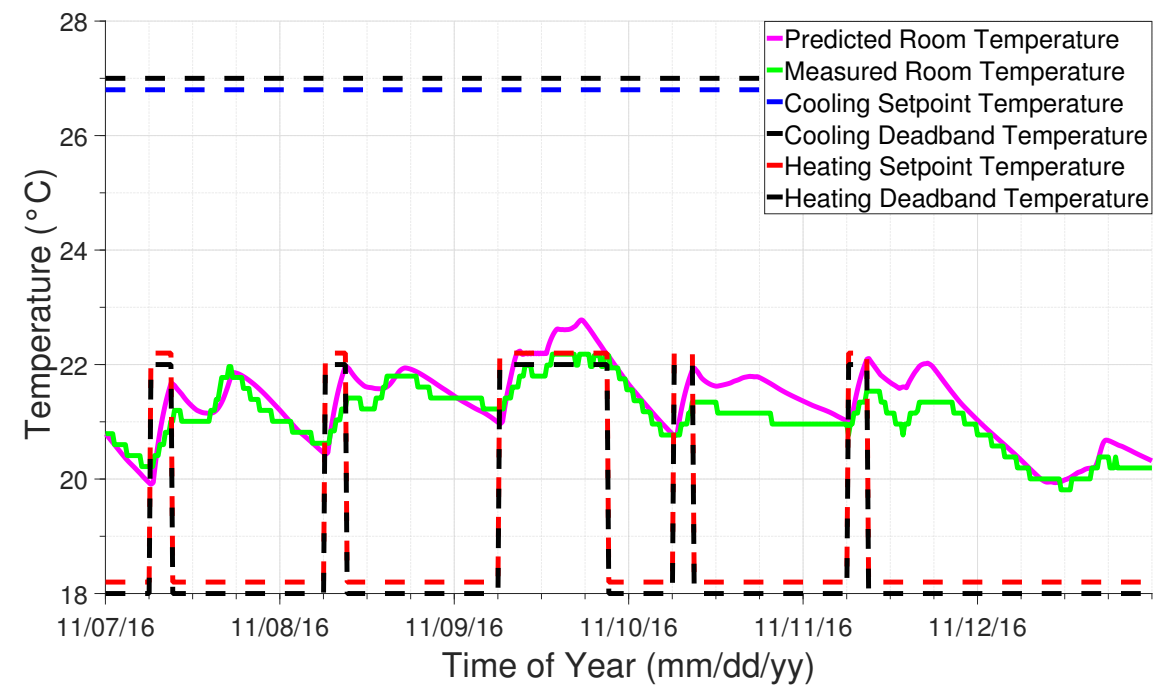

Figure 3.15: Room air temperature profiles for office 2 in November

Figure 3.16 shows the hydronic-based heating profiles for office 2 . The model typically predicted the radiator to be activated when the actual radiator was on. However, there were some noticeable discrepancies during the week, which resulted in a root mean square deviation of approximately $67 \mathrm{~W}$. On the evening of November $9^{\text {th }}$ the model did not predict heating until the very end of the day, while the radiator was actually on several times. The difference in the hydronic-based heating rate during the evening of November $9^{\text {th }}$ was a result of the difference in the temperature profiles, seen in Figure 3.15. The modelpredicted the room air temperature to exceed the set-point, as a result of the hydronic-based heating in the morning. Overall, there were many similarities in the hydronic-based heating profiles for office 2 , which verified the functionality of the model for this office. 


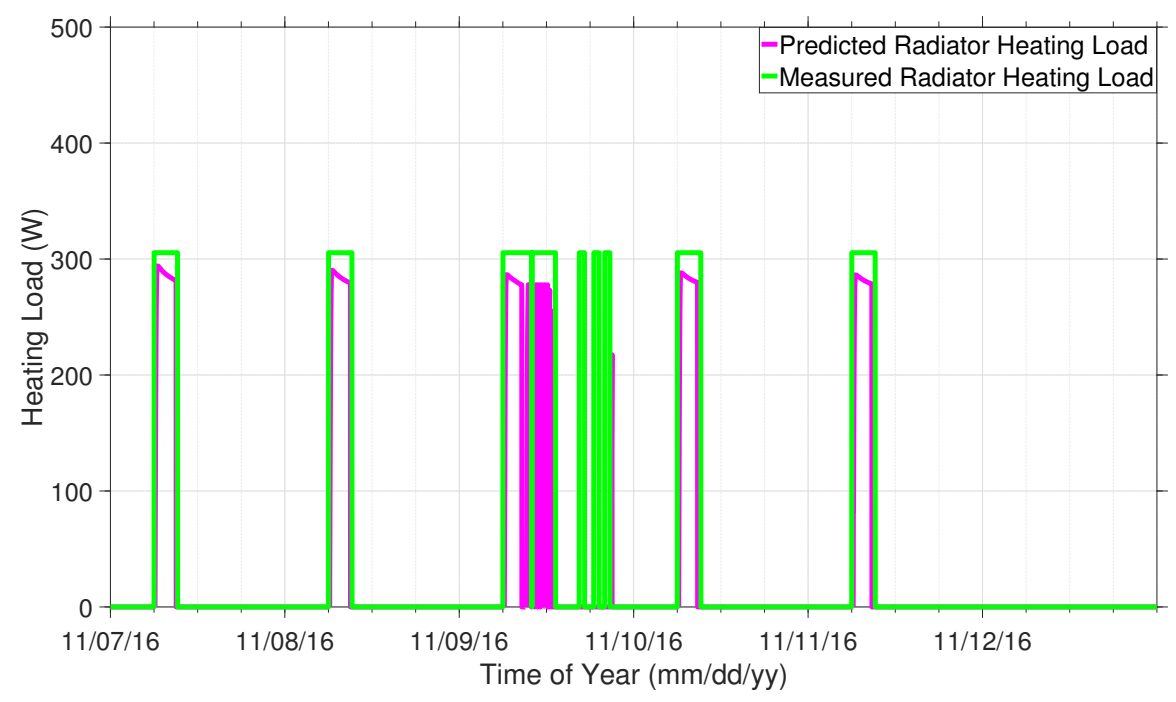

Figure 3.16: Hydronic-based heating profile for office 2 in November

Figure 3.17 shows the temperature profiles for office 3. Generally, the measured and theoretical temperature profiles were similar. Although, the model did exhibit some differences towards the end of the week. The root mean square deviation between the measured and predicted room air temperature for the week was calculated to be approximately 0.57 ${ }^{\circ} \mathrm{C}$. The root mean square deviation for the week was close to the fault detection threshold defined in section 3.4 for the temperature profiles. The main difference between the two temperature profiles occurred during November $11^{\text {th }}$. Strangely, the thermostat reading for office 3 plateaued at approximately $21^{\circ} \mathrm{C}$. Whereas, the model-predicted a more realistic value and plateaued at the set-point temperature. During this time the radiator was functioning and there were no issues at the building-level, yet the thermostat reading did not raise, even though approximately $300 \mathrm{~W}$ was being added to the space. The discrepancy in measured and predicted office air temperature carried through into November $12^{\text {th }}$, resulting in a relatively high root mean square deviation. Aside from the occurrence on the $12^{\text {th }}$ the model was capable of predicting the room air temperature for office 3 . 


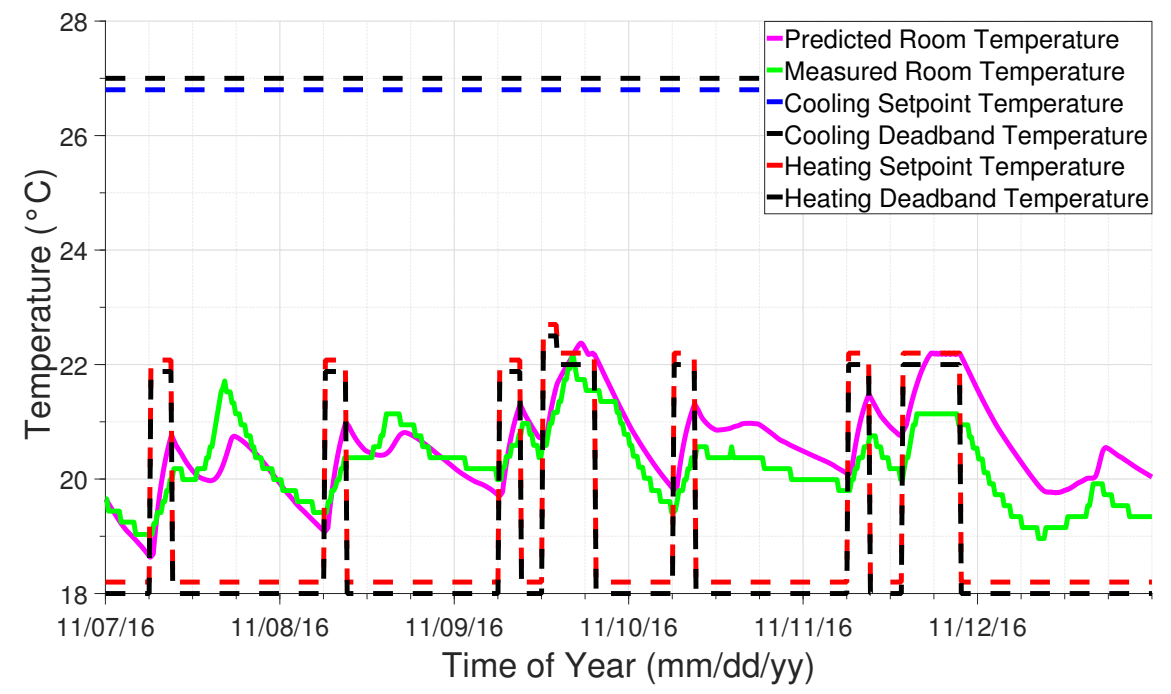

Figure 3.17: Room air temperature profiles for office 3 in November

Figure 3.18 shows the hydronic-based heating profiles for office 3 . The model typically predicted the radiator to be activated when the actual radiator was on. However, there were some discrepancies during the week, which resulted in a root mean square deviation of approximately $75 \mathrm{~W}$. On the evening of November $9^{\text {th }}$, the model did not predict the radiator to be on nearly as long as the radiator was actually on for. The difference in the hydronic-based heating rate on the evening of November $9^{\text {th }}$ was a result of the difference in the temperature profiles (Figure 3.17). Furthermore, on the evening of the $11^{\text {th }}$, the actual radiator remained activated all evening, as a result of the odd recordings from the thermostat. Overall, the hydronic-based heating trends for office 3 were similar, which verified the functionality of the model for this office. 


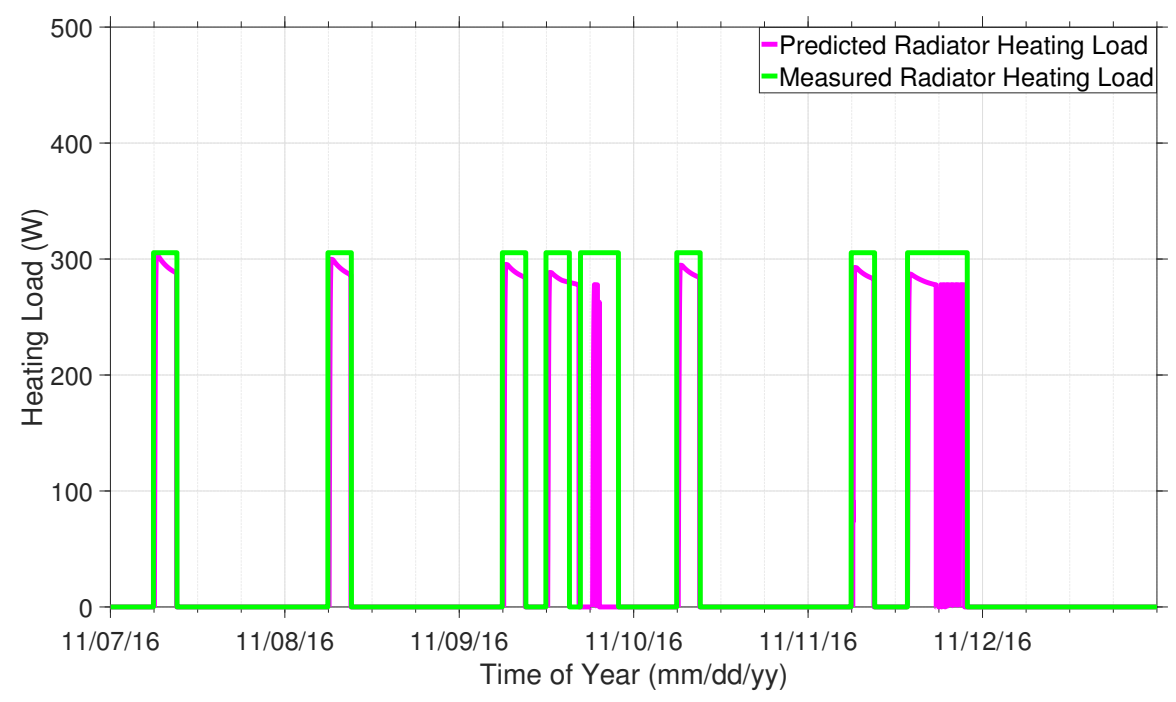

Figure 3.18: Hydronic-based heating profile for office 3 in November

Figure 3.19 shows the temperature profiles for office 4. Generally, the measured and theoretical temperature profiles were similar. Figure 3.19 did show minor differences between the measured and the model predictions. However, the root mean square deviation between the measured and predicted room air temperature for the week was calculated to be approximately $0.39{ }^{\circ} \mathrm{C}$. The root mean square deviation for the week fell within the fault detection threshold defined in section 3.4 for the temperature profiles. Thus, overall the model was capable of predicting the room air temperature in office 4 , with only minor deviations. 


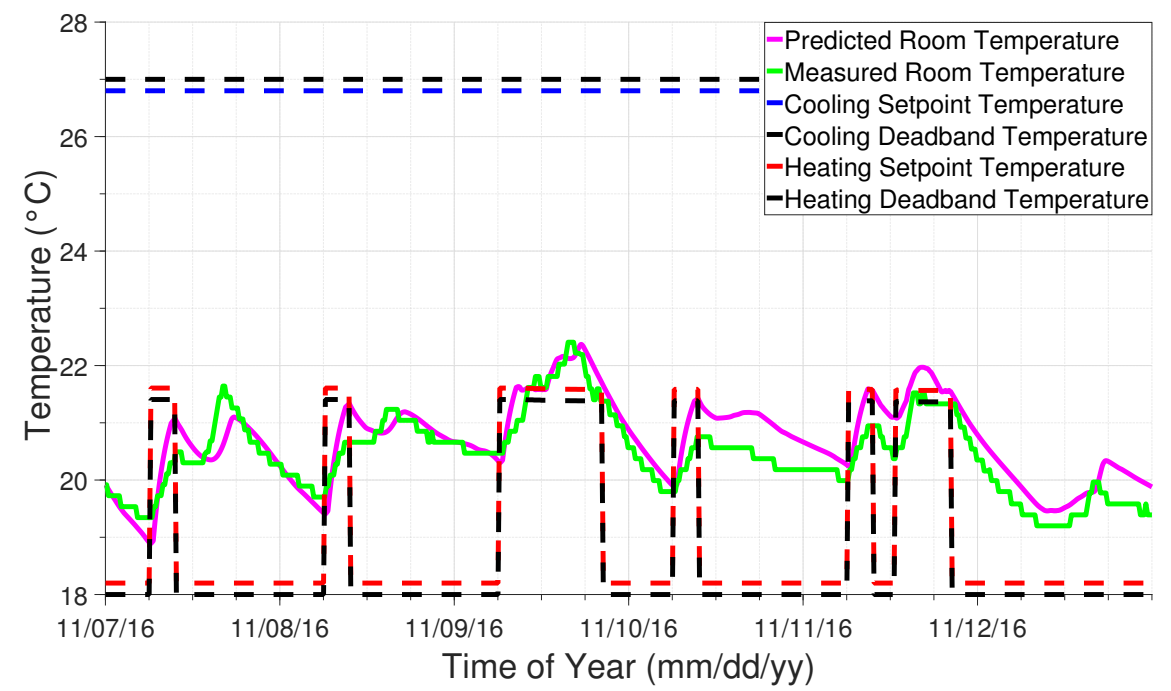

Figure 3.19: Room air temperature profiles for office 4 in November

Figure 3.20 shows the hydronic-based heating profiles for office 4 . The model typically predicted the radiator to be activated when the actual radiator was on. However, there were some noticeable discrepancies during the week, which resulted in a root mean square deviation of approximately $79 \mathrm{~W}$. On the evening of November $9^{\text {th }}$, the model did not predict the radiator to be on nearly as long as the radiator was actually on for. The difference in the hydronic-based heating rate on the evening of November $9^{\text {th }}$ was a result of the difference in the temperature profiles (Figure 3.19). Furthermore, on the evening of the $11^{\text {th }}$, the actual radiator remained activated all evening, as a result of the odd recordings from the thermostat. Overall, the hydronic-based heating trends for office 4 were similar, which verified the functionality of the model for this office. 


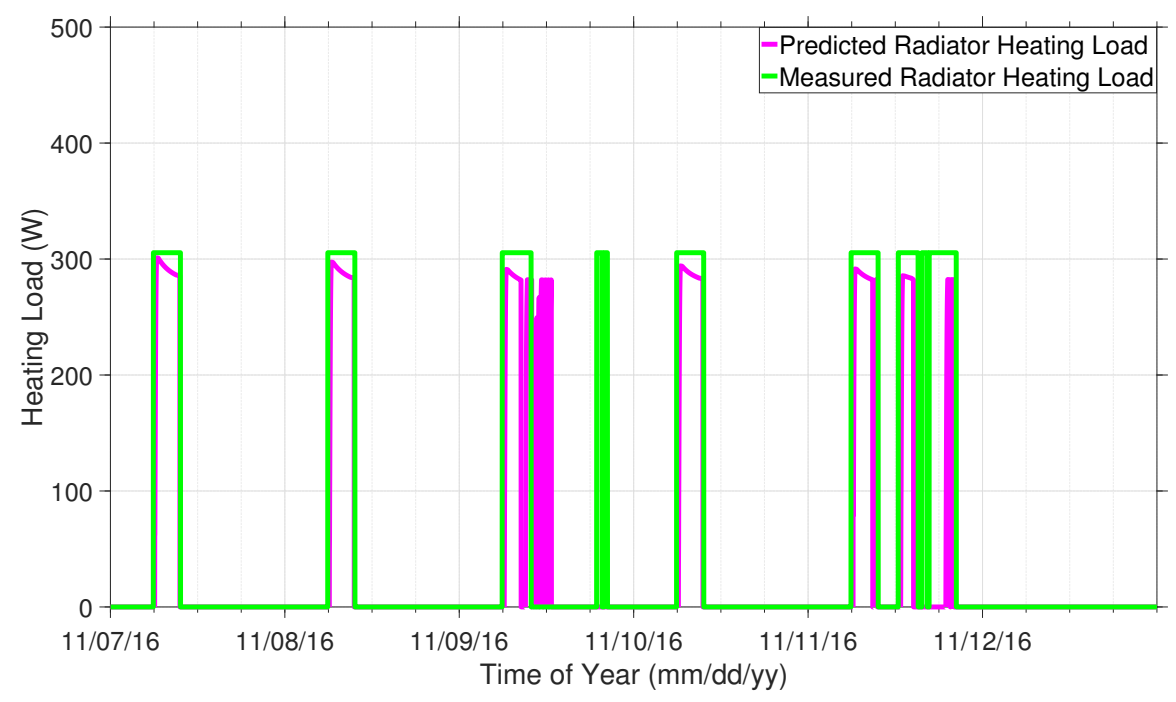

Figure 3.20: Hydronic-based heating profile for office 4 in November

During the verification process, the air-based heating and cooling rate predictions were found to be significantly different from the measured air-based heating and cooling rate estimations. The root mean square deviation for the week was found to be approximately $534 \mathrm{~W}$. Which was found to be over double the fault detection threshold that was found through the utilization of the methodology described in section 3.4 for the air-based heating and cooling profiles. The significant difference in the model-predicted and the measured air-based heating and cooling rates was a result of a fault in the SAT sensor, which has been described in section 4.1 .

The performance of the offices was closely examined during the week of November $7^{\text {th }}$, 2016. During this time no issues were detected in the functionality of the thermostats and radiators, with the exception of the peculiar thermostat recordings in office 3 on November $11^{\text {th }}$. The model-predicted temperature profiles for the four offices under evaluation followed similar trends to the temperatures recorded by the thermostats. The root mean square deviation for each office was calculated during the week. The root mean square 
deviation for one office fell just outside of the fault detection threshold defined in section 3.4 for the temperature profiles. However, the root mean square deviation for the other three offices fell well within the fault detection threshold defined in section 3.4 for the temperature profiles. The model-predicted hydronic-based heating rates for these four offices were also accurate. Any deviations from the measured hydronic-based heating rates were a result of discrepancies in the temperature profiles. Thus, the model displayed its capability to predict the room air temperature in the office spaces and of accurately predicting when hydronic-based heating was present, during a time where no faults existed.

\subsection{Fault Detection}

To determine if a fault existed in the system several system metrics needed to be estimated: the temperature in the offices, the hydronic-based heating rate for each office and the air-based heating and cooling rate for the zone. Once the measured and predicted system metrics for the zone and rooms were computed the results needed to be compared. If the measured system metrics exceeded a certain fault detection threshold a fault had been detected, otherwise, no fault had been detected. The selection of an appropriate fault detection threshold was important. A fault detection threshold that is too small can yield a significant amount of false alarms. While a fault detection threshold that is too large can result in faults going undetected. In this research, the fault detection threshold was computed based on the uncertainty in the model predictions and the sensors used to estimate the system metrics. The uncertainty associated with the model predictions was caused by the underlying assumptions in the tool, the uncertainty in the material properties that were selected and the uncertainty in the sensor measurements used within the tool. The uncertainty of each of these will now be discussed. The section closes with a discussion regarding the 
selection of the analysis duration and its role in the fault detection process.

\subsubsection{Temperature Profile Fault Detection Threshold}

There were several sources of uncertainty when comparing the measured temperature to the model-predicted temperature. There was uncertainty associated with the thermostat readings, model simplifications, the material property selections and the sensors used within the modeling tool. These sources of uncertainty will be now be discussed.

\section{Measured Office Air Temperature Uncertainty}

Each sensor has a specified accuracy associated with its measurements which can be found in the manufacturer's specifications for the device. The precision of a sensor is half of the measurements smallest incremental value. The precision of a sensor was often times significantly less than the specified accuracy of the device. For example, the thermostats in the offices under evaluation were accurate to within $\pm 0.2{ }^{\circ} \mathrm{C}[62]$. Whereas the obtained measurements go to the fourth decimal place, resulting in a precision of $\pm 0.00005{ }^{\circ} \mathrm{C}$. For this reason, the precision of the thermostat was neglected. Therefore, the uncertainty associated with the thermostats in the four offices under analysis was $\pm 0.2^{\circ} \mathrm{C}$.

\section{Model Uncertainty}

Uncertainty arises in all simulation tools due to the various simplifications that have been implemented in the tool's analysis. The developed software tool was created to find a proper balance between result accuracy and model simplification. Adequate results were produced while the model still had several underlying simplifications. These model simplifications 
were listed and justified in Table 3.10 .

Table 3.10: Underlying model assumptions

\begin{tabular}{|c|c|}
\hline Assumption & Assumption justification \\
\hline Perfectly mixed air & $\begin{array}{l}\text { This is a common assumption as systems are } \\
\text { designed to provide good mixing in the space. It } \\
\text { does have its limitations since it neglects } \\
\text { stratification effects, as well as temperature gradients } \\
\text { at the exterior surfaces. It is the default method in } \\
\text { EnergyPlus [58]. Finally, the validity of this } \\
\text { assumption is explored later, in Chapter } 4 .\end{array}$ \\
\hline $\begin{array}{l}\text { All solar radiation hits the } \\
\text { floor's surface }\end{array}$ & $\begin{array}{l}\text { A sensitivity analysis was conducted during a sunny } \\
\text { week, it displayed minimal fluctuation (11.8\%) in the } \\
\text { cooling rate when applying the solar gain to the other } \\
\text { surfaces in the office. Furthermore, due to the } \\
\text { geometry of the office, the floor will be the primary } \\
\text { absorber of the larger, direct solar gains throughout } \\
\text { the year. This is also the default method in } \\
\text { EnergyPlus [58]. }\end{array}$ \\
\hline $\begin{array}{l}\text { Internal walls have an } \\
\text { adiabatic boundary condition }\end{array}$ & $\begin{array}{l}\text { Reasonable given the minimal temperature } \\
\text { difference in neighbouring spaces. }\end{array}$ \\
\hline $\begin{array}{l}\text { Internal walls are represented } \\
\text { by one, equivalent wall node }\end{array}$ & $\begin{array}{l}\text { All internal surfaces will be influenced the same way } \\
\text { since the temperature gradient in the room air is } \\
\text { minimal (perfectly mixed), the majority of the solar } \\
\text { radiation strikes the floor and heat transfer from } \\
\text { neighbouring spaces is adiabatic, thus this is a } \\
\text { reasonable assumption. }\end{array}$ \\
\hline One dimensional heat flow & $\begin{array}{l}\text { Reasonable given perfectly mixed air assumption and } \\
\text { the minimal temperature fluctuation on surfaces. It is } \\
\text { the default method in EnergyPlus [58]. }\end{array}$ \\
\hline $\begin{array}{l}\text { Constant conductivity for all } \\
\text { materials }\end{array}$ & $\begin{array}{l}\text { The conductivity of materials depends on } \\
\text { temperature [50]. There is minimal temperature } \\
\text { fluctuations in each of the materials that are being } \\
\text { dealt with, thus this is a reasonable assumption. It is } \\
\text { the default method in EnergyPlus [58]. }\end{array}$ \\
\hline $\begin{array}{l}\text { Furniture capacity is included } \\
\text { in the air node's capacity }\end{array}$ & $\begin{array}{c}\text { Solar absorption in low mass objects are often } \\
\text { assumed to directly transfer to the air node [63]. } \\
\text { Since the majority of the furniture in these offices is } \\
\text { low in mass this assumption is considered } \\
\text { reasonable. }\end{array}$ \\
\hline
\end{tabular}




\section{Uncertainty in Material Properties}

Each material's density, specific heat capacity and conductivity/resistance needed to be acquired in order to adequately predict the performance of the spaces. However, the material properties that were obtained carried a degree of uncertainty, which had great implications on the model. To simplify the uncertainty analysis, only the uncertainty of material properties which greatly influenced the final results were addressed. Sensitivity analyses were performed to determine which values caused the greatest fluctuations in the final results. The sensitivity analyses were conducted during the changeover season so that there was minimal mechanical interference, that is, a limited air-based heating and cooling rate was supplied to the rooms and no hydronic-based heating was present. A time with minimal mechanical interference was selected so that there would be fewer variables influencing the predicted room air temperature in the model. Table 3.11 shows the material properties that had the greatest impacts on the final results. A range of values for the material properties was found in the 2013 ASHRAE Fundamentals Handbook [10] and was included in Table 3.11. The average room air temperature was recorded for each material properties maxima and minima, these values can also be seen in Table 3.11

Table 3.11: Temperature fluctuations caused by alteration in material properties

\begin{tabular}{||c|c|c||}
\hline Material property & Value range & $\begin{array}{c}\text { Average room air } \\
\text { temperature }\end{array}$ \\
\hline \hline Concrete density & $2080-2500 \mathrm{~kg} / \mathrm{m}^{3}$ & $22.50-22.52{ }^{\circ} \mathrm{C}$ \\
\hline Concrete specific heat capacity & $800-1000 \mathrm{~kJ} / \mathrm{kg} . \mathrm{K}$ & $22.51-22.54^{\circ} \mathrm{C}$ \\
\hline Carpet thermal resistance & $0.12-0.28 \mathrm{~m}^{2} . \mathrm{K} / \mathrm{W}$ & $22.62-22.46^{\circ} \mathrm{C}$ \\
\hline
\end{tabular}

Simulations were performed which combined the selection of material property values that would result in the extreme room air temperatures. That is, a low concrete density value, low concrete specific heat capacity value and high carpet resistance value would 
result in the lowest room air temperature results. A similar approach was taken to determine the highest room air temperature results. The lowest and highest average room air temperatures were found to be $22.36{ }^{\circ} \mathrm{C}$ and $22.59{ }^{\circ} \mathrm{C}$, respectively. The uncertainty in the room air temperature predictions, as a result of the uncertainty in the material property selection, was computed to be half of the difference in these extremities, approximately 0.11 ${ }^{\circ} \mathrm{C}$. The uncertainty in the room air temperature predictions, as a result of the uncertainty in the material property selection was then added and subtracted from the uncertainty of the predicted temperature values.

\section{Uncertainty in Sensor Measurements}

Sensor measurements were used within the energy simulation tool in order to predict the various system metrics. As discussed earlier, each sensor has a certain precision and accuracy associated with it. In comparison to the accuracy of the sensor, the precision value was often insignificant. For this reason, the precision of each sensor was neglected when calculating the uncertainty in the predicted temperature values. The measured variables that were utilized within the energy simulation program can be found in Table 3.12, along with the corresponding sensor accuracy.

Table 3.12: Uncertainty in sensor measurements for energy simulation program

\begin{tabular}{||c|c||}
\hline Sensor & Accuracy \\
\hline \hline Horizontal diffuse radiation & $\pm 10 \mathrm{~W} / \mathrm{m}^{2}[64]$ \\
\hline Global horizontal radiation & $\pm 10 \mathrm{~W} / \mathrm{m}^{2}[64]$ \\
\hline Outdoor temperature & $\pm 0.2^{\circ} \mathrm{C}[62]$ \\
\hline Room air temperature & $\pm 0.2^{\circ} \mathrm{C}[62]$ \\
\hline Plug Load & $\pm 0.5 \mathrm{~W}[65]$ \\
\hline
\end{tabular}

An initial uncertainty in the room air temperature predictions was caused by the initial 
condition method that was utilized. The room air temperature was assumed to be equivalent to the thermostat reading, which had a rated accuracy of $\pm 0.2{ }^{\circ} \mathrm{C}$ [62]. The error of propagation method was utilized within Matlab, to estimate the impact of the uncertainty in the other sensor measurements on the prediction of the room air temperature. Sensor measurements obtained for the horizontal diffuse radiation, global horizontal radiation and outdoor air temperature impacted the temperatures of other nodes, not the air node. There influence on other nodes indirectly caused more uncertainty in the room air temperature predictions. Any surfaces that were influenced by sensor measurements and interacted with the air node were included in the analysis (Equation 3.45), the propagation of uncertainty equation for the predicted room air temperature.

$$
\sigma_{T_{R t}}=\sqrt{\left(\frac{\delta T_{R t}}{\delta T_{F 1}}\right)^{2} \sigma_{T_{F 1}}^{2}+\left(\frac{\delta T_{R t}}{\delta T_{W i n}}\right)^{2} \sigma_{T_{W i n}}^{2}+\left(\frac{\delta T_{R t}}{\delta Q_{P L}}\right)^{2} \sigma_{Q_{P L}}^{2}+\left(\frac{\delta T_{R t}}{\delta Q_{L}}\right)^{2} \sigma_{Q_{L}}^{2}}
$$

The $\sigma$ terms represent the uncertainty in the sensors that were used to measure the respective variable. During the week of October $17^{\text {th }}, 2016$, the average uncertainty in the room air temperature predictions, as a result of the uncertainty in the sensor measurements, was approximately $\pm 0.06{ }^{\circ} \mathrm{C} . \pm 0.06{ }^{\circ} \mathrm{C}$ seemed low, however it raised the total uncertainty due to sensor measurements by approximately $30 \%$. Thus, at each time step the error of propagation method was utilized to estimate the effect of the sensor uncertainties on the room air temperature predictions.

\section{Total Uncertainty in Temperature Profiles}

When the predicted and measured room air temperatures differed from each other at a value which exceeded their respective uncertainty, a fault may have been detected. For visualization purposes, the source of uncertainty in thermostat reading was accounted for 
in the uncertainty in the model. Grouping the fault detection threshold did not change the outcome of the detection of faults. Rather, allowed for clarity in the plots by reducing two additional trends. The uncertainty trends will be referred to as the fault detection threshold and were represented by dashed magenta lines in all plots. Accounting for all sources of uncertainty in the measured and predicted room air temperatures yielded a fixed fault detection threshold of approximately $\pm 0.51^{\circ} \mathrm{C}$. However, there was an additional amount caused by the uncertainty in the sensor measurements. The additional uncertainty was calculated at each time step as it depended on the various sensor measurements that were required at each period in time. The various sensor measurements that were required will change based on the day and week under analysis as the computer and lights in the offices will be turned off at times.

\subsubsection{Air-Based Heating \& Cooling Profile Fault Detection Threshold}

There were two sources of uncertainty when comparing the measured air-based heating and cooling rate to the model-predicted air-based heating and cooling rate. There was uncertainty associated with the sensors required to measure the air-based heating and cooling rate and uncertainty in the model-predicted air-based heating and cooling rate, as a result of the uncertainty in the room air temperature predictions. These two sources of uncertainty will be now be discussed.

\section{Measured Air-Based Heating \& Cooling Rate Calculation Uncertainty}

The equation utilized to estimate the air-based heating and cooling rate was valid. However, to be computed, the measurements from various sensors were required. Each of these 
sensors had an uncertainty associated with it, which caused uncertainty in the estimated airbased heating and cooling rate. The total uncertainty associated with the air-based heating and cooling rate was calculated through the utilization of the propagation of uncertainty equation, equation 3.46 .

$$
\sigma_{\dot{Q}_{A i r}}=\sqrt{\left(\frac{\delta \dot{Q}_{\text {Air }}}{\delta T_{\text {Sup }}}\right)^{2} \sigma_{T_{S u p}}^{2}+\left(\frac{\delta \dot{Q}_{A i r}}{\delta T_{R}}\right)^{2} \sigma_{T_{R}}^{2}+\left(\frac{\delta \dot{Q}_{A i r}}{\delta \dot{m}_{A i r}}\right)^{2} \sigma_{\dot{m}_{A i r}}^{2}}
$$

The $\sigma$ terms represent the uncertainty in the sensors that were used to measure the respective variable. As discussed earlier, each sensor has a certain precision and accuracy associated with it. In comparison to the accuracy of the sensor, the precision value was often insignificant. For this reason, the precision of each sensor was neglected when calculating the uncertainty in the air-based heating and cooling rate. The measured variables that were utilized to estimate the air-based heating and cooling rate can be found in Table 3.13, along with the corresponding sensor accuracy.

Table 3.13: Uncertainty in the measured air-based heating and cooling rate sensors

\begin{tabular}{||c|c||}
\hline Measured variable & Accuracy \\
\hline \hline Supply air flow rate & $\pm 1 \%[66]$ \\
\hline Supply air temperature & $\pm 0.2^{\circ} \mathrm{C}[62]$ \\
\hline Return air temperature & $\pm 0.2^{\circ} \mathrm{C}[62]$ \\
\hline
\end{tabular}

Equation 3.46 was utilized within Matlab to estimate the impact of the uncertainty in the sensor measurements on the estimation of the air-based heating and cooling rate. Figure 3.21 represents the air-based heating and cooling rate during the week of November $7^{\text {th }}$, 2016. Figure 3.21 does not include the uncertainty associated with the calculation. 


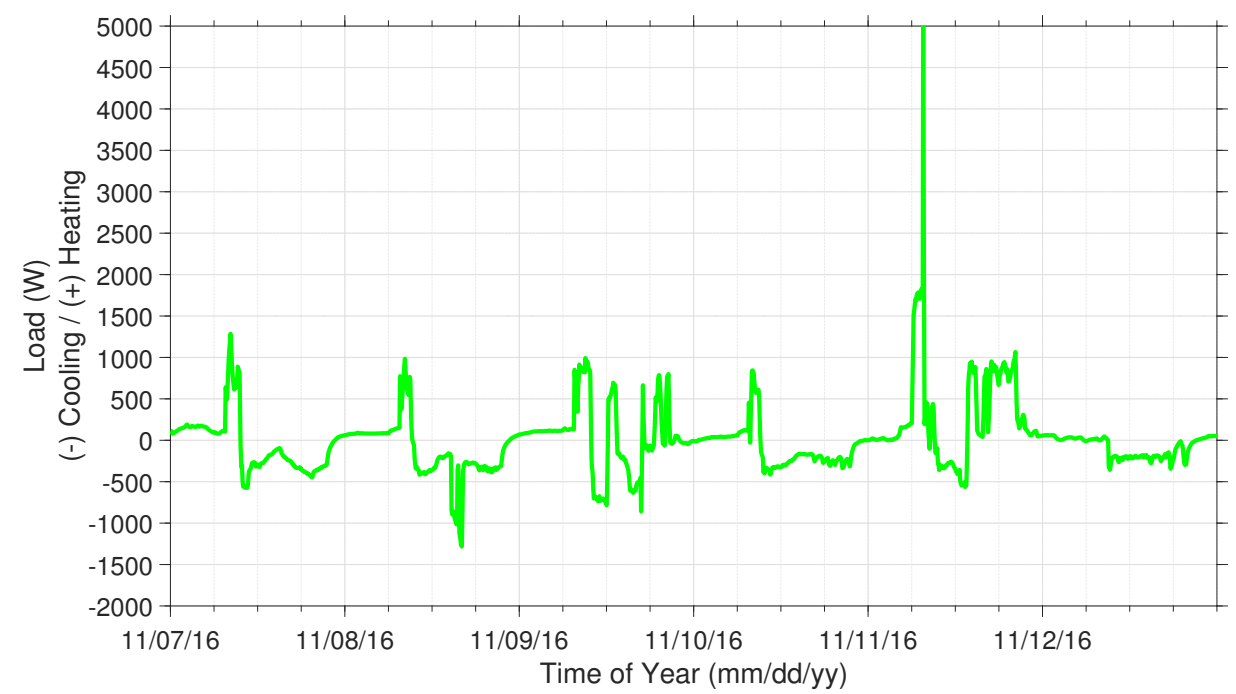

Figure 3.21: Measured air-based heating \& cooling rate without uncertainty of propagation

Figure 3.22 represents the air-based heating and cooling rate for the same week, but includes the uncertainty in the calculation, which was denoted by dashed magenta lines. The uncertainty during the week was minimal, causing it to be slightly visible in Figure 3.22

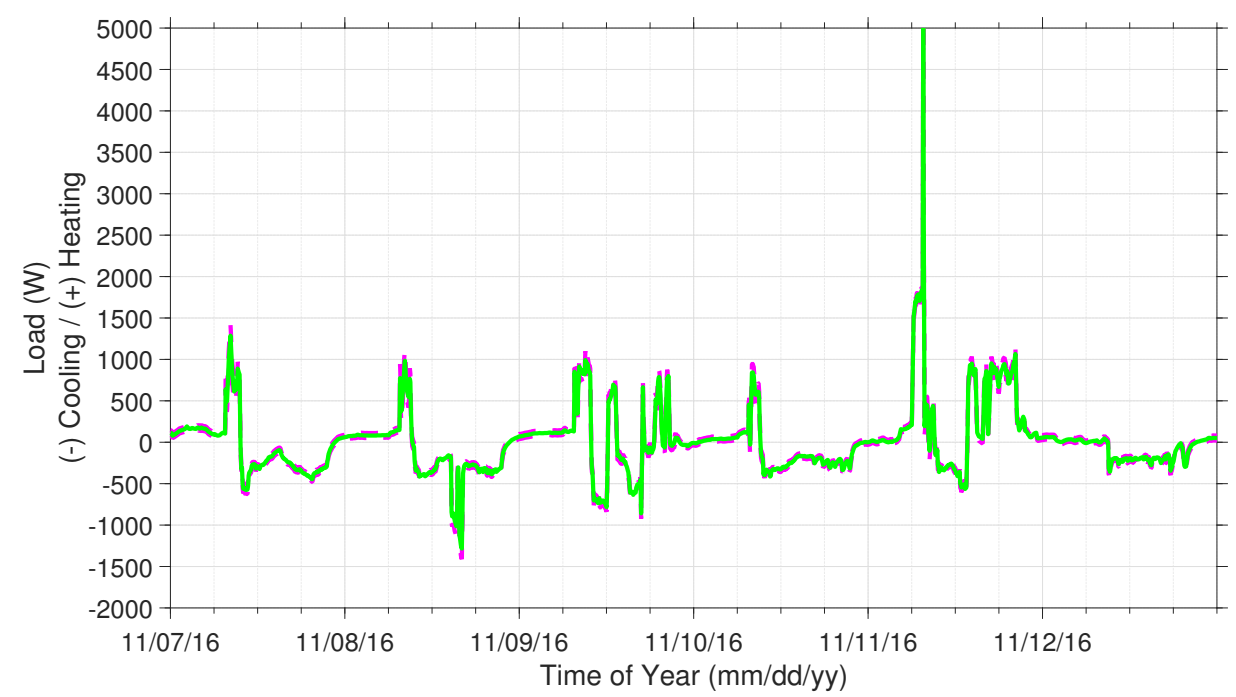

Figure 3.22: Measured air-based heating \& cooling rate with uncertainty of propagation 
Figures 3.21 and 3.22 show that the accuracy of the sensors being utilized yielded a slight source of uncertainty in the air-based heating and cooling rate calculations. Further calculations were conducted to estimate the percentage of the uncertainty due to the sensors. During this period, the average uncertainty in the measured air-based heating and cooling rate was $8.6 \%$, or $\pm 40 \mathrm{~W}$. For this reason, the uncertainty for the measured airbased heating and cooling rate was considered in the fault detection process.

\section{Predicted Air-Based Heating and Cooling Rate Uncertainty}

There was uncertainty in the predicted air-based heating and cooling rate as a result of the total uncertainty in the predicted room air temperature. The uncertainty in the airbased heating and cooling rate predictions was estimated by utilizing the uncertainty of propagation equation for the air-based heating and cooling rate, equation 3.47

$$
\sigma_{Q_{A i r}}=\sqrt{\left(\frac{\delta Q_{A i r}}{\delta T_{R t}}\right)^{2} \sigma_{T_{R}}^{2}}
$$

Substituting in the partial derivative of the air-based heating and cooling rate predictions with respect to the room air temperature yielded equation 3.48 .

$$
\sigma_{Q_{A i r}}=\sqrt{\left(k_{p} \times T_{R t}\right)^{2} \sigma_{T_{R} t}^{2}}
$$

Given the extremity of the uncertainty in the room air temperature predictions this analysis was conducted during each time step. 


\section{Total Air-Based Heating and Cooling Rate Profiles Uncertainty}

When the predicted and measured air-based heating and cooling rates differed from each other at a value which exceeded their respective uncertainty, a fault may have been detected. For visualization purposes, the source of uncertainty in the measured air-based heating and cooling rate was accounted for in the uncertainty in the model. Grouping the fault detection threshold did not change the outcome of the detection of faults. Rather, allowed for clarity in the plots by reducing two additional trends. The uncertainty trends will be referred to as the fault detection threshold and were represented by dashed magenta lines in all plots. When the measured air-based heating and cooling rate exceeded the fault detection threshold, a fault may have been detected. The fault detection threshold was computed at each time step as it was solely a result of the uncertainty in time-varying uncertainties. For this reason, an exact fault detection threshold cannot be determined prior to performing an analysis.

\subsubsection{Hydronic-Based Heating Profile Fault Detection Threshold}

There were two sources of uncertainty when comparing the measured hydronic-based heating rate to the model-predicted hydronic-based heating rate. There was uncertainty associated with the sensors required to estimate the hydronic-based heating rate and uncertainty in the model-predicted hydronic-based heating rate, as a result of the uncertainty in the room air temperature predictions. These two sources of uncertainty will be now be discussed. 


\section{Measured Hydronic-Based Heating Rate Calculation Uncertainty}

The equation utilized to estimate the hydronic-based heating rate was valid. However, to be computed, the measurements from various sensors were required. Each of these sensors had an uncertainty associated with it, which caused uncertainty in the estimated hydronicbased heating rate. The total uncertainty associated with the hydronic-based heating rate was calculated through the utilization of the propagation of uncertainty equation, equation 3.49

$$
\sigma_{Q_{\text {Rad }}}=\sqrt{\left(\frac{\delta \dot{Q}_{\text {Rad }}}{\delta T_{\text {Outlet }}}\right)^{2} \sigma_{T_{\text {Outlet }}}^{2}+\left(\frac{\delta \dot{Q}_{\text {Rad }}}{\delta T_{\text {Inlet }}}\right)^{2} \sigma_{T_{\text {Inlet }}}^{2}+\left(\frac{\delta \dot{Q}_{\text {Rad }}}{\delta \dot{m}_{\text {water }}}\right)^{2} \sigma_{\dot{m}_{\text {water }}}^{2}}
$$

The $\sigma$ terms represent the uncertainty in the sensors that were used to measure the respective variable. As discussed earlier, each sensor has a certain precision and accuracy associated with it. In comparison to the accuracy of the sensor, the precision value was often insignificant. For this reason, the precision of each sensor was neglected when calculating the uncertainty in the hydronic-based heating rate. The measured variables that were utilized to estimate the hydronic-based heating rate can be found in Table 3.13, along with the corresponding sensor accuracy.

Table 3.14: Uncertainty in the measured hydronic-based heating rate sensors

\begin{tabular}{||c|c||}
\hline Sensor & Accuracy \\
\hline \hline Inlet temperature & $\pm 0.2^{\circ} \mathrm{C}[62]$ \\
\hline Outlet temperature & $\pm 0.2^{\circ} \mathrm{C}[62]$ \\
\hline Supply water velocity & $\pm 7.5 \mathrm{~mm} / \mathrm{s}[6]$ \\
\hline
\end{tabular}

Equation 3.49 was utilized within Matlab to estimate the impact of the uncertainty in the sensor measurements on the calculation of the hydronic-based heating rate. Figure 3.23 
represents the hydronic-based heating rate for office 1 during the week of November $7^{\text {th }}$, 2016. Figure 3.23 did not include the uncertainty associated with the calculation.

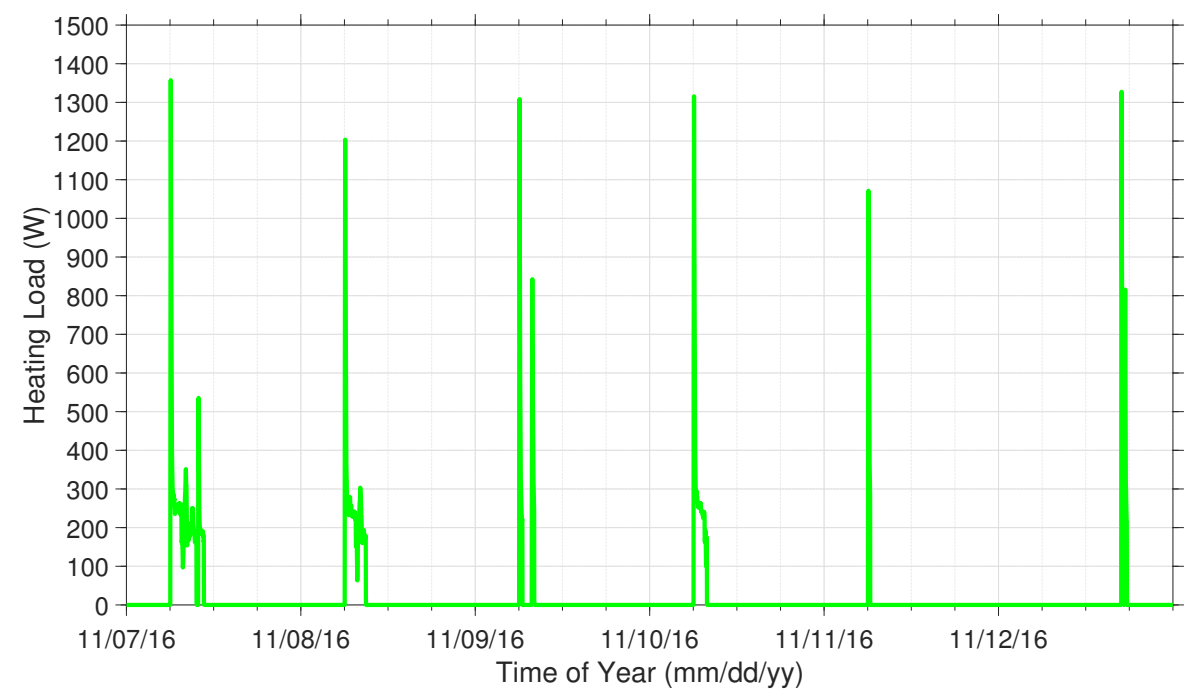

Figure 3.23: Measured hydronic-based heating rate without uncertainty of propagation

Figure 3.24 represents the hydronic-based heating rate for office 1 during the same week, but includes the uncertainty with the calculation, which was denoted by a dashed magenta line. The uncertainty during the week was so minimal it cannot be seen.

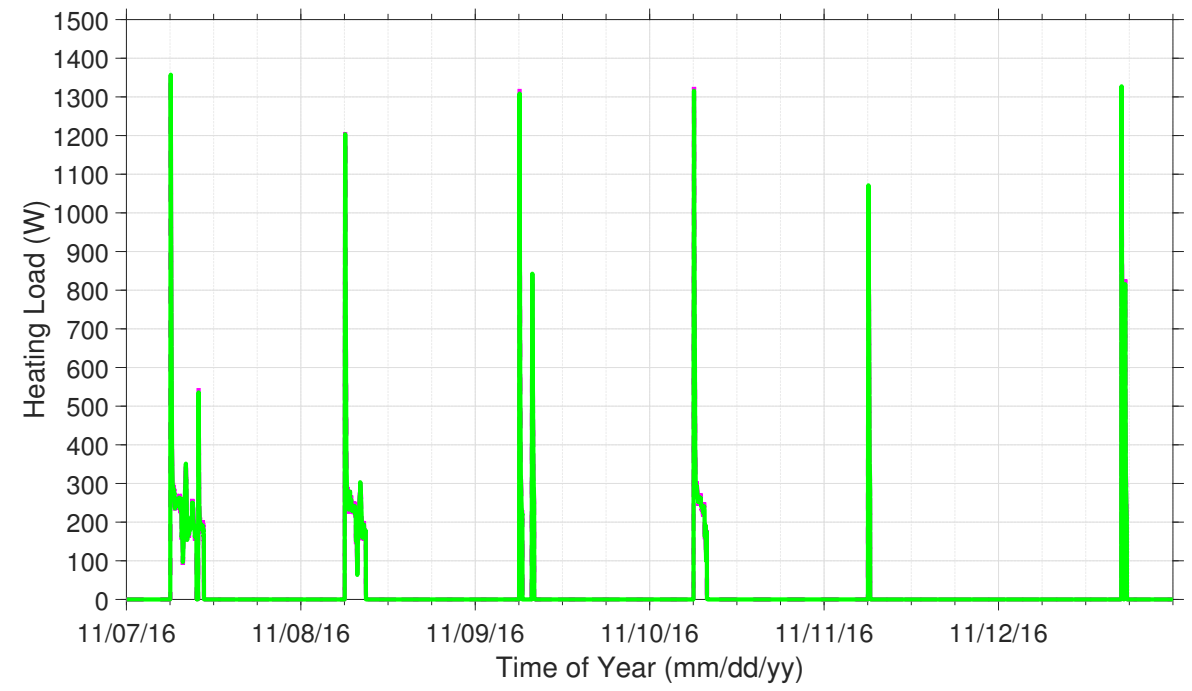

Figure 3.24: Measured hydronic-based heating rate with uncertainty of propagation 
Figures 3.23 and 3.24 show that the accuracy of the sensors being utilized yielded a minimal source of uncertainty in the hydronic-based heating rate calculations. Further calculations were conducted to determine the percentage of the uncertainty due to the sensors. During the times when a hydronic-based heating rate was present, the average uncertainty was minimal, approximately $3.5 \%$.

\section{Predicted Hydronic-Based Heating Rate Uncertainty}

There was uncertainty in the hydronic-based heating rate predictions as a result of the uncertainty in the predicted room air temperature. The uncertainty in the hydronic-based heating rate predictions was estimated by utilizing the uncertainty of propagation equation for the hydronic-based heating rate, equation 3.50

$$
\sigma_{Q_{\text {Radt }}}=\sqrt{\left(\frac{\delta Q_{\text {Radt }}}{\delta T_{R t}}\right)^{2} \sigma_{T_{R} t}^{2}}
$$

Substituting in the partial derivative of the hydronic-based heating rate predictions with respect to the room air temperature yielded equation 3.51 .

$$
\sigma_{Q_{\text {Radt }}}=\sqrt{\left(-(U A)_{\text {Rad }}-4 \times \sigma \times A_{R a d} \times T_{R t}^{3}\right)^{2} \sigma_{T_{R} t}^{2}}
$$

Equation 3.51 was utilized within Matlab to estimate the impact of the uncertainty in the predicted air temperature on the prediction of the hydronic-based heating rate. During the week of November $7^{\text {th }}, 2016$, the percentage of uncertainty was found to be approximately $0.15 \%$. 


\section{Total Hydronic-Based Heating Rate Profiles Uncertainty}

The uncertainty in the measured and predicted hydronic-based heating rate calculation was approximately $3.5 \%$ and $0.15 \%$, respectively. These percentages would be significant if aiming for optimal operations of the radiator was a part of the scope of this thesis. However, this was left out given the complexity of developing an accurate model representation of the radiator. Thus, this research aimed to detect more significant faults in the operations, such as a broken or faulty radiator valve, sensor faults and broken equipment at the buildinglevel. These types of faults will correspond to differences much greater than the combined $3.65 \%$. Realistically, these fault types will lead to the actual hydronic-based system being off when the model predicts it to be on, and vice versa. For these reasons, the uncertainty for the measured hydronic-based heating rate was neglected.

The Matlab function for determining the fault detection threshold for the office air temperature predictions and zone air-based heating and cooling rate predictions was called "Uncertainty" and can be found by following the link provided in Appendix A The "Uncertainty" function was utilized in the main Matlab script "ZoneLoadScript" which can also be found by following the link provided in Appendix A.

\subsubsection{Analysis Duration}

Analysis duration influences the results gained when utilizing this fault detection tool. As a result, selecting the appropriate length of analysis time was vital for ensuring success. A fault may have been detected if the temperature of the offices, hydronic-based heating rate for each office or the air-based heating and cooling rate for the zone deviated from the model predictions. In the event that the same deviation reoccurs, the system has detected a 
fault, allowing the fault diagnostics process to begin. For reoccurring faults to be detected a time period which allowed the system schedule to repeat was necessary. However, the model can drift from the measured results if the analysis duration is too long, resulting in false alarms. Therefore, weekly analyses were selected, as it offered a minimal duration period, while also allowing for all of the systems schedules to be analyzed: weekday, weeknight and weekend. It is important to note, that although the tool would ideally analyze all seven days of the week, ultimately the Sundays needed to be neglected due to consistent recording issues in the sensors early on Sunday mornings.

\subsection{Fault Diagnostics}

A situation was flagged as a potential fault if a measured value exceeded the fault detection threshold. A fault was detected if that same situation occurred more than once during a weekly analysis. The detection of a fault is valuable, however determining the cause of the detected discrepancy is the main priority of FDD. At this point, a heuristic-based rule set was utilized to pinpoint the fault in the system. Since the approach that was utilized was a bottom-up methodology the office air temperature predictions should be analyzed first. Figure 3.25 and 3.26 represent the heuristic-based rule set that was followed to diagnose the detection of a fault. In Figure 3.25 and 3.26 "discrepancy" was utilized to denote a reoccurring scenario that resulted in a measured value exceeding the fault detection threshold. Figure 3.25 and 3.26 both utilize a colour scheme to identify faults that were discovered in this research. The faults that were highlighted in red represent the faults that were discovered in this system and will be discussed in further detail in Chapter 4 .

Figure 3.25 represents the rule set that was followed after the detection of a room air temperature discrepancy. The flow chart shown in Figure 3.25 can identify the exact cause 
of the discrepancy, but it can also lead to "room-level fault", "zone-level fault" or "buildinglevel fault". These statements are vague since they require a more in-depth analysis to determine the root cause of the fault that was detected. A room-level design fault was an issue that was present within a specific office. A room-level fault diagnosis meant that a discrepancy was detected which was due to either poor thermostat placement, internal equipment influencing thermostat readings or a window being left open. Given the detail of the model, further inspection was required outside of the heuristic-based rule set to distinguish between these issues. A zone-level fault was an issue that was caused by the terminal unit. The zone-level fault category included poor controls logic, faulty damper and the undersizing or oversizing of the terminal unit. Finally, a building-level fault was an issue that was occurring in the primary loop equipment, which was out of the scope of this thesis. 


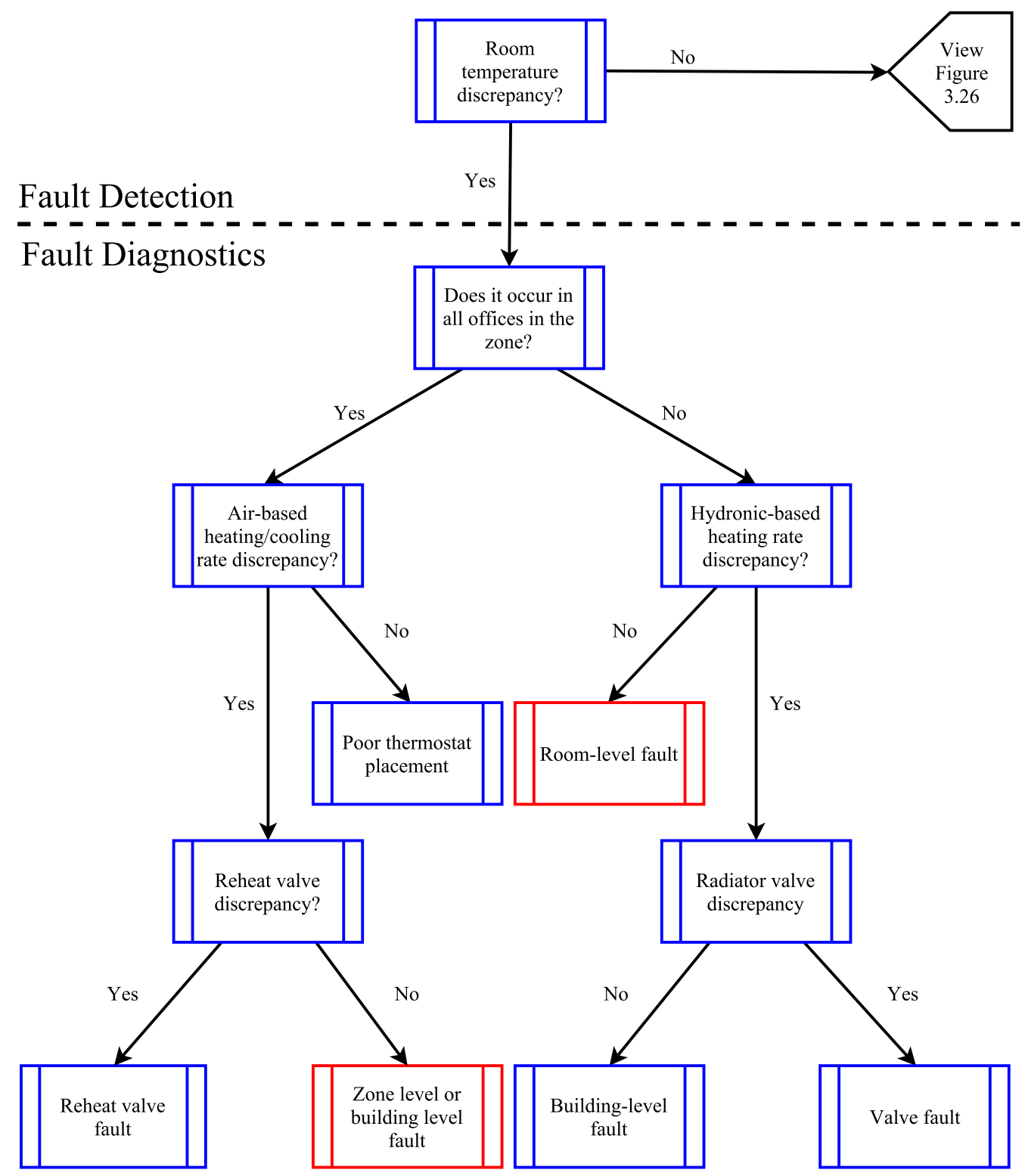

Figure 3.25: Heuristic-based rule set for diagnosing system faults

A fault was detected if the temperature being read by the thermostat exceeded the fault detection threshold of the temperature predictions, i.e. a discrepancy in the temperature profiles was detected. The process afterward began by determining if the discrepancy was consistent between the offices in the zone. Determining if the discrepancy was consistent between the offices in the zone was important because if this detection was not consistent 
the issue was likely within the radiator in that space. There could also be a room-level design fault in a particular office or a building-level fault might have been detected in the heating system. If the fault occurred in all of the offices it was likely that there was an issue with the VAV box, which meant the air based heating and cooling rate predictions should be analyzed. If these values were consistent it was likely that the thermostat locations in all of the offices were selected poorly. However, if there was a discrepancy between the two, the reheat valve predictions needed to be reviewed. A difference at this point, would mean that there was an issue with the reheat valve. If no difference existed, there could be a VAV box damper fault, consisting of either a stuck damper or a problem in the controls of the damper, and/or a fault was arising at the building-level. As previously mentioned, faults arising at the building-level were out of the scope of this thesis.

If there was an agreement between the room air temperature predictions and the thermostat readings, the heating and cooling rate predictions were evaluated next. It was important to evaluate the heating and cooling rate predictions even if the room air temperature predictions were similar because a discrepancy between the two could be a cause of faulty sensor measurements. These inconsistent readings could then be causing the system to operate inefficiently. The rule set that followed the evaluation of the air and hydronic-based heating and cooling rate predictions can be found in Figure 3.26 . 


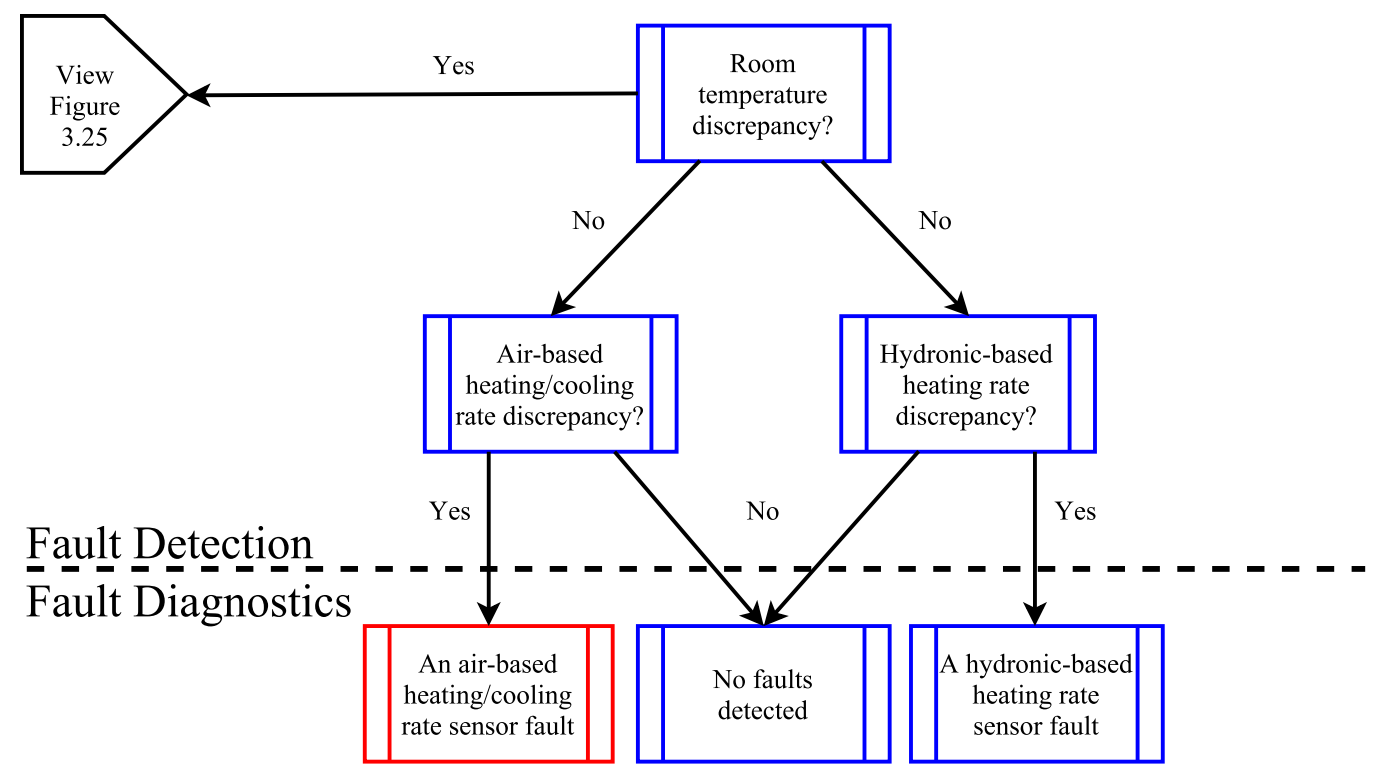

Figure 3.26: Heuristic-based rule set for diagnosing sensor faults

If there was a discrepancy in the hydronic-based heating rate predictions, then there was likely an issue with one of the sensors used to estimate the hydronic-based heating rate. The issue could be caused by either the inlet or outlet temperature sensors or the flow rate sensor and would require further analysis to determine which sensor was faulty. The airbased heating and cooling rates were also evaluated to ensure all mechanical systems were operating efficiently. If these predictions and the hydronic-based heating rate predictions were accurate no fault was detected. If however, there was a discrepancy at this stage, there was a fault in one of the sensors that were being used to estimate the air-based heating and cooling rate. This discrepancy could be caused by the SAT, return air temperature or air flow rate sensor and would also require further analysis to determine which sensor was at fault. 


\subsection{Summary}

An in-depth description of the methodology that was utilized to detect zone-level inefficiencies has been presented. Information from the BAS was utilized to measure the temperature in the offices, the hydronic-based heating rate in the offices and the air-based heating and cooling rate for the zone. A model was developed in Matlab which utilized the explicit finite difference methodology as a basis for predicting the temperature in the offices, the hydronic-based heating rate in the offices and the air-based heating and cooling rate for the zone. Once the proper balance between accurate results and complexity was achieved, a proper fault detection threshold needed to be selected. The fault detection threshold was determined by analyzing the uncertainty in the sensor measurements that were utilized to measure and predict the system metrics. It also considered the influence that the selection of material properties had on the model results. Upon completion of the Matlab tool, the system was capable of determining whether a fault had been detected. The detection of a fault was valuable, however further development was required to diagnose the detected fault. The fault diagnostics portion of the research utilized a heuristic-based rule set which served as a guideline for the user to follow. 


\section{Chapter 4}

\section{Results}

In Chapter 3, the methodology and development of the FDD tool were discussed in detail. After development, it was deployed in the Canal Building, in a zone containing four offices. The FDD methodology was tested during four weeks in 2016, one-week during the spring, summer, fall and winter. These times were analyzed to test the system's functionality during the heating, cooling and changeover seasons. The fault detection tool that was developed in Matlab produced the required plots to compare the measured temperature of the offices, hydronic-based heating rate for each office and air-based heating and cooling rate for the zone to the predicted values. Afterward, the fault diagnostics methodology was undertaken manually, which resulted in the diagnosis of five faults. Chapter 4 outlines each fault individually, covering the detection of the fault, the diagnostics of the fault and an evaluation of the fault. The faults will be addressed in the following order: supply air temperature (SAT) sensor offset, poor supply diffuser (SD) and return grille (RG) selection/placement, poor thermostat placement, poor variable air volume (VAV) box selection and poor VAV box control sequence.

\subsection{SAT Sensor Offset}

Sensor measurements can drift from accurate readings over the lifetime of that sensor, which has been recognized as a soft fault. These drifted readings have the potential to 
increase energy consumption and cause occupant discomfort, depending on whether or not the measurements have been utilized to control an aspect of the system. An analysis was performed to verify the functionality of the tool. The weekly analysis verified the tool's ability to predict the room air temperature and hydronic-based heating rate. However, it uncovered an offset in the SAT sensor located in the VAV box that serves zone 1, the zone that consists of offices 1, 2, 3 and 4. The method by which this fault was discovered will now be discussed, followed by an evaluation of the severity of the fault.

\subsubsection{Fault Detection}

The week of November $7^{\text {th }}, 2016$ was analyzed. During this time there was no discrepancy between the temperature profiles in the offices. An example of this is shown in Figure 4.1, which represents the temperature profiles for office 2. Included in Figure 4.1 is the fault detection threshold, which is represented by dashed magenta lines. The root mean square deviation during the week was $0.34{ }^{\circ} \mathrm{C}$, below the fixed fault detection threshold of \pm 0.51 ${ }^{\circ} \mathrm{C}$.

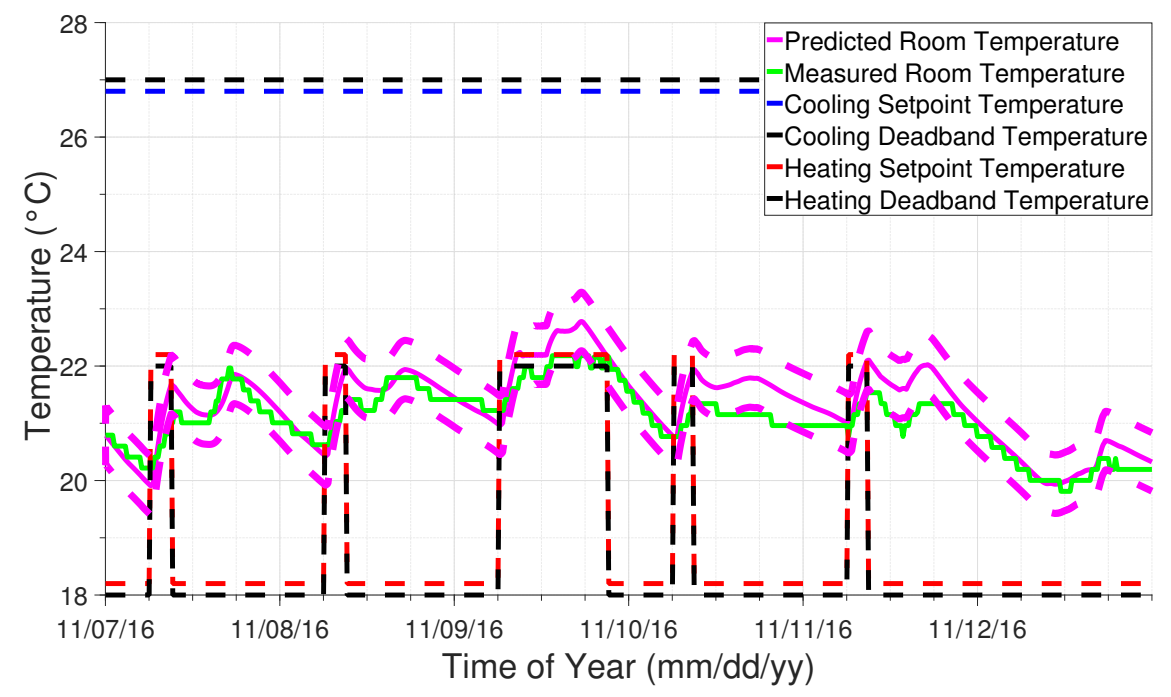

Figure 4.1: Room air temperature profiles for office 2 in November 
Following the flow chart in Figure 3.26 the hydronic-based heating profiles needed to be evaluated. Although the thermostat measurements during the week were below the fault detection threshold, there were some slight variations that influenced the radiator heating predictions. On the day of the $9^{\text {th }}$, the thermostat measurements were just above the lower fault detection threshold. However, they were also at the set-point temperature, which resulted in the system calling for heating, when the model did not. Figure 4.2 shows this discrepancy and resulted in a high root mean square deviation, approximately $67 \mathrm{~W}$. The discrepancy was not considered a fault since it was a result of a slight difference in the temperature profiles.

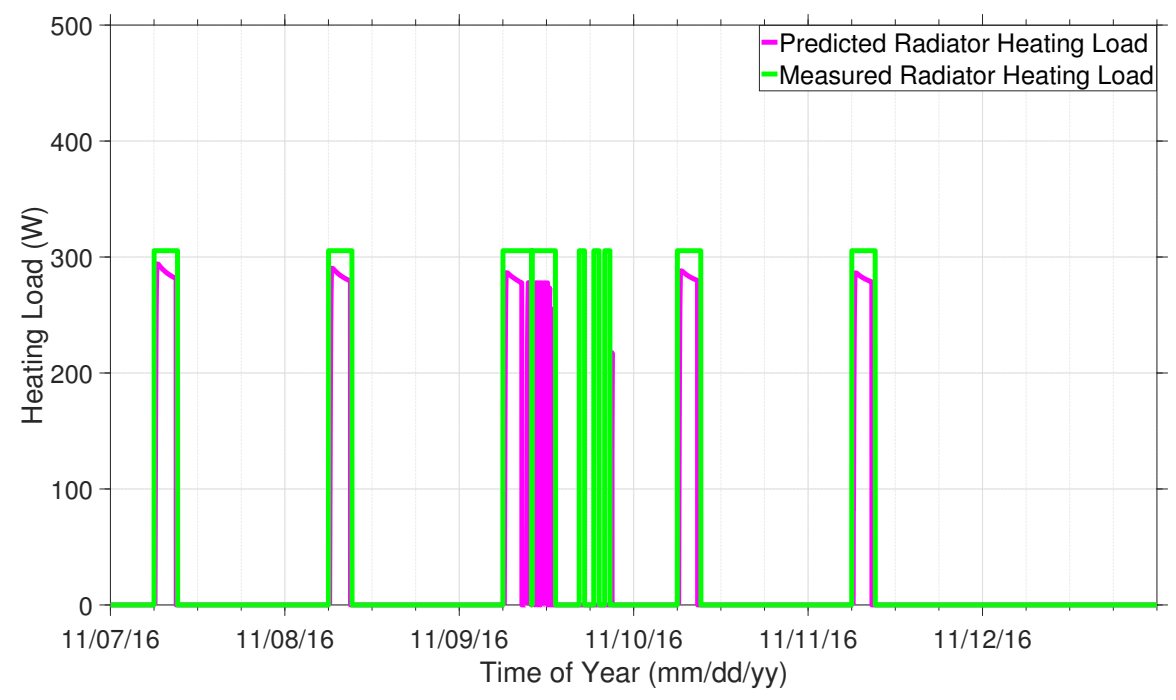

Figure 4.2: Hydronic-based heating profile for office 2 in November

Following the flow chart in Figure 3.26 the air-based heating and cooling profiles needed to be evaluated next. The air-based heating and cooling profile for the week of November $7^{\text {th }}, 2016$ is shown in Figure 4.3 . Included in Figure 4.3 is the fault detection threshold, which is represented by dashed magenta lines. Figure 4.3 shows that there was a significant, and consistent discrepancy between the predicted and the measured air-based heating and cooling rate during this week. The root mean square deviation throughout the 
week was approximately $534 \mathrm{~W}$, whereas the average fault detection threshold was approximately $\pm 212 \mathrm{~W}$.

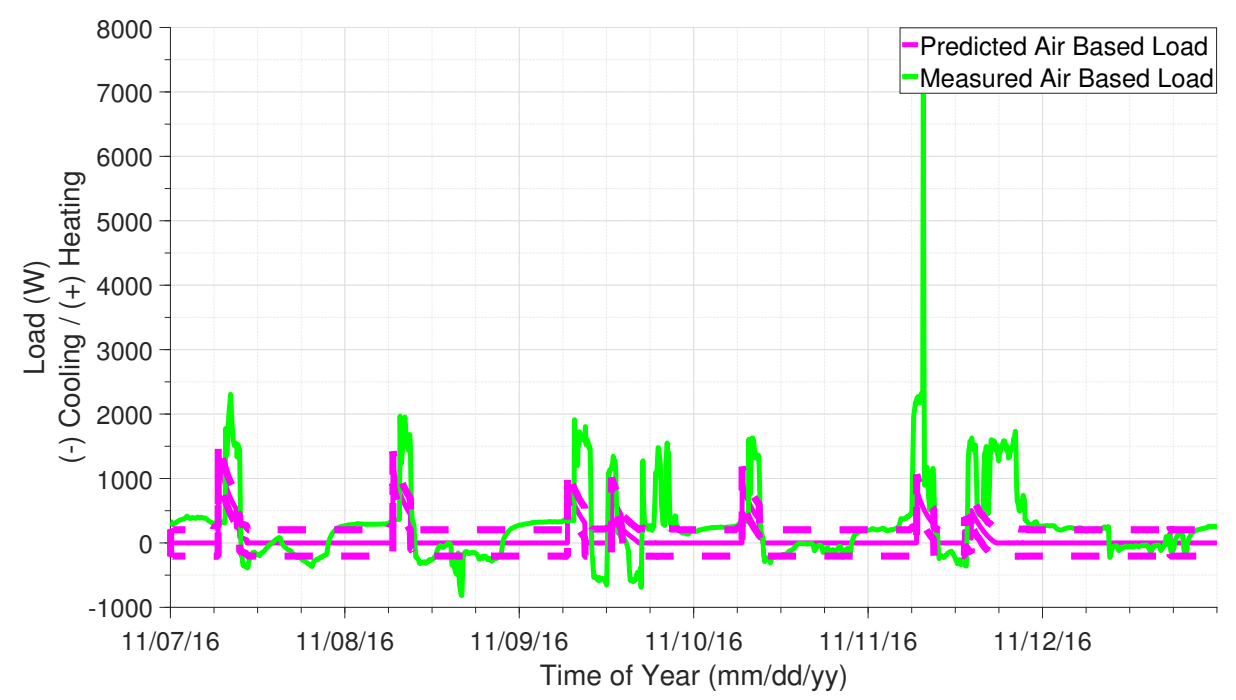

Figure 4.3: Air-based heating and cooling profile for zone 1 in November

Figure 4.3 shows that on several days, the system was predicted to supply and actually supplied heating to the zone at similar times. However, the estimated air-based heating and cooling rate was always greater than the model predictions. Thus, a fault was detected during the week of November $7^{\text {th }}, 2016$.

\subsubsection{Fault Diagnostics}

The difference between the predicted air-based heating and cooling rate and the measured air-based heating and cooling rate suggests that a fault was present in one of the sensors utilized to measured the air-based heating and cooling rate, when following the flow chart in Figure 3.26. Three sensor measurements were required to measure the air-based heating and cooling rate that was supplied to the room: the supply air flow rate, SAT and the 
thermostat reading (return air temperature). One of these sensors could have been broken or could have drifted during its life. To determine which sensor was at fault, further investigation outside of the diagnostics process needed to be conducted.

First, all sensor measurements were evaluated to ensure the sensors were still functioning. Figure 4.3 shows that the air-based heating and cooling rate was being measured, which meant that all three sensors were consistently recording data. Moreover, the measured and predicted air-based heating and cooling profiles were following a similar trend, just slightly offset. The slight offset suggested that one or more of these sensors had degraded over time and were reading values that were offset.

All of the sensor measurements needed to be evaluated to determine which sensor(s) were reading offset values. The thermostat reading was verified by evaluating Figure 4.1 However, the functionality of the supply air flow rate and SAT sensor required a different approach. These two sensors had been measuring data since the Canal Building officially opened in January 2011 and at least one could have degraded since that time. To determine if this was the case, an entire year of the recorded values were evaluated. Each parameter's data was checked to see if the sensor ever read values that were outside of the parameter's theoretical range.

Figure 4.4 shows the air flow rate readings for an entire year. The theoretical range of values of the supply air flow rate were the minimum and maximum set-points of the VAV box. The minimum and maximum values of air flow rate for the VAV that serves offices 1 , 2, 3 and 4 were found to be $300 \mathrm{~L} / \mathrm{s}$ and 1,010 L/s, respectively, from enteliWEB. However, the building operators had found that the VAV box could handle a minimum supply air flow rate of $100 \mathrm{~L} / \mathrm{s}$ and adjusted the system settings in order to reduce energy consumption. When evaluating Figure 4.4, it can be seen that the VAV box frequently read values around 
the adjusted minimum value and never exceeded the maximum value. It appeared that this sensor was functioning properly as the sensor was consistently reading the minimum flow rate that was specified by the operation managers, during ventilation periods.

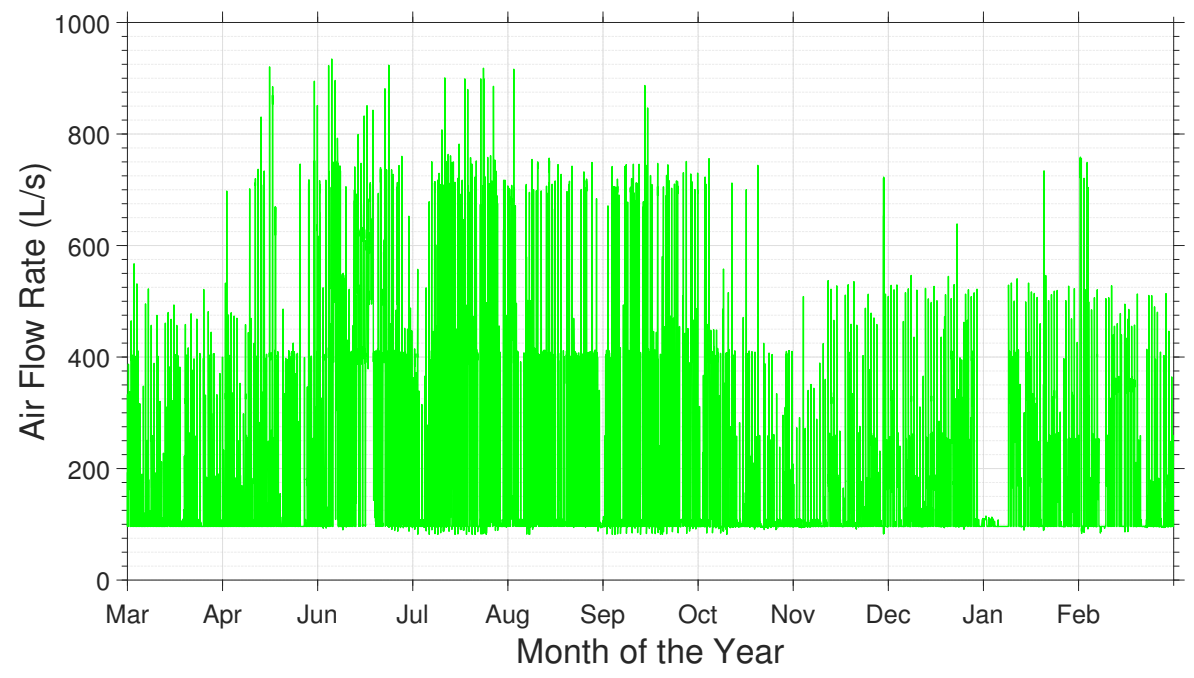

Figure 4.4: VAV box annual supply air flow rate

A similar analysis would be applied to the SAT readings. However, due to student experimentation with the VAV box reheat valve the measurements were skewed. Instead, to determine if this sensor had slowly degraded over time the measured values from this sensor were compared to a neighbouring VAV box's temperature measurements during the cooling season, when there was no VAV box reheat interference. The neighbouring VAV box was selected as it was served by the same AHU and thus, the recorded measurements should be similar. Minor differences could be present, as a result of the gains or losses through the ductwork to the plenum air. However, given that the temperature gradient between the supply air temperature and the plenum air would be minimal, these losses and gains would be negligible. Figure 4.5 shows that the measurements differed at a magnitude that was much greater than could be caused by the potential losses or gains through the ductwork. 


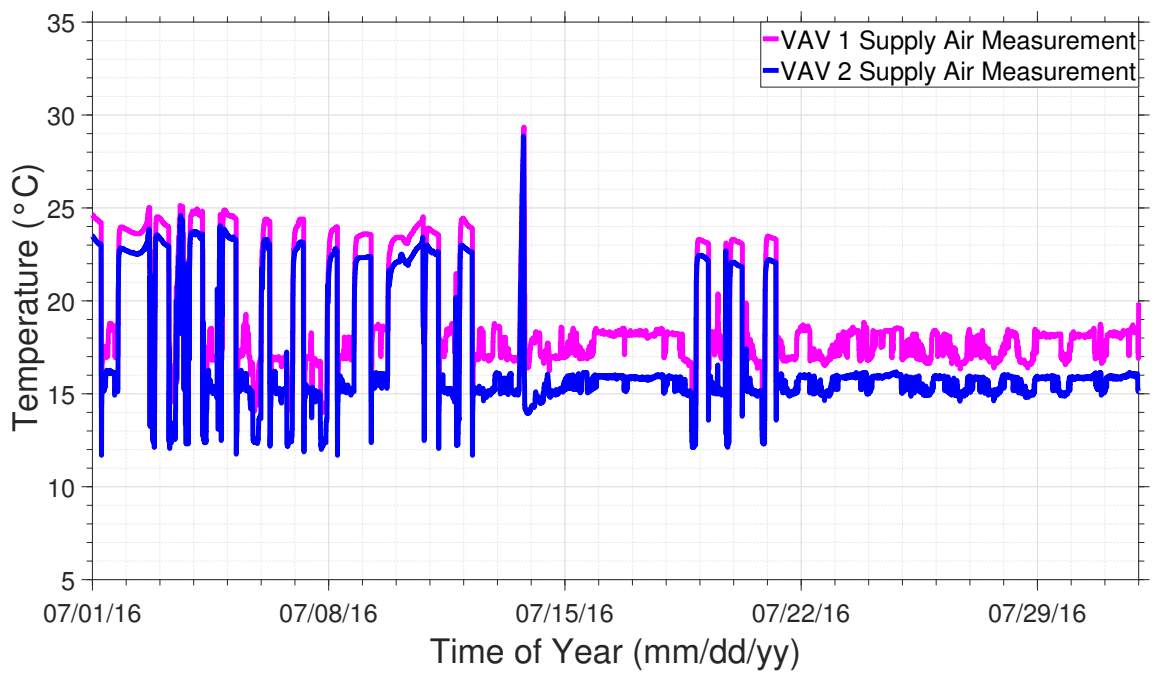

Figure 4.5: VAV box 1 and VAV box 2 SAT

The difference in recorded SATs revealed that one, or both of the sensors were misreading temperatures. The SAT values from VAV box 1 were compared to the AHU's SAT readings to ensure that the SAT sensor in VAV box 1 was the sensor that was reading offset values. Figure 4.6 shows the SAT measurements from VAV box 1 and the AHU.

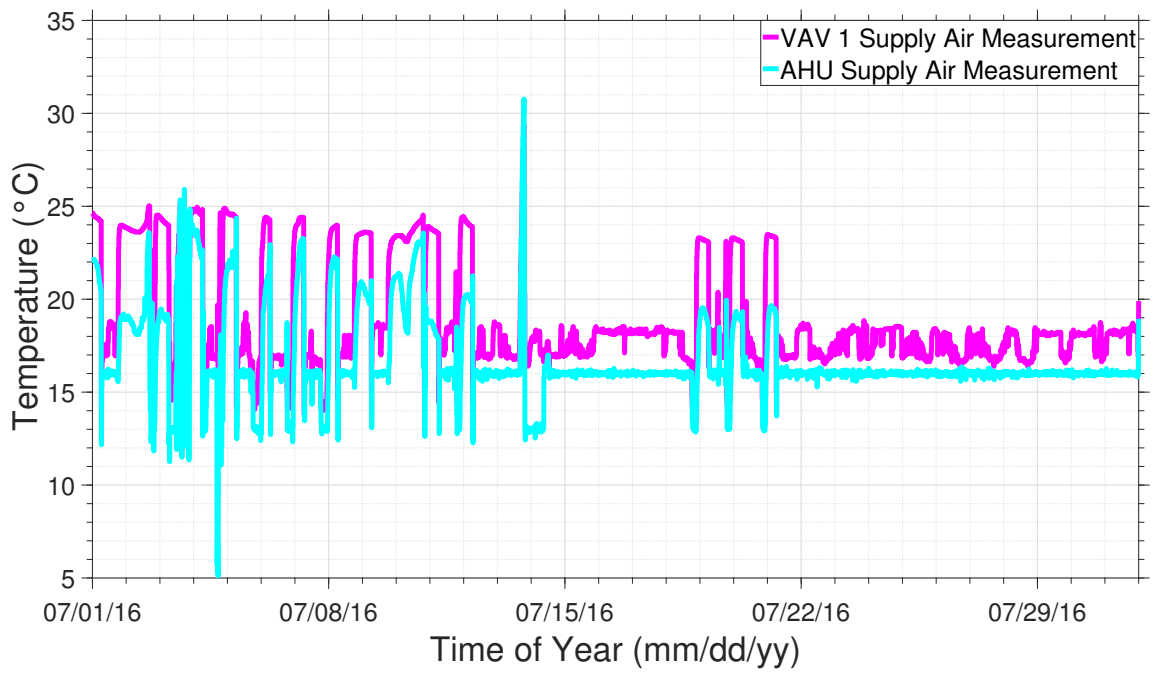

Figure 4.6: VAV box 1 and AHU SAT 
When comparing these three SAT readings it can be seen that the sensor in VAV box 1 was consistently reading values greater than the other two SAT sensors and that the other two SAT sensors were recording similar values. During the month of July, it was found that on average VAV box 1 consistently read a higher value than VAV box 2, approximately $1.88^{\circ} \mathrm{C}$. Further studies were conducted which consisted of placing an auxiliary sensor inside of the supply diffuser in office 1. In the end, the data obtained from this sensor confirmed that the SAT sensor in VAV box 1 was reading values approximately $2{ }^{\circ} \mathrm{C}$ higher. These analyses revealed that the detected discrepancy in the air-based heating and cooling rate profiles was caused by an offset in the SAT sensor. When considering this offset in the SAT measurements obtained the air-based heating and cooling rate can be accurately measured for the week of November $7^{\text {th }}, 2016$.

\subsubsection{Fault Evaluation}

Fortunately, the SAT sensor measurement does not influence any of the operations of the VAV box. As a result, no excess energy consumption occurred due to the offset in readings. However, it was shown in section 4.5 that not considering the SAT in the operations of the VAV box can result in significant excess energy consumption.

\subsection{Poor SD and RG Selection/Placement}

Proper selection and placement of supply diffusers and return grilles allow for better air circulation within the space. As a result, heating, cooling and fresh air can be more efficiently added to the space. If the selection and/or placement of supply diffusers and return grilles is poor, the air in the space will not mix well. Furthermore, this poor design can result in 
short-circuiting, where a portion of the supplied air exits through the return grille without mixing with the air in the space. The method by which this fault was discovered will now be discussed, followed by an evaluation of the severity of the fault.

\subsubsection{Fault Detection}

During the model verification, the measured air-based heating and cooling profile exceeded the fault detection threshold, indicating that there was an issue with one or more of the sensors utilized to measure the air-based heating and cooling rate. It was concluded that there was a SAT sensor offset. However, a week during the fall, October $17^{\text {th }}, 2016$ was analyzed afterward. During this week the predicted temperature profiles for each office were similar to the measured profiles. An example of this is shown in Figure 4.7, the temperature profiles for office 3. Included in Figure 4.7 is the fault detection threshold, which is represented by dashed magenta lines. The root mean square deviation for the week was approximately $0.37^{\circ} \mathrm{C}$, underneath of the fixed fault detection threshold of \pm $0.51^{\circ} \mathrm{C}$.

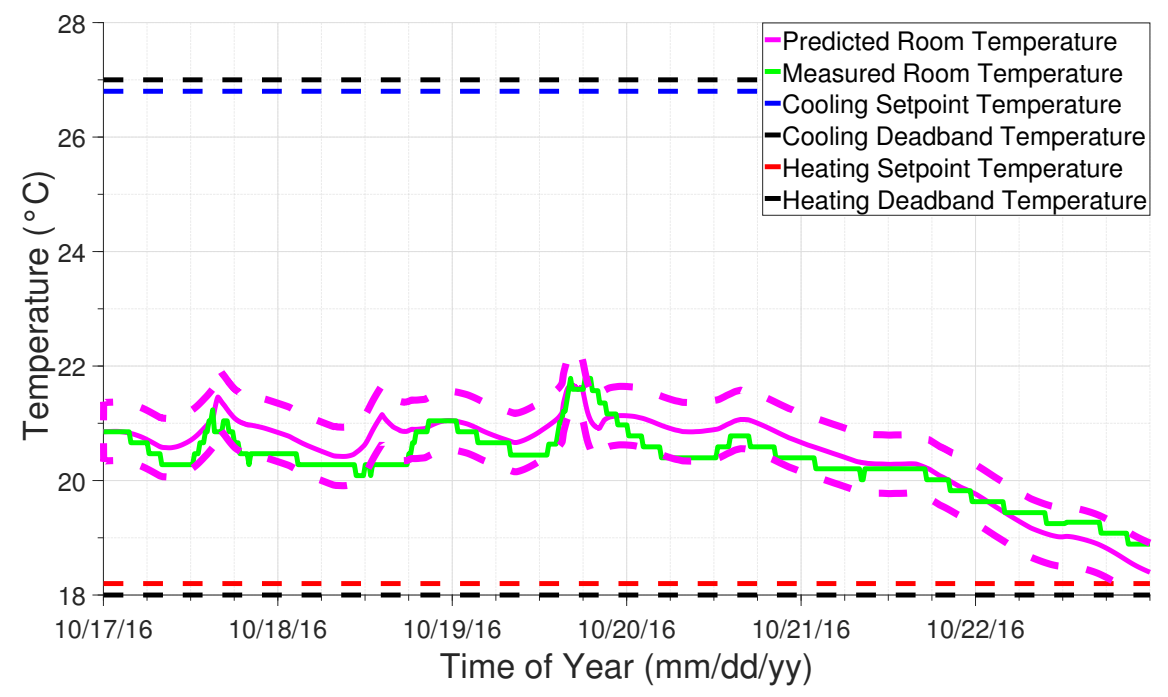

Figure 4.7: Room air temperature profiles for office 3 in October 
When following the flow chart seen in Figure 3.26 , the hydronic and air-based heating and cooling profiles needed to be evaluated next. During this week no hydronic-based heating was present in the model, or in reality. However, the air-based heating and cooling profile deviated from the model predictions, again. During this week the system was providing more cooling than the model was predicting. The root mean square deviation for the week was approximately $763 \mathrm{~W}$, significantly greater than the average fault detection threshold of $\pm 292 \mathrm{~W}$. The air-based heating and cooling profile for the zone can be seen in Figure 4.8, Included in Figure 4.8 is the fault detection threshold, which is represented by dashed magenta lines.

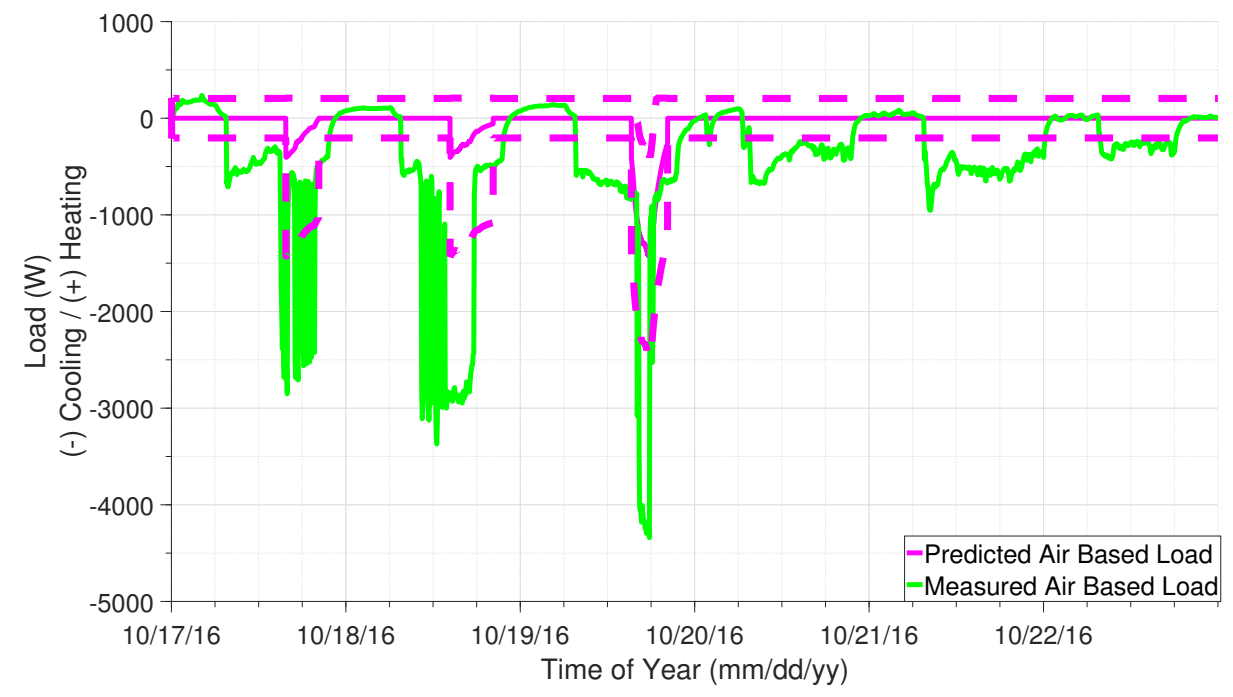

Figure 4.8: Air-based heating and cooling profile for zone 1 in October

A discrepancy can be seen in Figure 4.8. Thus, a fault was detected during the week of October $17^{\text {th }}, 2016$, when following Figure 3.26 . 


\subsubsection{Fault Diagnostics}

Figure 4.8 shows that the air-based heating and cooling rate that was supplied to the offices was less than the model predictions, yet the model was predicting a similar temperature profile for the office spaces. In section 4.1, it was determined that there was an offset in the SAT sensor measurements. All measurements from this sensor were found to be on average, $1.88{ }^{\circ} \mathrm{C}$ too high. To account for this issue all data obtained from this sensor were reduced by $1.88{ }^{\circ} \mathrm{C}$. Reducing the measurements by $1.88^{\circ} \mathrm{C}$ justified the issue in section 4.1. however, it resulted in the estimation of more cooling being supplied to the offices during the week of October $17^{\text {th }}, 2016$. When following Figure 3.26 the discrepancy was due to a fault in one or more of the three sensors utilized to measure the air-based heating and cooling rate.

In section 4.1 the thermostat, air flow rate and SAT sensors were evaluated to determine if a fault was present in the sensors. The thermostat readings were deemed accurate since the model was predicting values that resembled the obtained measurements. However, utilizing the thermostat as the return air temperature in equation 3.3 could be invalid if the perfectly mixed air assumption does not apply to the offices under analysis. If a space is perfectly mixed the temperature readings at all locations should be similar. However, these measurements differed by up to $2{ }^{\circ} \mathrm{C}$ at times. As a result, the return grille temperature readings replaced the thermostat temperature readings in equation 3.3 , the equation used for estimating the actual air-based heating and cooling rate. An analysis of these two temperatures was conducted and also included the adjusted SAT readings.

Figure 4.9 shows the supply, return and thermostat readings during a week when heating was present. 


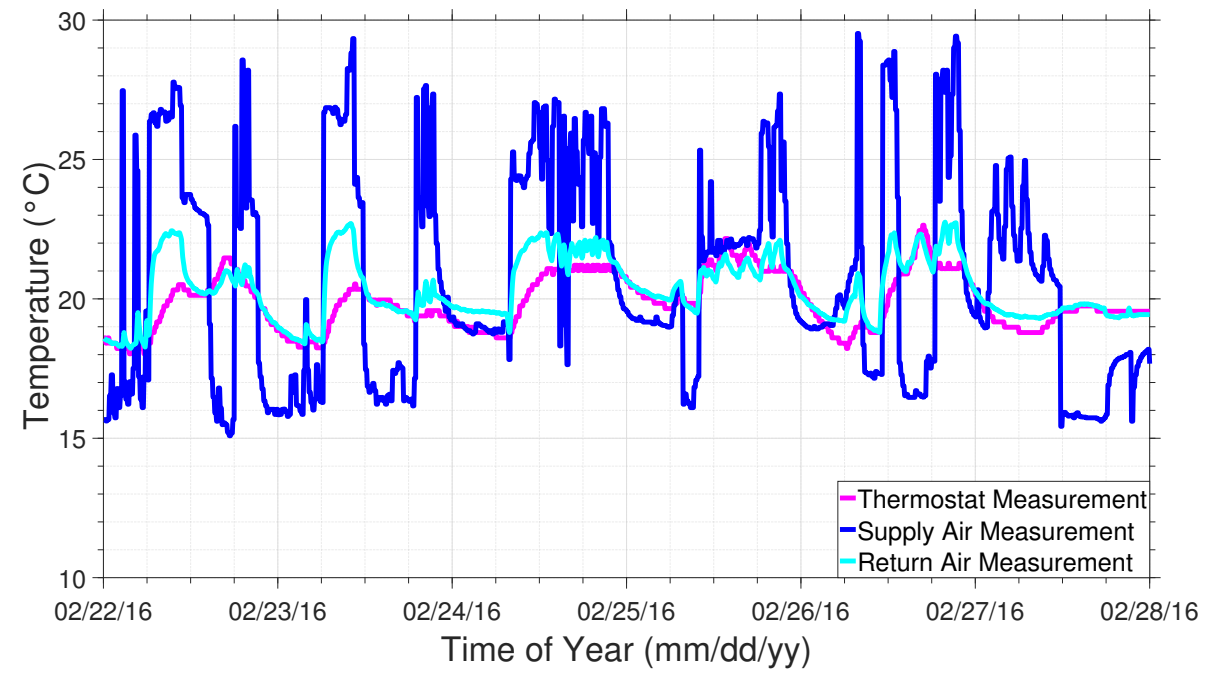

Figure 4.9: Supply, return and thermostat readings during a week in February

Figure 4.10 shows the supply, return and thermostat readings during a week where cooling was present.

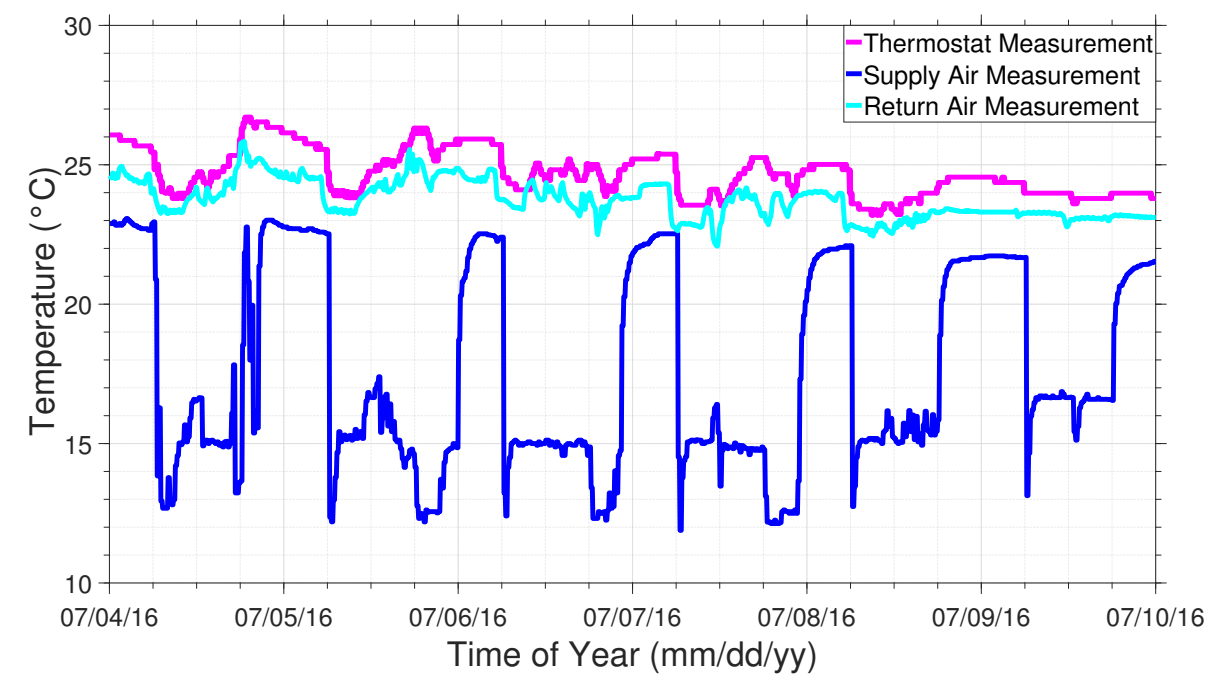

Figure 4.10: Supply, return and thermostat readings during a week in July

From Figure 4.9 and 4.10 it can be seen that the return grille temperature consistently read a value between the supply air and thermostat temperature readings during the heating 
season and cooling season, respectively.

Discrepancies between the temperatures at different locations in a room is a standard occurrence when considering the various internal gains, external gains/losses and buoyant forces that are present. Figure 4.9 shows that the return grille sensor read a higher temperature than the thermostat reading during February, which makes sense when considering buoyant forces. On the other hand, Figure 4.10 shows that the thermostat reading was higher during July, which implied that the discrepancies during the winter were not solely caused by buoyant forces. There was, however, a consistency, the return air temperature reading fell in between the thermostat reading and the VAV box supply air temperature reading. The consistency in these readings implied that a portion of the supply air was short-circuiting the room and going directly to the return grille.

\subsubsection{Fault Evaluation}

To quantify the amount of short-circuiting that was occurring in the room, a week during the heating and cooling season was analyzed. During these two weeks the room, return and supply air temperatures were obtained. By utilizing equation 4.1, the fraction of actual heating and cooling rate to the theoretical maximum heating and cooling rate can be determined, if the supply air was perfectly mixed with the room air. The thermostat measurements were assumed to give an accurate approximation of the global average temperature in the office and were used as $\mathrm{T}_{\mathrm{G}}$ in equation 4.1 .

$$
\% \text { ShortCircuited }=\frac{T_{R}-T_{G}}{T_{\text {Sup }}-T_{G}}
$$


During the week of July $4^{\text {th }}, 2016$ it was estimated through equation 4.1 that approximately $13.6 \%$ of the cooling was short-circuiting. Furthermore, during the week of February $22^{\text {nd }}, 2016$ it was estimated through equation 4.1 that approximately $22.5 \%$ of the heating was short-circuiting.

\subsection{Poor Thermostat Placement}

Traditional thermostats are utilized to measure the temperature in a space at a representative location and send a signal to the HVAC system to activate heating or cooling. The thermostats in the Canal Building measure temperature and send this information to a controller. When the thermostat location is placed well it yields an adequate average temperature measurement for the space. On the other hand, if their location is poor it can lead to an unnecessary amount of heating or cooling to be supplied, insufficient cooling or heating to be supplied, and uncomfortable occupants. Typically, the mechanical designer will place the thermostat just outside of the reach of a door and the contractor will install the thermostat approximately $1.5 \mathrm{~m}$ above the ground. The standard thermostat design process can result in inefficiencies if other parameters are overlooked during this process. An analysis was performed which showed that the thermostats in two offices were providing temperatures that were substantially different than from the other office thermostats, as a result of poor thermostat placement. The method by which this fault was discovered will now be discussed, followed by an evaluation of the severity of the fault. 


\subsubsection{Fault Detection}

During the week of August $15^{\text {th }}, 2016$ a discrepancy between the predicted and measured temperature profiles was found in select offices. During two days of this week the thermostat reading in offices 1 and 3 suddenly spiked to a temperature which exceeded the upper fault detection threshold. On the evening of the $18^{\text {th }}$ and $19^{\text {th }}$ the temperatures in these two offices exceeded the fault detection threshold by approximately $2{ }^{\circ} \mathrm{C}$ and $4{ }^{\circ} \mathrm{C}$, respectively.

Figure 4.11 represents the temperature profiles for office 1 during the week of August $15^{\text {th }}$, 2016. Included in Figure 4.11 is the fault detection threshold, which is represented by dashed magenta lines. The root mean square deviation for the week was approximately $0.64{ }^{\circ} \mathrm{C}$, over the fixed fault detection threshold of $\pm 0.51{ }^{\circ} \mathrm{C}$.

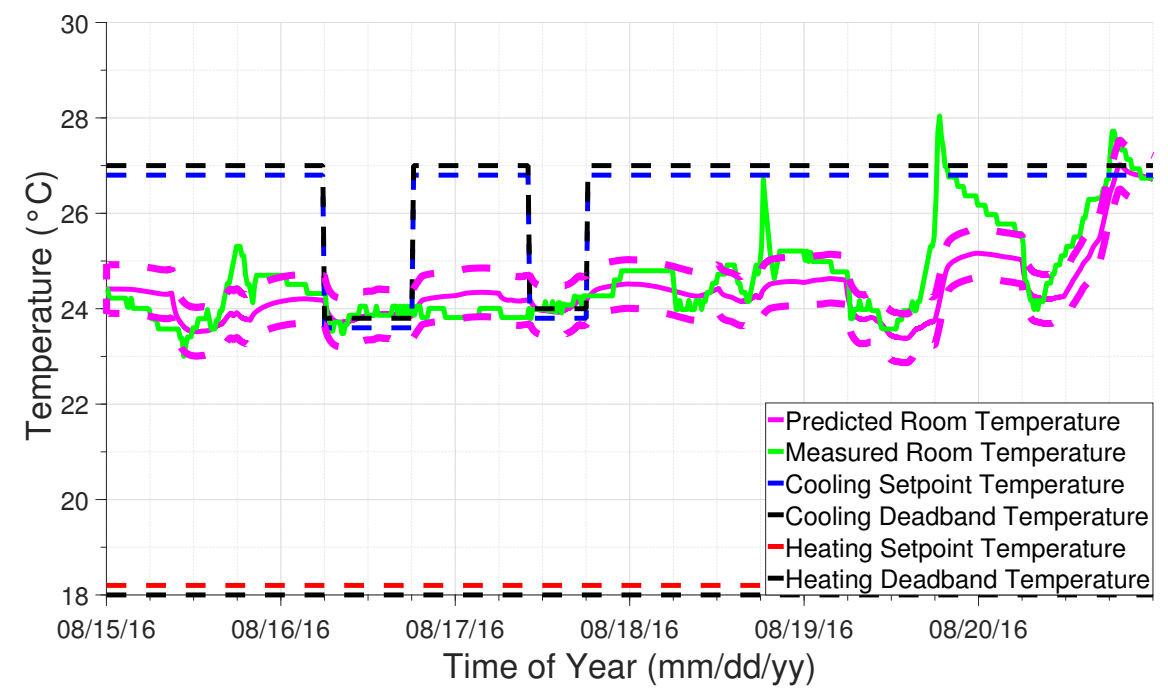

Figure 4.11: Room air temperature profiles for office 1 in August

Figure 4.12 represents the temperature profiles for office 2 during the week of August $15^{\text {th }}$, 2016. Included in Figure 4.12 is the fault detection threshold, which is represented by dashed magenta lines. The root mean square deviation for the week was approximately 
$0.44{ }^{\circ} \mathrm{C}$, underneath of the fixed fault detection threshold of $\pm 0.51{ }^{\circ} \mathrm{C}$.

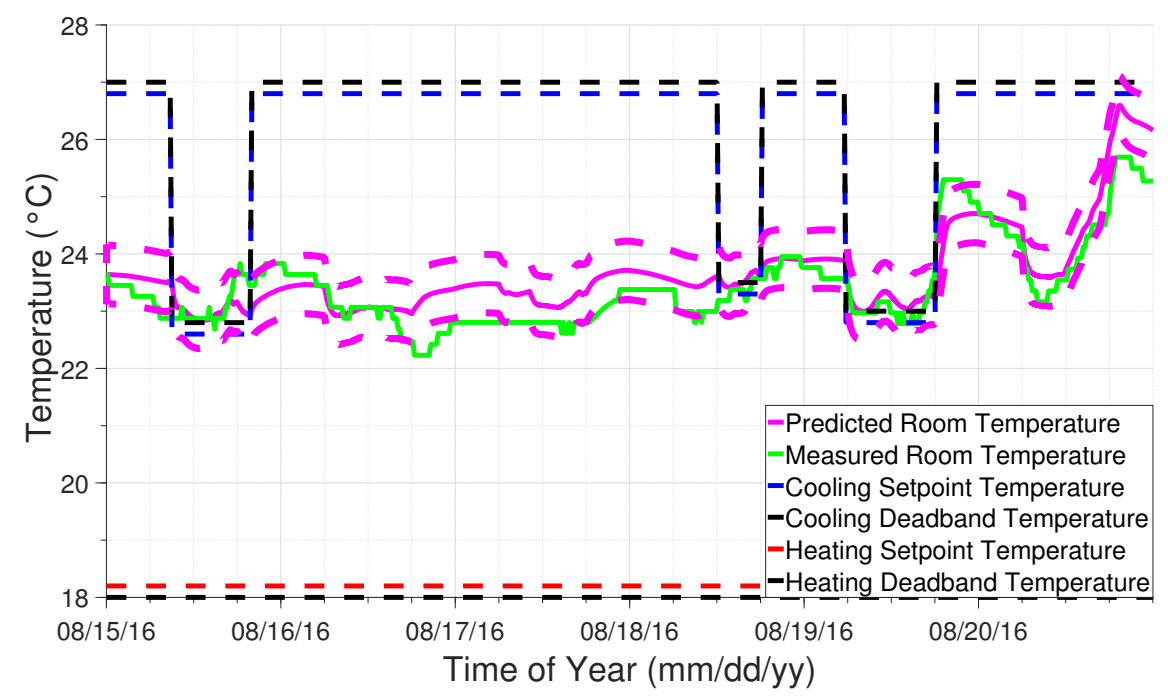

Figure 4.12: Room air temperature profiles for office 2 in August

Figure 4.13 represents the temperature profiles for office 3 during the week of August $15^{\text {th }}, 2016$. Included in Figure 4.13 is the fault detection threshold, which is represented by dashed magenta lines. The root mean square deviation for the week was approximately $0.97{ }^{\circ} \mathrm{C}$, significantly higher than the fixed fault detection threshold of $\pm 0.51{ }^{\circ} \mathrm{C}$.

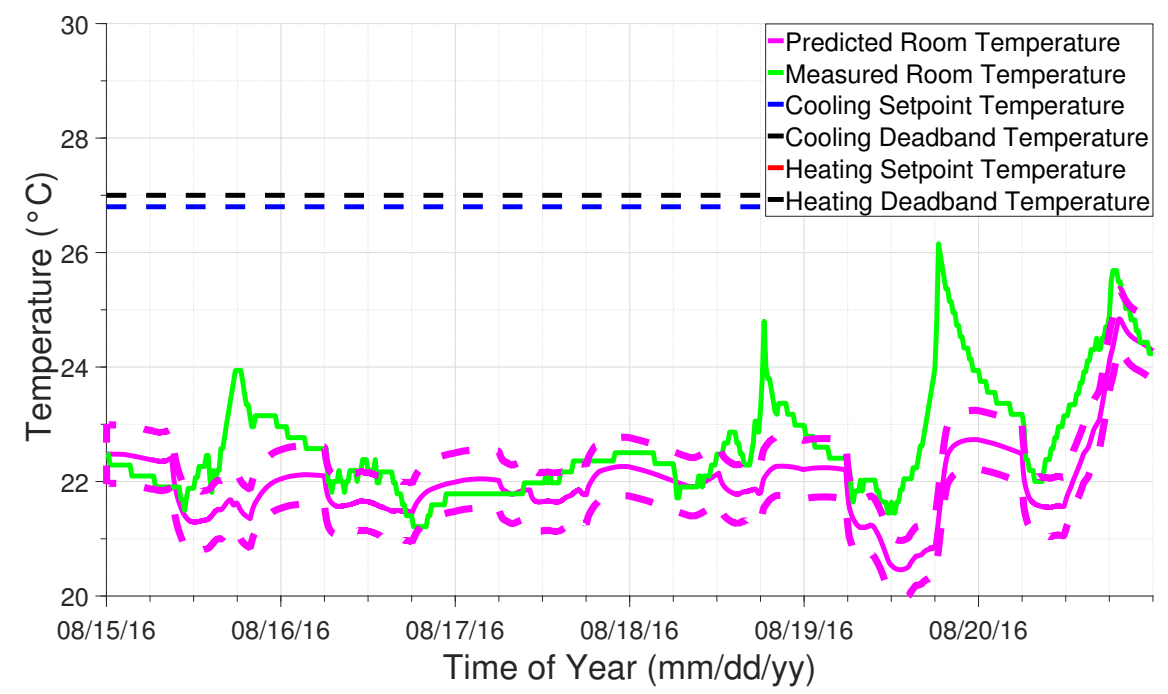

Figure 4.13: Room air temperature profiles for office 3 in August 
Figure 4.14 represents the temperature profiles for office 4 during the week of August $15^{\text {th }}, 2016$. Included in Figure 4.14 is the fault detection threshold, which is represented by dashed magenta lines. The root mean square deviation for the week was approximately $0.62{ }^{\circ} \mathrm{C}$, over the fixed fault detection threshold of $\pm 0.51{ }^{\circ} \mathrm{C}$.

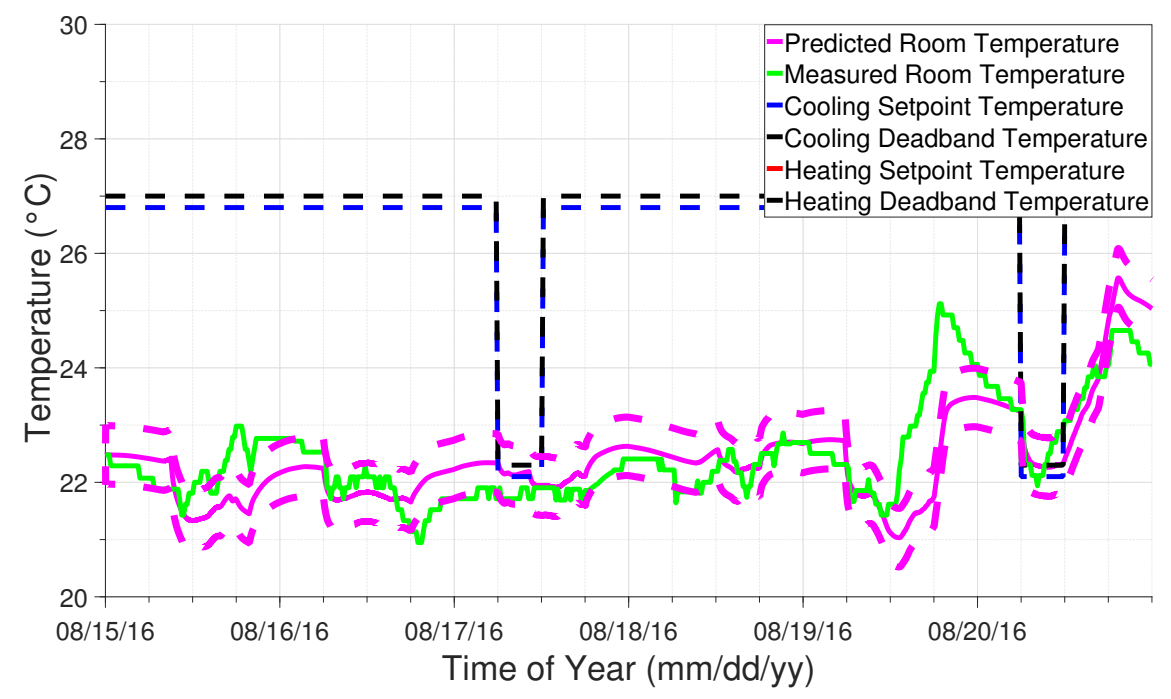

Figure 4.14: Room air temperature profiles for office 4 in August

Viewing the plots for the week the model predictions followed a very similar trend to the measured values for offices 2 and 4 . Offices 1 and 3 also followed a similar trend, however, at times the thermostat readings in these two offices suddenly spiked to a temperature that significantly exceeded the fault detection thresholds. Figure 4.15 shows the temperature difference between the predicted and measured temperature in office 1. Also included in this plot is the fault detection threshold. 


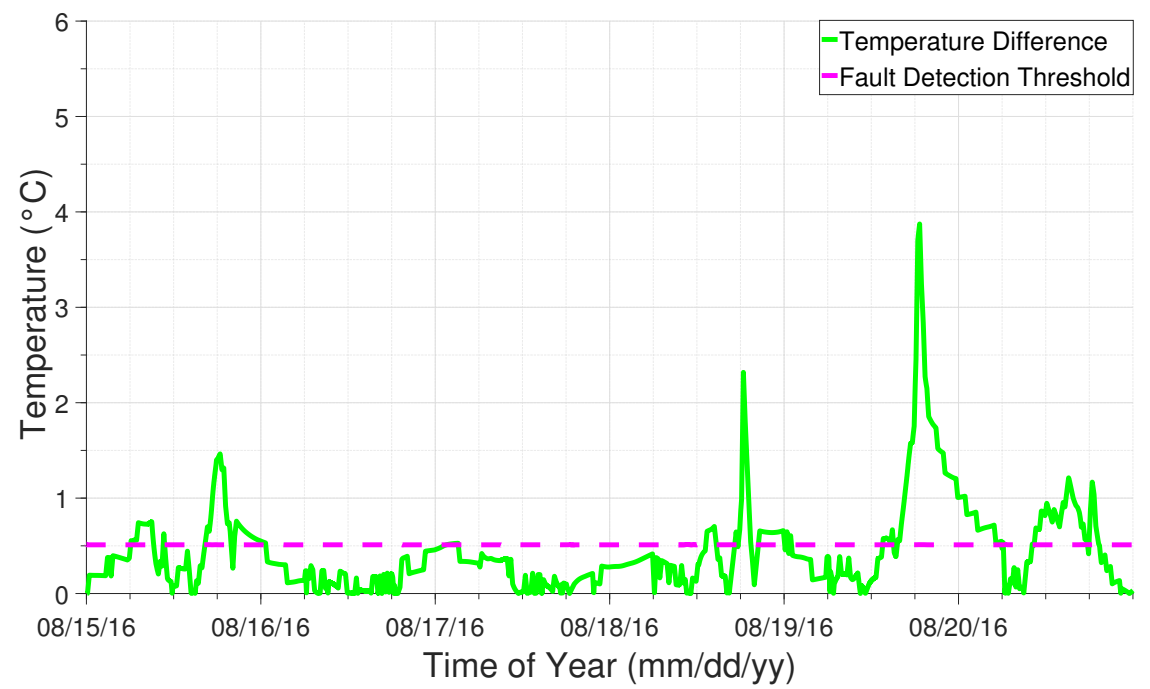

Figure 4.15: Theoretical and measured room air temperature difference for office 1

Figure 4.16 shows the temperature difference between the predicted and measured temperature in office 3. Also included in this plot is the fault detection threshold.

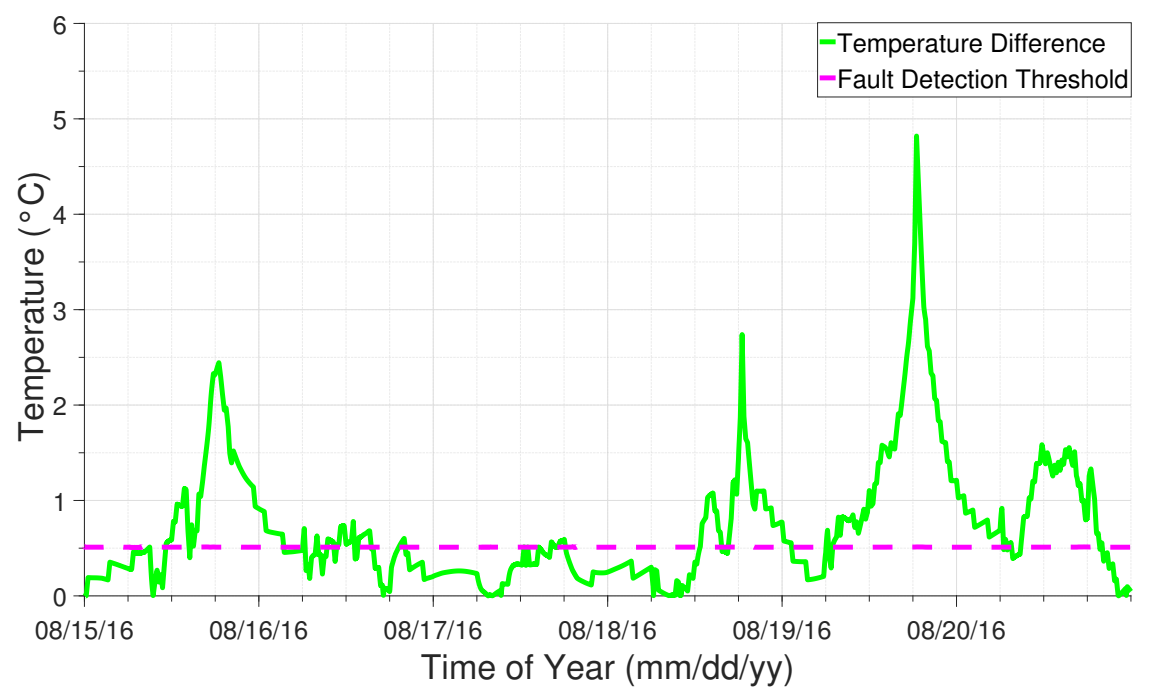

Figure 4.16: Theoretical and measured room air temperature difference for office 3

Figure 4.15 and 4.16 shows that the thermostat readings in office 1 and 3 significantly 
exceeded the predicted temperature for the spaces. In office 1 the thermostat reading exceeded the predicted value by nearly $4{ }^{\circ} \mathrm{C}$ on August $19^{\text {th }}$. During this same time the thermostat reading in office 3 exceeded the predicted temperature by almost $5{ }^{\circ} \mathrm{C}$. Figure 4.15 and 4.16 show that during August $15^{\text {th }}, 18^{\text {th }}$ and $19^{\text {th }}$ the spike in temperatures significantly exceeded the fault detection thresholds.

\subsubsection{Fault Diagnostics}

These spikes only occurred in two of the four offices, thus, the predicted radiator heating needed to be evaluated next, when following the flow chart seen in Figure 3.26. Since this detection occurred during the cooling season both the predicted and measured hydronicbased heating rates were zero, resulting in the determination that a room-level fault had been detected in these two offices. A room-level fault could be either poor thermostat placement, internal equipment influencing the thermostat readings or a window was left open. The realistic cause of the discrepancy is that these two thermostats were poorly placed since this temperature discrepancy occurred simultaneously in two offices.

When further analyzing the temperature plots it can be seen that the thermostats in offices 1 and 3 recorded spikes in the room air temperature in these two offices during three days; the $15^{\text {th }}, 18^{\text {th }}$, and $19^{\text {th }}$, late in the afternoon. These increases in temperature occurred at an approximate rate of $1.5{ }^{\circ} \mathrm{C}$ per 30 minutes, a rate which was impossible for the entire room to heat up at. Since offices 2 and 4 did not see these spikes it was likely that there was a design discrepancy between the thermostat locations in these offices, and offices 1 and 3. Figure 4.17 shows the zone layout including the thermostat locations for the four offices included in the zone under analysis. 


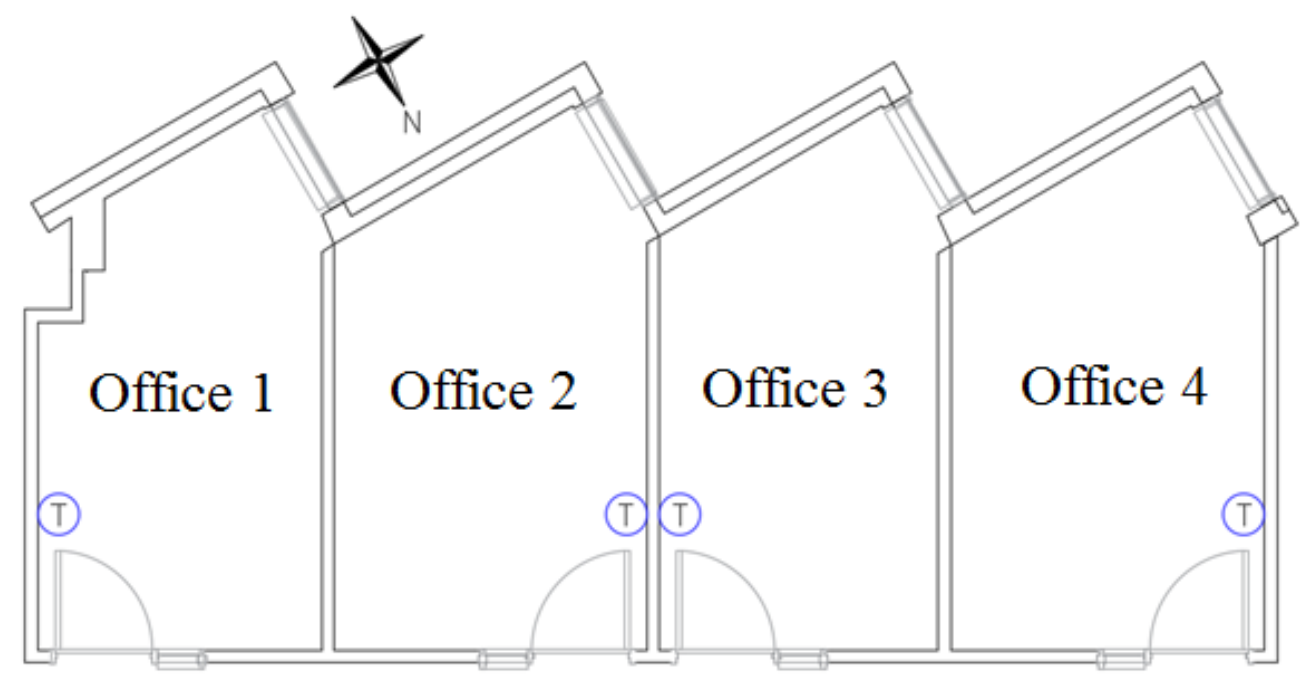

Figure 4.17: Zone layout

Figure 4.17 shows that the thermostat locations differ, offices 1 and 3 have the same location, and offices 2 and 4 have the same location. Figure 4.17 shows that the thermostats in offices 1 and 3 can potentially see direct sunlight, whereas rooms 2 and 4 will not, which follows the results, as rooms 2 and 4 did not see the sudden spikes in temperature that rooms 1 and 3 did. Given the time that these spikes occurred, approximately $6: 30$ in the afternoon and the west-facing direction of the facade it was hypothesized that direct sunlight was hitting the thermostats in these two offices.

To ensure that this was not just a random occurrence the west-facade offices on two floors of the Canal Building were evaluated. In total there were fourteen offices that were designed similarly to the initial four offices under evaluation. The main difference between these offices are the door locations, the door placement impacts the thermostat location as it is typical design strategy to place the thermostat just beyond the reach of the door (Figure 4.17). The thermostat locations were recorded for all fourteen offices and the measured temperatures were obtained on August $24^{\text {th }}, 2015$. Figure 4.18 shows that all thermostats that are located such that direct sunlight cannot hit the thermostat operate as expected. 


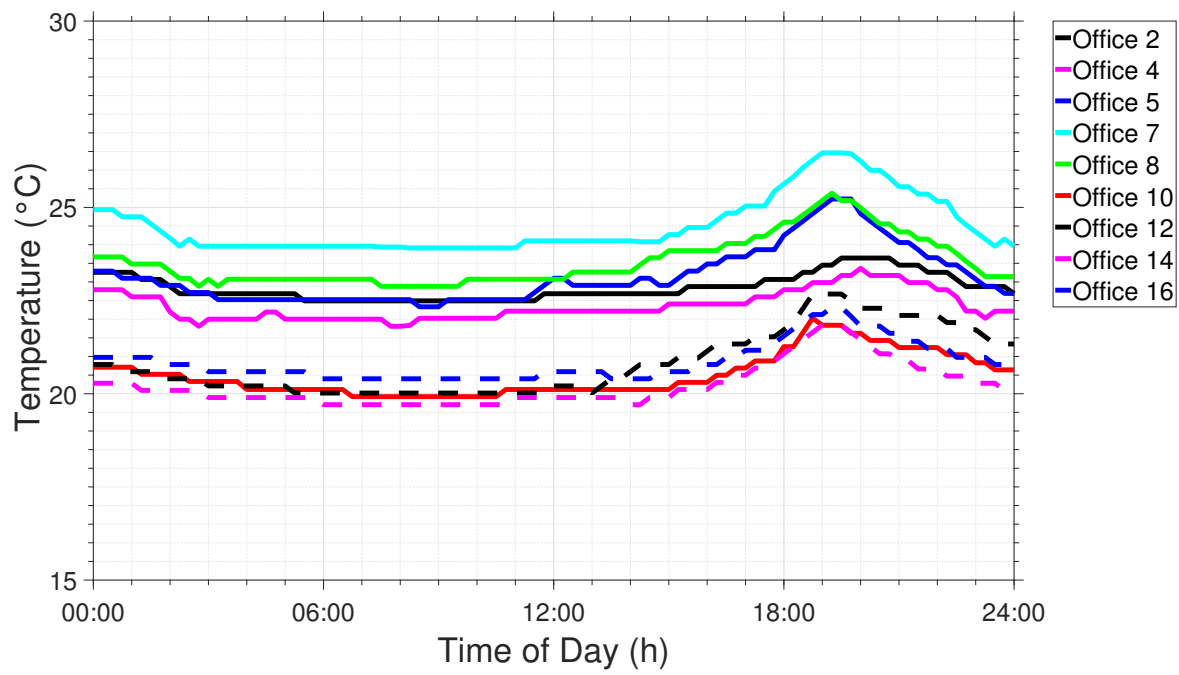

Figure 4.18: Thermostats that do not see direct sunlight

Figure 4.19 shows that four of the seven thermostats that can see direct sunlight see a sudden spike in their room air temperature readings in the afternoon. Three rooms do not see a large increase which could be due to blind positioning or other interferences. In one case, a book-shelf was partially blocking the window, which could be keeping the sunlight from affecting the area around the thermostat.

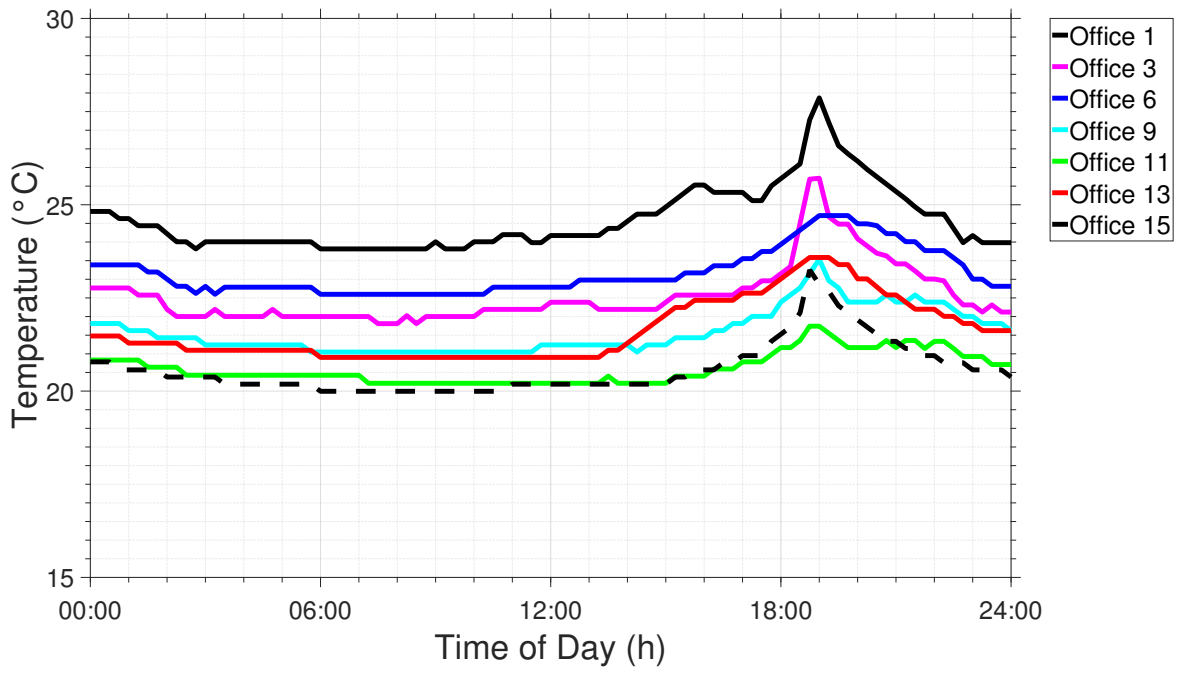

Figure 4.19: Thermostats that could see direct sunlight 
Figure 4.19 does not disprove the original hypothesis, but further investigation was required as three of the offices operated relatively normal. A SketchUp model was created for office 1, which included the thermostat location. SketchUp's shading tool was utilized to determine if this was the culprit of the fault. The daylighting in the room for an entire day, mid-month was evaluated. Of the twelve months, four resulted in times in the late afternoon that the sun could make direct contact with the thermostat. Figure 4.20 shows the shading results obtained through SketchUp and represents the time when the sun penetrated the furthest into the room, or was hitting the thermostat. Daylight savings hours have been incorporated in the times that are shown in Figure 4.20 .

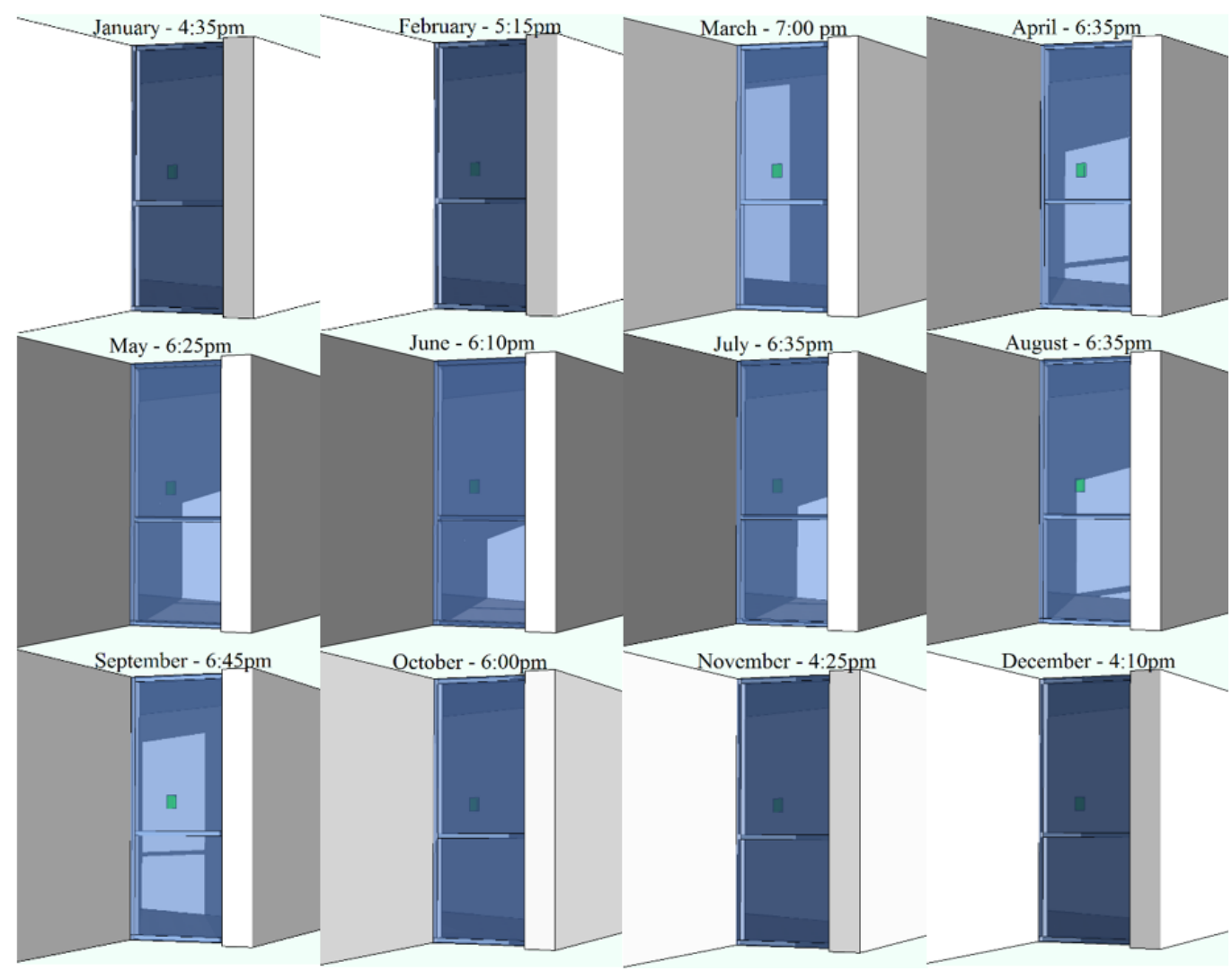

Figure 4.20: Daylighting results for a representative time each month of the year 


\subsubsection{Fault Evaluation}

The VAV box modulates its damper in order to meet the demand of the offices it serves. If a thermostat reading increases due to direct sunlight it will cause an increase in cooling to be supplied to the room, as long as the reading exceeds the set-point. If one office's temperature exceeds the set-point, the VAV box will allow more air to enter into the zone. The more offices in the zone that exceed the set-point, the more air that is permitted to the zone. To quantify the excess energy consumption that is caused by this poor thermostat placement, August $26^{\text {th }}, 2016$ was analyzed. Figure 4.21 shows the thermostat reading and set-point temperature in office 3 during the afternoon of August 26 ${ }^{\text {th }}$. Figure 4.21 also displays the VAV box supply air temperature and flow rate for zone 1 .

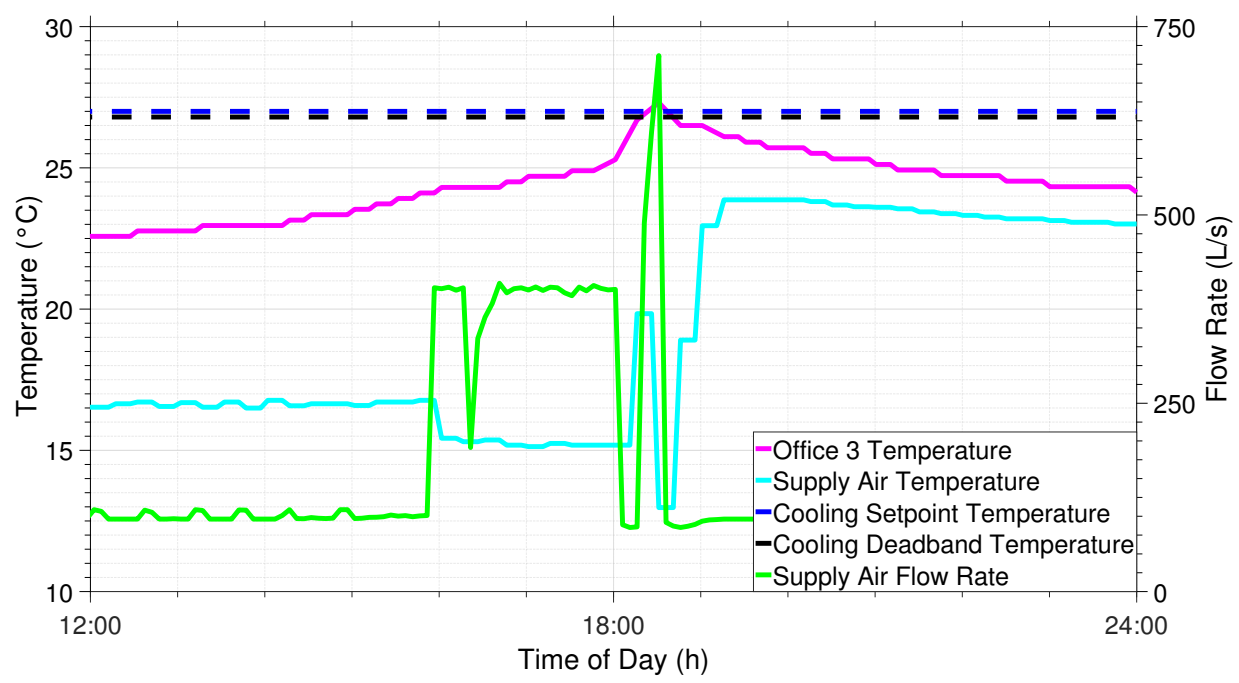

Figure 4.21: Measured performance for zone 1 and office 3 on August 26 ${ }^{\text {th }}, 2016$

Figure 4.21 shows that between $4 \mathrm{pm}$ and $6 \mathrm{pm}$ the operation of the VAV box was being dictated by another room and eventually goes back into ventilation mode, where it supplied its minimum flow rate at $6 \mathrm{pm}$. However, the thermostat reading in office 3 reached the setback temperature of $27^{\circ} \mathrm{C}$, which caused the VAV box supply air flow rate to spike. The increase in air flow to the zone was a result of the solar gains directly hitting the thermostat 
and caused the AHU supply and return fan to consume an excess amount of energy. The increase in energy can be quantified through the third fan law [68], equation 4.2.

$$
\frac{\text { Power } 1}{\text { Power } 2}=\frac{\text { FlowRate } 1^{3}}{\text { FlowRate } 2^{3}}
$$

Table 4.1 shows the measured air flow rate through the AHU and VAV box that serves zone 1 , and the corresponding increase in power. It is important to note, that equation 4.2 is an analysis that is used for the total air flow through a fan, not just the flow rate that is passing through the VAV box. Therefore, a baseline flow rate through the AHU was also obtained from enteliWEB at 6:20 pm, which was found to be $13,735.5 \mathrm{~L} / \mathrm{s}$. The air flow rate through the AHU was assumed to only fluctuate based on the change in the air flow rate through VAV box 1. Therefore, the supply fan values observed in Table 4.1 are all theoretical values, with the exception of the one measured value at 6:20 pm.

Table 4.1: Supply air flow rate and power increase

\begin{tabular}{||c|c|c|c||}
\hline $\begin{array}{c}\text { Time of } \\
\text { day }\end{array}$ & $\begin{array}{c}\text { VAV box 1 supply air } \\
\text { flow rate (L/s) }\end{array}$ & $\begin{array}{c}\text { AHU supply air flow } \\
\text { rate (L/s) }\end{array}$ & $\begin{array}{c}\text { Fan power increase } \\
(\%)\end{array}$ \\
\hline \hline $18: 15$ & 85.87 & $13,331.9$ & 0 \\
\hline $18: 20$ & 489.48 & $13,735.5$ & 9.36 \\
\hline $18: 25$ & 610.14 & $13,856.2$ & 12.27 \\
\hline $18: 30$ & 711.51 & $13,957.5$ & 14.75 \\
\hline $18: 35$ & 91.88 & $13,337.9$ & 0.14 \\
\hline
\end{tabular}

Table 4.1 shows that this fault can cause a fairly significant increase in the AHU's fan energy consumption. The magnitude of this fault when it does occur is large, however, the solar analysis results produced by SketchUp show that this fault is only able to occur during four months. Furthermore, a sunny day is required for the thermostat to reach the cooling set-point temperature during these months. Although when the fault occurs these offices will be overcooled, it does not occur over a significant duration. As a result, the 
occupants will not endure discomfort as the spaces will not see a large decrease in the room air temperature. Moreover, during the earlier months (March and April) the cooling system is not activated so an excess amount of cooling will not be supplied. In fact, a decrease in heating might occur if the system believes the space is warmer than it actually is, ultimately sacrificing the occupant's comfort.

This fault can occur in four of the west-facade zones in the Canal Building but does not appear to occur very frequently during the year and thus, may not be worth relocating the thermostats. However, this fault could be addressed by making an adjustment to the controls. The system could be programmed to temporarily allow the VAV box operation to be controlled exclusively by the thermostats in the other two offices. The new controls would allow for the sun's direct impact on the thermostat readings in offices 1 and 3 to be neglected. Although this fault does not appear to have significant impacts on the westfacade zones, it can cause significant issues if the scenario arose in a south facing office. Since an occupant would likely be present, along with a reasonable set-point temperature, resulting in a significant portion of excess cooling to be supplied to the space.

\subsection{Poor VAV Box Selection}

As stated earlier, a VAV box is a piece of equipment that varies the amount of air that enters into a zone. The quantity of air that can pass into the space is dictated by the VAV box's damper position. The positioning of the damper can be altered, but there is a minimum and maximum capability that the damper can handle. Damper positions below the minimum specified by the manufacturer can result in the damper operating unstably. If the damper starts to become unstable it can result in the damper fully closing at times and restricting the airflow more than was intended. VAV boxes operate at the minimum damper position 
a majority of the year. However, these units are often selected based on peak conditions, with little, to no consideration given to the minimum capability. To close this section the severity of neglecting the minimum VAV box capability during the selection process will be assessed. First, the method by which this fault was discovered will be discussed.

\subsubsection{Fault Detection}

During the week of August 15 $5^{\text {th }}, 2016$ the thermostat measurements suddenly spiked as a result of sunlight hitting the thermostat. These temperature measurements significantly decreased and fell within the fault detection threshold on the $15^{\text {th }}$ and $18^{\text {th }}$ once the sun set. However, after sunset, the thermostat reading increased to a value that once again exceeded the fault detection threshold. An example of this is shown in Figure 4.22, which shows the temperature profiles for office 1. Included in Figure 4.22 is the fault detection threshold, which is represented by dashed magenta lines. The root mean square deviation for the week was approximately $0.64{ }^{\circ} \mathrm{C}$, over the fixed fault detection threshold of $\pm 0.51{ }^{\circ} \mathrm{C}$.

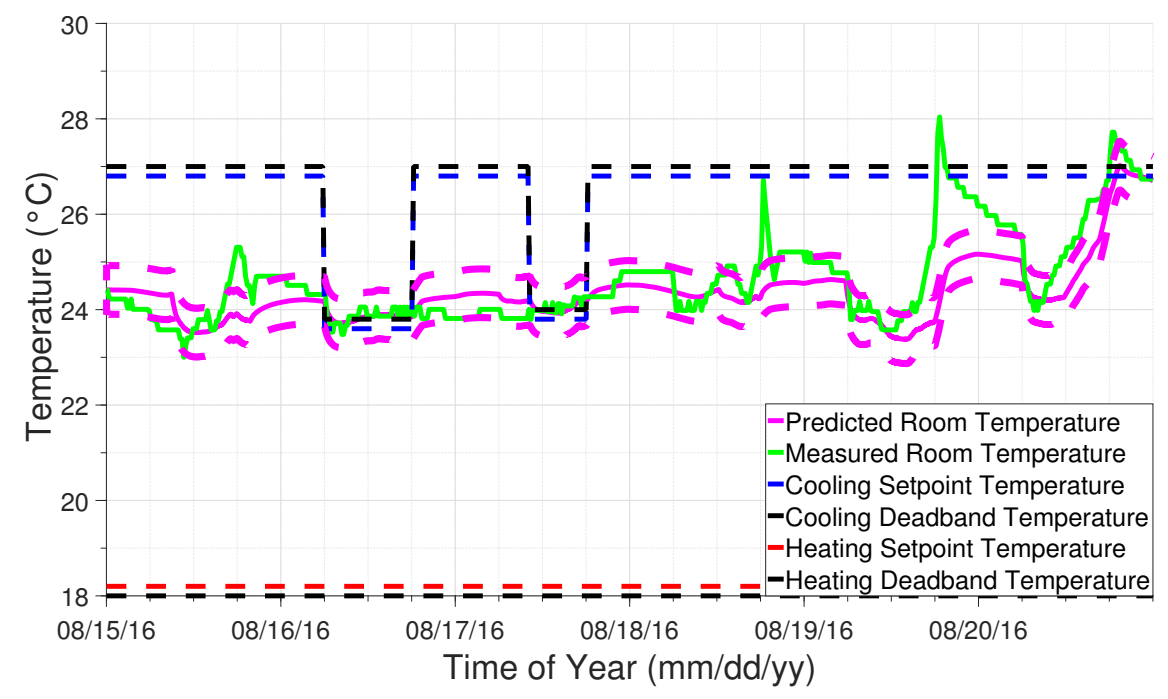

Figure 4.22: Room air temperature profiles for office 1 in August 
Figure 4.23 displays the absolute temperature difference between the predicted and measured temperature in office 1. Also included in this plot is the fault detection threshold.

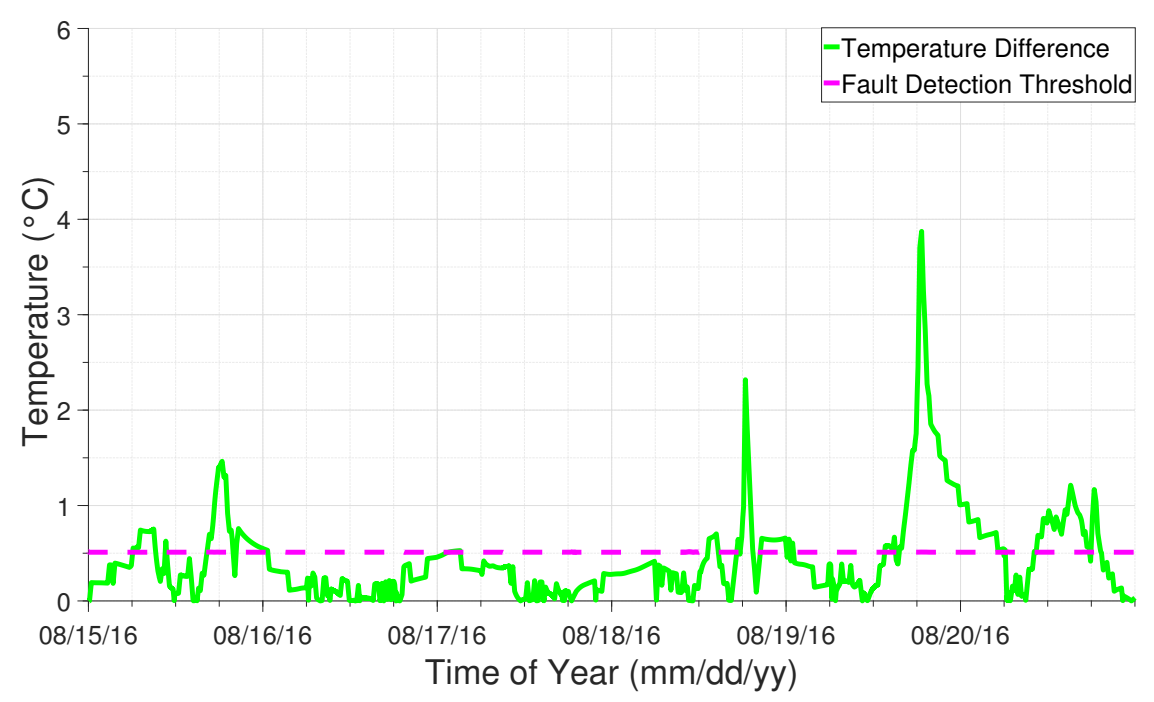

Figure 4.23: Theoretical and measured room air temperature difference for office 1

Figure 4.22 and 4.23 show that on August $15^{\text {th }}$ and $18^{\text {th }}$ an increase in the thermostat temperature occurred which exceeded the fault detection threshold. Furthermore, upon close inspection of this week, it can be seen that during the $16^{\text {th }}$ and $17^{\text {th }}$ a similar increase in temperature occurred at a similar time of the day. Although, the increase in temperatures on the $16^{\text {th }}$ and $17^{\text {th }}$ did not exceed the fault detection threshold.

\subsubsection{Fault Diagnostics}

A discrepancy was detected in office 1 and after evaluating all four office's temperature predictions it could be seen that each office underwent a similar issue, an increase in temperature after $10 \mathrm{pm}$. From Figure 3.26 the next set of results to evaluate was the air-based heating and cooling rate predictions at that time. The rate of change that the thermostat 
underwent implied that the system supplied more hot air to the space than the model was predicting. Figure 4.24 shows the air-based heating and cooling profiles for the week and confirmed that more hot air was being supplied to the space than the model was predicting. Included in Figure 4.24 is the fault detection threshold, which is represented by dashed magenta lines. The root mean square deviation during the week was approximately $761 \mathrm{~W}$, which was greater than the average fault detection threshold of $\pm 553 \mathrm{~W}$. However, it is important to note, that some of the cooling discrepancies during the daytime are a result of the sunlight increasing the thermostat measurements.

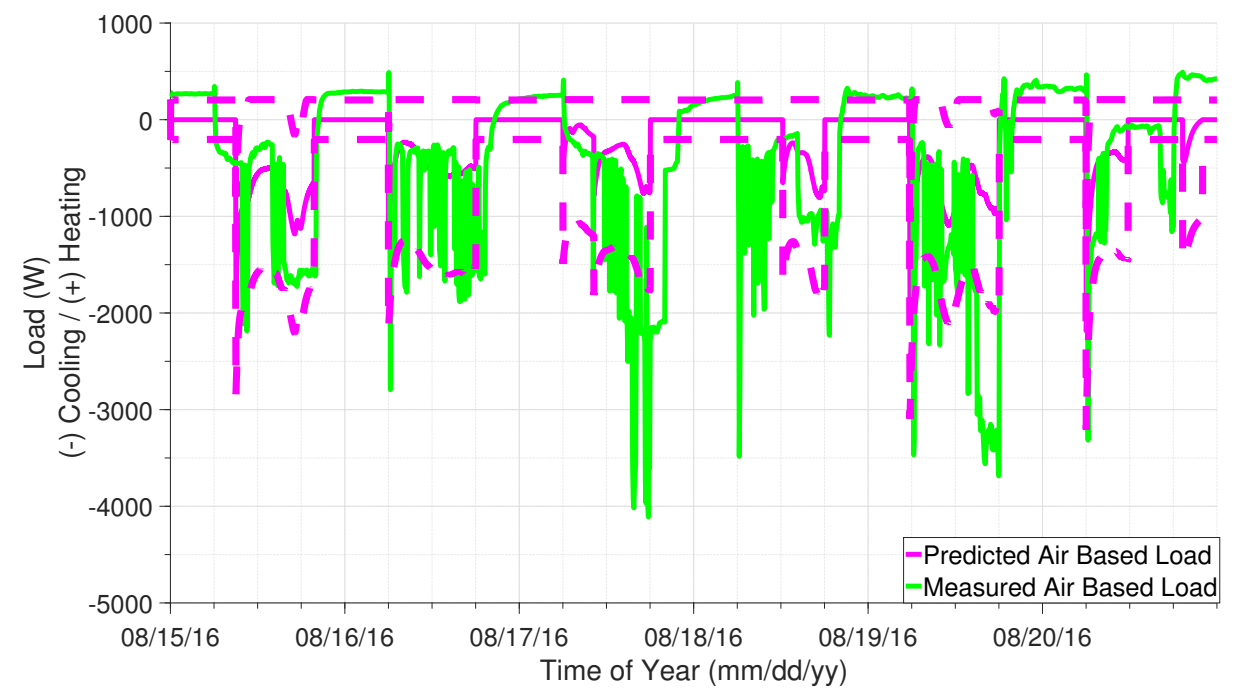

Figure 4.24: Air-based heating and cooling profiles for zone 1 in August

Figure 4.24 shows that there was a discrepancy in the air-based heating and cooling rate profiles during the same time of the thermostats deviation from the room air temperature predictions. As a result, the reheat valve predictions needed to be evaluated next, when following Figure 3.25. Upon evaluation it was determined that the results for the reheat valve were consistent with what was actually happening in the system. The consistency in the reheat valve operations and predictions meant that either a zone-level and/or a buildinglevel fault was present at this time, which required further investigation to diagnose. 
The functionality of the air-based system in the model was based on whether all rooms' set-points were being met. The system operates in a similar fashion, however, it constantly supplies air to the offices for ventilation and recirculation purposes. In turn, cooling or heating will also be supplied to the room if there is a temperature difference between the supply and room air. Figure 4.24 shows this occurrence, each night the system enters into recirculation mode which resulted in a slight addition of heat to the offices. The quantity of heat addition to the spaces was exemplified based on the minimum capability of the VAV box. Each VAV box has a specified minimum operating point that it is capable of handling before it starts to operate inefficiently. If the VAV box starts to operate inefficiently it can result in the damper fully closing at times. The damper closing causes the ventilation or recirculation air to be cut off from the space it serves. Air flow into office spaces is important as ASHRAE Standard 62.1 requires $8.5 \mathrm{~L} / \mathrm{s} /$ person of fresh air to be supplied in office buildings when occupants are present. Requirements aside, the occupants within the building will be more comfortable with air being supplied to the space. A lack of fresh air can reduce an occupant's productivity. Furthermore, a lack of recirculation air will cause the air inside the room to stagnate, resulting in an uncomfortable environment when the occupant does return back to the space. For these reasons, it is better to have all VAV boxes operate at their minimum specified damper capabilities during times when no heating or cooling is required. Figure 4.25 shows this situation, the flow rate of the VAV box serving the first zone is minimized throughout the winter break. 


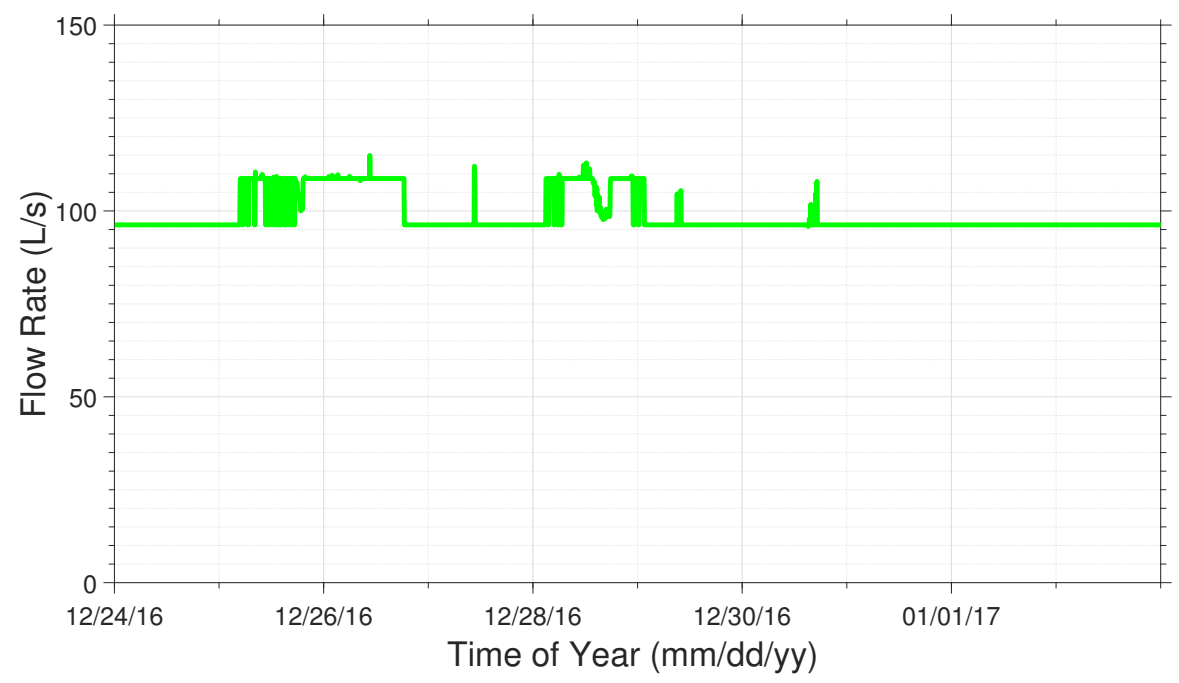

Figure 4.25: Measured VAV box supply air flow rate for zone 1 in December

\subsubsection{Fault Evaluation}

This addition of heat was not the issue, it did not result in the spaces exceeding the setback temperatures. However, the cost for the AHUs to constantly supply air is significant, the supply and return fans in the two AHUs combine for an approximated total of $331.57 \mathrm{GJ}$ per year. To reduce the cost associated with recirculating the air the damper positions in the VAV boxes need to be minimized. Unfortunately, these terminal units are typically sized to ensure that the worst case scenario can be met and little, to no consideration, is given to the minimum capabilities. Furthermore, the larger the VAV box, the larger the minimum capability is, which is a significant issue for the cost of operations, considering that this VAV box operates at its minimum capability approximately $65 \%$ of the year.

To quantify the fan energy consumption that would result from various VAV box selections, an EnergyPlus model was created and annual results were evaluated. VAV box specifications for various manufacturers were found online and implemented into the model. 
The manufacturers that were included in this analysis were Metalaire [69], Nailor [70], Titus [71], Kreuger [72], E.H. Price [73] and Tuttle \& Bailey [74]. The maximum capacity of cooling for each VAV box was calculated based on a SAT of $13^{\circ} \mathrm{C}$, the maximum specified air flow rate for the VAV box and an assumed room air temperature of $23{ }^{\circ} \mathrm{C}$. With this information the maximum cooling rate for the VAV box could be calculated by utilizing equation 3.3 . After this was calculated the value was used to set a capacity on the cooling system in the EnergyPlus model. The purpose of the model was to compare the performance of each VAV box selection relative to one another, not to actually quantify each individual VAV boxes performance and as such simplifications were made to ease the process. The model utilized a heating and cooling set-point of $20{ }^{\circ} \mathrm{C}$ and $23{ }^{\circ} \mathrm{C}$, respectively. These set-points were implemented during the operational hours of the system and at night the system was allowed to free float. The heating and cooling system implemented in EnergyPlus represented the air-based system in the building which only functions between 6 am and $10 \mathrm{pm}$. Allowing the system to free float during the heating season was determined to be an adequate simplification because the radiator is utilized instead of the air-based system in the event that the room air temperature falls below the setback temperature at night time. Allowing the system to free float during the cooling season was determined to be an adequate simplification since the EnergyPlus predictions never exceeded the setback temperature of $27{ }^{\circ} \mathrm{C}$ during the night time. The spaces were assumed to house one occupant for 8 hours each day, with a one-hour lunch break. The radiant fraction for the occupant was determined using Table 1 in Chapter 18 of the 2013 ASHRAE Fundamentals Handbook [10]. The occupant was considered to be seated, doing light work, with a low supply air velocity, resulting in a radiant fraction of $60 \%$. During the times that the occupants were present their lights and computers were turned on. The lighting load for these offices is 128 W and from Table 3 in Chapter 18 of the 2013 ASHRAE Fundamentals Handbook [10] the radiative fraction was $61 \%$ for a recessed fluorescent luminaire with lens. Each office 
was assumed to have one desktop and monitor, values for these components were obtained from Table 8 from Chapter 18 in the 2013 ASHRAE Fundamentals Handbook to total 107 $\mathrm{W}$ and resulted in $20 \%$ of this load being radiative. Table 4.2 shows the results for twelve different VAV box selections that were obtained through EnergyPlus simulations.

Table 4.2: VAV box results

\begin{tabular}{||c|c|c|c|c||}
\hline $\begin{array}{c}\text { VAV box } \\
\text { supplier }\end{array}$ & $\begin{array}{c}\text { VAV box } \\
\text { size }(\mathrm{mm})\end{array}$ & $\begin{array}{c}\text { Zone annual supply \& } \\
\text { return fan energy } \\
\text { consumption }(\mathrm{GJ})\end{array}$ & $\begin{array}{c}\text { Max temp } \\
\left({ }^{\circ} \mathrm{C}\right)\end{array}$ & $\begin{array}{c}\text { Minutes } \\
\text { exceeding } \\
\text { set-point }\end{array}$ \\
\hline Metalaire & 250 & $2.068 \& 1.384$ & 23 & 0 \\
\hline Metalaire & 200 & $1.372 \& 0.920$ & 24.48 & 1287 \\
\hline Nailor & 225 & $1.348 \& 0.904$ & 23 & 0 \\
\hline Nailor & 200 & $1.070 \& 0.717$ & 24.49 & 449 \\
\hline Titus & 225 & $5.028 \& 3.368$ & 23 & 0 \\
\hline Titus & 200 & $3.779 \& 2.532$ & 23.66 & 16 \\
\hline Kreugar & 200 & $1.281 \& 0.858$ & 23 & 0 \\
\hline Kreugar & 175 & $1.110 \& 0.744$ & 24.05 & 108 \\
\hline E. H. Price & 200 & $2.559 \& 1.714$ & 23 & 0 \\
\hline E. H. Price & 175 & $1.718 \& 1.151$ & 23.66 & 16 \\
\hline Tuttle \& Bailey & 200 & $1.396 \& 0.935$ & 23 & 0 \\
\hline Tuttle \& Bailey & 175 & $1.194 \& 0.800$ & 23.89 & 88 \\
\hline
\end{tabular}

Table 4.2 shows the annual supply and return fan energy consumption that was calculated based on the current consumption of the AHU fans. The annual energy consumed to supply cooling to the zone was approximately $8.524 \mathrm{GJ}$ regardless of the VAV box selection. The annual energy consumed does alter based on whether the VAV box can meet the peak demand of the zone, however, this did not cause significant changes in the annual cooling and therefore, was not included in Table 4.2. Included in Table 4.2 is the maximum temperature that was reached while the cooling system was on, not during the free float stage. Finally, the last column displays the total minutes in a year that the set-point 
temperature was predicted to not be met.

Colours were used to distinguish certain results in Table 4.2. Red was used to denote the Metalaire $250 \mathrm{~mm}$ VAV box because it is the current terminal unit that is used to supply air to the zone under analysis. The Kreugar $200 \mathrm{~mm}$ VAV box results are in green since they represent the best possible results out of the options that can always meet the demands of the space. The results that are in orange represent all VAV box selections that perform better than the Kreugar 200 mm VAV box from a fan energy consumption standpoint, but at times were predicted to allow the zone to exceed the set-point temperature.

The system currently has a $250 \mathrm{~mm}$ Metalaire VAV box installed. It can be seen from the results that if the system would have been designed utilizing a Kreugar $200 \mathrm{~mm}$ VAV box the fan energy consumption required for this zone could have been reduced by approximately $38 \%$ while also supplying enough cool air during peak demands. On the other hand, the Nailor $200 \mathrm{~mm}$, Kreugar $175 \mathrm{~mm}$ and Turtle \& Bailey $175 \mathrm{~mm}$ VAV boxes, 46\% and $42 \%$, respectively. Selecting these VAV boxes would have resulted in times where the required amount of cooling for the space exceeded the VAV box capabilities. However, this would not be the case very often during the year. The number of minutes which the temperature would exceed the set-point ranges between 88 and 449 minutes during an entire year. Furthermore, the maximum temperature that was reached during these times was only $24.49^{\circ} \mathrm{C}$. It may not be practical to undersize VAV boxes in typical commercial buildings, but this is a feasible design option in offices where on-site work hours are flexible and could have saved up to $48 \%$ of the energy required to transport the air from the AHU to this zone. Even if this is deemed not an acceptable design selection the Kreugar $200 \mathrm{~mm}$ selection could have exceeded the performance of the Metalaire $200 \mathrm{~mm}$ and resulted in $38 \%$ less energy consumption. Table 4.3 shows how the selection of the VAV box influences the energy consumption of the supply and return fan in the two AHU's that serve the Canal 
Building.

Table 4.3: VAV box's influence on AHU fan energy consumption

\begin{tabular}{||c|c|c|c||}
\hline $\begin{array}{c}\text { VAV box } \\
\text { supplier }\end{array}$ & $\begin{array}{c}\text { VAV box } \\
\text { size (mm) }\end{array}$ & $\begin{array}{c}\text { Fan energy requirement } \\
\text { for the zone }(\mathrm{GJ})\end{array}$ & $\begin{array}{c}\text { Percent of AHU's fan } \\
\text { energy consumption }(\%)\end{array}$ \\
\hline Metalaire & 250 & 3.452 & 1.04 \\
\hline Metalaire & 200 & 2.292 & 0.69 \\
\hline Nailor & 225 & 2.252 & 0.68 \\
\hline Nailor & 200 & 1.928 & 0.54 \\
\hline Titus & 225 & 8.396 & 2.53 \\
\hline Titus & 200 & 6.311 & 0.65 \\
\hline Kreugar & 200 & 2.139 & 0.56 \\
\hline Kreugar & 175 & 1.854 & 1.29 \\
\hline E. H. Price & 200 & 4.273 & 0.87 \\
\hline E. H. Price & 175 & 2.869 & 0.70 \\
\hline Tuttle \& Bailey & 200 & 2.331 & 0.60 \\
\hline Tuttle \& Bailey & 175 & 1.984 & \\
\hline
\end{tabular}

The fan energy requirement for the zone located in Table 4.3 is the combination of the supply and return fan energy consumption that was estimated through the EnergyPlus simulations. The respective percent of the AHU's fan energy consumption is a ratio of this value and the total annual fan energy consumption of the two AHU's that serve the Canal Building. These values were approximated based on the sensor recordings during the 2016 year. The total fan energy consumption for this year was determined to be approximately 331.57 GJ. Table 4.3 shows that one VAV box has little influence on the total AHU fan energy consumption. However, if a full building evaluation were conducted, it would likely lead to the conclusion that several VAV boxes were selected poorly. If several VAV boxes were selected poorly the potential energy savings would be significant. The results from this zone display that there is the potential to reduce approximately $0.39 \%$ of the AHU's fan energy consumption by switching to a Kreugar VAV box, without sacrificing occupant 
comfort. An identical zone layout was used in the design a total of 4 times, this already saves $1.56 \%$ of the AHU fan energy consumption. A study on another zone in the Canal Building revealed that with a more appropriate selection of the VAV box the requirement for the zone could have been reduced by $63.1 \%$ [75]. From an additional analysis, it was found that this selection would have reduced the AHU's fan energy consumption by $0.42 \%$.

Although this reduction in energy consumption appears to be insignificant when analyzing one zone, it is evident that significant energy and cost savings are possible if this fault is systemic in the building. The building operators have recognized the potential savings that are possible when limiting the air flow through the VAV box during unoccupied times. They have found that the VAV box damper can handle lower positions adequately and that the minimum capability of the VAV box serving zone 1 is actually $100 \mathrm{~L} / \mathrm{s}$. They have overridden the system to allow for this quantity of air to pass through during ventilation and recirculation periods. Although this is saving operational costs, the Kreguar $200 \mathrm{~mm}$ VAV box has been specified to handle approximately $75 \mathrm{~L} / \mathrm{s}$ adequately and would still be

a better selection, plus the operation managers could run a similar analysis on this terminal unit and potentially save even more energy.

\subsection{Poor VAV box Control Sequence}

As stated earlier, a VAV box is a piece of equipment that varies the amount of air that enters into a zone. The rate of air that can pass into the space is dictated by the VAV box's damper position. The positioning of the damper is altered based on the control sequence that was devised. In the Canal Building, the controls operate such that if one room's temperature exceeds the set-point an increased amount of air should be supplied to the room. If the temperature in another office within the zone exceeds the set-point, a further increase in the 
air flow should be supplied to the zone. The control sequence that was devised is not wrong, however, this leads to the VAV box operating under the assumption that if the offices are too hot, cool air will be supplied to the zone and vice versa. Typically this is the case, but if a fault occurred at the building-level the control sequence may falter. This software fault has the ability to increase energy consumption in the building, which was found to be the case during one-week in 2016 . The method by which this fault was discovered will now be discussed, followed by an evaluation of the severity of the fault.

\subsubsection{Fault Detection}

During the first half of the May $23^{\text {rd }}, 2016$ week the room air temperature predictions for all four offices deviated from the thermostat readings. The root mean square deviation for office 1 was approximately $1.43{ }^{\circ} \mathrm{C}$, greater than the fixed fault detection threshold of \pm $0.51{ }^{\circ} \mathrm{C}$. Figure 4.26 shows the temperature profiles for office 1 during this week. Included in Figure 4.26 is the fault detection threshold, which is represented by dashed magenta lines.

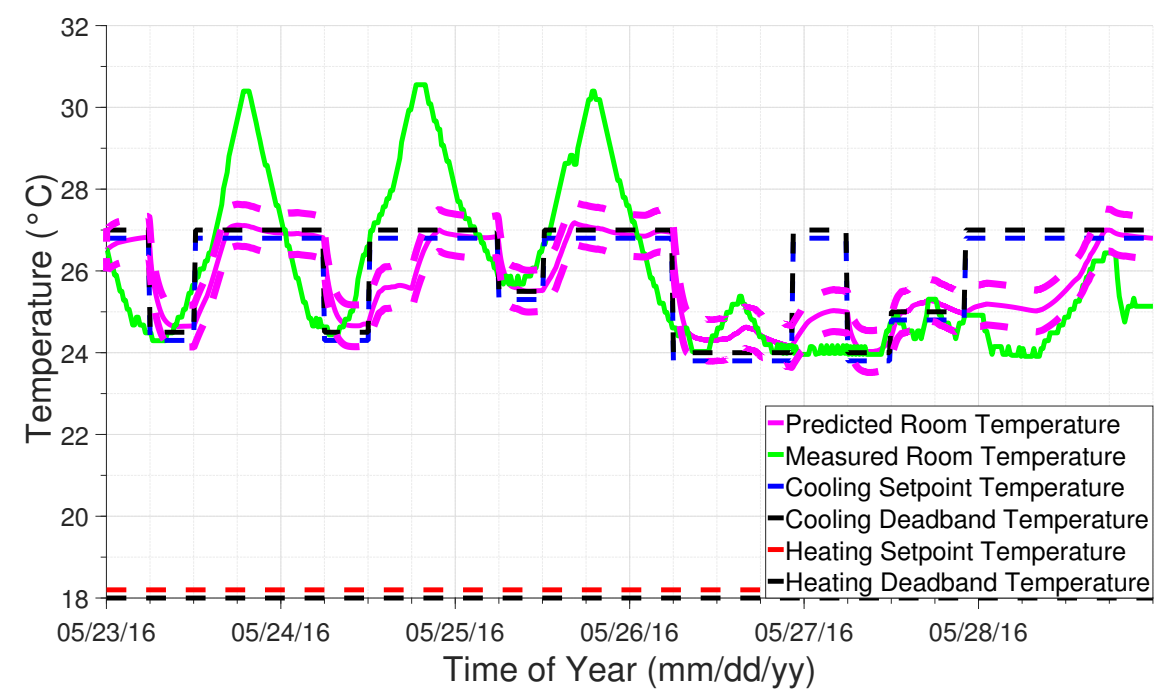

Figure 4.26: Room air temperature profiles for office 1 in May 
The other three offices all exhibited a similar trend. The root mean square deviation for office 2,3 and 4 was approximately $1.77^{\circ} \mathrm{C}, 2.38^{\circ} \mathrm{C}$ and $1.69^{\circ} \mathrm{C}$, respectively. These values were significantly greater than the fixed fault detection threshold of $\pm 0.51{ }^{\circ} \mathrm{C}$. Figure 4.27 displays the absolute temperature difference between the predicted and measured temperatures in office 1. Also included in this plot is the fault detection threshold.

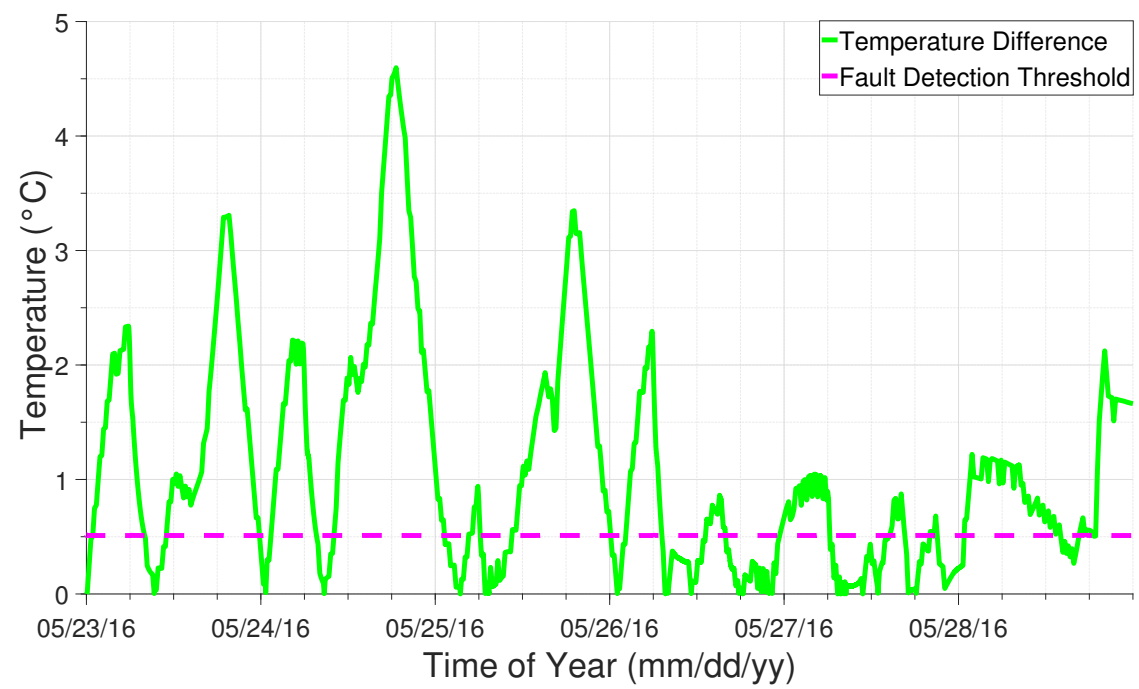

Figure 4.27: Theoretical and measured room air temperature difference for office 1 in May

Figure 4.23 shows that the thermostat reading in office 1 significantly exceeded the predicted temperature for the space. At one point during May $23^{\text {rd }}$ and $25^{\text {th }}$ the thermostat reading was approximately $3.4{ }^{\circ} \mathrm{C}$ higher than the model predictions. A greater difference was seen on May $24^{\text {th }}$, the thermostat exceeded the model predictions by approximately 4.5 ${ }^{\circ} \mathrm{C}$ at one point. The thermostat readings exceeded the fault detection threshold three days in a row and thus, a fault was detected. The exact reason will now be presented. 


\subsubsection{Fault Diagnostics}

A discrepancy in the room air temperature predictions occurred during the first three days of the week. As per Figure 3.25 the air-based heating and cooling rate profiles needed to be evaluated next, as all four offices saw the same trend. The air-based heating and cooling rate profiles had a root mean square deviation of 1,668 $\mathrm{W}$, significantly greater than the average fault detection threshold of $\pm 748 \mathrm{~W}$. Figure 4.28 shows the air-based heating and cooling rate profiles for this week. Included in Figure 4.28 is the fault detection threshold, which is represented by dashed magenta lines.

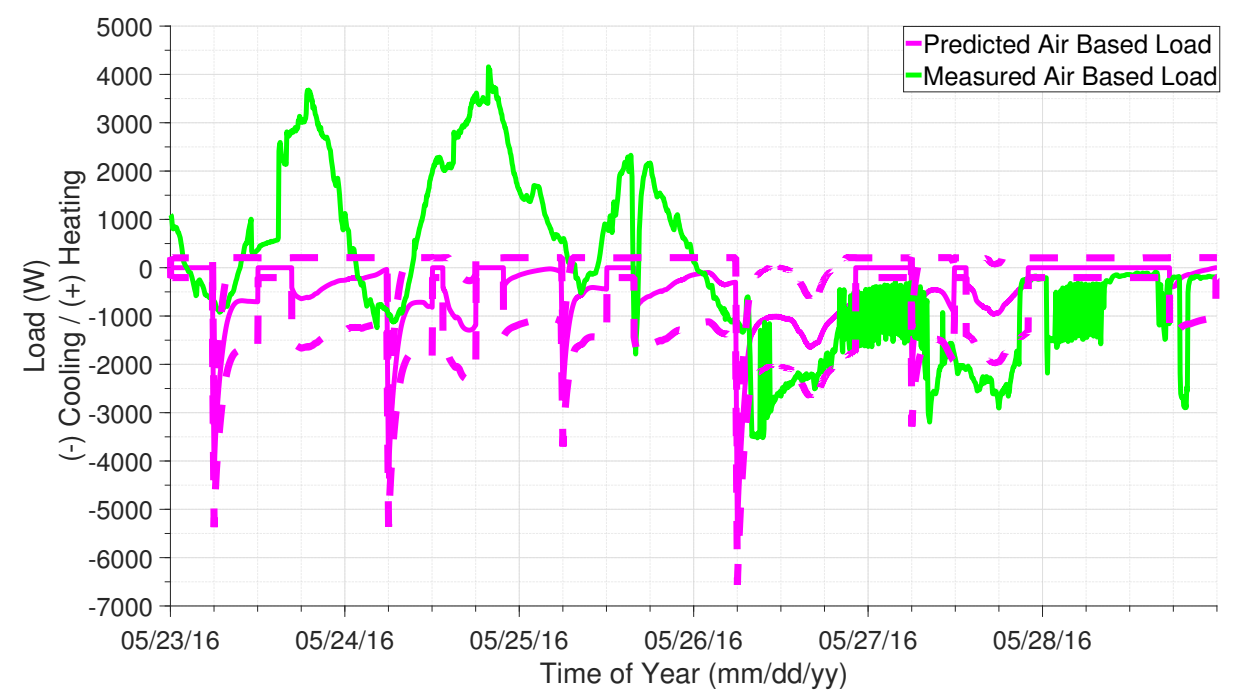

Figure 4.28: Air-based heating and cooling profiles for zone 1 in May

A discrepancy between the measured and predicted air-based heating and cooling profiles can be seen in Figure 4.28. The discrepancy in the air-based heating and cooling rates meant that the reheat valve needed to be analyzed next, when following Figure 3.25. Since the system is in cooling mode the valve was closed for both the predicted and actual operations. Following Figure 3.25 the discrepancy could be caused by either a zone and/or building-level fault. Further investigation was required to diagnose the root cause of the 
fault.

Figure 4.28 shows that during the first three days of the week that heating was supplied to the offices when the model was predicting that cooling should be supplied. The week under analysis was one of the first weeks of the cooling season, meaning that the building should have been in cooling mode. Since there was no issue with the reheat valve operations a fault must have been present at the building-level. Building-level faults are out of the scope of this research, but this occurrence was discussed with the building operators. They had some difficulty getting the cooling to start, and unfortunately, the chiller was not running until mid-week, approximately when the room air temperature predictions and measurements started to align.

Although a building-level fault was confirmed, this did not explain why such a significant amount of heating was supplied to the spaces. A peak heating rate of $4000 \mathrm{~W}$ was supplied during the first two days. The SAT was definitely greater than the temperatures in the offices. However, the air flow rate would have to be greater than the minimum capability of the VAV box to reach such a high peak, which can be seen in Figure 4.29.

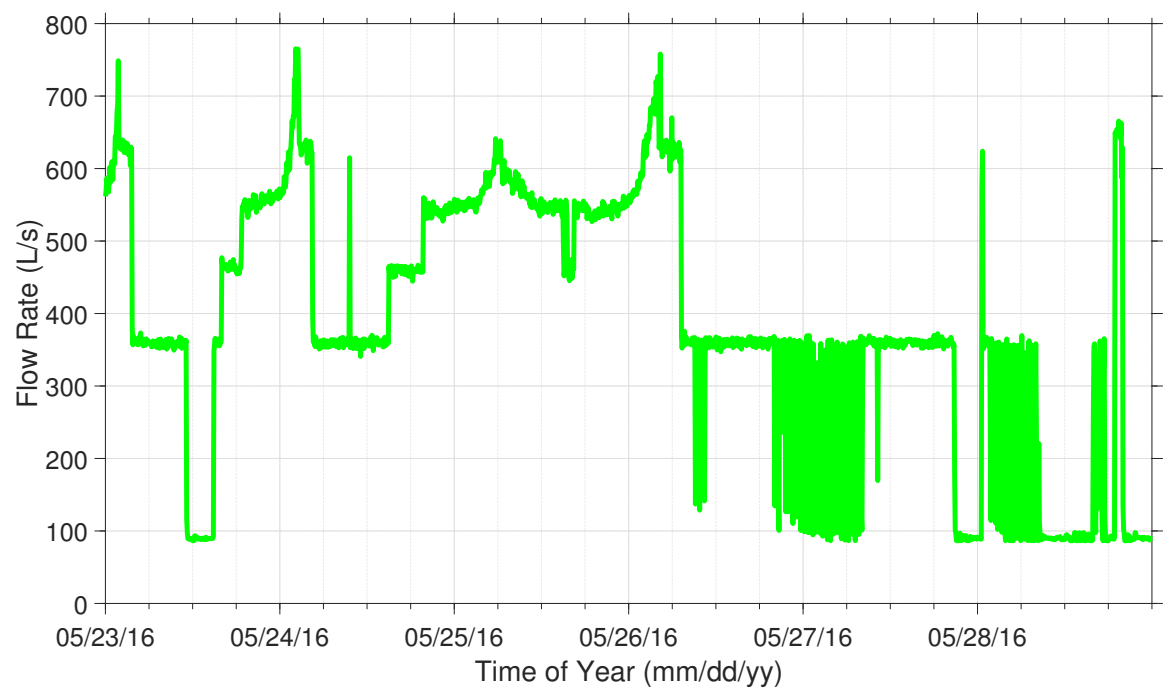

Figure 4.29: Measured VAV box air flow rate for zone 1 in May 
The reason that the air flow rate was increased to values greater than the minimum capability of the VAV box was because no consideration was given to the SAT when selecting the VAV damper position. Rather, the control sequence assumed that if the offices required cooling, that the AHU was supplying cool air to the building. The fact that this was not considered resulted in much more air to be supplied to the zone than was actually necessary. The additional supply air resulted in excessive fan energy consumption in the AHU, which will be discussed in greater detail in the fault evaluation section.

\subsubsection{Fault Evaluation}

The lack of consideration to the SAT led to the VAV box damper opening when it should have remained at its minimum capability. During the first three days of the week under analysis, the air flow rate through the VAV box averaged approximately $530 \mathrm{~L} / \mathrm{s}$. A value that was significantly greater than the minimum air flow rate of the VAV box. Previous analyses showed that this increase in air flow results in a significant increase in power consumption through the utilization of the fan law equation (equation 4.2).

In previous analyses, it would have been very difficult to measure the excess energy consumption for the entire building as the faults would only be reoccurring in some of the other zones, not all of them. The discovered fault in the control sequence was present in all VAV boxes in the Canal Building. Since the fault was present in all VAV boxes an analysis of the excess energy consumption for the whole building was possible. For this, the AHU supply fan energy consumption for May of 2016 was compared to May of 2017, which allowed for a month when the fault was present (May 2016) to be compared to a month when the fault was not present (May 2017). The fan law equation yielded that 834 times the energy consumption occurred during May of 2016, when the fault was present. However, 
this analysis did not consider the difference in weather patterns that may have been present for these two months. Instead, a one-week comparison was conducted which included the first week of the cooling season in 2016 and 2017. Comparing the first two weeks of cooling in these two years ensured that the weather patterns were similar as the cooling system was supposed to begin once the outdoor temperature had consistently reached a specified temperature. The weekly analysis resulted in the determination that the AHU supply fan energy consumption in May of 2016 was approximately 2,314\% of the energy consumption in May of 2017, an extraordinarily large differential in energy consumption. Further investigation revealed that the May 2016 week accounted for approximately 3.2\% and $3.5 \%$ of the annual fan energy consumption in AHU 1 and 2, respectively. These percentages in the annual fan energy consumption corresponded to approximately 11.17 GJ of fan energy consumption. Approximately 6.83 GJ of energy was wasted during this week if it is assumed that every week of the year consumed the same amount of energy to run the fans in the AHUs. $6.83 \mathrm{GJ}$ is a significant excess in energy consumption for the building, even-more so when considering that this can be resolved by altering the controls so that the SAT is considered.

\subsection{Summary}

The FDD methodology was tested during four weeks in 2016, one-week during the spring, summer, fall and winter. The analysis of these four weeks displayed the methodology's capability of detecting and diagnosing faults, revealing several faults in the system: three zone-level design faults, two zone-level soft faults and one building-level hard fault. The zone-level faults included thermostat misreadings, SAT sensor offsets, short-circuiting, poor selection of terminal units and poor VAV box control sequencing. The short-circuiting 
that occurred in each room in the zone varied between $13.6 \%$ and $22.5 \%$ throughout the year, depending on the season. The thermostat misreading in an office caused the energy consumption of the AHU fans to increase by $14.75 \%$ during select times of the year. The poor selection of one VAV box resulted in approximately $0.39 \%$ of excess fan energy consumption per year. Finally, a common, poor VAV box control sequence increased the AHU fan energy consumption by $2,314 \%$ one week. 


\section{Chapter 5}

\section{Discussion}

Chapter 4 presented the application of the FDD tool through a case study conducted on the Canal Building. The application of the methodology outlined in Chapter 3 resulted in the detection and diagnosis of five faults. These faults were then evaluated to determine the severity of their occurrence. What these results mean has yet to be addressed. Chapter 5 opens by presenting the significance of these findings. Following this, the applicability of the developed FDD tool on other buildings is discussed. Afterward, how the discovered design faults can be conveyed to designers is considered. Chapter 5 then closes by addressing the current limitations of the developed FDD tool and the required future work.

\subsection{Significance of Research and Findings}

A majority of the previous research on FDD for buildings has focused on equipment in the primary loop, typically the optimization of AHUs. AHUs have drawn a large amount of focus in the past due to the significant portion of energy that they consume throughout any given year. As a result, FDD at the room and zone-level has been overlooked. Since this area has not been widely explored, the research aimed to fill this gap through the development of a system that detects and diagnoses faults at the room and zone-level. A case study was conducted, revealing several faults in the system: three zone-level design faults, two 
zone-level soft faults and one building-level hard fault. The zone-level faults included thermostat misreadings, SAT sensor offsets, short-circuiting, poor selection of terminal units and poor VAV box control sequencing. The fault evaluations outlined in subsections 4.2.3, 4.3.3, 4.4.3 and 4.5.3 revealed that the AHU supply and return fans expend more energy on the zone under evaluation than is necessary. The short-circuiting that occurred in each room in the zone varied between $13.6 \%$ and $22.5 \%$ throughout the year, depending on the season. The thermostat misreading in an office caused the energy consumption of the AHU fans to increase by $14.75 \%$, during select times of the year. The poor selection of one VAV box resulted in approximately $0.39 \%$ of excess fan energy consumption per year. Finally, a common, poor VAV box control sequence increased the AHU fan energy consumption by $2,314 \%$ one week. At first glance, it might appear that the design faults have negligible influence on the operational cost of buildings. However, the probability of these faults occurring in several other zones is high, and the redundancy of these issues results in a significant portion of excess energy consumption. Although these faults may only be costing pennies individually, the accumulation of these faults in the building results in dollars being wasted.

\subsection{Applicability of Development in Other Buildings}

The developed FDD tool is advantageous, displaying its ability to detect faults in the mechanical system in a building. However, to maximize its value the tool needs to be applicable in other buildings, existing and/or new buildings. 


\subsubsection{Applicability of Development in Existing Buildings}

The developed FDD tool can be applied to heritage and other existing buildings. However, the BAS in this type of building is limited in its scope; lacking sensors at the zone-level and long term data storage capabilities. The absence of these makes implementation more difficult since all of the required equipment would need to be setup. Setting up all of the required equipment is possible, but more work would be necessary in order to achieve a full zone-level analysis. Ideally, a "sensor kit" would be developed, having many of the required sensors set up which could measure various information, such as the room air temperature, light intensity and plug loads. A "sensor kit" would allow for the analysis to be more easily transferred to other spaces. In addition, other information would also be required, such as outdoor air temperature, solar radiation, SAT, supply air flow rate and return air temperature. If an analysis of the radiator heating rate is also required the set up is even more time consuming and expensive. Furthermore, it is difficult to monitor the air flow rate of the supply air as the sensor needs to be located in the ductwork. Fortunately, even though this analysis might not be realistic for all existing building's the insight that the research has provided regarding design faults is valuable if/when retrofits are required for the building.

\subsubsection{Applicability of Development in New Buildings}

The implementation of this development in newer buildings is easier than for older buildings. It is easier to implement into newer buildings because buildings that are currently being designed or have been designed over the past decade will have a lot of accessible data regarding the system's actual performance metrics. Additional sensors will still be re-

quired to allow for the model to predict the required room and zone metrics, but not nearly 
as many as with older buildings. Moreover, once a tool has been developed to automate the process of obtaining room information from the BIM, and as a result of the increasing use of BIM prior to construction of buildings, it will become easier to implement this system. The implementation of this system in the buildings will help monitor the operations of the system and detect/diagnose any faults that arise, ultimately ensuring optimum system operations. Similar to existing buildings, the results regarding design faults allow for better retrofits to be implemented in the existing buildings. Furthermore, better initial designs may also be selected for new building projects as long as the identified design faults are properly conveyed to designers.

\subsection{Conveying Design Faults to Designers}

The evaluation of these detected faults displayed the importance of addressing the issues that were discovered in the design of the system. These findings offer valuable insight for future designs, but the value is limited if they can not be properly conveyed to designers. Some of these design faults can be avoided by implementing tools into BIM software, others require the implementation of new design standards.

\subsubsection{Conveying Design Faults in BIM}

BIM has increased in popularity during the design stage of buildings as it offers a way to see the building prior to construction. It also has the ability to limit poor designs from being developed by providing insight within the software. For example, when placing a thermostat, the tool can display appropriate locations for the thermostat placement. A colour scheme 
can be devised that highlights the more appropriate locations for the thermostat. The appropriateness of the location would depend on its sunlight visibility, as well as the distance from windows and external walls. Similarly, a colour scheme can be utilized for the ceiling when selecting the locations of the supply diffusers and return grilles. The tool can highlight more appropriate locations for these pieces of equipment based on their distance from each other, as well as their distance from walls. Distances that are further apart limit the percentage of air that short-circuits. In addition, the return grille's distance from the walls also influences the amount of short-circuiting that occurs, as the air could be pushed up off the wall to the return grille, instead of flowing underneath.

\subsubsection{Conveying Design Fault in New Design Standards}

The ability to implement tools to avoid certain design faults may not be applicable in BIM software. Instead, new design standards could be put into effect, for example, the selection of an appropriate terminal unit manufacturer and size for the zones in the building. Mechanical systems need to be designed to meet the load requirements all year round, therefore, undersizing terminal units is not an appropriate solution to minimizing its lower limit. However, in subsection 4.4.3 the influence of VAV box manufacturers on the AHU fan energy consumption was evaluated. It was shown that selecting a different VAV box manufacturer could result in operational cost savings, while also allowing for the peak load requirements to be met. Instead of selecting the terminal unit manufacturer prior to size selections, a design guide to manufacturer selection could be implemented. The mechanical designers would have to do the peak load calculations for each zone in the building and select the manufacturer that provides the most terminal units with the lowest minimum flow capabilities. 


\subsection{Limitations of Research}

Although the FDD tool successfully diagnosed several faults for the Canal Building, there were some limitations in the research that was conducted. There were also some limitations as a result of the underlying FDD methodologies utilized in the tool.

\subsubsection{Quantitative Model-Based Fault Detection}

Firstly, some limitations in the research were caused by the selection of the quantitative model-based method for the fault detection portion of the development. The quantitative model-based methodology did lead to valuable results, obtaining insight regarding design faults. However, ensuring that the building is operating efficiently requires the implementation of this methodology into the building, which is more difficult to complete for several reasons. One of the causes of this can be attributed to the number of sensors that are required in order to perform an adequate room-level FDD analysis. All of the sensors that were utilized in this research were required and ideally a few additional sensors would be implemented in future work. A temperature sensor on each offices' return grille would allow for a more accurate measurement of the air-based heating and cooling rate for the zone. A contact sensor on each office's door would allow for a better understanding of the mixing

of the office and hallway air, leading to more accurate model predictions. The building in the case study did not have operable windows. However, other buildings may, in which case contact sensors on each office's window would allow for a more accurate quantification of the infiltration/exfiltration in the spaces, also leading to more accurate model predictions.

Additionally, sensor measurements were not verified at the beginning of this research, rather a comparison of the measured and predicted metrics was utilized to determine if 
sensors were measuring inaccurate values. However, some of the sensor measurements that were incorporated in this work were verified in previous years and during the case study. The thermostat temperature readings were verified in the past through the utilization of spot checks by the controls contractor. The supply air temperature sensor measurements were analyzed after discrepancies were found in the predicted and measured air-based heating and cooling rates. A LogTag was installed inside of the supply diffuser and revealed that the VAV box's supply air temperature sensor was reading offset values. The lack of sensor verification is a limitation in the research to be addressed for future studies.

Moreover, this quantitative model-based methodology was tailored to a four office zone, in a building that possesses a hydronic and air-based system. Although this system type is extremely common in today's design practice, it is not the only system type and thus, the tool may need to be tailored depending on the building's system. Furthermore, if an analysis were to be conducted on a new zone that does not contain four offices, the tool would also have to be tailored accordingly. The need to tailor the FDD tool for implementation in other buildings may take a significant amount of time, as the full development of the model took approximately one year to finalize. Also, the building operators may find it difficult to implement a white box technique into the building. Obtaining all of the required material properties would be even more time consuming if as-built drawings were not readily available. However, the material properties could be selected by training the model based on real data, ultimately transitioning the development into more of a gray-box methodology.

\subsubsection{Heuristic-Based Rule Set Fault Diagnostics}

Even though the heuristic-based rule set for the fault diagnostics portion of the tool led to the successful determination of several faults, this methodology does have its limitations. 
For example, it is tailored to the system type that is under analysis, which in this case study was a hydronic and air-based system. Meaning that direct implementation, without altering the rule set, can lead to false diagnostics. That being the case, implementing this tool into other buildings requires care and knowledge of the system to ensure adequate FDD.

\subsection{Recommended Future Work}

\subsubsection{Continuation of Work}

Ideally, human intervention in the FDD tool's process would be limited as much as possible. Limiting human intervention could be accomplished by automating the tool wherever possible. Several aspects of the tool could be automated to limit this interaction.

\section{Importing BIM into FDD Tool}

Preferably, the system would automatically obtain the required information regarding the room and zone from the BIM. The system would gather information, such as the wall, floor and ceiling area and composition, room orientation, etc.

\section{Increase Model Resolution}

The system operated well, but to have it operate seamlessly the resolution of the model needs to be increased to limit the occurrence of false alarms. Increasing the model resolution can be accomplished by reducing the number of simplifying assumptions that the current model utilizes. Limiting false alarms could also be resolved by testing to verify 
if the fault that was diagnosed is the cause of the discrepancy. Upon diagnosing a certain fault, the system would automatically isolate the alleged fault in a manner which forces the system to primarily rely on that one variable. If the performance of the space is only dependent on this one alleged fault, the results can be analyzed to determine if the fault is the cause. This process could be used to check to see if the diagnosis was accurate, ultimately reducing the number of false alarms. Lastly, by increasing the prediction thresholds, the number of false alarms could be reduced. However, this is not the ideal solution since high residuals can result in faults going undetected.

\section{Reduce Computational Time}

Currently, the computational time required for the system to produce results for one week is minimal. However, the increase in model complexity will result in an increase in the computational demand to run the tool. If this system were to be formalized, the tool would need to be able to operate in real time with the BAS, requiring it to be extremely time efficient.

\section{More Detailed Theoretical System}

The heuristic-based rule set at times requires the user to further investigate the scenario in order to obtain an exact diagnostics of the fault. To fully automate the development, the model would have to be able to take in more measurements obtained from the BAS to predict certain aspects. For example, the model currently predicts the air-based heating and cooling rates, but then utilizes the SAT sensor in the VAV box to predict the required air flow rate. Since this is the case, further investigation is required to determine if the air flow sensor or temperature sensor is at fault when a discrepancy occurs between the 
air-based heating and cooling rates. The AHU selects the SAT by evaluating all of the room's temperatures and set-points. For the model to accurately predict the SAT, a similar approach would be required, meaning that the system needs to obtain every thermostat reading in the building.

\subsubsection{New Research Areas}

\section{Model-Based Predictive Controls}

The developed parametric energy model could be utilized in a model-based predictive controls application. By predicting the room air temperature and required heating and cooling rates, either air-based or hydronic-based, the controls can be adjusted, before the room or zone absolutely needs it. Implementing this alongside a model-based FDD tool would allow the system to control itself and perform routine checks to ensure that the system is functioning properly. 


\section{Chapter 6}

\section{Conclusion}

The thesis was divided into the following chapters:

Chapter 1 introduced the current problem with HVAC systems, how this issue has been resolved and what areas required more focus.

Chapter 2 discussed a survey of literature on the use of FDD in building applications, as well as the fault categories the literature addressed. The chapter concluded with a summary that discussed the motivation for this work.

Chapter 3 described the utilized theory in detail. The two main sections of Chapter 3 discussed the development of the fault detection tool and the fault diagnostics methodology. The fault detection section described the model-based approach that was undertaken, and the fault diagnostics section discussed the heuristic-based rule set used to explain various discrepancies between the measured and theoretical zone performance.

Chapter 4 began by presenting the faults that the system detected. Each fault was then addressed individually, starting with an analysis of the results obtained through the fault detection tool, which compared the simulation and real model results. The fault diagnostics section followed, which contained an analysis of each result and the depiction of the inefficiency that was present. Afterward, the severity of the fault was quantified in the fault evaluation section. 
Chapter 5 began with a discussion of the significance of the research and findings. The FDD tool's applicability in other buildings was then discussed, followed by methods to convey the identified design faults to designers. The chapter closed by addressing the limitations of the development and the required future work.

In Chapter 6 conclusions regarding the FDD methodology and implementation are provided. The chapter contains an overview of the research and findings, how it ties in with the required internship and finishes with a closing remark regarding the research.

\subsection{Overview of Research \& Findings}

In this study, the methodology of a quantitative model-based FDD system was presented. Development began in Matlab where the creation of a basic model was completed. Model resolution was increased until accurate results for a thermal zone were obtained. Once the proper balance between accurate results and complexity was achieved the model was finalized. Following this, analyses were conducted for a zone in the Canal Building, located on Carleton campus, in Ottawa.

The weekly analyses that were conducted resulted in the discovery of five faults; an offset in the VAV box's SAT sensor, poor SD and RG selection/placement, poor thermostat placement, poor VAV box selection and poor VAV box control sequence. The severity of these inefficiencies was analyzed and found that four of them contributed to an excessive amount of AHU fan energy consumption. Poor SD and RG selection/placement resulted in wastage between $22.5 \%$, during times of heating and $13.6 \%$, during times of cooling. Two of the four offices in the zone under analysis have thermostats that were poorly located. The placement of these thermostats exposed them to direct sunlight late in the afternoon, 
during select months. When this scenario did arise it caused an increase of up to $14.75 \%$ in the AHU fan energy consumption. A third fault was caused by a lack of consideration to the minimum capability of the VAV box, during the selection of equipment. The lack of consideration to the minimum capability of the VAV box for one zone caused the AHU fans to consume approximately $0.39 \%$ more energy annually. Finally, the building operators had difficulty getting the cooling system functioning properly at the beginning of the cooling season. During this time a fault at the zone-level was revealed in the VAV box control sequence. The VAV box was calling for more air to be supplied to the room as a result of the set-points not being met. However, it did not have knowledge of the SAT and since the SAT was greater than the room air temperatures the rooms were being overheated, rather than cooled. The lack of consideration to the SAT increased the AHU fan energy consumption by $2,314 \%$ one week.

Although the faults in a single zone make up minimal energy savings potential, the redundancy of these faults in the building force the AHU to expend an unwarranted amount of energy. Even though the required sensor set-up and model development for a proper zonelevel analysis is time-consuming, the case study highlighted the importance of utilizing FDD for the zone-level to improve building operations. Recommendation for future work includes further automating the tool, allowing the development to be easily transferred to other buildings so that these buildings can also reap the benefits of the development. Benefits of the current methodology include the detection of pre-existing faults originating from the initial design, allowing insight for future design; and the ability for it to improve the efficiency of the building. The insight that is gained for future design can be utilized in new HVAC design automation tools, an area that was explored during the program required internship. 


\subsection{Autodesk Internship}

In May of 2016, an internship with Autodesk was undertaken in Toronto to fulfill the degree requirements. During this time, work on the concept of Generative Design for Heating, Ventilation and Air-Conditioning began in collaboration with Alex Tessier, Ramtin Attar and Azam Khan. The generative design work led to the development of a Matlab program that could generate potential thermal zoning strategies and VAV box sizing given the room information for a floor plan. The work yielded great results and upon the completion of the project in Toronto, the development of a paper began. "An Investigation of Generative Design for Heating, Ventilation and Air-Conditioning" [75] was later accepted into the SimAUD Conference as a paper and presentation. Future work within this development would be to combine the knowledge of the design faults that the FDD tool revealed, allowing for new designs, with an improved system efficiency to be created.

\subsection{Closing Remarks}

While the FDD tool requires further development, this research has demonstrated progress and improved capability. Faults were detected through the utilization of a quantitative model-based methodology in Matlab. The fault in the system was diagnosed through a heuristic-based rule set. Afterward, fault evaluations were conducted for each diagnosed fault to determine the severity of the fault's occurrence. It was determined that when these faults were viewed singularly, the overall addition to the energy consumption in the building was minimal. However, the percentage of energy consumption increased significantly for the zone during the times of the faults. When considering the likelihood of these faults being redundant throughout the zones in the building, a significant portion of the building's 
energy consumption can be reduced by addressing these faults in each office and/or zone. By changing the original design in a manner which eliminates the occurrence of these faults, a new design with improved energy efficiency can be achieved. 


\section{Bibliography}

[1] U. E. I. Administration, "Chapter 6: Building sector energy consumption,” 2016.

[2] N. R. Canada, "Chapter 3: Residential sector - residential energy use and ghg emissions," 2012.

[3] N. R. Canada, "Energy use data handbook," 2013.

[4] M. A. Piette, S. K. Kinney, and P. Haves, "Analysis of an Information Monitoring and Diagnostic System to Improve Building Operations," Energy and Buildings, vol. 33, no. 8, pp. 783-791, 2001.

[5] B. Narayanaswamy, B. Balaji, R. Gupta, and Y. Agarwal, "Data Driven Investigation of Faults in HVAC Systems with Model, Cluster and Compare (MCC)," in Proceedings of the 1st ACM Conference on Embedded Systems for Energy-Efficient Buildings, pp. 50-59, ACM, 2014.

[6] S. Wang and J. Cui, "A Robust Fault Detection and Diagnosis Strategy for Centrifugal Chillers," HVAC\&R Research, vol. 12, no. 3, pp. 407-428, 2006.

[7] J. Cui and S. Wang, "A model-based online fault detection and diagnosis strategy for centrifugal chiller systems," International Journal of Thermal Sciences, vol. 44, no. 10, pp. 986-999, 2005.

[8] M. S. Breuker and J. E. Braun, "Common Faults and Their Impacts for Rooftop Air Conditioners," HVAC\&R Research, vol. 4, no. 3, pp. 303-318, 1998.

[9] M. R. Brambley, N. Fernandez, W. Wang, K. A. Cort, H. Cho, H. Ngo, and J. Goddard, 
"Final project report self-correcting controls for vav system faults," Pacific Northwest National Laboratory, PNNL-20452, 2011.

[10] C. Callaway, ASHRAE Fundamentals Handbook. 1791 Tullie Circle, N.E., Atlanta, GA 30329: W. Stephen Comstock, 2013.

[11] D. E. Claridge, C. H. Culp, M. Liu, S. Deng, W. D. Turner, and J. S. Haberl, "CampusWide Continuous Commissioningsm of University Buildings," in Proc. of ACEEE 2000 Summer Study on Energy Efficiency in Buildings, vol. 3, pp. 101-112, 2000.

[12] J. Schein, S. T. Bushby, N. S. Castro, and J. M. House, "A rule-based fault detection method for air handling units," Energy and buildings, vol. 38, no. 12, pp. 1485-1492, 2006.

[13] B. Dong, Z. O'Neill, and Z. Li, "A BIM-enabled information infrastructure for building energy Fault Detection and Diagnostics," Automation in Construction, vol. 44, pp. 197-211, 2014.

[14] B. Gunay, W. Shen, and C. Yang, "Characterization of a Building's Operation Using Automation Data: a Review and Case Study," Building and Environment, 2017.

[15] B. Yu, A. van Paassen, and S. Riahy, "Open window and defective radiator valve detection," Building Services Engineering Research and Technology, vol. 24, no. 2, pp. 117-124, 2003.

[16] P. Haves, "Overview of Diagnostic Methods," in Diagnostics for Commercial Buildings: Research to Practice, pp. 1-10, 1999.

[17] H. Yang, S. Cho, C.-S. Tae, and M. Zaheeruddin, "Sequential rule based algorithms for temperature sensor fault detection in air handling units," Energy Conversion and Management, vol. 49, no. 8, pp. 2291-2306, 2008. 
[18] G. Zimmermann, Y. Lu, and G. Lo, "Automatic HVAC fault detection and diagnosis system generation based on heat flow models," HVAC\&R Research, vol. 18, no. 1-2, pp. 112-125, 2012.

[19] T. M. Rossi and J. E. Braun, "A Statistical, Rule-Based Fault Detection and Diagnostic Method for Vapor Compression Air Conditioners," HVAC\&R Research, vol. 3, no. 1, pp. 19-37, 1997.

[20] H. Cheung and J. E. Braun, "Simulation of fault impacts for vapor compression systems by inverse modeling. Part i: Component modeling and validation," $H V A C \& R$ Research, vol. 19, no. 7, pp. 892-906, 2013.

[21] H. Cheung and J. E. Braun, "Simulation of fault impacts for vapor compression systems by inverse modeling. Part ii: System modeling and validation," $H V A C \& R R e-$ search, vol. 19, no. 7, pp. 907-921, 2013.

[22] H. Li and J. E. Braun, "A Methodology for Diagnosing Multiple Simultaneous Faults in Vapor-Compression Air Conditioners," HVAC\&R Research, vol. 13, no. 2, pp. 369395, 2007.

[23] R. A. Buswell, P. Haves, and J. A. Wright, "Model-based condition monitoring of a HVAC cooling coil sub-system in a real building," Building Services Engineering Research and Technology, vol. 24, no. 2, pp. 103-116, 2003.

[24] X. Li, Y. Li, and J. E. Seem, "Dynamic Modeling of Mechanical Draft Counter-Flow Wet Cooling Tower with Modelica," in ASME 2010 Dynamic Systems and Control Conference, pp. 687-694, American Society of Mechanical Engineers, 2010.

[25] D.-c. Gao, S. Wang, K. Shan, and C. Yan, "A system-level fault detection and diagnosis method for low delta-T syndrome in the complex HVAC systems," Applied Energy, vol. 164, pp. 1028-1038, 2016. 
[26] J. D. Bynum, D. E. Claridge, and J. M. Curtin, "Development and testing of an Automated Building Commissioning Analysis Tool (ABCAT)," Energy and Buildings, vol. 55, pp. 607-617, 2012.

[27] D. E. Claridge and G. Lin, "Retrospective Testing of an Automated Building Commissioning Analysis Tool (ABCAT)," tech. rep., Energy Systems Laboratory, 2009.

[28] J. Schein and S. T. Bushby, "A Hierarchical Rule-Based Fault Detection and Diagnostic Method for HVAC Systems," HVAC\&R Research, vol. 12, no. 1, pp. 111-125, 2006.

[29] M. R. Brambley, N. Fernandez, W. Wang, K. A. Cort, H. Cho, H. Ngo, and J. Goddard, "Final project report self-correcting controls for vav system faults," Pacific Northwest National Laboratory, PNNL-20452, 2011.

[30] A. Beghi, L. Cecchinato, F. Paggiaro, and M. Rampazzo, "VAVAC Systems Modeling and Simulation for FDD Applications," in Control and Automation (ICCA), 2011 9th IEEE International Conference on, pp. 800-805, IEEE, 2011.

[31] S. Wu and J.-Q. Sun, "Cross-level fault detection and diagnosis of building HVAC systems," Building and Environment, vol. 46, no. 8, pp. 1558-1566, 2011.

[32] E. Azar and C. C. Menassa, "A Data Collection and Analysis Framework to Improve the Performance of Energy-Intensive Commercial Buildings," in Computing in Civil and Building Engineering (2014), pp. 1142-1149, 2014.

[33] J. Schein and S. T. Bushby, "Fault Detection \& Diagnostics for AHUs and VAV Boxes," ASHRAE journal, vol. 47, no. 7, pp. 58-63, 2005.

[34] S. M. Namburu, M. S. Azam, J. Luo, K. Choi, and K. R. Pattipati, "Data-Driven Modeling, Fault Diagnosis and Optimal Sensor Selection for HVAC Chillers," IEEE 
Transactions on Automation Science and Engineering, vol. 4, no. 3, pp. 469-473, 2007.

[35] H. Li and J. E. Braun, "A Methodology for Diagnosing Multiple Simultaneous Faults in Vapor-Compression Air Conditioners," HVAC\&R Research, vol. 13, no. 2, pp. 369$395,2007$.

[36] D. E. Claridge and G. Lin, "Retrospective Testing of an Automated Building Commissioning Analysis Tool (ABCAT)," tech. rep., Energy Systems Laboratory, 2009.

[37] A. Beghi, L. CecChinato, L. Corso, M. Rampazzo, and F. Simmini, "Process HistoryBased Fault Detection and Diagnosis for VAVAC Systems," in Control Applications (CCA), 2013 IEEE International Conference on, pp. 1165-1170, IEEE, 2013.

[38] A. Beghi, R. Brignoli, L. Cecchinato, G. Menegazzo, M. Rampazzo, and F. Simmini, "Data-driven Fault Detection and Diagnosis for HVAC water chillers," Control Engineering Practice, vol. 53, pp. 79-91, 2016.

[39] G. Zimmermann, Y. Lu, and G. Lo, "Automatic HVAC fault detection and diagnosis system generation based on heat flow models," HVAC\&R Research, vol. 18, no. 1-2, pp. 112-125, 2012.

[40] L. Song, M. Liu, D. E. Claridge, and P. Haves, "Study of On-Line Simulation for Whole Building Level Energy Consumption Fault Detection and Optimization,” in Architectural Engineering 2003: Building Integration Solutions, pp. 1-8, 2003.

[41] J. Gertler, Fault Detection and Diagnosis in Engineering Systems. CRC press, 1998.

[42] J. D. Bynum, D. E. Claridge, and J. M. Curtin, "Development and testing of an Automated Building Commissioning Analysis Tool (ABCAT)," Energy and Buildings, vol. 55, pp. 607-617, 2012. 
[43] W. Simpson and T. Sherwood, "Performance of Small Mechanical Draft Cooling Towers," Refrigerating Engineering, vol. 52, no. 6, pp. 525-543, 1946.

[44] P. Sreedhara and P. Haves, "Comparison of Chiller Models for use in Model-Based Fault Detection,” 2001.

[45] P. Angelov, R. A. Buswell, V. I. Hanby, and J. A. Wright, "A methodology for modeling HVAC components using evolving fuzzy rules," in Industrial Electronics Society, 2000. IECON 2000. 26th Annual Conference of the IEEE, vol. 1, pp. 247-252, IEEE, 2000.

[46] "Solids - Specific Heats." http://www.engineeringtoolbox.com/ specific-heat-solids-d_154.html. Accessed: 2016-10-05.

[47] B. Nagy, S. G. Nehme, and D. Szagri, "Thermal properties and modeling of fiber reinforced concretes," Energy Procedia, vol. 78, pp. 2742-2747, 2015.

[48] "CAVITY ROCK Technical Information." http://www.roxul.com/ products/cavityrock/. Accessed: 2016-10-05.

[49] D. D. B. Michael J. Moran, Howard N. Shapiro and M. B. Bailey, Fundamentals of Engineering Thermodynamics $7^{\text {th }}$ Edition. John Wiley \& Sons, 2011.

[50] F. P. Bergman, T. L. DeWitt, D. P. Incropera, and A. S. Lavine, Fundamentals of Heat and Mass Transfer. John Wiley \& Sons, $7^{\text {th }}$ edition ed., 2013.

[51] J. A. Clarke, Energy Simulation in Building Design. Routledge, 2001.

[52] R. Heinzi, "Finite Differences." http://www.iue.tuwien.ac.at/phd/ heinzl/node27.html, Accessed: 2017-07-08. 
[53] G. W. Recktenwald, "Finite-Difference Approximations to the Heat Equation," Mechanical Engineering, vol. 10, pp. 1-27, 2004.

[54] A. K. Athienitis, Building Thermal Analysis. Centre for Building Studies, Concordia University, 2000.

[55] W. S. Dols, S. J. Emmerich, and B. J. Polidoro, "Coupling the multizone airflow and contaminant transport software CONTAM with EnergyPlus using co-simulation," in Building simulation, vol. 9, pp. 469-479, Tsinghua University Press, 2016.

[56] J. Bambara and A. Athienitis, "Experimental evaluation and energy modeling of a greenhouse concept with semi-transparent photovoltaics," Energy Procedia, vol. 78, pp. 435-440, 2015.

[57] T. P. McDowell, S. Emmerich, J. W. Thornton, and G. Walton, "Integration of Airflow and Energy Simulation Using CONTAM and TRNSYS," Transactions - American Society of Heating Refrigerating and Air Conditioning Engineers, vol. 109, no. 2, pp. 757-770, 2003.

[58] E. Plus, "Engineering reference manual," Building Technologies Program, US Department of Energy (DOE), 2008.

[59] C. Callaway, ASHRAE Fundamentals Handbook 18.35. 1791 Tullie Circle, N.E., Atlanta, GA 30329: W. Stephen Comstock, 2013.

[60] L. Peeters, I. Beausoleil-Morrison, and A. Novoselac, "Internal convective heat transfer modeling: critical review and discussion of experimentally derived correlations," Energy and Buildings, vol. 43, no. 9, pp. 2227-2239, 2011. 
[61] I. Beausoleil-Morrison, "An algorithm for calculating convection coefficients for internal building surfaces for the case of mixed flow in rooms," Energy and Buildings, vol. 33, no. 4, pp. 351-361, 2001.

[62] D. Controls, "Network Sensors IO Expansion Modules," 2017.

[63] J. D. Balcomb, Passive solar buildings, vol. 7. MIT press, 1992.

[64] D. T. Services, "SPN1 Sunshine Pyranometer Specification,” 2017.

[65] Plugwise, "Getting started with Plugwise," 2015.

[66] S. Systems, "Model 263 Very Low Differential Pressure Transducer." Accessed: 2016-07-03.

[67] Endress+Hauser, "Technical Information - Proline Prosonic Flow 91W."

[68] "Designing Air Flow Systems." https://www.captiveaire.com/ MANUALS/AIRSYSTEMDESIGN/DESIGNAIRSYSTEMS.HTM, Accessed: 2017-05-05.

[69] “Variable Volume Box Schedule.” Carleton University Building Drawings. Accessed: 2016-10-12.

[70] "Single Duct Terminal Units." https://nailor.com/sites/ nailor.com/files/images/product/catalog/NailorCatalogAirTerminalSingleDuctSupply3000.pdf. Accessed: 2016-07-12.

[71] "Single/Dual Duct Terminals." https://www.titus-hvac.com/docs/ 2014\%20catalog/singledual_2013.pdf. Accessed: 2016-07-12.

[72] "Single-Duct \& Retro Fit Terminal Units." https://www.krueger-hvac. com/file/7365/SIDOM.pdf. Accessed: 2016-07-12. 
[73] "Single Duct Terminal Units." https://www.priceindustries.com/ content/uploads/assets/literature/catalogs/performancedata/section\%20a/spvsdv-performance-data.pdf. Accessed: 2016-07-12.

[74] "Engineering Data." https://www.tuttleandbailey.com/Ecatalog/ docs/TU SD_ENG0 4_09.pdf. Accessed: 2016-07-12.

[75] J. Berquist, A. Tessier, W. O’Brien, R. Attar, and A. Khan, “An Investigation of Generative Design for Heating Ventilation and Air Conditioning," in Symposium on Simulation for Architecture and Urban Design, 2017. 


\section{Appendix A}

\section{Model Software Matlab Scripts}

All Matlab scripts and functions that were utilized in this research can be obtained through the following link.

https://carleton.ca/hbilab/thesis-matlab-scripts/ 